Fernando de Oliveira

\title{
LIGNOPOLIURETANOS: PREPARAÇÃO, CARACTERIZAÇÃO E APLICAÇÃO EM COMPÓSITOS DE SISAL
}

\author{
Tese apresentada ao Instituto de Química de São \\ Carlos da Universidade de São Paulo como parte \\ dos requisitos para obtenção do título de Doutor \\ em Ciências.
}

Área de concentração: Físico-Química

Orientadora: Prof. ${ }^{a}$ Dr. ${ }^{a}$ Elisabete Frollini

São Carlos

2014 

Dedico este trabalho às pessoas de grande importância em minha vida

Pelo apoio incondicional e incessante, pelo que me ensinaram e transmitiram, e pelo que sou hoje

Aos meus pais e meus irmãos

A todos familiares

Aos meus amigos 



\section{AGRADECIMENTOS}

Hoje em dia, pouca coisa seria possivel sem as trocas científicas e humanas que permitem à cada pesquisador avançar em quaisquer que sejam as etapas e as dificuldades com que se é confrontado durante o processo de pesquisa. Assim, escrever agradecimentos é uma contrapartida natural no fim de um trabalho de doutorado.

Em primeiro lugar, gostaria de agradecer àquele que esteve presente em todos os momentos e sempre estará. Agradeço a Deus por me iluminar e me fortalecer, permitindo superar todos os obstáculos que surgiram no desenvolvimento deste trabalho.

A minha eterna gratidão à minha família por ter me apoiado e me encorajado durante todo este percurso. Obrigado pai Mário e mãe Geneci, pelo extraordinário carinho, zelo e apoio durante toda minha vida. Aos meus queridos irmãos Vagner, Rodrigo e Fernanda; minhas cunhadas Juliana e Manuela; meus sobrinhos Lorena, Lucas e André (este último também afilhado); e também às minhas queridas avós Elza e Geralda, por sempre me apoiarem e esperarem o dia da minha volta para casa. A todos vocês, o meu muitíssimo obrigado.

Eu gostaria de expressar minha gratidão à professora Elisabete Frollini (Instituto de Química de São Carlos/USP), minha orientadora, por ter me confiado este trabalho. Obrigado pelos bons conselhos, atenção, paciência, e pelo conhecimento e experiência que me foram transmitidos, e que eu tenho certeza que me serão profícuos nos anos futuros.

Expresso também meus agradecimentos ao professor Mohamed Naceur Belgacem por ter me acolhido em sua equipe de pesquisa, no Laboratoire Génie des Procédes Papetiers (LGP2, Grenoble INP/Pagora), assim como pela supervisão, atenção, e dedicação prestada.

Agradeço à Universidade de São Paulo, ao Instituto de Química de São Carlos e aos membros do Departamento de Físico-Química (DFQ) que, de alguma forma, contribuíram para a realização deste trabalho.

Eu não deixaria de lembrar daqueles que acompanharam e colaboraram para a realização de diversas análises, serviços técnicos e apoio administrativo. Deixo aqui meus agradecimentos a Central de Análises Química (CAQUI) pela disponibilidade de utilização do Microscópio Eletrônico de Varredura e ao Dr. Márcio, responsável pela operação do equipamento e obtenção das imagens, assim como pela disponibilidade de uso dos espectrômetros de infravermelho. Um agradecimento aos funcionários da Biblioteca Prof. Johannes Rüdiger Lechat, das oficinas mecânica, vidraria e eletrônica, do serviço de pós-graduação, das secretarias de departamentos, da portaria, da equipe de limpeza e também aos químicos Bel. Márcia Dib Zambon e Dr. Luiz Ramos.

Ao Prof. Dr. Leonardo Bresciani Canto (DEMa-UFSCar) por permitir a realização dos ensaios de impacto e flexão; e ao técnico Fernando pelo auxílio na realização destes ensaios.

Agradeço às agências de fomento à pesquisa que contribuíram financeiramente para a realização deste trabalho. Ao $\mathrm{CNPq}$, pelas bolsas de doutorado e doutorado-sanduíche concedidas e pelo suporte financeiro; bem como à CAPES e FAPESP, também pelo suporte financeiro. 
Este trabalho foi beneficiado com a doação de matérias-primas para realização das pesquisas. Agradeço à LignoTech Brasil Produtos de Lignina Ltda. (Grupo Borregaard), pela gentil doação do lignossulfonato de sódio; e à BASF Poliuretanos e Bayer Materials Science pela doação do MDI polimérico.

Agradeço aos professores e pesquisadores que participaram da comissão julgadora da defesa desta tese: prof. Dr. Reinaldo Ruggiero (UFU, Uberlândia-MG), prof. Dr. Holmer Savastano Junior (FZEA-USP, Pirassununga-SP), prof. Ruy A. C. Altafim (EESC-USP, São Carlos-SP) e prof. Dr. Sergio Paulo Campana Filho (IQSC-USP, São Carlos-SP). Obrigado por terem dedicado parte de seu tempo para avaliar o meu trabalho. Manifesto aqui todo meu respeito e reconhecimento.

Muito obrigado aos pesquisadores (doutores, doutorandos, mestrandos e alunos de iniciação científica) do Grupo de Materiais Macromoleculares e Fibras Lignocelulósicas e do Grupo de Físico-Química Orgânica, com quem eu compartilhei todos estes anos de laboratório: Daniele, Bruno, Rachel, Elaine, Talita, Érika, Cris, Bibi, Joice, Daiana, Marcela, Juliana, Bruna, Roberta, prof. Campana, Jorge, Tonimar, Anderson, Virgínia, Daniella, Lilian, Adriana, Willian, Danilo e Andrea.

Deixo aqui um agradecimento especial à Dra. Elaine Cristina Ramires que foi companheira de linha de pesquisa, colaboradora e incentivadora deste trabalho; e além disso, por ser uma grande amiga que sempre se fez presente de longe ou de perto. Muito obrigado, Elaine!

Dedico um parágrafo aos seis meses que passei em Grenoble (França):

Les six mois vécus à Grenoble étaient inoubliables. Je souhaiterais exprimer ma sympathie et tous mes remerciements à l'ensemble des membres du LGP2 (Grenoble INP/Pagora): les professeurs, les techniciens, les doctorants et des personnels divers. Un grand merci à l'ensemble de l'Association Isèreanybody (Pastorale de Jeunes du Diocèse de Grenoble) pour le chaleureux accueil pendant mon séjour en France. Une pensée toute particulière pour mes colocataires de Saint Joseph (Colocation Jeunes Pro). Merci à toutes les personnes liées aux Focolari en France et, de manière géneral, merci aussi à tous ceux avec qui j'ai pu vivre des moments agréables pendant ce séjour.

Expresso minha gratidão ao Ministério Universidades Renovadas pelo carinho e por ser também minha família desde à minha chegada em São Carlos no início de 2008. Ao Movimento dos Focolares, presente naqueles da Unidade Gen, encontros da Palavra de Vida, assistentes e membros diversos: muito obrigado pelas experiências, comunhões, orações e por todas situações em que pude contar com a Unidade de vocês.

A todos os meus amigos. Àqueles que tive a graça de encontrar ao longo destes anos de pós-graduação. Aos queridos amigos da época de graduação em Maringá, que vivem no meu coração e que sempre torcem e rezam por mim, mesmo eu estando longe. Aos amigos de infância/adolescência, com os quais mantenho contato e sempre se preocupam comigo.

Eu chego ao fim dos agradecimentos e só me resta enfatizar, mais uma vez: MUITO OBRIGADO a todos que, de que alguma forma, contribuíram para meu enriquecimento intelectual e pessoal. 
"Pode-se tirar tudo de um homem, exceto uma coisa: a última das liberdades humanas - escolher a própria atitude em qualquer circunstância, escolher o próprio caminho"

Viktor Frankl 



\section{RESUMO}

A valorização racional da lignina e seus derivados é um dos maiores desafios ligado às biorrefinarias em que estas macromoléculas são geradas como subprodutos. Os lignossulfonatos, obtidos através do processo de polpação sulfito da madeira, são produzidos em larga escala e pouco utilizados como reagentes na preparação de compostos macromoleculares. A presença de grupos $\mathrm{OH}$ em sua estrutura permite o seu uso como macromonômero na obtenção de poliuretanos (PUs). O presente estudo teve como meta a obtenção de lignopoliuretanos e de compósitos baseados principalmente em matérias primas obtidas a partir de fontes renováveis. O óleo de mamona (OM) e lignossulfonato de sódio (NaLS), ambos oriundos de matérias primas renováveis, foram utilizados, em composições variadas, como substitutos de polióis convencionais, juntamente com difenilmetano diisocianato (MDI), na reação de obtenção de PUs. Inicialmente, PUs foram preparados a partir de NaLS e outros polióis, como dietilenoglicol (DEG), polietilenoglicol (PEG) e OM, assim como a partir destes reagentes, exceto NaLS (amostras controles). Visando aumentar a reatividade das hidroxilas do NaLS frente aos grupos isocianatos na síntese dos lignopoliuretanos, o NaLS foi oxipropilado (reação com óxido de propileno, gerando LSOxi) e hidroxialquilado (reações com glutaraldeído e formaldeído, gerando NaLS-Glu e NaLS-For, respectivamente). O uso de aldeídos na modificação do $\mathrm{NaLS}$, até onde se tenha conhecimento, foi uma abordagem inédita no que se refere à síntese de lignopoliuretanos. Os produtos, (LS-Oxi, NaLS-Glu, NaLS-Glu) foram caracterizados por espectroscopia na região do infravermelho (IV) e, associados ou não com OM, foram usados na preparação de lignopoliuretanos (também caracterizados por IV). Fibras lignocelulósicas extraídas de sisal (Agave sisalana), cujo maior produtor mundial é o Brasil, foram utilizadas como reforço dos lignopoliuretanos preparados. Os compósitos lignopoliuretânicos, bem como os lignopoliuretanos não reforçados, foram caracterizados por análise termogravimétrica (TG), resistência ao impacto, resistência à flexão, microscopia eletrônica de varredura (MEV) e análise térmica dinâmico-mecânica (DMA). Os resultados mostraram que as fibras de sisal aumentaram consideravelmente a resistência ao impacto de todos os lignopoliuretanos. Entre os compósitos baseados em NaLS não modificado (Grupo I), o DEG/NaLS/MDI/Sisal foi o que apresentou melhor resistência ao impacto $\left(472 \mathrm{~J} \mathrm{~m}^{-1}\right)$ e melhor resistência à flexão (47 MPa). Quando o NaLS oxipropilado foi utilizado (Grupo 2), o compósito LS- 
Oxi/MDI/Sisal apresentou resistência ao impacto de $459 \mathrm{~J} \mathrm{~m}^{-1}$ e resistência à flexão de 43 $\mathrm{MPa}$, enquanto que o compósito NaLS-Glu/MDI/Sisal, preparado a partir do $\mathrm{NaLS}$ hidroxialquilado (Grupo 3), apresentou resistência ao impacto de $945 \mathrm{~J} \mathrm{~m}^{-1}$ e resistência à flexão de $23 \mathrm{MPa}$. As imagens de MEV da superfície de fratura pós-ensaio de impacto revelaram uma forte adesão na interface fibra/matriz, como consequência da presença de ligações hidrogênio entre os grupos uretanos da matriz e os grupos hidroxila das fibras, além das interações entre os domínios hidrofóbicos de ambos, fibra e matriz. Materiais com grau de entrecruzamento diversificados, com características entre elastomérica a termorrígidos, foram obtidos a partir do uso do NaLS e do OM, o que faz com que eles se tornem atrativos para diferentes aplicações, como em partes automotivas e painéis de uso arquitetônico. Neste sentido, e atendendo às expectativas atuais, materiais com excelentes propriedades e com elevada proporção de matérias-primas obtidas de fontes renováveis foram desenvolvidos. 


\begin{abstract}
The rational valuing of lignin and its derivatives is one of the major challenges in the biorefinery context where these macromolecules are generated as byproducts. Lignosulfonates obtained through the wood sulfite pulping process are produced on a large scale. However, they are rarely used as reagents in the preparation of macromolecular compounds. The presence of $\mathrm{OH}$ groups in their structure allows their use as a macromonomer to obtain polyurethanes (PU). This study aimed at obtaining lignopolyurethanes and composites based mainly on raw materials obtained from renewable sources. Castor oil (CO) and sodium lignosulfonate (NaLS), both derived from renewable raw materials, were used in different compositions as replacements for conventional polyols along with diphenylmethane diisocyanate (MDI) in the PU synthesis. Initially, polyurethanes were prepared from NaLS and other polyols such as diethylene glycol (DEG), polyethylene glycol (PEG), and OM, as well as by using these reagents, except for NaLS (control samples). In order to increase the reactivity of the $\mathrm{OH}$ groups of $\mathrm{NaLS}$ against isocyanates in the lignopolyurethanes synthesis, NaLS was oxypropylated (reaction with propylene oxide, generating LS-Oxy) and hydroxyalkylated (reaction with formaldehyde and glutaraldehyde, generating NaLS-Glu-For NaLS, respectively). The use of aldehydes in the NaLS modification, as far as we know, is a novel approach with regard to the lignopolyurethane synthesis. The products (LS-Oxy, NaLS-Glu, and NaLS-For) were characterized by infrared spectroscopy (IR) and associated or not with $\mathrm{CO}$ were also used in lignopolyurethanes preparation (also characterized by IR). Lignocellulosic fibers extracted from sisal (Agave sisalana), which has Brazil as its largest producer in the world, were used as reinforcement for the prepared lignopolyurethanes. Lignopolyurethanic composites and the non-reinforced lignopolyurethanes were characterized by thermogravimetric analysis (TG), impact test, flexural strength, scanning electron microscopy (SEM) and dynamic mechanical analysis (DMA). Results showed that sisal fibers substantially increased the impact strength of all lignopolyurethanes. Among the composites based on unmodified NaLS (Group I), DEG/NaLS/MDI/Sisal showed the best impact strength $\left(472 \mathrm{~J} \mathrm{~m}^{-1}\right)$ and the best flexural strength (47 MPa). When the oxypropylated NaLS was used (Group 2), the composite LS-Oxy/MDI/Sisal showed impact strength of $459 \mathrm{~J} \mathrm{~m}^{-1}$ and flexural strength of $43 \mathrm{MPa}$, while the composite NaLS-Glu/MDI/Sisal prepared from the hydroxyalkylated NaLS (Group 3)
\end{abstract}


showed impact strength of $945 \mathrm{~J} \mathrm{~m}^{-1}$ and flexural strength of $23 \mathrm{MPa}$. The SEM images of the fracture surface after the impact test revealed a strong adhesion in the fiber/matrix interface as a consequence of the presence of hydrogen bonds between the urethane groups of the matrix and the hydroxyl groups of the fibers, in addition to the interactions between the hydrophobic domains of both fiber and matrix. Materials with different degrees of crosslinking and characteristics from elastomeric to thermoset were obtained from the use of $\mathrm{NaLS}$ and $\mathrm{CO}$, which makes them attractive for different applications such as automotive parts and panels for architectural use. In general, materials with excellent properties and prepared with a high proportion of renewable raw materials were developed, thus meeting the current expectations concerning biobased materials. 


\section{LISTA DE FIGURAS}

Figura I - Estrutura da celobiose (unidade repetitiva da celulose). 30

Figura 2 - Estruturas de unidades de monossacarídeos presentes na hemiceluloses (polioses)

Figura 3 - Estrutura de uma fibra lignocelulósica. 32

Figura 4 - (a) Planta de sisal (Agave sisalana) e (b) fibras de sisal. 34

Figura 5 - Produção mundial e brasileira de sisal das safras de 2011 e 2012 (baseado em dados da FAO).

Figura 6 - Três principais precursores da lignina (monolignóis) e suas estruturas correspondentes presente na lignina. 36

Figura 7 - Estrutura de lignina de coniferas proposta por Adler (1977). 37

Figura 8 - Parte da estrutura de um lignossulfonato. .39

Figura 9 - Reação de obtenção de um poliuretano. .43

Figura 10 - Estruturas de ressonância do grupo isocianato. 44

Figura II - Reação dos isocianatos: adição à ligação CN. 44

Figura 12 - (a) Reação entre isocianato e uretano; (b) Reação entre isocianato e ureia. ........45

Figura 13 - Reações de condensação dos isocianatos. 45

Figura 14 - (a) Representação esquemática de um polímero poliuretânico com baixo grau de entrecruzamento e (b) com alto grau de entrecruzamento (IONESCU, 2005)... .46

Figura 15 - (a) Estruturas químicas presentes no MDI puro, (b) Oligoisocianatos .48 Figura 16 - Ácidos graxos presentes no OM: (a) triglicerídeo do ácido ricinoleico; (b) ácido oleico e (c) ácido linoleico. 50

Figura 17 - (a) Representação esquemática da oxipropilação de polímeros naturais; .53 Figura 18 - (a) Representação esquemática da reação (favorável) de substituição nucleofilica de segunda ordem e (b) da reação não favorável.

Figura 19 - (a) Reação envolvida na homopolimerização do OP; (b) poli(propileno glicol)...55 Figura 20 - Hidroxialquilação do NaLS com formaldeído (a) e glutaraldeído (b). 57 Figura 21 - (a) Obtenção de poliuretano baseado em lignossulfonato de sódio e MDI e componentes principais das fibras lignocelulósicas: (b) celobiose: unidade repetitiva da celulose e (c) unidades típicas de lignina 
Figura 22 - Estrutura do (a) lignossulfonato de sódio (NaLS); (b) MDI polimérico; (c) glutaraldeído; (d) formaldeído; (e) OP; (f) dietilenoglicol (DEG); (g) polietilenoglicol (PEG); e (h) ácido ricinoléico: principal componente do OM (OM).

Figura 23 - Representação do processo de obtenção dos compósitos de matriz lignopoliuretânica e fibras de sisal. 73

Figura 24 - Esquema representativo do ensaio de flexão em três pontos 86

Figura 25 - Difratograma de raios $X$ da fibra de sisal. 90

Figura 26 - Espectro na região de infravermelho da fibra de sisal.

Figura 27 - Curvas TG e dTG da fibra de sisal, em atmosfera de $\mathrm{N}_{2}$, fluxo de $50 \mathrm{~mL} \mathrm{~min}^{-1}$ e razão de aquecimento de $10^{\circ} \mathrm{C} \mathrm{min}^{-1}$....

Figura 28 - Imagens de MEV da superfície (a) e do corte transversal da superfície (b) das fibras de sisal. 93

Figura 29 - Espectro na região do infravermelho do lignossulfonato de sódio (NaLS). 95

Figura 30 - Curva TG e dTG do lignossulfonato de sódio ( $\mathrm{NaLS}$ ), em atmosfera de $\mathrm{N}_{2}$, fluxo de $20 \mathrm{~mL} \mathrm{~min}{ }^{-1}$ e razão de aquecimento de $10^{\circ} \mathrm{C} \mathrm{min}^{-1}$.

Figura 3 I - Titulação condutométrica do lignossulfonato de sódio na presença de $48 \mathrm{~mL}$ de $\mathrm{HCl} \mathrm{0,I} \mathrm{M.}$ 97

Figura 32 - Espectros de diferença na região do ultravioleta visível do lignossulfonato de sódio. 99

Figura 33 - Proposta das principais unidades presentes na estrutura do lignossulfonato de sódio.

Figura 34 - Espectro na região de infravermelho OM (OM), polietilenoglicol (PEG) e dietilenoglicol (DEG). 103

Figura 35 - Espectros na região de infravermelho de (a) poliuretano DEG/MDI e lignopoliuretano DEG/NaLS/MDI; (b) poliuretano PEG/MDI e lignopoliuretano $\mathrm{PEG} / \mathrm{NaLS} / \mathrm{MDI}$; (c) poliuretano OM/MDI e lignopoliuretano OM/NaLS/MDI.

Figura 36 - (a, c, e) Curvas TG de poliuretanos e lignopoliuretanos e (b, d, f) respectivos compósitos, em atmosfera de $\mathrm{N}_{2}$, fluxo de $50 \mathrm{~mL} \mathrm{~min}{ }^{-1}$ e razão de aquecimento de $10{ }^{\circ} \mathrm{C}$ $\min ^{-1}$

Figura 37 - (a, c, e) Curvas dTG de poliuretanos e lignopoliuretanos e (b, d, f) respectivos compósitos, em atmosfera de $\mathrm{N}_{2}$, fluxo de $50 \mathrm{~mL} \mathrm{~min}^{-1}$ e razão de aquecimento de $10{ }^{\circ} \mathrm{C}$ $\min ^{-1}$. 
Figura 38 - Resistência ao impacto Izod (corpos de prova não-entalhados) de (a) Poliuretanos e Compósitos poliuretânicos e (b) Lignopoliuretanos e Compósitos lignopoliuretânicos; ambos grupos de materiais descritos nos Quadros I e 2. 109

Figura 39 - Fenômeno fiber bridging observado em corpos de prova do compósito DEG/NaLS/MDI/Sisal* após o ensaio de impacto. 110

Figura 40 - Representação estrutural de poliuretano obtido à partir de (a) DEG e (b) PEG.

Figura 4I - Imagens de MEV das superfícies fraturadas do (a) DEG/MDI; (b) DEG/MDI/Sisal; (c) PEG/MDI; (d) PEG/MDI/Sisal; (e) OM/MDI (fraturado em $\mathrm{N}_{2}$ ); e (f) OM/MDI/Sisal........I I 3 Figura 42 - Imagens de MEV das superfícies fraturadas do (a) DEG/NaLS/MDI; (b) DEG/NaLS/MDI/Sisal; (c) PEG/NaLS/MDI; (d) PEG/NaLS/MDI/Sisal; (e) OM/NaLS/MDI; e (f) $\mathrm{OM} / \mathrm{NaLS} / \mathrm{MDI} / \mathrm{Sisal}$

Figura 43 - Resistência à flexão de (a) PUs e Compósitos poliuretânicos (Quadro 2) e (b) Lignopoliuretanos e Compósitos lignopoliuretânicos (Quadro I).

Figura 44 - Módulo de flexão de (a) PUs e compósitos poliuretânicos (Quadro 2) e (b) lignopoliuretanos e compósitos lignopoliuretânicos (Quadro I).

Figura 45 - Curvas DMA dos lignopoliuretanos não reforçados descritos no Quadro I (Experimental): (a) módulo de armazenamento (E'); e (b) módulo de perda (E') versus temperatura.

Figura 46 - Curvas DMA dos compósitos lignopoliuretânicos descritos no Quadro I (Experimental): (a) módulo de armazenamento (E'); e (b) módulo de perda (E’) versus temperatura.

Figura 47 - Espectros na região do infravermelho do lignossulfonato de sódio (NaLS) e do lignossulfonato oxipropilado (LS-Oxi). 123

Figura 48 - Representação esquemática da (a) reação de oxipropilação do lignossulfonato de sódio e (b) reação de polimerização do OP iniciada por um grupo hidroxila

Figura 49 - Espectros na região do infravermelho dos lignopoliuretanos NaLS/MDI, OM/LS/MDI, LS-Oxi/MDI e OM/LS-Oxi/MDI. (a) 4000-400 cm-1, (b) $2000-720 \mathrm{~cm}^{-1}$. Figura 50 - Curvas (a) TG e (b) dTG dos lignopoliuretanos não reforçados NaLS/MDI, OM/NaLS/MDI, LS-Oxi/MDI e OM/LS-Oxi/MDI, em atmosfera de $\mathrm{N}_{2}$, fluxo de $50 \mathrm{~mL} \mathrm{~min}^{-1}$ e razão de aquecimento de $10^{\circ} \mathrm{C} \mathrm{min}^{-1}$ 
Figura 5 I - Curvas (a) TG e (b) dTG dos compósitos NaLS/MDI/Sisal, OM/NaLS/MDI/Sisal, LS-Oxi/MDI/Sisal e OM/NaLS-Oxi/MDI/Sisal; em atmosfera de $\mathrm{N}_{2}$, fluxo de $50 \mathrm{~mL} \mathrm{~min} \mathrm{~m}^{-1}$ e razão de aquecimento de $10^{\circ} \mathrm{C} \mathrm{min}^{-1}$.

Figura 52 - Resistência ao impacto Izod (corpos de prova não-entalhados): (a) lignopoliuretanos não reforçados e (b) compósitos lignopoliuretânicos reforçados com fibras de sisal; fotos que mostram o fenômeno fiber bridging observado nos compósitos LSOxi/MDI/Sisal e OM/LS-Oxi/MDI/Sisal.

Figura 53 - Imagens de MEV da superfície de fratura dos lignopoliuretanos não reforçados OM/NaLS/MDI, LS-Oxi/MDI e OM/LS-Oxi/MDI

Figura 54 - Imagens de MEV da superfície de fratura dos compósitos lignopoliuretânicos (Quadro 3).

Figura 55 - (a) Resistência à flexão e (b) Módulo de flexão dos lignopoliuretanos não reforçados e dos compósitos lignopoliuretânicos reforçados com fibras de sisal (Quadro 3 Experimental)...

Figura 56 - Curvas DMA dos lignopoliuretanos não reforçados (Quadro 3 - Experimental): (a) Módulo de armazenamento (E') versus temperatura e (b) Módulo de perda (E’) versus temperatura. 138

Figura 57 - Curvas DMA dos compósitos lignopoliuretânicos (Quadro 3): (a) Módulo de armazenamento (E') versus temperatura e (b) Módulo de perda (E’) versus temperatura..I39 Figura 58 - Espectro na região de infravermelho do lignossulfonato de sródio (NaLS), lignossfulfonato de sódio modificado com formaldeído (NaLS-For) e lignossulfonato de sódio modificado com glutaraldeído (NaLS-Glu).

Figura 59 - Espectros na região de infravermelho dos lignopoliuretanos OM/NaLS-Glu/MDI, OM/NaLS-Glu-FOR/MDI, NaLS-Glu/MDI e NaLS-For/MDI. 142 Figura 60 - Curvas (a) TG e (b) dTG para lignopoliuretanos (Grupo 3); em atmosfera de $\mathrm{N}_{2}$, fluxo de $50 \mathrm{~mL} \mathrm{~min}^{-1}$ e razão de aquecimento de $10^{\circ} \mathrm{C} \mathrm{min}^{-1}$.

Figura $6 I$ - Curvas (a) TG e (b) dTG para compósitos lignopoliuretânicos (Grupo 3); em

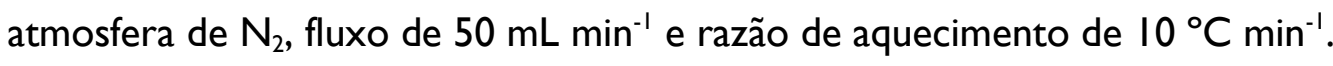
.145 Figura 62 - Resistência ao impacto (corpos de prova não-entalhados) de lignopoliuretanos não reforçados e compósitos lignopoliuretânicos descritos nos Quadros 4 e 5 (Experimental). 146 
Figura 63 - Imagens de MEV das superfícies fraturadas do (a) OM/NaLS/MDI e (b) $\mathrm{OM} / \mathrm{NaLS} / \mathrm{MDI} /$ Sisal (novo tempo de mistura) .............................................................................. 148

Figura 64 - Imagens de MEV das superfícies fraturadas do (a) lignopoliuretano OM/NaLSGlu/MDI e (b) compósito OM/NaLS-Glu/MDI/Sisal.

Figura 65 - Imagens de MEV das superfícies fraturadas do (a) lignopoliuretano NaLS-Glu/MDI e (b) compósito NaLS-Glu/MDI/Sisal; (c) fenômeno fiber bridging em corpo de prova do compósito NaLS-Glu/MDI/Sisal.

Figura 66 - Imagens de MEV das superfícies fraturadas do compósito OM/NaLSFor/MDI/Sisal

Figura 67 - Resistência à flexão de lignopoliuretanos e compósitos lignopoliuretânicos descritos nos Quadros 4 e 5 (Experimental).

Figura 68 - Módulo de flexão de lignopoliuretanos e compósitos lignopoliuretânicos que compreendem os Quadros 4 e 5 (Experimental). 


\section{LISTA DE TABELAS}

Tabela I - Ciclo I para obtenção de PUs, lignopoliuretanos e respectivos compósitos..........74

Tabela 2 - Ciclo 2 para obtenção de PUs, lignopoliuretanos e respectivos compósitos..........79

Tabela 3 - Ciclo 3 para obtenção de PUs, lignopoliuretanos e respectivos compósitos..........82

Tabela 4 - Composição da fibra de sisal

Tabela 5 - Principais absorções observadas no espectro na região do infravermelho da fibra de sisal e seus respectivos modos vibracionais (SILVERSTEIN; BASSLER; MORRIL, I994). ..91

Tabela 6 - Composição do lignossulfonato de sódio (NaLS).

Tabela 7 - Principais absorções observadas em espectro de infravermelho de lignossulfonatos (RODRIGUEZ, 2005; SHEN; ZHANG; ZHU, 2008; SHUL'GA; GOMOLKO; KRUT'KO, 2008; KIM et al., 2009).

Tabela 8 - Absortividades e teores de $\mathrm{OH}$ fenólicas do lignossulfonato de sódio obtidos à partir dos espectros UV de diferença.

Tabela 9 - Porcentagens em massa e teor em $\mathrm{mmol} \mathrm{g}^{-1}$ de grupos hidroxilas e sulfonatos no lignossulfonato de sódio.

Tabela 10 - Principais absorções observadas nos espectros de óleo de mamona, polietilenoglicol e dietilenoglicol (SCHNEIDER, 2002).

Tabela II - Principais absorções observadas em espectro de PUs e lignopoliuretanos preparados à partir de DEG, PEG, OM e NaLS (CIOBANU et al., 2004; CUl et al., 2007; WANG et al., 20I0; HUO et al., 20I I; FARIA et al., 20I2; RISTIĆ et al., 20I2)

Tabela 12 - Informações sobre fratura e deformação durante o ensaio de flexão (sistema 3 pontos) para os materiais descritos nos Quadros I e 2 (Experimental).

Tabela 13 - Comparação entre compósitos de matrizes lignopoliuretanas reforçadas com diferentes fibras lignocelulósicas (curauá, coco e sisal).

Tabela 14 - Fratura e deformação durante o ensaio de flexão (sistema de 3 pontos) para os lignopoliuretanos não reforçados e respectivos compósitos.

Tabela 15 - Informações sobre fratura e deformação durante o ensaio de flexão (sistema 3 pontos) para os materiais preparados conforme descrito nos Quadros 4 e 5 


\section{LISTA DE ABREVIATURAS, SIGLAS E SÍMBOLOS}

\begin{tabular}{|c|c|}
\hline DEG & Dietilenoglicol \\
\hline dTG & Primeira derivada da curva TG \\
\hline E' & Módulo de armazenamento \\
\hline E” & Módulo de perda \\
\hline$E_{f}$ & Módulo de flexão \\
\hline For & Formaldeído \\
\hline Glu & Glutaraldeído \\
\hline $\mathbf{I}_{\mathbf{c}}$ & Índice de cristalinidade \\
\hline $\mathrm{IOH}$ & İndice de hidroxilas ou número de hidroxilas \\
\hline IV & Espectroscopia na região do infravermelho \\
\hline LS-Oxi & Lignossulfonato oxipropilado \\
\hline MDI & Difenilmetano diisocianato \\
\hline MEV & Microscopia eletrônica de varredura \\
\hline$M_{n}$ & Massa molar numérica média \\
\hline$M_{w}$ & Massa molar ponderal média \\
\hline NaLS & Lignossulfonato de sódio \\
\hline NaLS-For & Lignossulfonato modificado com formaldeído \\
\hline NaLS-Glu & Lignossulfonato modificado com glutaraldeído \\
\hline $\mathbf{O M}$ & Oleo de mamona \\
\hline OP & Oxido de propileno \\
\hline PEG & Polietilenoglicol \\
\hline PU & Poliuretano [PUs = Poliuretanos $]$ \\
\hline TG & Análise termogravimétrica \\
\hline$\sigma_{\mathrm{f}}$ & Resistência à flexão \\
\hline
\end{tabular}




\section{SUMÁRIO}

\section{RESUMO}

\section{ABSTRACT}

\section{LISTA DE FIGURAS}

\section{LISTA DE TABELAS}

\section{LISTA DE ABREVIATURAS, SIGLAS E SÍMBOLOS}

I. INTRODUÇÃO

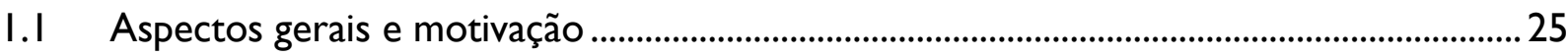

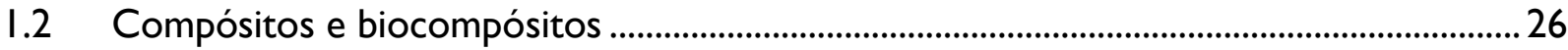

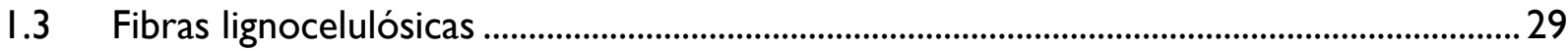

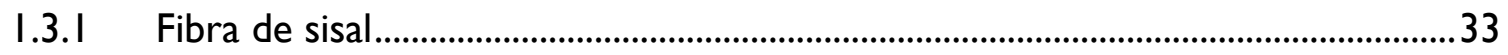

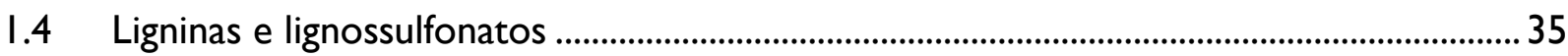

I.5 Emprego de ligninas e lignossulfonatos na síntese de polímeros e novos materiais....... 40

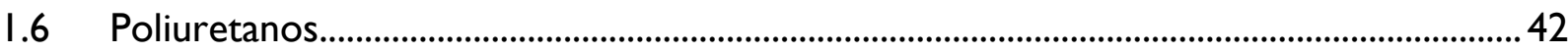

I.7 Uso do óleo de mamona em poliuretanos............................................................................... 49

I.8 Formas de uso da lignina como macromonômero na síntese de PUs ................................5।

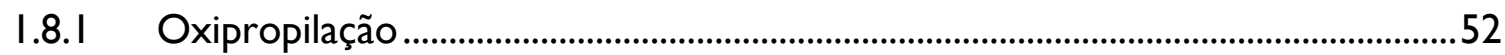

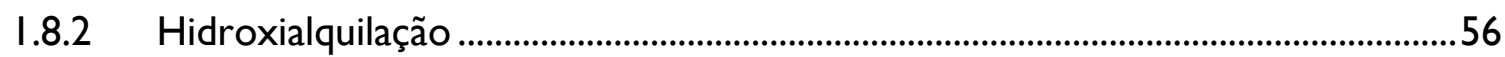

I.9 Uso de lignopoliuretanos como matrizes de compósitos reforçados por fibras naturais .

2. OBJETIVOS

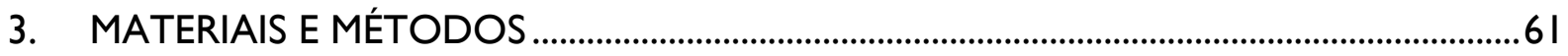

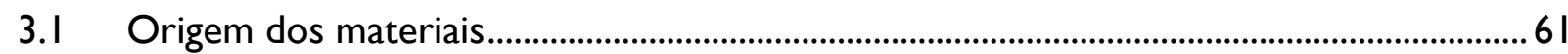

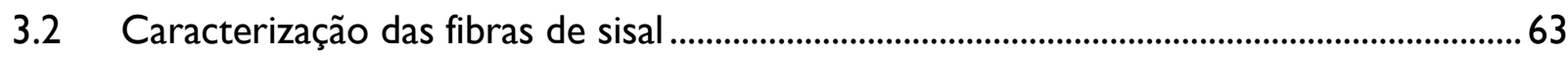

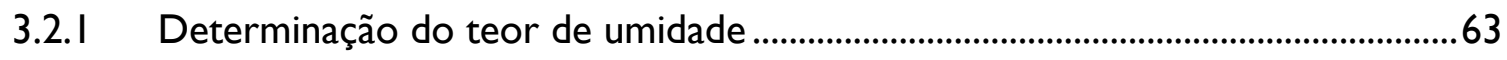

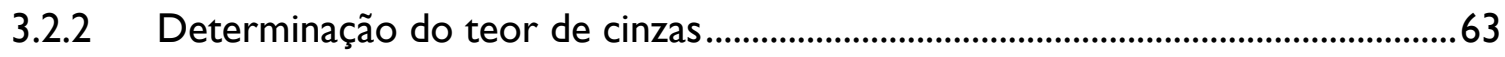

3.2.3 Determinação do teor de holocelulose..................................................................64

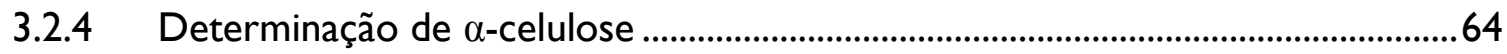

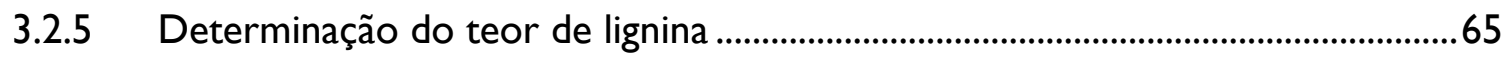


3.2.6 Determinação do índice de cristalinidade (Ic).

3.3 Caracterização do lignossulfonato de sódio ( $\mathrm{NaLS}$ )

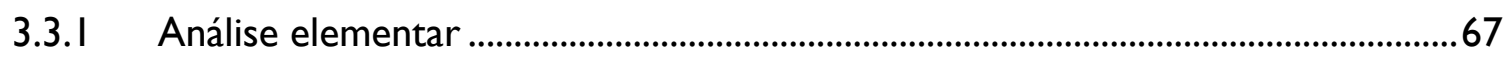

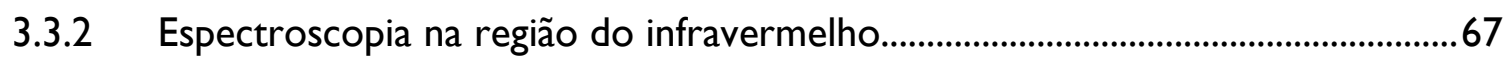

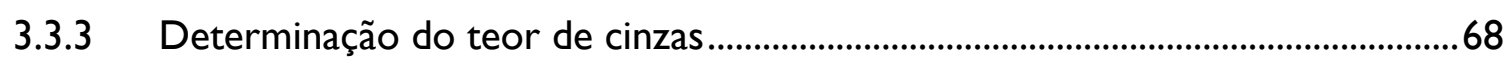

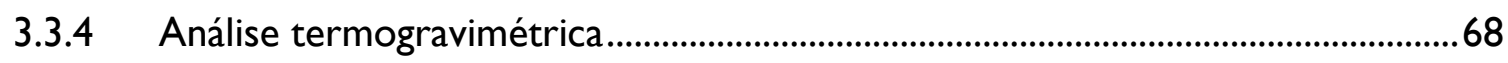

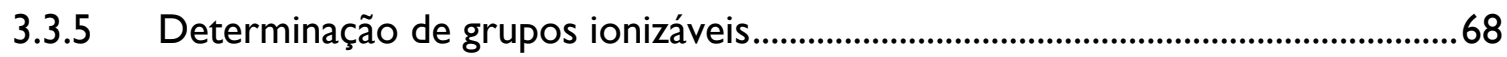

3.3.6 Determinação do teor de hidroxilas fenólicas por espectroscopia na região do ultravioleta visível (UV-Vis)

3.4 Síntese de poliuretanos, lignopoliuretanos e preparação dos respectivos compósitos. 70

3.5 Grupo I: poliuretanos, lignopoliuretanos e respectivos compósitos à partir do NaLS e polióis convencionais (DEG, PEG e OM)

3.5.I Procedimento de obtenção do compósito lignopoliuretano

DEG/NaLS/MDI/Sisal e do lignopoliuretano não reforçado DEG/NaLS/MDI......................72

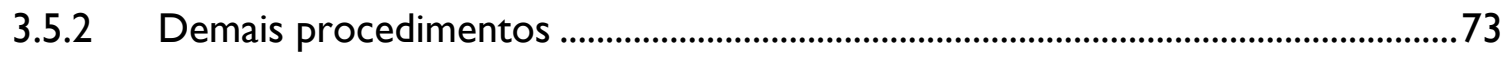

3.6 Grupo 2: lignopoliuretanos e respectivos compósitos à partir do NaLS oxipropilado (LS-Oxi) e OM..

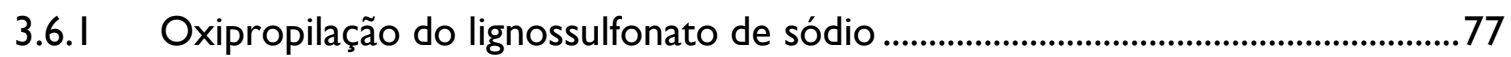

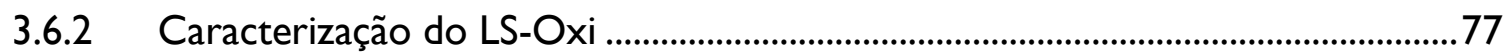

3.6.3 Procedimentos de preparação de lignopoliuretanos e compósitos .......................79

3.7 Grupo 3: lignopoliuretanos e respectivos compósitos à partir do NaLS hidroxialquilado (NaLS-Glu e NaLS-For).

3.7.I Hidroxialquilação do lignossulfonato de sódio: reação com glutaraldeído (NaLS-

Glu) 81

3.7.2 Hidroxialquilação do lignossulfonato de sódio: reação com formaldeído (NaLSFor) 81

3.7.3 Procedimento de obtenção dos lignopoliuretanos e compósitos lignopoliuretânicos 82

3.8 Caracterização dos poliuretanos, lignopoliuretanos e compósitos

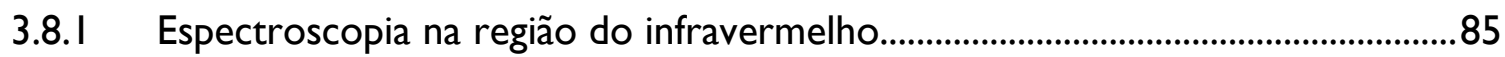

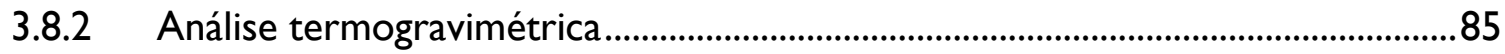

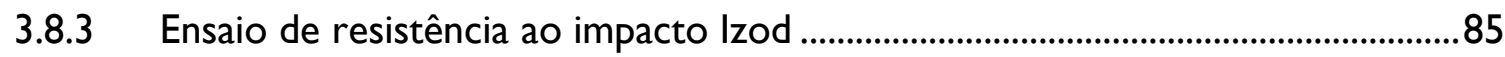




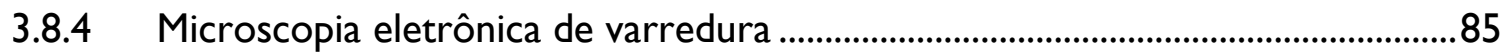

3.8.5 Ensaio de resistência à flexão..........................................................................................

3.8.6 Análise térmica dinâmico-mecânica (DMA) ...............................................................8

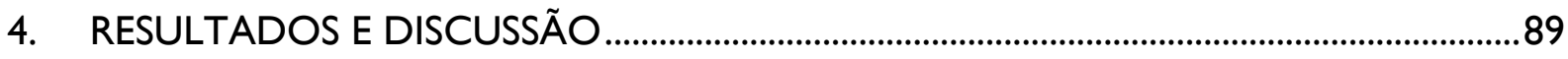

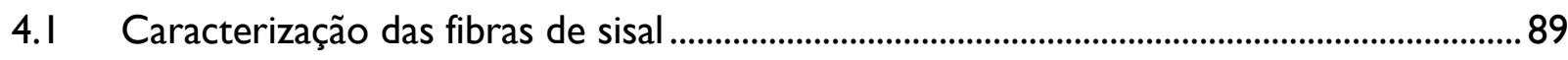

4.2 Caracterização do lignossulfonato de sódio (NaLS) ……………...........................................94

4.2.I Análise elementar, teor de cinzas, espectroscopia na região do infravermelho e

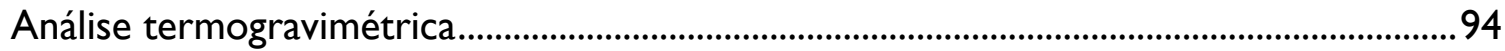

4.2.2 Determinação dos grupos ionizáveis por titulação condutométrica .....................97

4.2.3 Determinação do teor de hidroxilas fenólicas por espectroscopia UV-Vis.......99

4.2.4 Considerações envolvendo todas as análises em relação ao teor de hidroxilas do lignossulfonato de sódio 100

4.3 Grupo I: poliuretanos, lignopoliuretanos e respectivos compósitos à partir do NaLS e polióis convencionais (DEG, PEG e OM)

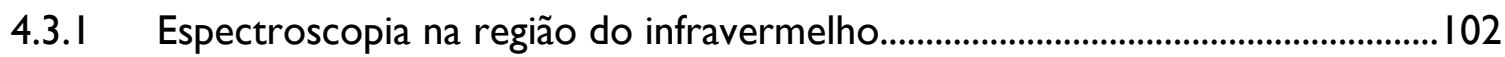

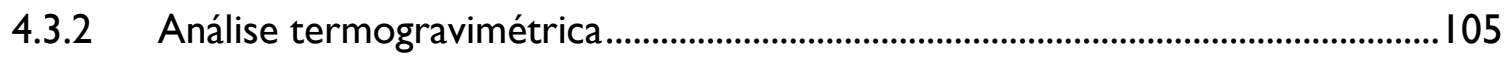

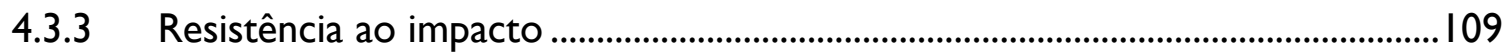

4.3.4 Microscopia eletrônica de varredura ......................................................................... I I

4.3.5 Resistência à flexão ................................................................................................ I I5

4.3.6 Comparação com estudos anteriores................................................................ 18

4.3.7 Análise térmica dinâmico-mecânica ............................................................................. 120

4.4 Grupo 2: lignopoliuretanos e respectivos compósitos à partir do NaLS, NaLS oxipropilado (LS-Oxi) e OM

4.4.I Oxipropilação do lignossulfonato de sódio ........................................................... 23

4.4.2 Espectroscopia na região do infravermelho dos lignopoliuretanos...................... 125

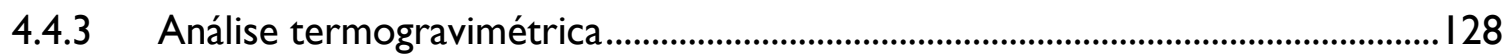

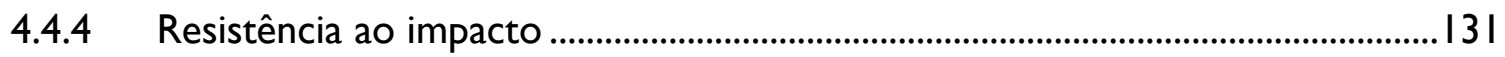

4.4.5 Microscopia eletrônica de varredura ......................................................................... 133

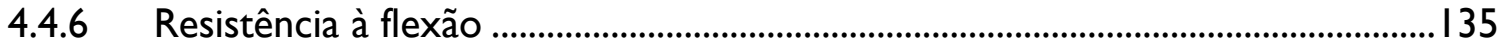

4.4.7 Análise térmica dinâmico-mecânica (DMA) ................................................................ 138

4.5 Grupo 3: lignopoliuretanos e respectivos compósitos à partir do NaLS hidroxialquilado (NaLS-Glu e NaLS-For). 
4.5.I Hidroxialquilação do lignossulfonato de sódio

4.5.2 Espectroscopia na região do infravermelho dos lignopoliuretanos (Quadro 5) $|4|$

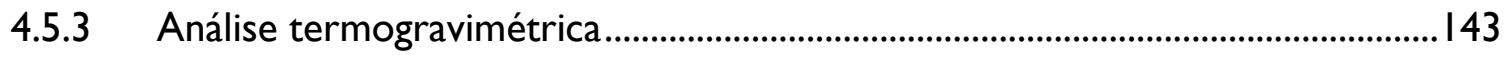

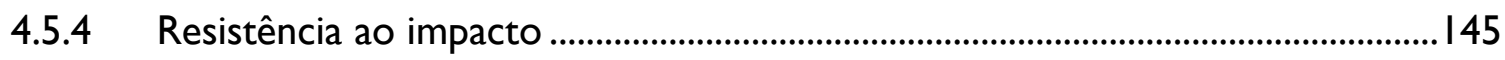

4.5.5 Microscopia eletrônica de varredura ......................................................................... 44

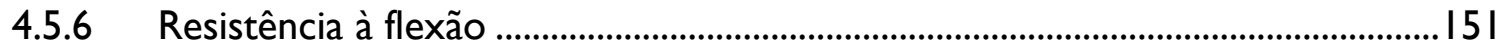

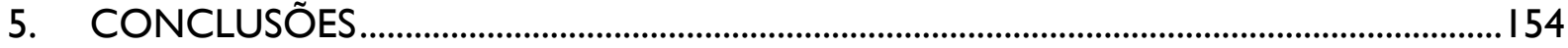

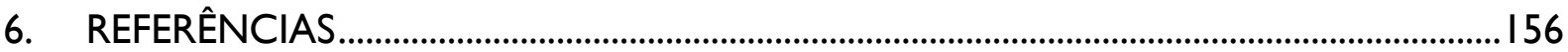




\section{INTRODUÇÃO}

\section{I.I Aspectos gerais e motivação}

A maioria dos produtos químicos usados atualmente em nossa sociedade é originada de fontes fósseis, sendo obtidos através de processos de refinaria. No entanto, a utilização de recursos renováveis como matérias-primas na produção de energia e novos materiais vem ganhando destaque nos últimos anos. As exigências ambientais, cada vez mais rigorosas, que buscam a minimizar os impactos ambientes e a possível diminuição de combustíveis fósseis não renováveis, são alguns dos fatores que têm impulsionado a busca pelo uso de matérias primas não agressivas ao meio-ambiente (RAQUEZ et al., 2010; POHJANLEHTO et al., 20I4).

Além dos fósseis, uma outra fonte para produção de produtos químicos é a biomassa, e de forma mais específica os materiais lignocelulósicos (biomassa vegetal, composta predominantemente de celulose, hemiceluloses e lignina). A biomassa chama a atenção pois é amplamente disponível, renovável e promissora na produção sustentável de produtos químicos como alternativa ao petróleo (WANG et al., 20I3; LAURICHESSE; AVÉROUS, 20I4). O uso eficaz de matérias-primas originadas da biomassa em aplicações de grande escala evoluirá a partir de pesquisas inovadoras que visam o desenvolvimento e implementação de biorrefinarias - com múltiplas etapas e múltiplos produtos - estabelecidas para matérias primas específicas de origem biológica (FITZPATRICK et al., 20I0; CHERUBINI; STRØMMAN, 20II). Grande parte da biomassa que é atualmente considerada como lixo pode se tornar uma matéria-prima valiosa. Assim, em um futuro próximo, o principal objetivo das biorrefinarias poserá ser a transformação de biomassa lignocelulósica através da reciclagem de resíduos florestais e agrícolas. Estas refinarias poderão produzir energia de base biológica e produtos químicos de alto valor agregado. No entanto, elas devem ter como base unidades pequenas e flexíveis para superar eventuais problemas com o transporte de biomassa (STRASSBERGER; TANASE; ROTHENBERG, 20I4).

Considerando a área disponível para cultivo no país, e a relevância do desenvolvimento de pesquisas relacionadas à utilização de biomassa, assim como a importância da formação de recursos humanos na área, é imperativo que esforços sejam concentrados no sentido de valorizar a matéria-prima proveniente da agricultura, com destaque para as fibras 
lignocelulósicas e um de seus componentes majoritários, a lignina. Dentre os componentes da biomassa lignocelulósica, a lignina ganha destaque, pois é o segundo biopolímero mais abundante na Terra, atrás somente da celulose, constituindo cerca de um quarto a um terço da massa seca da madeira. As ligninas, constituídas de vários anéis fenilpropânicos substituídos, são obtidas principalmente como um subproduto da indústria de papel e celulose, onde mais de 70 milhões de ton são produzidas por ano (FARIA et al., 20I2), assim como de outras indústrias que processam a biomassa.

Em décadas recentes têm-se renovado o interesse em pesquisas com fibras oriundas de fontes naturais sustentáveis como potenciais reforços de materiais de alto desempenho, como os compósitos (THOMASON et al., 20ll). As fibras lignocelulósicas extraídas de plantas cultivadas como sisal, curauá, juta, cânhamo, coco, linho, madeira, abacaxi, banana e buriti são exemplos típicos de materiais naturais que podem ser utilizados como reforços (MONTEIRO et al., 2009; JAWAID; ABDUL KHALIL, 20II). Entre as inúmeras vantagens destas fibras, pode-se destacar sua natureza renovável, baixa densidade, alta resistência específica, boas propriedades térmicas, natureza não abrasiva, biodegradabilidade, grande disponibilidade mundial, além de causarem baixa irritação respiratória e de pele, se comparada às fibras sintéticas, como as de vidro. Ainda, o uso de materiais agrícolas como matérias-primas na indústria não somente oferece um recurso renovável compatível com questões ambientais, mas também gera uma fonte não alimentar de desenvolvimento econômico para as regiões rurais (SINGHA; RANA, 20I2).

O presente estudo foi centrado no uso em potencial do lignossulfonato de sódio (NaLS), disponível comercialmente, como matéria-prima na produção de lignopoliuretanos entrecruzados. O NaLS, modificado quimicamente ou não, devido à presença de hidroxilas em sua estrutura, foi escolhido como um poliol oriundo de fonte renovável. Os lignopoliuretanos obtidos foram também usados na preparação de compósitos atuando como matriz, e fibras lignocelulósicas de sisal foram usadas como reforço. A abordagem, até onde se conheça, é inédita.

\section{I.2 Compósitos e biocompósitos}

De forma simplificada, um compósito pode ser definido como um material que apresenta duas ou mais fases distintas sendo, portanto, um material heterogêneo 
(HERAKOVICH, 1998). As duas fases quimicamente distintas presentes nos compósitos são: matriz, que é contínua e circunda a outra fase, e reforço, que é o constituinte disperso. As propriedades de compósitos são funções das propriedades das fases constituintes, das suas quantidades relativas e da geometria da fase dispersa (CALLISTER, 2007).

Existem diversos tipos de materiais que podem ser empregados como matriz. Estes materiais podem ser cerâmicos, poliméricos ou metálicos (MATTHEWS, 1999). As matrizes poliméricas podem ser divididas em termorrígidas ou termoplásticas. Compósitos confeccionados com matriz polimérica têm se tornado mais comum e são largamente utilizados em diversas indústrias. Os compósitos de matriz polimérica termorrígida representam 70\% do total destes materiais (MOREL, 2009).

Os compósitos podem ser classificados em três principais divisões: reforçados por partícula, reforçados por fibras e estruturais. Em se tratando de compósitos reforçados por fibras, pode-se citar como reforço as fibras de vidro, fibras poliméricas sintéticas (por exemplo, PET ou PVA), fibras de alto desempenho (como as de carbono e aramidas) e as fibras lignocelulósicas (LA MANTIA; MORREALE, 20II). O presente estudo trata de compósitos de matriz poliméricas (termorrígidas ou entrecruzadas com característica elastomérica) reforçada por fibras naturais.

Entre as funções das fibras em um compósito, pode-se citar a transferência de carga da matriz para a fibra; fornecimento de rigidez, força, estabilidade térmica e estrutural; condutividade elétrica ou isolamento, dependendo do tipo de fibra utilizada. As funções importantes de uma matriz incluem a transferência de carga às fibras. A matriz isola as fibras de modo que possam agir separadamente, o que interrompe ou retarda a propagação de uma rachadura. Ainda, a matriz protege as fibras de danos ambientais, decorrentes, por exemplo, de altas temperaturas e umidade (MAZUMDAR, 2002).

Os reforços, tais como as fibras, são adicionados a polímeros (matriz) para melhorar as propriedades, o que pode ainda estar aliado à busca pela redução de custos. $\bigcirc$ grande desafio consiste em combinar fibras e matriz de tal forma que um material mais eficiente para determinada aplicação seja produzido (BERLIN et al., 1986; HERAKOVICH, 1998).

As resinas termorrígidas são as mais utilizadas como matrizes por razões de preço, de facilidade de fabricação (resinas geralmente líquidas que impregnam facilmente as fibras), de ajuste de diferentes propriedades e de desempenhos finais. Diversas famílias de resinas termorrígidas têm sido bastante utilizadas na fabricação de compósitos: os poliésteres 
insaturados (JIANG et al., 20I4), os epóxidos (MOHAN, 20I3; SPRENGER, 20I3), os vinil ésteres (ZHU et al., 20I2), as fenólicas (FROLLINI; SILVA; RAMIRES, 20I3) e as poliuretânicas (MOHAMED et al., 20I4). Entre estas, as resinas poliuretânicas têm sido pouco utilizadas na para aplicações em compósitos (MOREL, 2009).

A interface fibra/matriz desempenha vários papéis essenciais para $\bigcirc$ bom comportamento do compósito (BATHIAS, 2009):

(a) garantir a continuidade física de um constituinte ao outro por todo o material, impedindo, por exemplo, a formação de porosidades;

(b) transferência de carga da matriz para as fibras por intermédio das interfaces;

(c) proteção de uma das fases, como por exemplo, contra a umidade.

Polímeros reforçados com fibras naturais começaram a ser preparados em 1908, com fibras de celulose em compostos fenólicos (JOHN; THOMAS, 2008), mais tarde estendendo à ureia e melamina, atingindo o status de commodity (mercadorias) com plásticos reforçados com fibra de vidro. A variedade de aplicações dos compósitos é muito grande: construção civil, eletrônicos, indústria automobilística e aeroespacial, artigos esportivos, embalagens e aplicações mecânicas em geral (MOHANTY et al., 2005; FARUK et al., 20I4). A fibra de vidro é usada em $95 \%$ dos compósitos termoplásticos e termorrígidos reforçados (MOHANTY et al., 2005; JOHN; THOMAS, 2008).

Atualmente, é considerado como de extrema importância a necessidade de desenvolver e comercializar materiais baseados em constituintes de origem natural (biobased composites, biocompósitos), o que terá impacto do ponto de vista da redução da dependência de materiais provenientes de combustíveis fósseis, e também do ponto vista ambiental e econômico. A necessidade de desenvolver tecnologia aliada com a preservação ambiental tem criado um interesse renovado no mundo científico para estudar a viabilidade do uso de fibras naturais como agente de reforço em matrizes de biopolímeros. Tais compósitos baseados em fibras, geralmente apresentam boas propriedades mecânicas e reduz a dependência de materiais obtidos de fontes não renováveis (derivados do petróleo), levando a ambos benefícios ambientais e econômico. As vantagens das fibras naturais sobre as fibras sintéticas (como as de vidro ou carbono) são o baixo custo, baixa densidade, propriedades mecânicas específicas aceitáveis, facilidade de separação, sequestradoras de dióxido de carbono e biodegradabilidade (MUKHERJEE; KAO, 20I I). 
Destaca-se que o termo biocompósito pode ser aplicado a materiais em que uma ou mais fases têm origem biológica (FOWLER; HUGHES; ELIAS, 2006). A partir dessa definição, biocompósitos podem ser aqueles preparados com fibras naturais, em matrizes poliméricas oriundas de fontes renováveis ou não. Quando a fibra e a matriz têm origem biológica (matriz baseada em biopolímeros), os biocompósitos são geralmente chamados de green composites (compósitos verdes) (MOHANTY et al., 2005). O que chama a atenção para os green composites é que os mesmos devem ser compatíveis com o meio ambiente, completamente degradáveis e sustentáveis, isto é, eles devem ser verdadeiramente "verde" em qualquer aspecto. No fim de suas vidas eles seriam facilmente eliminados ou compostados sem causar danos ao meio-ambiente (JOHN; THOMAS, 2008).

No presente trabalho, biocompósitos foram preparados a partir de matriz lignopoliuretânicas, baseadas em lignossulfonato de sódio e óleo de mamona (OM, cujo principal componente é o ácido ricinoleico, como detalhado posteriormente), e do reforço de fibras de sisal. Em ambas as fases, tem-se a presença de matérias-primas obtidas a partir de fontes renováveis.

\section{I.3 Fibras lignocelulósicas}

Geralmente, a utilização de fibras vegetais como reforço de materiais compósitos se justifica por valorizar um recurso local de países em desenvolvimento e desenvolver materiais e tecnologias com impacto ambiental reduzido. Neste contexto, se propõe o uso de fibras lignocelulósicas como alternativa ao uso de fibras sintéticas (como as de vidro) porque estas matérias-primas obtidas de fontes renováveis possuem vantagens ambientais, já citadas anteriormente.

Existem milhares de fibras diferentes no mundo e, de fato, somente algumas dessas têm sido estudadas. Pelo menos em parte, aspectos como disponibilidade em grandes quantidades devem ser considerados para aprofundar estudos. Na maioria das pesquisas investiga-se o potencial das fibras lignocelulósicas para uso em aplicações técnicas. Dentre as fibras naturais, pode-se destacar fibras como a de linha, juta, cânhamo, sisal, rami e quenafe como amplamente investigadas e empregadas em diferentes aplicações. Atualmente, fibras de abacá, folhas de abacaxi, coco, bambu, palha de trigo, dendezeiro e cascas de arroz estão 
ganhando interesse e importância em pesquisas e aplicações devido as suas propriedades específicas e disponibilidade (FARUK et al., 20I4).

As fibras lignocelulósicas têm características de compósitos, onde uma matriz amorfa de lignina permeia as microfibrilas de celulose organizadas helicoidalmente. A hemiceluloses presente atuaria como um agente compatibilizante entre a celulose e a lignina (KALIA et al., 20I3). Pequenas proporções de proteínas, lipídeos (gorduras, ceras, óleos) e cinzas (material inorgânico) geralmente também estão presentes. A seguir, se discorre sobre os dois principais componentes das fibras lignocelulósicas: celulose e hemiceluloses. Devido à importância da lignina neste estudo, a mesma será descrita em detalhes no item I.4.

A celulose é o principal constituinte dos tecidos vegetais. Trata-se de um polissacarídeo que consiste de unidades de $D$-anidroglicose $\left(\mathrm{C}_{6} \mathrm{H}_{10} \mathrm{O}_{5}\right)_{n}$, conectadas por ligações I,4- $\beta-D$-glicosídicas no $\mathrm{Cl}$ e C4 (Figura I). A estrutura de celulose presente nos tecidos das plantas é a mesma, com longas cadeias poliméricas contendo unidades de glicose. As diferenças nas propriedades de celulose são devidas, principalmente, aos diferentes graus de polimerização e de cristalinidade. A Figura I mostra a unidade repetitiva da celulose, a celobiose. A presença de grupos hidroxilas e suas habilidades para ligações hidrogênio definem a cristalinidade, e também governam as propriedades físicas da celulose $(\mathrm{OOHN}$; THOMAS, 2008).

Figura I - Estrutura da celobiose (unidade repetitiva da celulose).

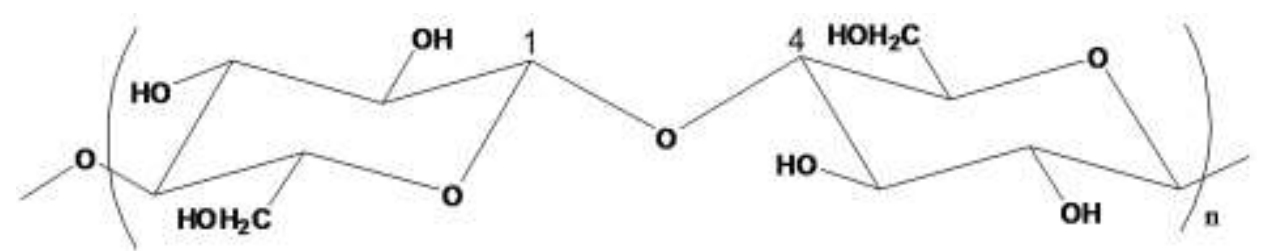

Fonte: (FENGEL; WEGENER, 1989)

As hemiceluloses, também chamadas de polioses (Figura 2), correspondem a polissacarídeos com grau de polimerização menor (aproximadamente de 10 a 100 vezes menor) comparativamente ao da celulose (FENGEL; WEGENER, 1989). Ela difere da celulose por conter diferentes unidades de açúcares, enquanto a celulose possui apenas a Danidroglicose. Holocelulose é o termo utilizado para indicar a fração total de carboidratos da 
planta (hemiceluloses e celulose), a qual permanece após a remoção da lignina (PATURAU, 1989). A hemiceluloses pode ser considerada como um compatibilizador entre celulose e lignina na fibra lignocelulósica (ACHA; MARCOVICH; REBOREDO, 2009).

Figura 2 - Estruturas de unidades de monossacarídeos presentes na hemiceluloses (polioses)

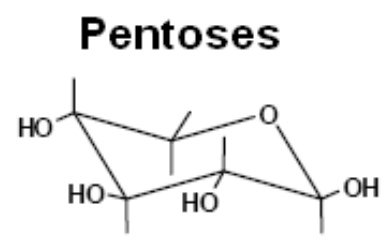

$\beta$-D-xilanopiranose

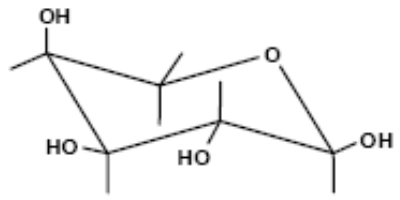

$\alpha$-L-arabinopiranose

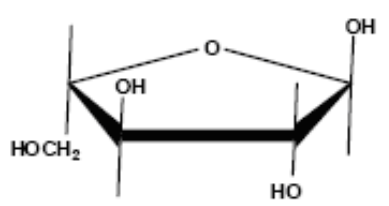

$\alpha$-L-arabinofuranose

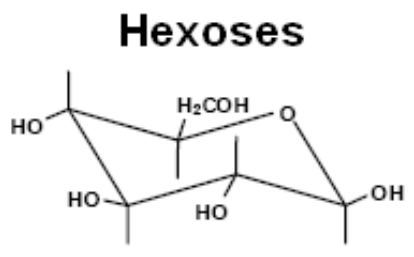

$\beta$-D-glicopiranose

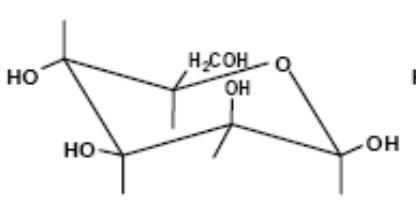

$\beta$-D-manopiranose

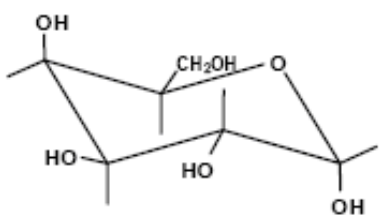

$\alpha$-D-galactopiranose

\section{Ácidos hexourônicos}

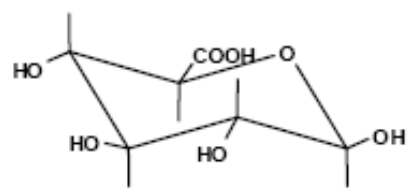

Acido $\beta$-D-glicurônico

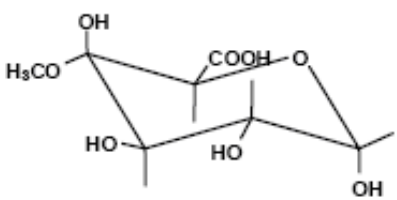

Acido $\alpha$-D-4-0-metil-glicurônico

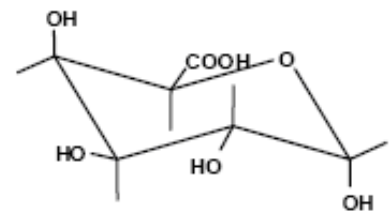

Acido $\alpha$-D-galacturônico

Fonte: (FENGEL; WEGENER, 1989)

A composição química e estrutura das fibras naturais podem variar conforme a espécie, de planta para planta, e até em diferentes partes da mesma planta. Outros fatores como diferentes regiões geográficas, idade, clima e condições de solo também podem afetar a composição da fibra. Estas características influenciam as propriedades mecânicas das fibras (KOMPELLA; LAMBROS, 2002; FARUK et al., 20I2).

A parede celular na fibra não é uma membrana homogênea (Figura 3). Cada microfibrila tem uma estrutura complexa, que consiste em camadas de uma parede fina principal que é a primeira camada depositada durante o crescimento celular que rodeia uma parede secundária. A parede secundária é formada por três camadas e a camada de espessura média determina as propriedades mecânicas da fibra. A camada do meio é constituída por uma série de microfibrilas de celulose enroladas em hélice seguindo um ângulo chamado ângulo microfibrilar (que é o ângulo entre a microfibrila e o eixo da fibra). 
O valor característico para este parâmetro varia de uma fibra para outra (JOHN; THOMAS, 2008).

Figura 3 - Estrutura de uma fibra lignocelulósica

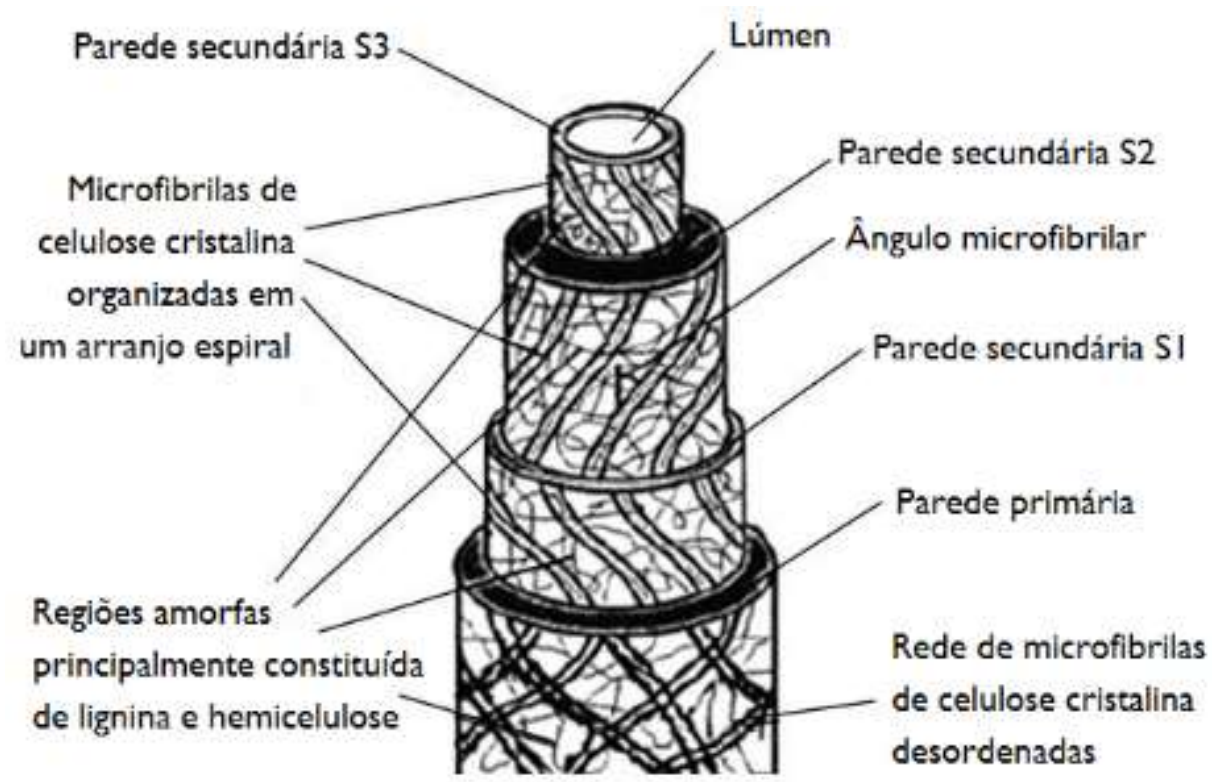

Fonte: (JOHN; THOMAS, 2008)

Em geral, o teor do reforço e a orientação das fibras condicionam as características elásticas de um material compósito. Da mesma maneira, em uma fibra lignocelulósica, as propriedades físicas das fibras são principalmente determinadas pela composição química, porcentagem de celulose, ângulo microfibrilar, estrutura, seção e grau de polimerização (BLEDZKI; GASSAN, 1999). Para uma dada quantidade de celulose, quanto menor o ângulo microfibrilar, mais elevada será a rigidez e resistência mecânica da fibra. $O$ alongamento na ruptura da fibra está diretamente ligado ao ângulo microfibrilar. As propriedades específicas (razão propriedade/densidade) das fibras lignocelulósicas, particularmente a rigidez, são comparáveis àquelas das fibras de vidro (WAMBUA; IVENS; VERPOEST, 2003). Portanto, elas são apropriadas para uso como reforço de matrizes poliméricas termorrígidas e termoplásticas.

Anualmente, aproximadamente 30 milhões de ton de fibras lignocelulósicas são produzidas e utilizadas como principal componente em vestuários, estofamentos e outros setores têxteis. As aplicações do uso de fibras lignocelulósicas como reforços pode ser encontradas em diferentes tipos de mercado, como as embalagens, diferentes produtos 
industriais e de consumo (como os equipamentos esportivos), a indústria automobilística e naval, setores de infraestrutura e materiais para construção civil (JAWAID; ABDUL KHALIL, 20II).

\section{I.3.I Fibra de sisal}

O nome 'Sisal' veio do nome do porto no estado de Yucatán, no México, a partir do qual a fibra foi exportada pela primeira vez (BASU et al., 20I2). O sisal (Agave sisalana, Figura 4a) é uma planta originária do México, e cresce em países tropicais como a Tanzânia e o Brasil, sendo estes atualmente os dois maiores produtores mundiais (RIBEIRO; BARRETO; COELHO, 2014).

O ciclo de transformação do sisal em fios naturais tem início aos 3 anos de vida da planta, ou quando suas folhas atingem até cerca de $140 \mathrm{~cm}$ de comprimento que podem resultar em fibras de 90 a $120 \mathrm{~cm}$. As fibras representam apenas 4 a $5 \%$ da massa bruta da folha do sisal'. As folhas são cortadas a cada 6 meses durante a vida útil da planta que pode ir de 7 a 10 anos, que a caracteriza como uma planta semi-perene. Cerca de 200 e 250 folhas utilizáveis comercialmente são produzidas durante todo o tempo de vida da planta. É considerada uma planta de trópicos e sub-trópicos, uma vez que a produção se beneficia de temperaturas acima de $25^{\circ} \mathrm{C}$ e da luz do sol (BASU et al., 2012). As fibras de sisal (Figura 4b) assim como os demais materiais lignocelulósicos, é constituída principalmente por celulose, hemiceluloses, lignina, além de pectina e ceras. A celulose, hemiceluloses e lignina são os principais componentes responsáveis pelas propriedades físicas das fibras (GEORGOPOULOS et al., 2005).

\footnotetext{
' COSIBRA (Companhia de Sisal do Brasil). <http://www.cosibra.com.br/materia_prima.php> Acesso em: 6 de set. 2014.
} 
Figura 4 - (a) Planta de sisal (Agave sisalana) e (b) fibras de sisal.

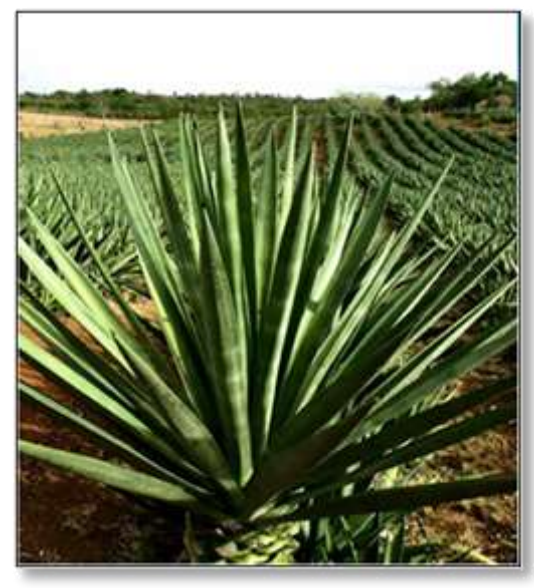

(a)

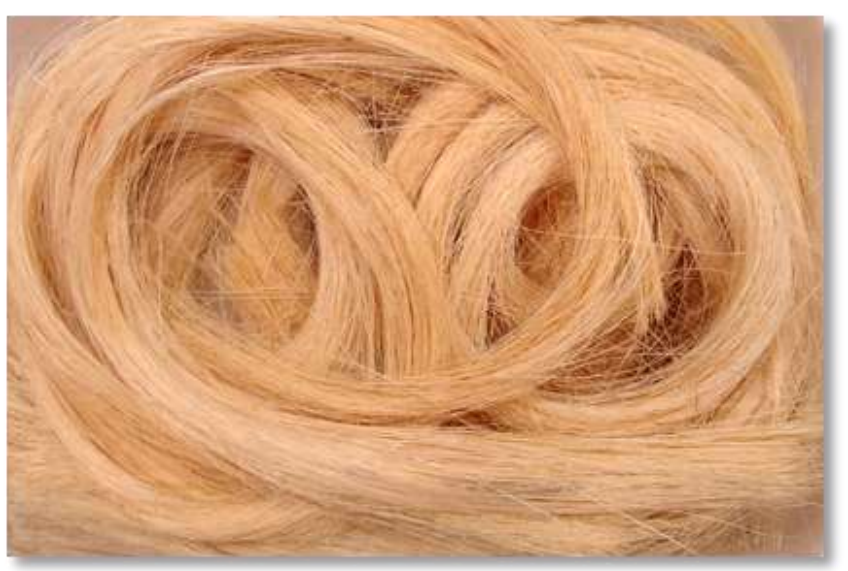

(b)

Este material fibroso sustentável é muito desejado na produção de fios, cordas, cordames, forros marinhos e redes de pesca devido à sua extensão, alta resistência, módulo e durabilidade (especialmente em água salgada). As fibras também são utilizadas na fabricação de placas de dardo, panos de polimento, filtros, colchões, sacos de café, sacos de compras, entre outros (BASU et al., 20I2).

Aproximadamente 4,5 milhões t de fibras de sisal são produzidas anualmente em todo mundo (BISMARCK; MISHRA; LAMPKE, 2005). No Brasil, a produção de fibras de sisal na safra $201 \mathrm{l}$ foi de $285832 \mathrm{t}^{2}$. O sisal é o principal produto agroindustrial do semiárido brasileiro. A cadeia do sisal gera empregos diretos e indiretos de 700 mil pessoas nesta região. O Brasil é o maior produtor e exportador mundial da fibra, sendo o estado da Bahia responsável pela produção de aproximadamente $95 \%$ da produção nacional. Historicamente, em torno de $80 \%$ da produção são comercializados para cerca de cem países ${ }^{3}$. Uma estiagem prolongada no nordeste do Brasil ano de $2012^{4}$ afetou a produção de sisal, que diminuiu cerca de $75 \%$ em relação à safra de $201 \mathrm{I}$, como pode ser observado na Figura 5 . Ainda assim, no mesmo ano, o Brasil não perdeu o posto de maior produtor mundial.

\footnotetext{
2 Fonte: FAOSTAT (Food and Agriculture Organization of the United Nations - Statistics Division). <http://faostat3.fao.org/faostat-gateway/go/to/browse/Q/QC/E> Acesso em: 25 ago. 2014

3 Fonte: CONAB (Companhia Nacional de Abastecimento - Ministério da Agricultura, Pecuária e Abastecimento) <http://www.conab.gov.br/OlalaCMS/uploads/arquivos/I2_I0_29_II_45_3I_sisal20I2.pdf> Acesso em: 26 ago. 2014.

4 Fonte: Revista Globo Rural. <http://revistagloborural.globo.com/Revista/Common/0,,EMI32832I-I8078,00$P R O D U C A O+D E+S I S A L+D E V E+C A I R+E S T E+A N O+P O R+C A U S A+D A+S E C A . h t m l>$ Acesso em: 26 ago. 2014.
} 
Figura 5 - Produção mundial e brasileira de sisal das safras de 20 I I e 20 I 2 (baseado em dados da FAO).

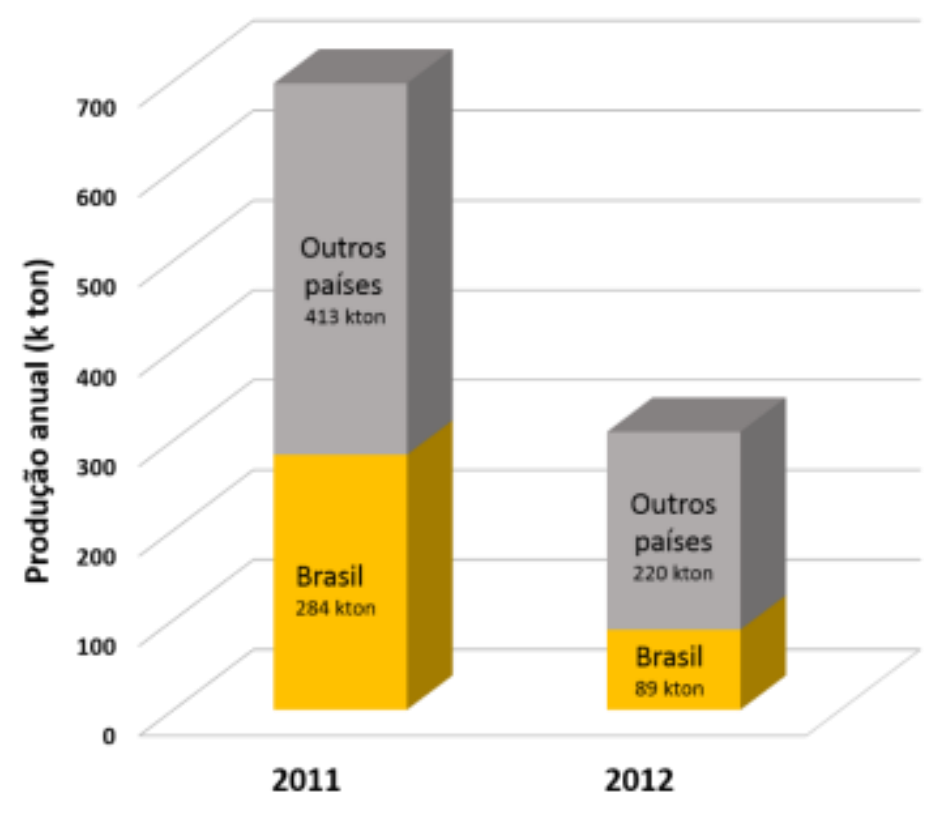

Devido às excelentes propriedades mecânicas, as fibras de sisal podem ser consideradas como bons reforços para matrizes poliméricas (MEGIATTO JUNIOR et al., 2007). No presente estudo, esta fibra foi usada como reforço de matrizes do tipo poliuretânica e lignopoliuretânica.

\section{I.4 Ligninas e lignossulfonatos}

O termo "lignina" foi utilizado pela primeira vez pelo botânico suisso A. P. Candolle (I778 - I84I), sendo derivado da palavra em latim lignum, que significa madeira (CHAKAR; RAGAUSKAS, 2004). A protolignina presente nos vegetais é uma macromolécula tridimensional complexa e não cristalina, sendo o segundo material mais abundante após a celulose. Suas principais funções na biomassa lignocelulósica é providenciar resistência mecânica, rigidez à parede celular e resistência à biodegradação. A estrutura química da lignina consiste de grupos aromáticos e alifáticos, com vários anéis fenilpropânicos substituídos, ligados através de diferentes tipos de ligações, como do tipo éter ou carbonocarbono. Estas unidades de fenilpropano são originárias de três precursores alcóolicos aromáticos (monolignóis), os alcóois cumarílicos, coniferílicos e sinapílico. As estruturas 
fenólicas que são originadas a partir destes monolignóis são chamadas, respectivamente, de p-hidroxifenila $(H)$, guaiacila $(G)$ e siringila $(S)$, como mostrados na Figura 6 (LAURICHESSE; AVÉROUS, 20I4; STRASSBERGER; TANASE; ROTHENBERG, 20I4). No entanto, a estrutura específica da lignina varia com a espécie a partir da qual ela é obtida, pois cada espécie produz uma lignina rica em um tipo de unidade (guaiacila, siringila e p-hidroxifenila), sendo ainda afetada pelo método utilizado para extração (ROWELL; HAN, 2000).

\section{Figura 6 - Três principais precursores da lignina (monolignóis) e suas estruturas correspondentes presente na lignina.}

\section{Monolignóis}

ácool cumarílico álcool coniferílico álcool sinapilico<smiles>OCC=Cc1ccc(O)cc1</smiles><smiles>COc1cc(/C=C/CO)ccc1O</smiles><smiles>COc1cc(/C=C/CO)cc(OC)c1O</smiles><smiles></smiles>

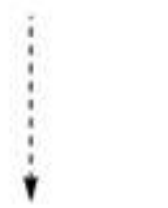

$$
\vdots
$$

Residuos presentes na lignina<smiles>[R]c1cc(C)cc([R])c1O</smiles><smiles>[R]c1cc(C)cc(OC)c1O</smiles><smiles>COc1cc(C)cc(OC)c1O</smiles>

\section{p-hidroxifenila}

\section{guaiacila}

siringila

$$
\mathrm{R}_{1}, \mathrm{R}_{2}=\mathrm{H} \text { ou lignina }
$$

Fonte: (LAURICHESSE; AVÉROUS, 20I4)

Baseado na primeira estrutura de lignina completa proposta por Adler (1997), mostrada na Figura 7, a lignina é reconhecida como uma macromolécula que possui uma variedade de grupos funcionais: hidroxilas alcóolicas e fenólicas, grupos carboxilas, carbnolinas e metoxilas. A abundância de sítios reativos oferece diversas possibilidades para modificação química e sugere que a lignina pode desempenhar um papel central como 
insumo químico, particularmente na formação de arquitetura supramolecular (RAMIRES; MEGIATTO; et al., 20I0; SILVA et al., 20I2; DA SILVA et al., 20I3; RAMIRES; DE OLIVEIRA; FROLLINI, 20I3) e produtos químicos aromáticos (LAURICHESSE; AVÉROUS, 20I4).

Figura 7 - Estrutura de lignina de coníferas proposta por Adler (1977).

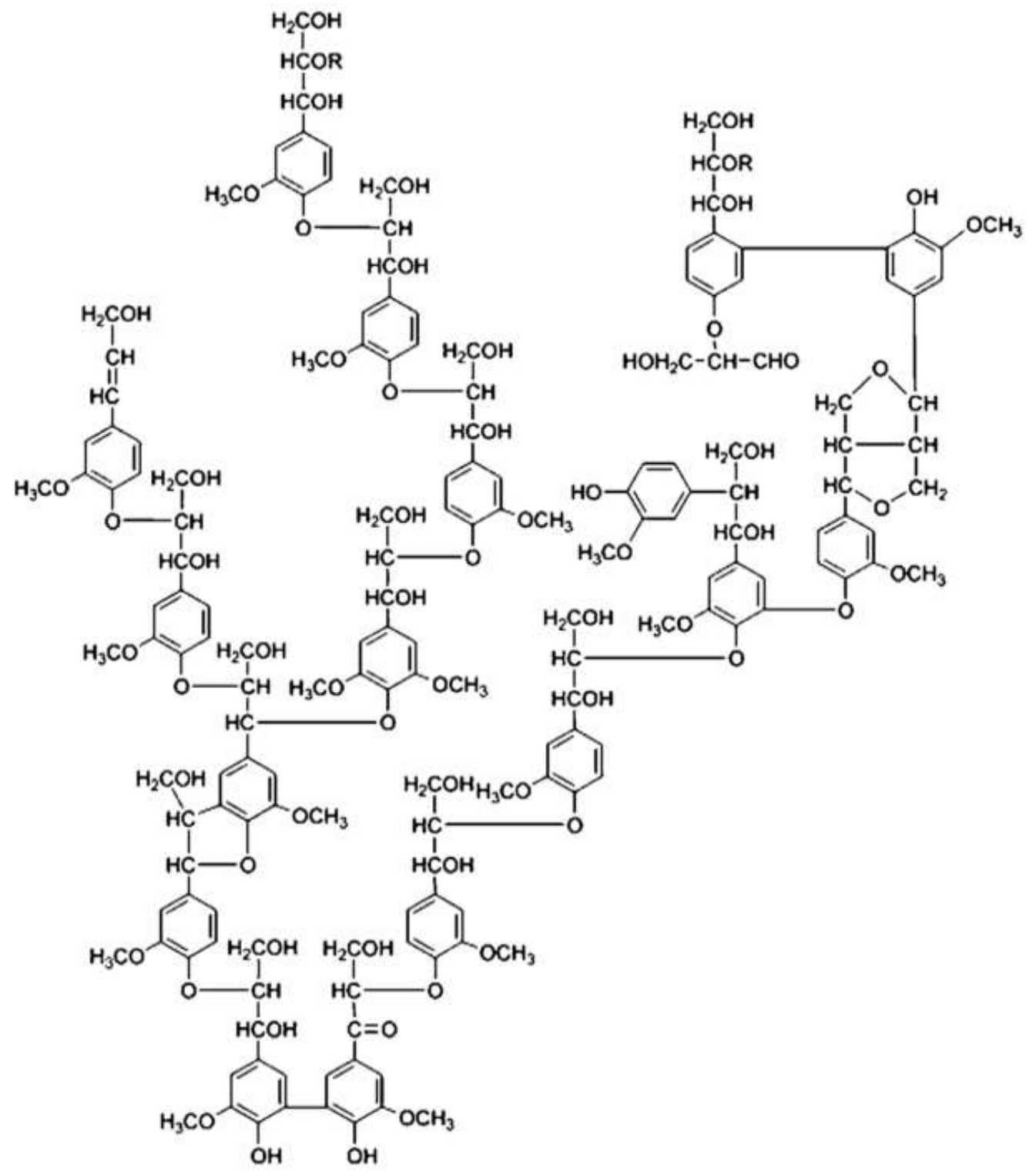

Fonte: (ADLER, 1977)

Ligninas industriais (ou técnicas) são atualmente obtidas como subprodutos da indústria de papel e celulose e alguns produtos químicos derivados. Embora a quantidade de lignina extraída em processos de polpação seja estimada em 70 milhões de toneladas por 
ano, menos de $2 \%$ são realmente aproveitados como produto químico. A maior parte da lignina extraída em processos de polpação é queimada para gerar energia para a própria usina que a produziu. $O$ tipo de processo de polpação determina 0 tipo de lignina indsutrialmente disponível. Existem três tipos de lignina, que correspondem aos três principais processos de polpação, chamados sulfito, kraft e soda. Durante a polpação, a estrutura da lignina é invevitavelmente modificada com relação àquela presente na matériaprima original (LORA, 2008).

\section{No presente estudo, o lignossulfonato de sódio, um tipo de lignina técnica, foi utilizado como macromonômero na preparação de resinas lignopoliuretânicas.}

Os lignossulfonatos (Figura 8) também chamados de ligninas sulfonadas, são obtidos como subproduto do processo de polpação sulfito da madeira na obtenção da polpa celulósica. Podem ser obtidos também pela sulfonação de ligninas obtidas por processos kraft. Dependendo do tipo de processo de polpação, lignossulfonatos diversificados podem ser obtidos, como os de cálcio, sódio, magnésio e amônio. Ao contrário da lignina, os lignossulfonatos são solúveis em água, devido à fragmentação e introdução de grupos sulfonatos, sendo considerados por alguns como polieletrólitos ramificados (FREDHEIM; BRAATEN; CHRISTENSEN, 2002; FREDHEIM; CHRISTENSEN, 2003; MYRVOLD, 2008). Devido a estas propriedades, eles representam as ligninas técnicas que são mais exploradas para diversas aplicações industriais como aglomerantes, agentes dispersantes, surfactantes, adesivos e aditivos de cimento (QIU et al., 20I0; DENG et al., 20II; LAURICHESSE; AVÉROUS, 2014). 
Figura 8 - Parte da estrutura de um lignossulfonato

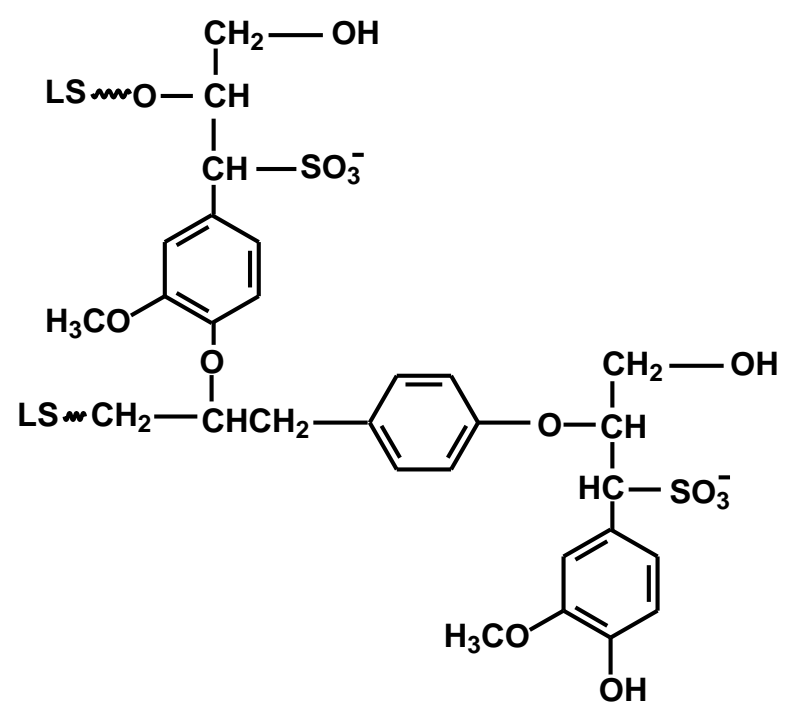

No processo de polpação sulfito, a madeira é digerida à temperaturas que vão de 140 a $170{ }^{\circ} \mathrm{C}$ com solução aquosa de sais sulfito ou bisulfito de sódio, amônio, magnésio ou cálcio. O tipo de sal e sua característica de dissociação determina $\circ \mathrm{pH}$ da digestão. Por exemplo, o meio de polpação é altamente ácido quando bisulfito de cálcio é o agente de polpação, enquanto que o meio é altamente alcalino quando o sulfito de sódio é utilizado. Durante o processo de digestão acontecem diversas transformações químicas, incluindo a quebra de ligações entre a lignina e os carboidratos, a cisão de ligações carbono-oxigênio que interconectavam unidades de lignina e a sulfonação de cadeias alifáticas da lignina. Esta última reação é a mais crítica na polpação sulfito e fornece as principais características da lignina derivda desse processo, o lignossulfonato (LORA, 2008).

Durante a polpação, cerca de 4 a $8 \%$ de enxofre é incorporado nas moléculas da lignina, a maioria na forma de grupos sulfonatos. Tais grupos tornam o derivado de lignina solúvel em água, e impedem a sua recondensação, uma reação que é prejudicial à polpação, pois resulta na redeposição de lignina nas fibras de celulose. Como a lignina é removida, as fibras celulósicas são liberadas e, uma vez que o grau de deslignificação exigido tenha sido alcançado, a polpa resultante é separada do licor de polpação por filtração e lavagem. A maior parte dos lignossulfonatos disponíveis no mercado hoje são co-produzidos com polpas celulósicas de baixo teor de lignina, mas alguns podem ser obtidos a partir de produção de polpas com teor relativamente alto de lignina, como a polpa utilizada para os papéis 
utilizados em embalagens. Essas diferenças na intensidade do processo de polpação sulfito provavelmente causa variações na estrutura da lignina obtida (LORA, 2008).

Os lignossulfonatos são comumente utilizados como estabilizantes de suspensões coloidais, agentes dispersantes, aglutinantes, alimentos para animais, surfactantes, adesivos e aditivos de cimento (VISHTAL; KRASLAWSKI, 20II; ZHOU et al., 20I3). Uma pequena parte é empregada na produção de produtos químicos de valor agregado, como a vanilina (LAURICHESSE; AVÉROUS, 20I4). A produção de lignossulfonato no mundo é estimada em I milhão de ton por ano (STRASSBERGER; TANASE; ROTHENBERG, 20I4). A Borregaard LignoTech, que possui unidades de produção em vários países, é a principal produtora de lignossulfonatos do mundo, com uma gama de mais de 200 produtos baseados principalmente em lignossulfonatos de cálcio e de sódio ${ }^{5}$.

\section{I.5 Emprego de ligninas e lignossulfonatos na síntese de polímeros e novos materiais}

As ligninas e seus derivados geralmente não apresentam toxicidade, são baratas e disponíveis em grandes quantidades. No entanto, o grande potencial das ligninas não é satisfatoriamente aproveitado, pois menos de $2 \%$ da produção mundial é recuperada para utilização como um produto químico, sendo as demais quantidades queimadas para a geração de energia (FARUK et al., 20I3). Nas últimas décadas, muitos esforços têm sido feitos para o desenvolvimento de materiais macromoleculares baseados em lignina, com a finalidade de encontrar novas alternativas para os produtos petroquímicos e seus derivados. Atualmente, o uso da lignina assume ainda maior relevância, devido ao fato de corresponder ao subproduto das biorrefinarias que produzem etanol a partir da celulose encontrada em fibras lignocelulósicas (RAMIRES; MEGIATTO; et al., 2010).

A lignina tem um potencial significativo para ser um componente de produtos de valor agregado; no entanto, não tem sido uma tarefa fácil criar materiais de alto desempenho a partir da lignina (SAITO et al., 20I3). As ligninas têm sido diretamente incorporadas em materiais poliméricos, assim como após transformações (CALVO-FLORES; DOBADO, 2010). Diversos grupos de pesquisa têm realizados estudos que envolvem o uso de lignina na

5 Borregaard LignoTech. <http://www.lignotech.com/About-us/History/\%28language\%29/eng-GB> Acesso em: 4 set. 2014. 
preparação de materiais poliméricos, dos quais podemos destacar seu uso na preparação de PUs (KELLEY; GLASSER; WARD, 1989; VANDERLAAN; THRING, 1998; NADJl et al., 2005; WANG et al., 20I0; HUO et al., 20II; FARIA et al., 2012; PAN; SADDLER, 20I3; POHJANLEHTO et al., 20I4; XUE; WEN; SUN, 20I4), blendas contendo lignina e diferentes polímeros (POUTEAU et al., 2004; PUCCIARIELLO et al., 2004; LI, 20I0; MOUSAVIOUN; HALLEY; DOHERTY, 2013 ; CHAUHAN et al., 20I4), resinas fenólicas (NADA et al., 1999; DE PAIVA; FROLLINI, 200I; DE PAIVA; FROLLINI, 2006; RAMIRES; MEGIATTO; et al., 20I0; PÉREZ; FERNÁNDEZ, 20I2; DA SILVA et al., 20I3; DOMÍNGUEZ et al., 20I3), epóxidos (ISMAIL et al., 2009; SASAKI et al., 20I3; HUO et al., 20I4), poliésteres (GUO; GANDINI, I99I; BONINI et al., 2005; SHIKINAKA et al., 2013), e outros copolímeros (SIVASANKARAPILLAI; MCDONALD; LI, 20I2; IBRAHIM et al., 20I4; LIU et al., 20I4; MA; $\mathrm{BU}$; CHEN, 20I4), incluindo redes de polímeros interpenetradas.

Entre os estudos já realizados que abordam o uso de lignossulfonatos na preparação de materiais macromoleculares, pode-se destacar o seu uso como substituto do fenol na preparação de resinas do tipo fenólica (ALONSO et al., 2004; PÉREZ et al., 2007; OLIVEIRA, 2010; SILVA et al., 20I2), sendo algumas destas resinas utilizadas como matrizes de compósitos reforçados por fibras lignocelulósicas, e o seu uso como poliol na síntese de PUs (ASANO; HATAKEYAMA; HATAKEYAMA, 2003; HATAKEYAMA; ASANO; HATAKEYAMA, 2003; HATAKEYAMA; NAKAYACHI; HATAKEYAMA, 2005; CUI et al., 2007; HATAKEYAMA; KOSUGI; HATAKEYAMA, 2008; RAMIRES; DE OLIVEIRA; FROLLINI, 20I3; RUDNITSKAYA et al., 20I3), sendo neste último caso pouco explorada a sua modificação química. Outros poucos estudos envolvem a síntese de resinas epóxi (ISMAIL et al., 2009), de resinas cetônicas (KIZILCAN, 20I2), o uso como reforço de borracha estireno-butadieno (BAHL; JANA, 20I4), componente de blendas poliméricas (CAZACU et al., 2004; LI, 20I0; DUVAL; MOLINA-BOISSEAU; CHIRAT, 20I3), monômero de copolímeros (SHOGREN; BISWAS, 20I3) e componente de hidrogéis (XIANG et al., 20I3).

De modo geral, a maior parte dos esforços tem sido investidos na valorização de ligninas, mesmo se estas não possuem a mesma disponibilidade comercial se comparada aos lignossulfonatos. Os lignossulfonatos são os derivados de ligninas mais disponíveis comercialmente, sendo produzidos em diversos países. No entanto, o estudo destes 
derivados visando à obtenção de novos materiais poliméricos é pouco explorado, se comparados aos estudos dedicados à lignina (SUN; BAl; GU, 20l4).

Neste sentido, a escolha do lignossulfonato como matéria prima de novos materiais macromoleculares assume um aspecto relevante no presente estudo, visando preparar produtos de valor agregado a partir de um subproduto de biorrefinaria.

\section{I.6 Poliuretanos}

Os poliuretanos (PU) são definidos como polímeros que contém grupos uretanos (ésteres carbâmicos, -NHCOO-) na cadeia polimérica principal. No entanto, nos PUs importantes, do ponto de vista tecnológico, o grupo uretano não é o único grupo presente, podendo estar presentes grupos ésteres, éteres, amidas e ureias (SAUNDERS, 1988). Os PUs podem ser produzidos a partir de uma variedade de reagentes e isso faz com que eles formem uma classe bastante versátil de materiais utilizados em diversos segmentos da ciência e tecnologia. Abrangem desde elastômeros, fibras e espumas a adesivos e revestimentos de superfície (PRISACARIU, 20II). Além disso, alguns tipos de PUs são biocompatíveis, ou seja, são materiais que tem capacidade de apresentar uma resposta apropriada numa aplicação específica, com o mínimo de reações alérgicas, inflamatórias ou tóxicas, quando em contato com tecidos vivos ou fluidos orgânicos (LAMBA; WOODHOUSE; COOPER, 1998).

A classe de polímeros que abrange os PUs não é o produto de uma descoberta acidental, mas sim de um trabalho sistemático desenvolvido por Otto Bayer e seus colaboradores da I.G. Farbeindustrie, em Leverkusen, Alemanha, na década de 1930, que visava a obtenção de novos materiais que pudessem competir com as fibras de poliamida (Nylon), desenvolvidas por Carothers na Du Pont, USA, e comercialmente bem sucedidas (COUTINHO; DELPECH, 1999).

Poliuretanos são formados a partir de compostos em que grupos hidroxilas $(\mathrm{OH})$ e isocianatos (NCO) estão presentes, ambos com funcionalidade igual ou superior a dois. A reação geral de obtenção de um poliuretano linear, derivado de um composto di-hidroxilado e de um diisocianato, está representada na Figura 9. 
Figura 9 - Reação de obtenção de um poliuretano.

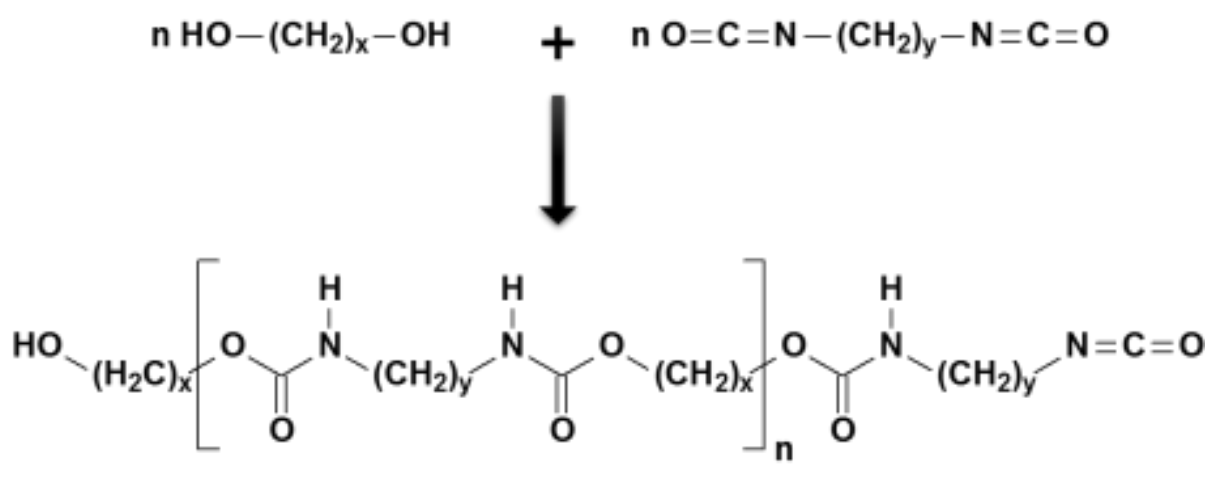

Os monômeros hidroxilados podem ser de baixa massa molar, como o I,4butanodiol, que dá origem à fibras, polímeros sintéticos, como poliéteres, poliésteres, incluindo policaprolactonas e polibutadienos hidroxilados, ou ainda naturais como polissacarídeos, celulose, lignina e OM. Os isocianatos, chamados genericamente de poliisocianatos quando a funcionalidade é maior do que dois, podem ser aromáticos, aromático-alifáticos, alifáticos e cicloalifáticos (COUTINHO; DELPECH, 1999).

Uma das grandes vantagens dos PUs decorre da alta reatividade dos isocianatos, que podem reagir com uma série de substâncias com diferentes grupos funcionais. Em alguns casos, a polimerização ocorre em temperaturas relativamente baixas e em tempos curtos (KRICHELDORF; NUYKEN; SWIFT, 2005), como no caso de obtenção de espumas poliuretânicas em que a reação acontece em temperatura ambiente $\left(25^{\circ} \mathrm{C}\right)$ (RIBEIRO DA SILVA et al., 2013) ou temperaturas moderadamente superiores à temperatura ambiente (40 $\left.-70{ }^{\circ} \mathrm{C}\right)$ (HUO et al., 20l I), com o tempo reação na ordem de minutos. No entanto, em alguns casos, como no presente estudo, dependendo de fatores como reatividade dos reagentes de partida, do objetivo de etapa de entrecruzamento durante a reação, temperaturas mais altas podem ser necessárias, como por exemplo, no intervalo entre 60 a $150^{\circ} \mathrm{C}$ (VERONESE et al., 20I I; RAMIRES; DE OLIVEIRA; FROLLINI, 20I3).

A alta reatividade do grupo isocianato é resultado de sua estrutura eletrônica, que pode ser representada pela estrutura de ressonância apresentadas na Figura 10. 
Figura 10 - Estruturas de ressonância do grupo isocianato.

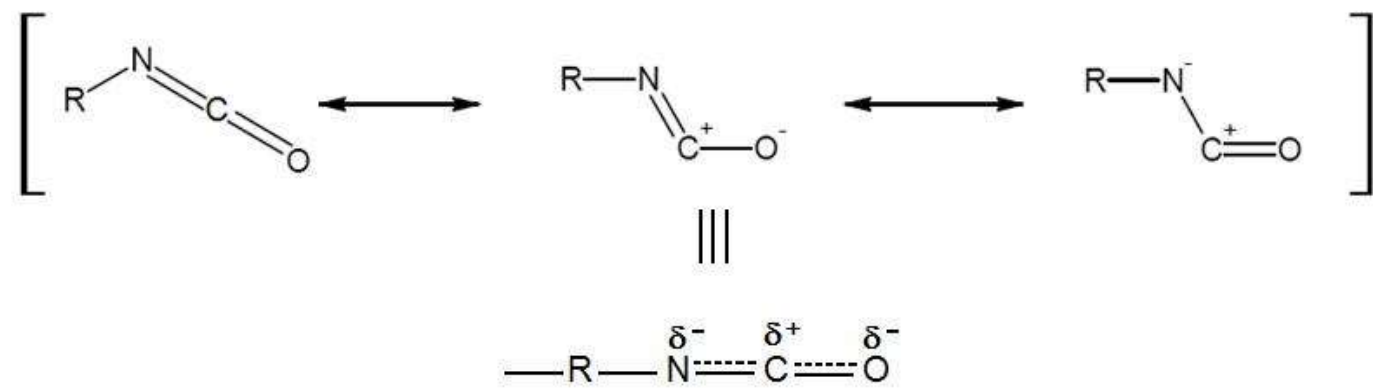

A deficiência em densidade eletrônica do carbono the confere caráter altamente eletrofílico, o que o torna muito sensível ao ataque de um nucleófilo, em que um próton esteja ligado ao átomo nucleofílico. A reação de isocianatos com compostos que tenham hidrogênio ácido é de fato uma adição à ligação dupla C=N (Figura II).

Figura I I - Reação dos isocianatos: adição à ligação CN.

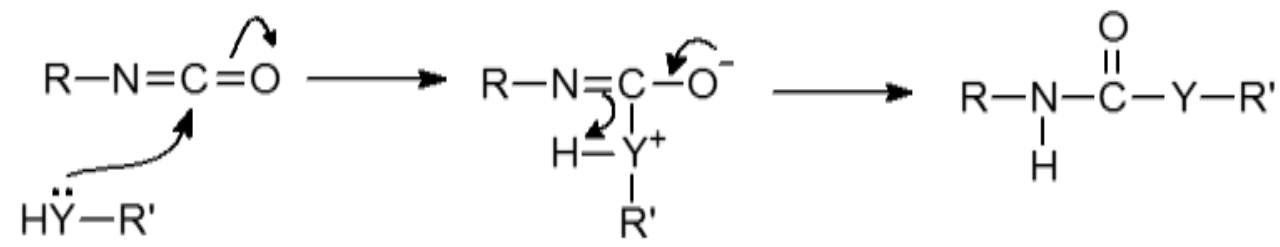

grupo isocianato também pode reagir com grupos funcionais recentemente formados no polímero, se o isocianato estiver presente em excesso. Estas reações podem ser utilizadas para obter a estrutura entrecruzada. Quando um grupo uretano doa o próton que está ligado ao nitrogênio e este nitrogênio reage com o isocianato, forma-se a ligação cruzada alofanato (Figura 12a). Na formação da ligação cruzada biureto, o grupo ureia doa o próton que está ligado no átomo de nitrogênio para o isocianato, e este nitrogênio reage com o grupo isocianato (Figura I2b). Um grupo isocianato terminal (que se encontra no final de uma cadeia) também pode reagir com grupos ureia ou uretano para formar ramificações ou polímero com estrutura entrecruzada. As ligações alofanatos e biuretos possuem baixa estabilidade térmica podendo reconverter-se em seus componentes originais em temperaturas acima de $150{ }^{\circ} \mathrm{C}$ (PETROVIĆ; FERGUSON, I99I; LAMBA; WOODHOUSE; COOPER, 1998). 
Figura I2 - (a) Reação entre isocianato e uretano; (b) Reação entre isocianato e ureia.

(a)

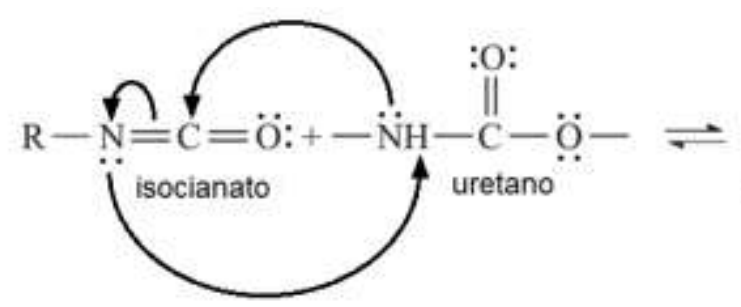<smiles>[R]C1CN(C(=O)OC)C1=O</smiles>

(b)

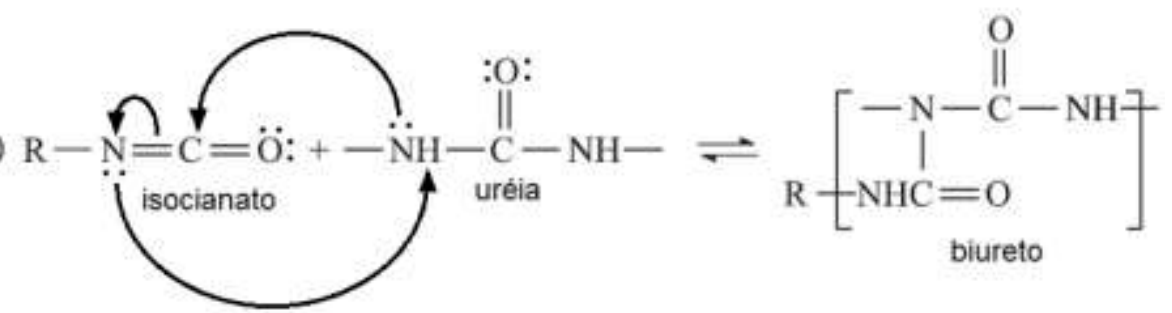

Além das reações citadas anteriormente, que são as mais frequentes em química de $\mathrm{PU}$, existem também as reações dos isocianatos entre si, que podem ocorrer durante o armazenamento - podendo criar um problema -, ou realizadas intencionalmente para obter novos produtos (KRICHELDORF; NUYKEN; SWIFT, 2005). Dessa maneira, os isocianatos podem reagir entre si formando dímeros, trímeros, polímeros, carbodiimidas e uretanoimidas, cujas estruturas são mostradas na Figura 13.

Figura 13 - Reações de condensação dos isocianatos.

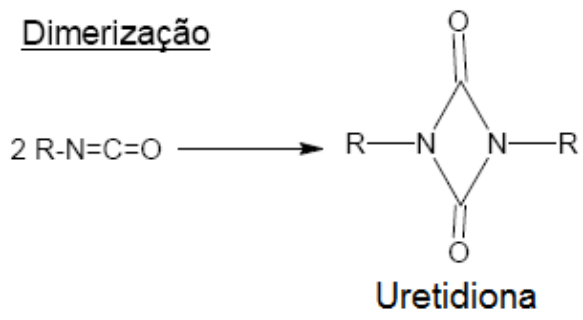

Formação de carbodiimida

$\mathrm{R}-\mathrm{N}=\mathrm{CO}+\mathrm{OCN}-\mathrm{R}$ $\mathrm{R}-\mathrm{N}=\mathrm{C}=\mathrm{N}-\mathrm{R}+\mathrm{CO}_{2}$
Trimerização

$3 \mathrm{R}-\mathrm{N}=\mathrm{C}=\mathrm{O}$<smiles>[R]n1c(=O)n([R])c(=O)n([R])c1=O</smiles>

Formação de uretanoimida

$\mathrm{R}-\mathrm{N}=\mathrm{C}=\mathrm{N}-\mathrm{R}+\mathrm{R}-\mathrm{N}=\mathrm{C}=\mathrm{O}$

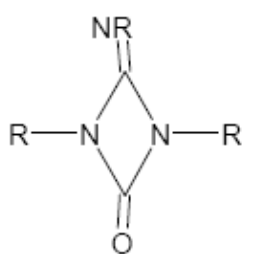

A estrutura molecular dos PUs pode criar desde polímeros termorrígidos (reticulados), até elastômeros de cadeias lineares e flexíveis. As espumas flexíveis e os elastômeros têm estruturas segmentadas constituídas por longas cadeias flexíveis 
(provenientes dos polióis) unidas por segmentos aromáticos rígidos de poliuretano e poliuréia. Suas características dependem fortemente das ligações hidrogênio entre grupos polares da cadeia polimérica, principalmente entre os grupos $\mathrm{N}-\mathrm{H}$ e as carbonilas dos grupamentos ureia e uretano. Os segmentos rígidos dos PUs flexíveis, especialmente os de poliuréia, formam ligações secundárias fortes e tendem a se aglomerar em domínios. As propriedades físicas e mecânicas de PUs que contem esses tipos de segmentos podem ser explicadas em termos de estrutura morfológica, isto é, domínios rígidos dispersos em uma matriz de domínios flexíveis (SZYCHER, 1999).

Os PUs termorrígidos, por outro lado, têm um alto teor de ligações cruzadas e não apresentam estruturas segmentadas, presentes nos flexíveis. A extensão do entrecruzamento em um poliuretano afetará suas propriedades mecânicas, pois ligações cruzadas afetam a mobilidade das cadeias de polímeros. Se o grau de entrecruzamento é baixo em um elastômero, como representado esquematicamente na Figura 14a, as propriedades elásticas, como o módulo de elasticidade, podem ser mantidas comparativamente ao polímero não entrecruzado, mas haverá aumento da resistência ao impacto e resistência à fluência. Com o aumento do grau de entrecruzamento, o módulo de elasticidade aumenta, assim como a dureza. Os materiais não se comportam mais como elastômeros, e começam a se assemelhar com plásticos termorrígidos. $\mathrm{O}$ alto grau de entrecruzamento geralmente gera materiais com baixa resistência ao impacto (são materiais rígidos, mas frágeis).

Figura 14 - (a) Representação esquemática de um polímero poliuretânico com baixo grau de entrecruzamento e (b) com alto grau de entrecruzamento (IONESCU, 2005).

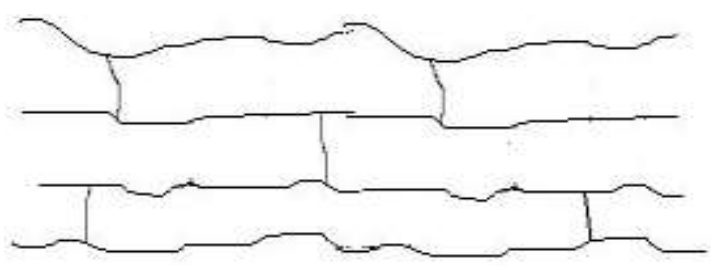

(a)

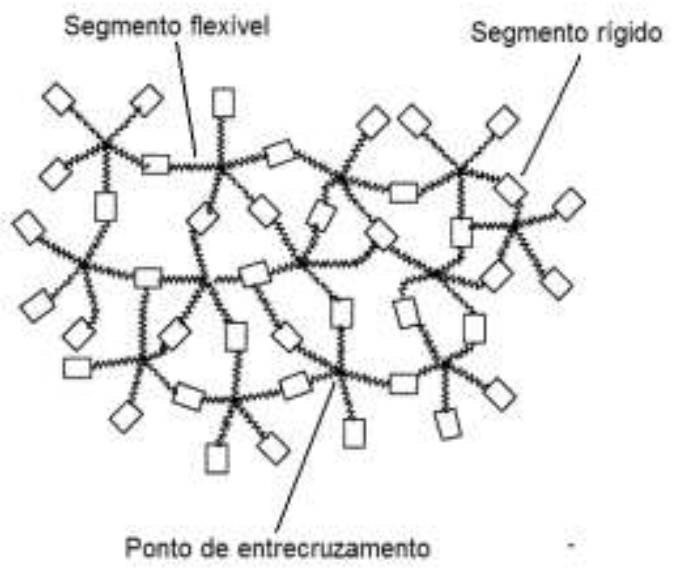

(b) 
Em PUs que possuem microfases separadas (segmentos flexíveis e segmentos rígidos, como mostrado na Figura (4b), as ligações cruzadas ocorrem tipicamente através de reações com polióis multifuncionais ou moléculas extensoras de cadeia. Os extensores de cadeia são empregados na obtenção de polímeros com alta massa molar, esses compostos devem ser bifuncionais $(f=2)$ e possuir baixa massa molar (LAMBA; WOODHOUSE; COOPER, 1998).

Quando um poliuretano linear segmentado é reticulado, os efeitos das ligações cruzadas predominam sobre os efeitos oriundos da segregação de fases. Polímeros preparados com reagentes polifuncionais, possuindo ligações cruzadas em sua estrutura macromolecular, têm menor tendência a formar domínios com áreas reticuladas fisicamente, pois suas cadeias têm menor mobilidade do que as dos PUs lineares.

A grande variedade de isocianatos e polióis disponíveis para a síntese de PUs possibilita a produção de polímeros lineares, ramificados ou reticulados, contendo não só ligações uretânicas, que são a base de sua classificação, mas também outros tipos de ligações, provenientes dos monômeros e extensores de cadeia (COUTINHO; DELPECH, 1999). Além da possibilidade de escolha de matérias-primas, catalisadores e reagentes auxiliares, as propriedades dos PUs podem ser modificadas pelo emprego de diferentes métodos de produção ou de processamento, e ainda pelas condições de moldagem dos produtos finais. A estrutura específica dos PU, que é formada por segmentos de cadeias rígidos e segmentos de cadeias flexíveis, faz com que estes materiais possam apresentar boa elasticidade, com alta resistência às solicitações mecânicas e resistência ao desgaste ao mesmo tempo, além de dureza controlável (KROL, 2007).

Os isocianatos usados em síntese de PUs podem ser alifáticos ou aromáticos, sendo os aromáticos geralmente mais reativos (devido a estabilização da ressonância do anel fenila) do que os alifáticos. O difenilmetano diisocianato (MDI) e o tolueno diisocianato (TDI) dominam o mercado mundial de isocianatos, correspondendo juntos a cerca de $90 \%$ do mercado (ALLPORT; GILBERT; OUTTERSIDE, 2003).

O termo genérico MDI é frequentemente utilizado para MDI puro e para o grau técnico de $\mathrm{MDI}$ vulgarmente conhecido como MDI polimérico. O MDI puro, por vezes também chamado MDI monomérico (Figura 15a), possui dois grupos -NCO por mol, é comercializado principalmente como isômeros 4,4'; no entanto, os produtos comerciais 
geralmente contém de I a $2 \%$ de isômeros 2,4' e 2,2'. As principais aplicações do MDI puro são: elastômeros de PU, elastômeros microcelulares e algumas espumas flexíveis.

Apesar de bastante utilizado comercialmente, o termo “MDI polimérico" é inadequado, pois não se trata de um polímero. Trata-se de uma mistura líquida (de cor marrom translúcida) contendo isômeros de MDI monomérico (4,4', 2,4' ou 2,2'-MDI) e oligoisocianatos de estrutura geral mostrada na Figura I5b, em que $n$ assume valores baixos, geralmente entre I e 4.

Figura I5 - (a) Estruturas químicas presentes no MDI puro, (b) Oligoisocianatos

(a) Isômeros do MDI monomérico<smiles>O=Nc1ccc(Cc2ccc(N=O)cc2)cc1</smiles>

4,4'-MDI<smiles>O=[N+]([O-])c1ccc(Cc2ccccc2[N+](=O)[O-])cc1</smiles>

2,4'-MDI<smiles>O=Nc1ccccc1Cc1ccccc1N=O</smiles>

2,2'-MDI

(b) Oligoisocianatos<smiles>CC(Cc1ccc([N+](=O)[O-])c(C([Tl])[Tl])c1)c1ccc(Cc2ccc([N+](=O)[O-])cc2)cc1[N+](=O)[O-]</smiles>

$n=1,2,3$ etc.

O termo poliol abrange uma grande variedade os compostos contendo grupos hidroxilas, capazes de reagir com os isocianatos para formar os PU. Os principais polióis podem ser do tipo poliéter ou poliéster e podem apresentar uma grande variedade de propriedades em relação à funcionalidade, comprimento de cadeia e reatividade. Polietileno glicol (PEG), polipropileno glicol (PPG) e poliTHF (politetrahidrofurano) são exemplos de polióis poliéteres. Policaprolactonas $(\mathrm{PCL})$, poliadipatos $(\mathrm{PA})$ e polióis obtidos de óleos naturais, como o óleo de mamona (OM), são exemplos de polióis do tipo poliéster (SZYCHER, 1999).

No contexto de preparação de materiais sustentáveis, PUs têm sido preparados a partir de polióis obtidos de fonte renovável, dentre os quais pode-se destacar aqueles obtidos a partir de óleos vegetais - de mamona, de soja, de canola, entre outros (VERONESE et al., 20I I; STIRNA et al., 20I2; MIAO et al., 20I4), de ligninas (CATETO et al., 2009; AHVAZI et al., 20II; XUE et al., 20I2; MAHMOOD et al., 2013), e da 
oxipropilação e/ou liquefação de diferentes tipos de biomassa (EVTIOUGUINA et al., 2000; FERNANDES et al., 2008; ANICETO; PORTUGAL; SILVA, 20I2; D'SOUZA; CAMARGO; YAN, 20I4; HU; LUO; LI, 20I4). Os isocianatos são ainda obtidos principalmente a partir do petróleo. No entanto, em estudos recentes síntese de isocianatos a partir de matérias primas renováveis já é considerada (RAQUEZ et al., 20I0; RAGHUNANAN; YUE; NARINE, 20I4), além de recentes interesses em PUs livres de isocianatos (GUAN et al., 20II; DELEBECQ et al., 20I3; KATHALEWAR et al., 20I3).

Os isocianatos e os polióis são matérias-primas básicas para produção de PU, porém, uma grande variedade de produtos químicos podem ser adicionados com a finalidade de controlar ou modificar a reação e/ou as propriedades do produto final. Esses aditivos incluem: catalisadores, inibidores, extensores de cadeia, agentes de reticulação, agentes de sopro, surfactantes, retardantes de chama, corantes/pigmentos, cargas e desmoldantes (VILAR, 2005).

No presente estudo, lignopoliuretanos foram preparados a partir de diferentes polióis, com destaque para o lignossulfonato de sódio e $O M$, ambos obtidos a partir de fontes renováveis. $O$ isocianato utilizado em todo trabalho foi o MDI polimérico.

\section{I.7 Uso do óleo de mamona em poliuretanos}

Óleos vegetais têm chamado a atenção como uma alternativa às matérias-primas oriundas do petróleo na preparação de materiais poliméricos. Atualmente, a maioria dos polióis utilizados em síntese de PUs são produzidos de derivados do petróleo. Os óleos vegetais são excelentes matérias primas obtidas de fontes renováveis para a produção de polióis para a síntese de PUs (RISTIĆ et al., 20I2). Em alguns casos, os óleos vegetais passam por reações antes de serem usados na síntese de PUs, tais como, epoxidação, ozonólise, hidroformilação e transesterificação/amidação. Dependendo da reação e do óleo vegetal usado, são obtidos polióis derivados de óleos vegetais com diferentes estruturas e propriedades, de acordo com as diferentes aplicações pretendidas (HU; LUO; LI, 20I4).

O óleo de mamona (OM) contém componentes com grupos hidroxilas e pode ser usado diretamente como uma matéria-prima na preparação de PUs (RISTIĆ et al., 20I2), como ocorreu no presente estudo. Este óleo, um dos mais importantes óleos comerciais, é 
extraído da semente da planta Ricinus communis, encontrada em regiões tropicais e subtropicais, sendo muito abundante no Brasil (CHIERICE; CLARONETO, 200I). O maior produtor mundial de OM é a Índia. O Brasil produziu em 2012 cerca de 26 mil toneladas de semente de mamona, alcançando nos últimos anos o posto de terceiro maior produtor mundial ${ }^{6}$.

Aproximadamente $90 \%$ do OM corresponde ao triglicerídeo do ácido ricinoleico (Figura 16a), e os 10\% restantes são ácidos oleicos (Figura 16b) e linoleicos (Figura 16c). 0 ácido ricinoleico é um ácido que contém 18 carbonos com uma dupla ligação entre as posições do $9^{\circ}$ e $10^{\circ}$ carbono. Esta combinação de grupo hidroxila e instauração ocorre somente no OM (RISTIĆ et al., 20I2).

Figura 16 - Ácidos graxos presentes no OM: (a) triglicerídeo do ácido ricinoleico; (b) ácido oleico e (c) ácido linoleico.

(a)<smiles>CCCCCCC(O)C/C=C/CCCCCCCC(=O)OC</smiles><smiles>CCCCCCCCCCCC(=O)OC(C)COC(=O)CCCCCCCC=CCC(O)CCCCCCC</smiles>

(b)

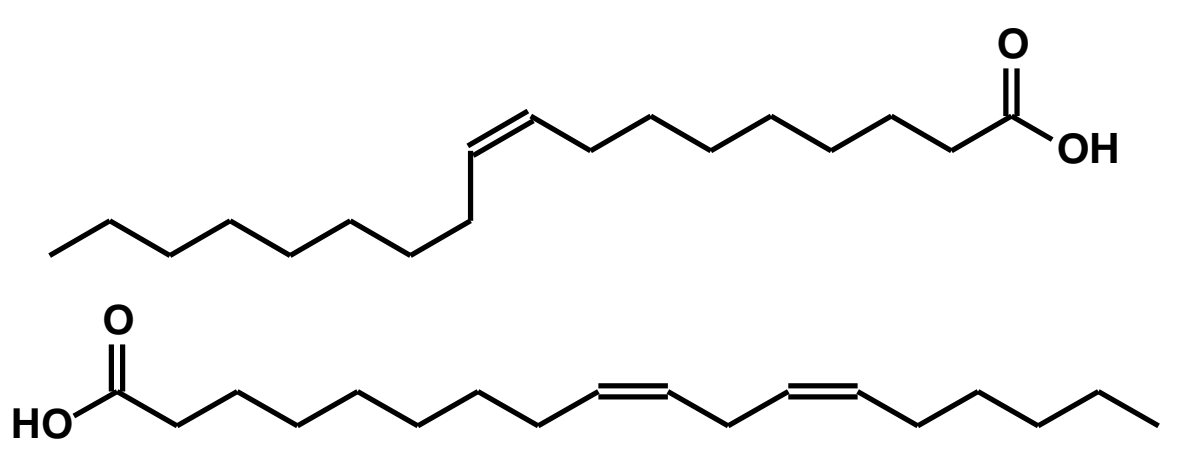

Vários estudos têm sido relatados sobre o uso de OM na síntese de PUs para as mais diversas aplicações, as quais incluem matrizes de compósitos (ARANGUREN; RÁCZ; MARCOVICH, 2007; WANG et al., 2008; LEE et al., 2009; CHEN; WANG; WANG, 20I3; GANETRI et al., 20I3; MARINHO et al., 20I3), matrizes de nanocompósitos (LIN et al.,

\footnotetext{
${ }^{6}$ Fonte: FAOSTAT (Food and Agriculture Organization of the United Nations - Statistics Division). <http://faostat3.fao.org/faostat-gateway/go/to/browse/Q/QC/E> Acesso em: 9 set. 2014.
} 
20I3; KAUSHIK; GARG, 20I4; SARALEGI et al., 20I4; THAKUR; KARAK, 20I4), materiais para aplicações biomédicas (BONFIL et al., 20I4; MORRAL-RUIZ et al., 20I4), materiais para circuitos eletroeletrônicos (CARDOSO; DE CARVALHO BALABAN, 20I3), revestimentos diversos (CHANG; LU, 20I2; GHARIBI; YOUSEFI; YEGANEH, 20I3), adesivos (VALERO; GONZALEZ, 20I2; WANG; CHEN; CHEN, 20I3), entre outros.

\section{I.8 Formas de uso da lignina como macromonômero na síntese de PUs}

A presença de grupos hidroxilas fenólicos e alifáticos (que atuam como sítios de reação com isocianatos) em ligninas ou lignossulfonatos permite que estes sejam utilizados como substitutos parciais de dióis ou polióis na síntese de PUs (XUE; WEN; SUN, 2014). A exploração da lignina como matéria-prima para síntese de PUs tem sido bastante investigada, o que tem levado a vários tipos de materiais (espumas rígidas, elastômeros, selantes), os quais são produzidos usando uma ampla série de sistemas químicos (SILVA et al., 2009; AHVAZI et al., 20II). As propriedades exibidas se mostraram promissoras e, em alguns casos, similar àquelas de PUs convencionais (SILVA et al., 2009).

O uso de lignina como macromonômero na síntese de PUs geralmente segue dois tipos de abordagem: (i) o uso direto da lignina sem nenhuma modificação química, sozinha ou em combinação outros polióis (CIOBANU et al., 2004; HATAKEYAMA et al., 2004; TANAMACHI et al., 2007; HATAKEYAMA; KOSUGI; HATAKEYAMA, 2008; HATAKEYAMA et al., 20I3; XUE; WEN; SUN, 20I4); ou (ii) tornando os grupos funcionais hidroxilas mais disponíveis através de modificação química, tais como as reações de esterificação ou eterificação (THIELEMANS; WOOL, 2005; CATETO et al., 2009; AHVAZI et al., 20II; LI; RAGAUSKAS, 20I2; SADEGHIFAR; CUI; ARGYROPOULOS, 20I2; PAN; SADDLER, 20I3).

O objetivo da modificação da lignina é aumentar a reatividade de grupos funcionais específicos na lignina e melhorar o processo de policondensação durante a produção de PUs baseado em fontes renováveis. Em alguns casos, a presença da lignina modifica a taxa de cura dos PUs através da contribuição dos grupos aromáticos e aumento do grau de cruzamento. A lignina pode agir como um agente que aumenta a rigidez da matriz polimérica. Outros estudos têm sugerido que a solubilidade em determinados solventes e a presença de certa uniformidade nos grupos funcionais presentes na estrutura da lignina, o que pode ser 
atingido através de modificação química, são os parâmetros-chaves mais importantes que afetam sua reatividade como substitutos de polióis na produção de PUs (AHVAZI et al., 20II).

A modificação da lignina pode ser classificada em três tipos: a fragmentação (ou despolimerização da lignina) para usá-la como fonte de carbono ou para quebrar a estrutura da lignina em macromonômeros aromáticos; a modificação pela criação de novos sítios químicos ativos; e a modificação química dos grupos hidroxilas (LAURICHESSE; AVÉROUS, 20I4).

No presente estudo, o lignossulfonato de sódio ( $\mathrm{NaLS}$ ) foi inicialmente utilizado na síntese de lignopoliuretanos sem modificação prévias, apenas combinado com outros polióis (DEG, PEG, OM). Posteriormente, o NaLS foi modificado via oxipropilação (modificação química dos grupos hidroxilas) e via hidroxialquilação (criação de novos sítios ativos), visando aumentar a reatividade da lignina frente aos isocianatos.

\section{I.8.I Oxipropilação}

Dentre as modificações químicas já realizadas em ligninas, a reação de oxialquilação, especialmente a com óxido de propileno (OP), a oxipropilação, é a mais conhecida (WU; GLASSER, 1984; SADEGHIFAR; CUI; ARGYROPOULOS, 2012). A oxipropilação é reconhecida como uma abordagem viável e promissora para superar as limitações técnicas e restrições impostas pela natureza polimérica da lignina quando usada diretamente como macromonômero com objetivos de síntese (LORA; GLASSER, 2002).

Por meio da oxipropilação, os grupos hidroxilas, em particular os fenólicos que são menos reativos como nucleófilo, e também menos acessíveis estericamente, passam a participar de ligações éter, nas quais o outro carbono ligado está inserido em um grupo de hidroxialquila (Figura 17a,b). Assim, ao invés de uma hidroxila fenólica, tem-se uma hidroxila alcoólica, ou seja, um sítio mais reativo como nucleófilo. Além disso, a extensão da cadeia hidroxialquila introduzida torna o sítio reativo mais acessível, tanto comparativamente às hidroxilas fenólicas como as alcoólicas presentes na estrutura da lignina. Não menos importante é o fato de a lignina sólida tornar-se um poliol líquido, graças à introdução de múltiplos segmentos contendo ligações éter (CATETO et al., 2009; SILVA et al., 2009; AHVAZI et al., 20II). 
Esta reação tem sido investigada extensivamente em diferentes biopolímeros e materiais biobaseados que possuem grupos hidroxilas, como a quitosana (FERNANDES et al., 2008), cortiça (EVTIOUGUINA et al., 2000; EVTIOUGUINA et al., 200I), casca de pinheiro, amido de milho (DE MENEZES et al., 2009), polpa de beterraba (PAVIER, CLAIRE; GANDINI, ALESSANDRO, 2000b; PAVIER, C.; GANDINI, A., 2000; PAVIER, CLAIRE; GANDINI, ALESSANDRO, 2000a) e bagaço de cana de açúcar. Este caminho tem trazido vários polióis derivados de diferentes resíduos de biomassa e que possuem potencial para ser usado na produção de novos materiais poliméricos (ANICETO; PORTUGAL; SILVA, 2012). Glasser e colaboradores foram os pioneiros nos anos 1980 ao investigar esta reação para a formulação de PUs e resinas epóxi (GLASSER et al., 1984).

Figura 17 - (a) Representação esquemática da oxipropilação de polímeros naturais;

(b) Reação de oxipropilação no lignossulfonato de sódio
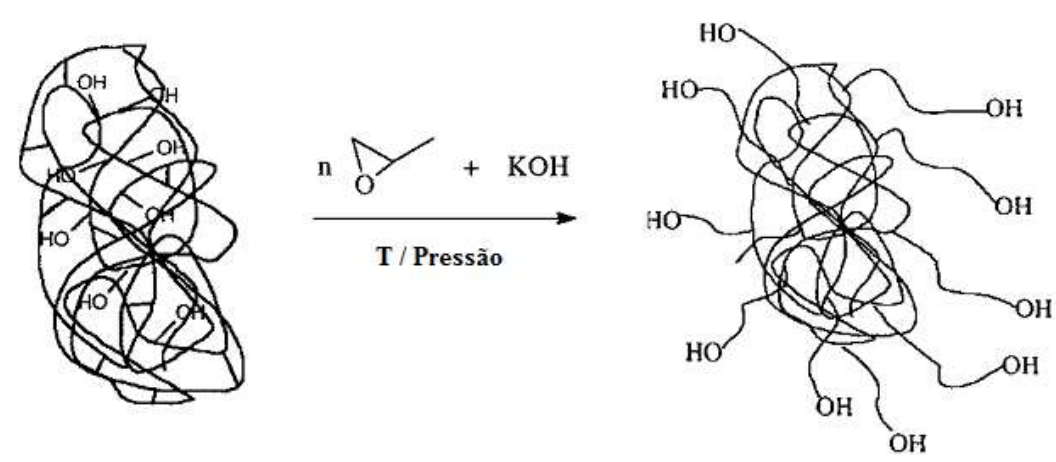

(a)<smiles>COc1cc(C(C[C@H](O)[As])[Sn](=O)[O-])ccc1O</smiles>

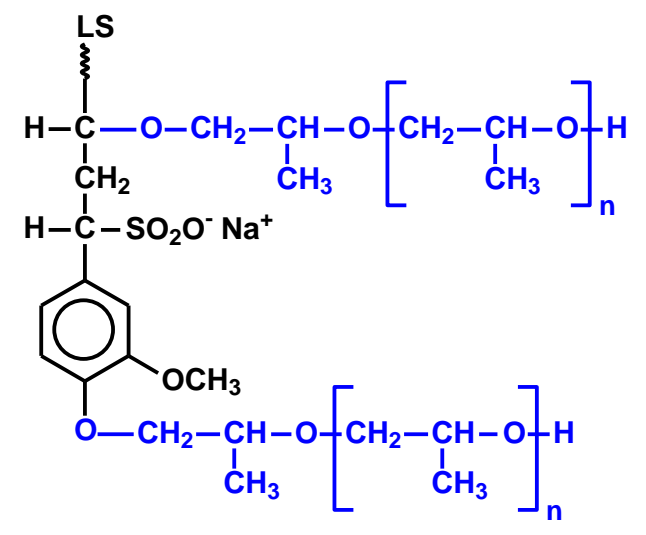

(b)

Fonte (a): (GANDINI; BELGACEM, 2002) 
De modo geral, a reação de oxipropilação inicia com a ativação de grupos hidroxilas pelo catalisador, isto é, a formação de um grupo alcóxido $\left(\mathrm{RO}^{-}\right)$. Geralmente, $\mathrm{KOH}$ é usado para catalisar a oxialquilação com grupos hidroxilas (IONESCU, 2005). O grupo alcóxido formado ataca o anel epóxido de uma molécula de OP, gerando um outro grupo alcóxido, após a inserção do segmento de OP. Este ataque acontece preferencialmente no carbono $\alpha$ do anel epóxido (Figura 18a), devido ao baixo impedimento estérico deste átomo. Consequentemente, os grupos hidroxilas serão predominantemente ligados a um carbono secundário (94-96\%) e a microestrutura da cadeia será predominantemente (90\%) como na Figura 18a. Embora menos provável, o ataque do grupo alcóxido pode também ocorrer na posição $\beta$ do anel epóxido (Figura 18b). Esta situação, considerada não favorável, leva a obtenção de grupos hidroxilas ligados a um carbono primário (4-6\%). As reações descritas são reações de substituição nucleofílica de segunda ordem, repetida pela ataque do grupo alcóxido fortemente nucleofílico aos átomos do anel epóxido.

Figura 18 - (a) Representação esquemática da reação (favorável) de substituição nucleofílica de segunda ordem e (b) da reação não favorável.

(a)

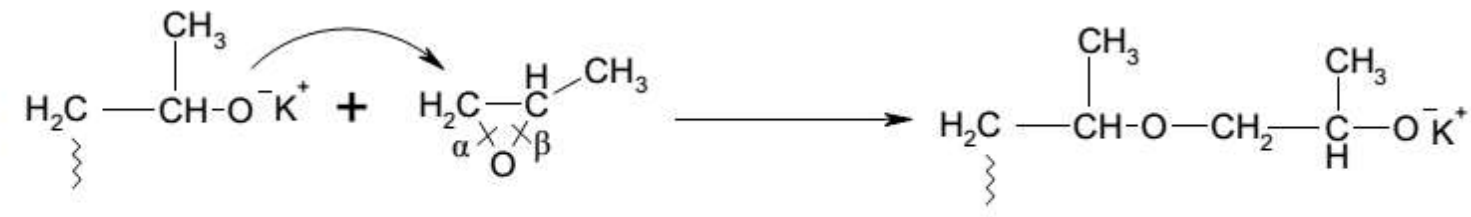

(b)

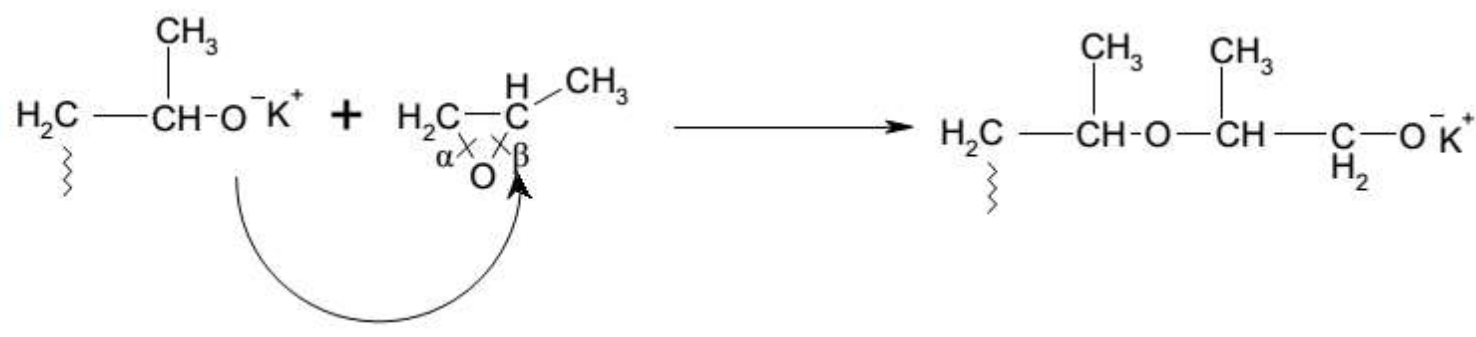

Fonte: (IONESCU, 2005; CATETO, 2008)

A reação de oxipropilação é, no geral, acompanhada pela homopolimerização do OP, devido à presença de umidade residual no meio reacional. Ânions $\mathrm{OH}^{-}$podem atacar diretamente o OP (Figura 19a), gerando um alcóxido que reagirá com outro molécula de $\mathrm{OP}$, e assim sucessivamente. A transferência de um próton $\left(\mathrm{H}_{2} \mathrm{O} /\right.$ umidade $)$ conduz à formação de dióis poliéter [poli(óxido de propileno), Figura 19b] (IONESCU, 2005). 
Figura 19 - (a) Reação envolvida na homopolimerização do OP;

(b) poli(propileno glicol)

(a)

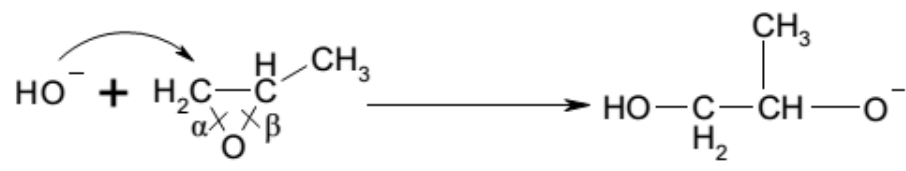

(b)<smiles>[R]C(C)(C)OCC(C)C(C)O</smiles>

Os polióis produzidos no meio, corresponderão a uma mistura de ligninas oxipropiladas, tendo tanto funções hidroxilas como as presentes no substrato original, como aquelas geradas via extensão de cadeia (Figura I7b) e alguns produtos de baixa massa molar, como os oligômeros de poli(óxido de propileno). Usualmente não são feitos esforços para retirar estes oligômeros do meio reacional, pois eles constituem um co-monômero útil na reação posterior com isocianatos para obtenção de PUs. Além disso, a presença destes polióis de baixa massa molar média, diminuem a viscosidade da mistura, comparativamente à lignina oxipropilada isoladamente (CATETO et al., 2009), o que pode facilitar etapas posteriores.

Como já citado anteriormente, é possível encontrar na literatura PUs baseados em lignossulfonatos, dentre esses, do tipo espumas rígidas, geocompósitos, e filmes (ASANO; HATAKEYAMA; HATAKEYAMA, 2003; HATAKEYAMA; ASANO; HATAKEYAMA, 2003; HATAKEYAMA et al., 2004; CUI et al., 2007; HATAKEYAMA; KOSUGI; HATAKEYAMA, 2008; RUDNITSKAYA et al., 20I3). No entanto, quase não há trabalhos na literatura que relatam o uso do lignossulfonato oxipropilado na síntese de lignopoliuretanos (MOZHEIKO et al., 1981).

Neste contexto, um dos objetivos do presente estudo foi preparar biopolímeros do tipo poliol a partir de lignossulfonato previamente oxipropilado (LS-Oxi) para posterior uso na preparação de lignopoliuretanos entrecruzados. 


\section{I.8.2 Hidroxialquilação}

A substituição do fenol comercial (de origem não renovável) por produtos químicos de origem renovável, como a lignina, na síntese de resinas do tipo fenólica e outros adesivos tem apresentado forte desenvolvimento. Algumas similaridades na estrutura química e suas reatividades com formaldeído tem gerado novas rotas para a produção de adesivos para madeira baseados em lignina. A reação química da lignina e lignossulfonato com formaldeído está descrita em detalhes em diversos estudos da literatura (TRUTER; PIZZI; VERMAAS, 1994; SANTOS; CURVELO, 1999; ALONSO et al., 2004; DE PAIVA; FROLLINI, 2006; EL MANSOURI; FARRIOL; SALVADÓ, 2006; EL MANSOURI; PIZZI; SALVADO, 2007; PÉREZ et al., 2007; RAMIRES; MEGIATTO; et al., 20I0; DA SILVA et al., 20I3).

Enquanto a integração de ligninas em resinas fenólicas tem utilizado a reação com formaldeído, o uso de outros aldeídos, incluindo glioxal (EL MANSOURI; YUAN; HUANG, 20II; NAVARRETE et al., 20I2), furfural (SCHNEIDER; PHILLIPS, 2004) e mais recentemente o glutaraldeído (DA SILVA et al., 2013) também tem sido descritos. Por exemplo, o glioxal representa uma alternativa interessante ao formaldeído, pois ele não é tóxico e é um dialdeído não volátil (EL MANSOURI; PIZZI; SALVADÓ, 2007) que pode ser obtido de fontes naturais tais como a oxidação de lipídios ou como subprodutos de processos biológicos (RAMIRES; MEGIATTO JUNIOR; et al., 20I0).

Apesar do lignossulfonato de sódio possuir hidroxilas que possibilita seu uso como poliol na síntese de PU, foi observado, no presente estudo, que esta macromolécula apresenta baixa reatividade frente aos grupos isocianatos. Em ordem de reatividade, as hidroxilas fenólicas apresentam menor reatividade frente ao grupo NCO se comparada às hidroxilas alcóolicas. As hidroxilas alcóolicas possuem maior reatividade pois a cadeia carbônica ligada ao átomo de oxigênio exerce um efeito doador de elétrons, o que faz aumentar o caráter nucleofílico desse grupo, enquanto que nas hidroxilas fenólicas, a presença de ressonância no anel aromático diminui o caráter nucleofílico do oxigênio, fazendo das hidroxilas fenólicas menos reativas que as alcóolicas. Além disto, os impedimentos estéricos também são responsáveis pela baixa reatividades destas hidroxilas frente aos grupos NCO.

Em estudos anteriores, foi observado que a presença de hidroxilas fenólicas no lignossulfonato aumenta a reatividade desta macromolécula com $\circ$ formaldeído e glutaraldeído na obtenção de resinas fenólicas (SILVA et al., 2012). Neste contexto, no 
presente estudo o NaLS foi modificado com glutaraldeído e formaldeído, pois estas reações inserem hidroxilas alcóolicas (que são mais reativas) na estrutura do NaLS, como pode ser observado na Figura 20.

Figura 20 - Hidroxialquilação do NaLS com formaldeído (a) e glutaraldeído (b).

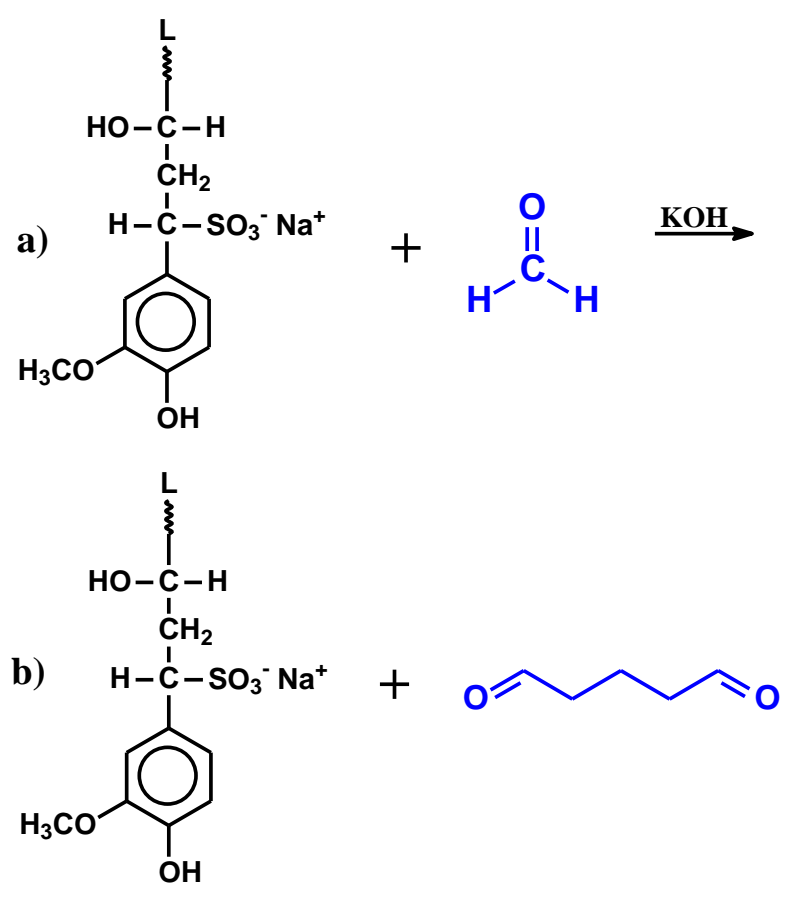

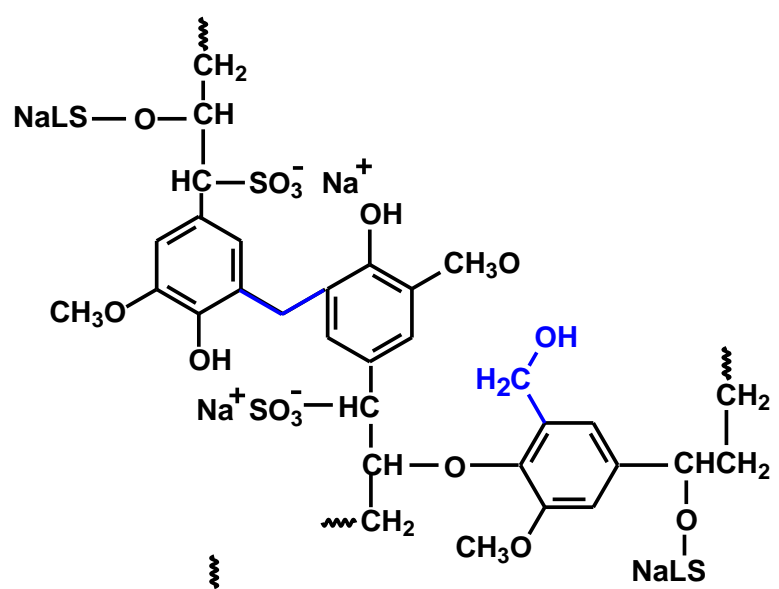

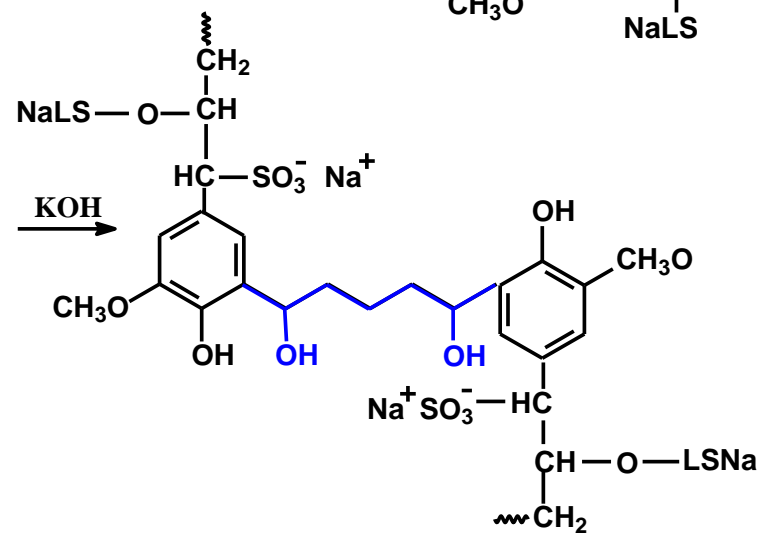

O uso do NaLS modificado com glutaraldeído e formaldeído, para posterior utilização na síntese de PUs é uma abordagem até então nunca explorada na literatura.

I.9 Uso de lignopoliuretanos como matrizes de compósitos reforçados por fibras naturais

Sabe-se que as propriedades mecânicas de compósitos é resultado das propriedades das fibras, da matriz e da interface fibra/matriz (CHAWLA, 1998). Estas propriedades dependem também da boa dispersão da fibra na matriz, da minimização de vazios e adequada adesão interfacial fibra/matriz (ISLAM et al., 2010). No que se refere à região de interface 
fibra/matriz, esta deve ter uma boa adesão interfacial para garantir a transferência de carga da matriz para o reforço (HABIBI et al., 2008; SINGHA; THAKUR, 2008).

Uma ótima compatibilidade é esperada entre as matrizes lignopoliuretânicas e fibras lignocelulósicas, devidos às similaridades estruturais. A Figura 21 a mostra a estrutura hipotética de um lignopoliuretano obtido somente a partir de NaLS e MDI. A presença de grupos hidroxilas nos principais componentes das fibras lignocelulósicas (celulose e lignina, Figura $2 \mathrm{lb}$ e $4 \mathrm{c}$ ) favorece as interações intermoleculares entre fibra e matriz e, portanto, a adesão fibra/matriz na interface. Ainda, uma vez que os grupos hidroxilas das fibras são reativos frente a grupos isocianatos, podem se tornar quimicamente ligada à matriz poliuretânica (ARANGUREN; RÁCZ; MARCOVICH, 2007).

O isocianato utilizado no presente trabalho, MDI polimérico, possui em sua estrutura anéis aromáticos (Figura 22c), assim como o lignossulfonato de sódio. Estes anéis aromáticos podem interagir com os anéis aromáticos presentes na lignina, um dos componentes da fibra lignocelulósica. Desse modo, a adesão na interface fibra-matriz pode também ser intensificada devido a este tipo de interação entre domínios hidrofóbicos, além das ligações hidrogênios entre grupos presentes na matriz e nas fibras, conforme já mencionado.

É possível encontrar na literatura PUs baseados em ligninas e lignossulfonatos. No entanto, é muito pouco explorado o uso destes lignopoliuretanos como matrizes em compósitos reforçados com fibras lignocelulósicas (RAMIRES; DE OLIVEIRA; FROLLINI, 20I3).

Figura 2 I - (a) Obtenção de poliuretano baseado em lignossulfonato de sódio e MDI e componentes principais das fibras lignocelulósicas: (b) celobiose: unidade repetitiva da celulose e (c) unidades típicas de lignina

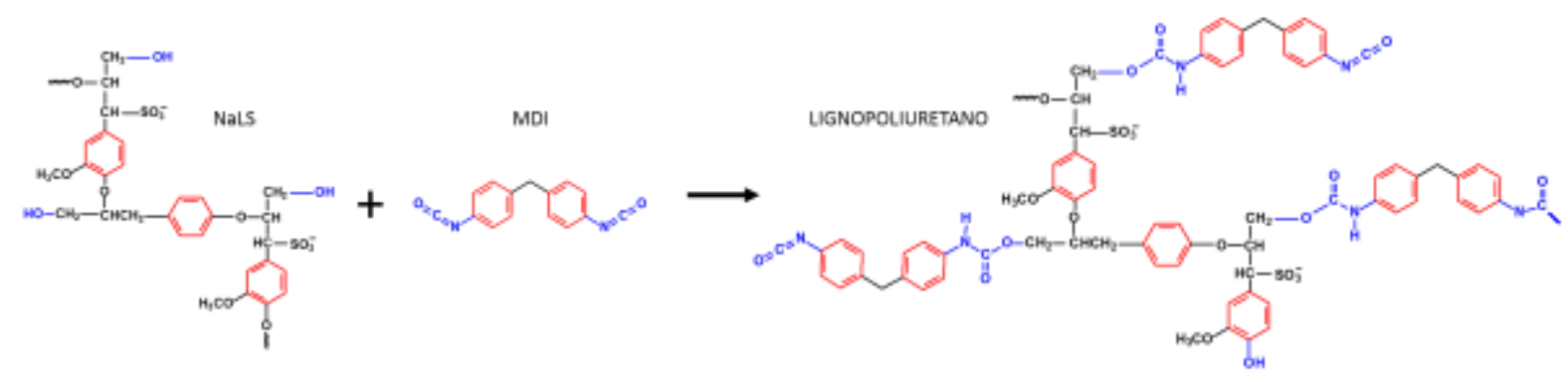

(a)

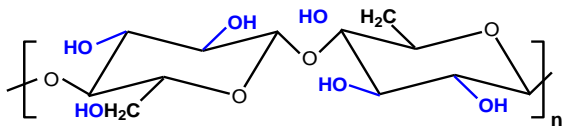

(b)

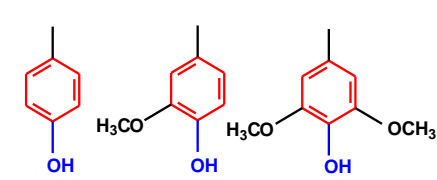

(c) 
No presente trabalho, foram utilizados polióis oriundos de fontes renováveis (óleo de mamona e lignossulfonato de sódio - modificado ou não) na formulação dos lignopoliuretano e fibras lignocelulósicas, também de origem renovável, como reforços destas matrizes. A escolha dos polióis, da modificação do lignossulfonato e a combinação entre eles foram articuladas segundo a perspectiva de obtenção de compósitos em que a adesão fibra-matriz fosse favorecida, no intuito de obter materiais com boas propriedades mecânicas. 


\section{OBJETIVOS}

Este estudo teve como principal meta a preparação e caracterização de compósitos baseados principalmente em matéria-prima proveniente de fontes renováveis, ou seja, compósitos biobaseados. Buscou-se preparar matrizes poliuretânicas (materiais controle) e lignopoliuretânica a partir de diferentes polióis, com destaque para o óleo de mamona (OM) e lignossulfonato de sódio ( $\mathrm{NaLS}$ ), ambos oriundos de matérias primas renováveis, sendo as matrizes reforçadas com fibras lignocelulósicas de sisal.

De forma mais específica, os objetivos podem ser descritos como:

(a) Obtenção de resinas lignopoliuretânicas através do uso de lignossulfonato de sódio como macromonômero em combinação com polióis tradicionais oriundos de fontes não renováveis (DEG e PEG) e renováveis (OM);

(b) Modificações do lignossulfonato de sódio através da oxipropilação e hidroxialquilação, visando obter lignopolióis com maior reatividade frente aos grupos isocianatos na reação de obtenção de resinas lignopoliuretânicas.

(c) Aplicação das resinas lignopoliuretânicas como matrizes em compósitos reforçados com fibras de sisal, visando também explorar a afinidade entre grupos funcionais presentes em ambos, matriz e reforço (matrizes poliuretânicas/lignopoliuretânicas e fibras lignocelulósicas), e a consequente melhora na adesão na interface fibra/matriz, a fim de preparar materiais com alto teor de matéria-prima oriunda de fonte renovável e com boas propriedades. 


\section{MATERIAIS E MÉTODOS}

\section{I Origem dos materiais}

As fibras de sisal utilizadas neste trabalho foram adquiridas na forma de fios da empresa Sisal Sul Indústria e Comércio Ltda., São Paulo, SP. Não houve necessidade de lavar o material antes do pré-tratamento, pois o beneficiamento da fibra na indústria incluiu etapas de lavagem em água da mesma, segundo informações do fornecedor.

O lignossulfonato de sódio (NaLS, Figura 22a), sob o nome comercial "VIXILEX SD sódio desaçucarado" (cor marrom, $M_{w}=6129 \mathrm{~g} \mathrm{~mol}^{-1}$, densidade aparente $=0,41 \mathrm{~g} \mathrm{~cm}^{-3}, \mathrm{pH}$ $=8,0,5 \%$ de enxofre total, $1,7 \%$ de magnésio, $0,2 \%$ de cálcio, $0,9 \%$ de açúcares, $5,2 \%$ de umidade e 20 a $21 \%$ de cinzas, conforme informado pelo fornecedor) foi gentilmente cedido pela LignoTech Brasil Produtos de Lignina Ltda., Cambará do Sul, RS, Brasil. Este lignossulfonato é obtido através do processo de polpação sulfito da madeira (Pinus taeda), como subproduto da obtenção da polpa de celulose. O NaLS foi utilizado como recebido, sem purificação adicional.

Figura 22 - Estrutura do (a) lignossulfonato de sódio (NaLS); (b) MDI polimérico; (c) glutaraldeído; (d) formaldeído; (e) OP; (f) dietilenoglicol (DEG); (g) polietilenoglicol (PEG); e (h) ácido ricinoléico: principal componente do OM (OM).

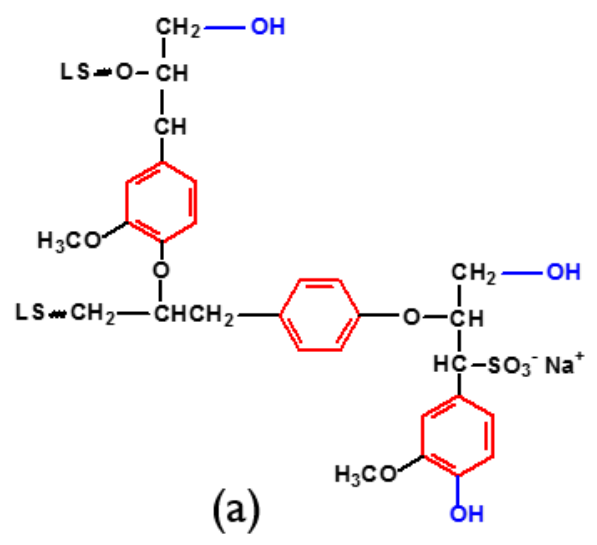<smiles>O=C=Nc1ccc(CCc2ccc(N=C=O)c(CCc3ccc(N=C=O)cc3)c2)cc1</smiles>

(b)<smiles>O=CCCCC=O</smiles>

(c)<smiles>C=O</smiles>

(d)

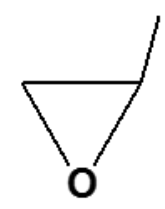

(e)

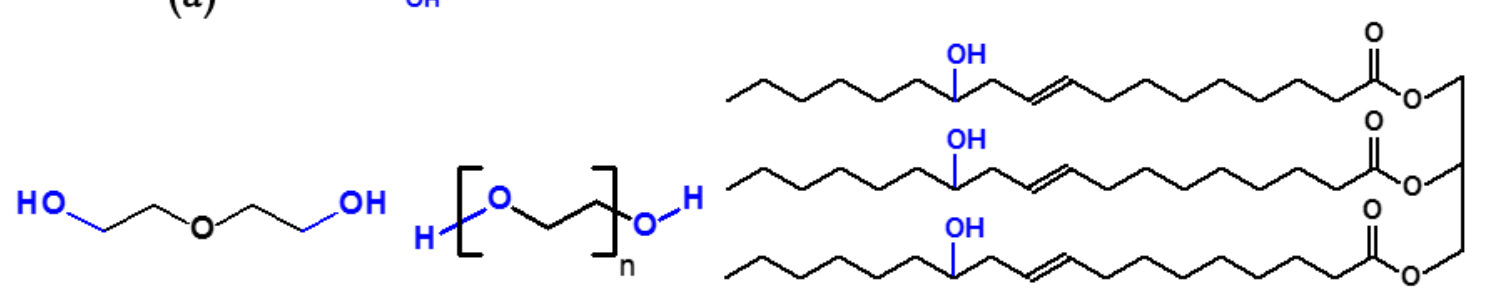

(f)

(g) 
O difenilmetano diisocianato (MDI polimérico) (Figura 22b) utilizado na preparação de PUs e lignopoliuretanos, foi fornecido por duas companhias, devido à interrupção do fornecimento por uma delas. Nos materiais descritos nos Quadros I e 2, foi usado o IsoPMDI 9214 da BASF Poliuretanos Ltda. (Mauá, SP). Nos materiais descritos nos Quadros 3, 4 e 5, foi usado o DESMODUR® 44V20L da Bayer Materials Science (São Paulo, SP). Ambos MDl's apresentavam as mesmas características físico-químicas, dentre elas o teor de $31,5 \%$ de grupos NCO, utilizado para os cálculos estequiométricos.

O glutaraldeído (Figura 22c) (VETEC, 25\% em solução aquosa) e o formaldeído (Figura 22d) (Synth, 37\% em solução aquosa) foram utilizados na hidroxialquilação do NaLS, enquanto que o óxido de propileno (OP) (Figura 22e) (Aldrich, p.a.) foi utilizado na oxipropilação do NaLS.

O dietilenoglicol (DEG) (Figura 22f) e o polietilenoglicol (PEG) (Figura 22g) de massa molar numérica média de $300 \mathrm{~g} \mathrm{~mol}^{-1}$ usados são da marca Synth. Para os devidos cálculos estequiométricos, considerou-se a massa molar do dietilenoglicol (DEG) de 106, $14 \mathrm{~g} \mathrm{~mol}^{-1}$, e funcionalidade 2, ou seja, em cada 106,14 g de DEG há 2 mols de hidroxilas. Para o polietilenoglicol (PEG), considerou-se a massa molar de $300 \mathrm{~g} \mathrm{~mol}^{-1}$, e funcionalidade 2, ou seja, em cada 300 g de PEG há 2 mols de hidroxilas.

O óleo de mamona (OM) foi adquirido da empresa A. Azevedo Indústria e Comércio de Óleos Ltda. O OM tem como principal componente o ácido ricinoléico (Figura 22h), possui índice de hidroxila de $155 \mathrm{mg} \mathrm{KOH} \mathrm{g}^{-1}$ (dado retirado da ficha técnica do óleo) e $\mathrm{M}_{\mathrm{n}}$ $\cong 980 \mathrm{~g} \mathrm{~mol}^{-1}$. A massa molar numérica do $O M$ foi calculada a partir da Equação I (IONESCU, 2005):

$$
O H \#=\frac{f .5600}{M_{n}}
$$

em que:

$\mathrm{OH \#}=$ índice ou número de hidroxila de poliol em $\mathrm{mg}$ de $\mathrm{KOH} / \mathrm{g}$

$M_{\mathrm{n}}=$ massa molar numérica média $\left(\mathrm{g} \mathrm{mol}^{-1}\right)$

$\mathrm{f}=$ funcionalidade, número de grupos $\mathrm{OH}$ por mol

$5600=$ massa equivalente de $\mathrm{KOH}$, em miligramas 
Através do índice de hidroxila do OM (OM), $155 \mathrm{mg} \mathrm{KOH} \mathrm{g} \mathrm{g}^{-1}$, e da funcionalidade 2,7 (CUNHA et al., 2004), chegou-se à massa molar do $O M, M_{n}=977,22 \mathrm{~g} \mathrm{~mol}^{-1}$. Assim, a cada 977,22 g de OM tem-se 2,7 mols de hidroxilas.

\subsection{Caracterização das fibras de sisal}

\subsection{Determinação do teor de umidade}

Esta determinação foi realizada de acordo com a Norma ABNT (NBR 9656), e foi realizada em triplicata. Em pesa-filtros previamente tarados, pesou-se I,0 g de amostra $\left(m_{1}\right)$. As amostras foram secas em estufa com circulação de ar a $105{ }^{\circ} \mathrm{C}$ por 4 h. Após este período as amostras foram transferidas para um dessecador e em seguida foram pesadas até massa constante. $O$ teor de umidade foi calculado pela Equação 2:

$$
\% \text { Umidade }=\frac{m_{1}-m_{2}}{m_{1}} \times 100
$$

Onde

$\mathrm{m}_{1}=$ massa $(\mathrm{g})$ inicial da amostra de fibra

$\mathrm{m}_{2}=$ massa $(\mathrm{g})$ da amostra seca

\subsubsection{Determinação do teor de cinzas}

As cinzas foram determinadas segundo a norma TAPPI 413 om-02 (adaptada), em triplicata. Em cadinhos de porcelana refratária previamente tarados a $900{ }^{\circ} \mathrm{C}$, foram adicionados amostras de $1,0 \mathrm{~g}$ de fibra seca e moída. Os cadinhos foram então levados ao bico de Bunsen para combustão lenta da amostra até desaparecer a chama do seu interior. Em seguida, os cadinhos foram levados à mufla, a temperatura de $900^{\circ} \mathrm{C}$, por 4 h. Após este período, as amostras calcinadas foram colocadas em dessecador para resfriamento, até massa constante. A porcentagem de cinzas foi calculada pela Equação 3.

$$
\% \text { Cinzas }=\frac{\mathrm{m}_{1}}{\mathrm{~m}_{2}} \times 100
$$

onde:

$\mathrm{m}_{1}=$ massa $(\mathrm{g})$ de cinzas

$\mathrm{m}_{2}=$ massa $(\mathrm{g})$ da amostra seca de fibra 


\subsubsection{Determinação do teor de holocelulose}

O teor de holocelulose, que corresponde aos teores de celulose e hemiceluloses juntas, foi determinado de acordo com o método descrito na norma TAPPI TI9-54, adaptada para as fibras lignocelulósicas, e em triplicata, conforme descrito a seguir.

Em um erlenmeyer de I L foi adicionado cerca de 3,0 g de amostra seca e moída, 120 $\mathrm{mL}$ de água destilada, I,0 mL de ácido acético glacial e 2,5 g de clorito de sódio. Fechou-se o recipiente com outro erlenmeyer de $250 \mathrm{~mL}$ invertido sobre o primeiro, sendo o conjunto colocado em um banho termostatizado a $70 \pm 2^{\circ} \mathrm{C}$.

A mistura foi mantida sob agitação constante e, após I h, foram adicionados mais I,0 $\mathrm{mL}$ de ácido acético glacial e $2,5 \mathrm{~g}$ de clorito de sódio. Esta etapa foi repetida mais uma vez, e ao final de $3 \mathrm{~h}$, a mistura foi resfriada abaixo de $10{ }^{\circ} \mathrm{C}$ e, em seguida, filtrada em um funil de vidro sinterizado ASTM 2 ou M, previamente tarado. A holocelulose (sobrenadante) foi lavada com água destilada até pH idêntico ao da água utilizada, lavada com metanol e seca em estufa a $105{ }^{\circ} \mathrm{C}$, até massa constante. A amostra foi resfriada em dessecador até massa constante. A porcentagem de holocelulose foi obtida pela Equação 4.

$$
\% \text { Holocelulose }=\frac{\mathrm{m}_{1}}{\mathrm{~m}_{2}} \times 100
$$

onde:

$\%$ Holocelulose $=$ porcentagem do teor de holocelulose

$\mathrm{m}_{1}=$ massa $(\mathrm{g})$ de holocelulose seca

$\mathrm{m}_{2}=$ massa $(\mathrm{g})$ de amostra

Neste processo, a lignina é totalmente eliminada e a amostra final é composta de holocelulose, ou seja, celulose e hemiceluloses (ou polioses).

\subsubsection{Determinação de $\alpha$-celulose}

A determinação do teor de celulose foi realizada com as amostras resultantes da determinação do teor de holocelulose e foi realizada em triplicata. Colocou-se $1,0 \mathrm{~g}$ de amostra de holocelulose em um almofariz e adicionou-se $10 \mathrm{~mL}$ de solução de $\mathrm{NaOH}$ 17,5\%. Deixou-se em repouso por 2 min e triturou-se por $8 \mathrm{~min}$. Adicionou-se então mais $10,0 \mathrm{~mL}$ de solução de $\mathrm{NaOH}$ 17,5\% e deixou-se em repouso por mais 20 min. Adicionou-se então $40 \mathrm{~mL}$ de água destilada e filtrou-se a vácuo em funil de vidro sinterizado (previamente 
tarado). Lavou-se o material retido (celulose) com água destilada até neutralizar. Lavou-se então com $200 \mathrm{~mL}$ de ácido acético diluído (20\%) e com mais $200 \mathrm{~mL}$ de água destilada. Secou-se em estufa de circulação de ar a $105^{\circ} \mathrm{C}$. Resfriou-se em dessecador e pesou-se. A determinação do teor de celulose presente na holocelulose foi feito de acordo com a Equação 5.

$$
\% \text { Celulose }=\frac{m_{1}}{m_{2}} \times 100
$$

onde:

$\%$ Celulose $=$ porcentagem do teor de celulose presente na amostra de holocelulose

$\mathrm{m}_{1}=$ massa $(\mathrm{g})$ de celulose seca

$\mathrm{m}_{2}=$ massa $(\mathrm{g})$ de holocelulose seca

O percentual de hemiceluloses (polioses) foi determinado pela diferença entre a porcentagem de holocelulose e $\alpha$-celulose da fibra.

\subsubsection{Determinação do teor de lignina}

Esta determinação foi realizada segundo a norma TAPPI T 222 om-22, com modificações, e fundamenta-se na separação da lignina após hidrólise dos polissacarídeos com o uso de ácido sulfúrico (72\%).

\section{(a) Determinação do teor de lignina Klason insolúvel em meio ácido}

Essa análise foi realizada em triplicata. Pesou-se cerca de I,0 g amostra, colocou-se em um erlenmeyer de $250 \mathrm{~mL}$ com I5,0 mL de ácido sulfúrico $72 \%$, e deixou-se em agitação mecânica constante por $2 \mathrm{~h}$ a temperatura ambiente. Em seguida, transferiu-se para um balão de $1000 \mathrm{~mL}$ adicionando-se $560 \mathrm{~mL}$ de água, seguindo de refluxo por $4 \mathrm{~h}$. Filtrou-se a lignina insolúvel obtida em funil de vidro sinterizado ASTM tipo C ou 4 (previamente tarado), lavando-se várias vezes com água. A lignina insolúvel foi então seca em estufa a $105^{\circ} \mathrm{C}$ até massa constante. A porcentagem de lignina Klason insolúvel foi calculada de acordo com a Equação 6:

$$
\% \text { Lignina Insolúvel }=\frac{m_{1}}{m_{2}} \times 100
$$

onde:

$\mathrm{m}_{1}=$ massa $(\mathrm{g})$ de lignina Klason insolúvel

$\mathrm{m}_{2}=$ massa $(\mathrm{g})$ de amostra seca de fibra 


\section{(b) Determinação do teor de lignina Klason solúvel em meio ácido}

O filtrado obtido da lignina Klason insolúvel foi analisado através de espectroscopia na região de ultravioleta (UV), sendo determinadas as absorbâncias nos comprimentos de onda de 280 e $215 \mathrm{~nm}$, baseado no método de Goldschmid (197I). As amostras foram diluídas com ácido sulfúrico $3 \%$ até que a absorbância ficasse menor que I. As concentrações de lignina em $\mathrm{g} \mathrm{L}^{-1}$ nas amostras diluídas foram calculadas pela Equação 7:

$$
\mathrm{C}\left(\mathrm{g} \mathrm{L}^{-1}\right)=\frac{4,53 \cdot\left(\mathrm{A}_{215}\right)-\mathrm{A}_{280}}{300}
$$

onde:

$\mathrm{C}\left(\mathrm{g} \mathrm{L}^{-1}\right)=$ concentração em $\mathrm{g} \mathrm{L}^{-1}$ de lignina Klason solúvel nas amostras diluídas $A_{215}=$ valor da absorbância a $215 \mathrm{~nm}$

$\mathrm{A}_{280}=$ valor da absorbância a $280 \mathrm{~nm}$

Para obtenção do percentual de lignina Klason solúvel na fibra, utilizou-se a Equação 8:

$$
\% \text { Lignina solúvel }=\frac{m_{1}}{m_{2}} \times 100
$$

onde:

$\mathrm{m}_{1}=$ massa (g) de lignina Klason solúvel, calculada a partir da concentração de lignina de solúvel (Equação 6), levando em consideração o volume final da determinação de lignina Klason insolúvel $(575 \mathrm{~mL})$ e o fator de diluição (relacionado ao número de vezes que a alíquota foi diluída previamente à análise de UV).

$\mathrm{m}_{2}=$ massa $(\mathrm{g})$ de amostra seca de fibra

O teor total de lignina nas amostras foi obtido pela soma do teor de lignina Klason insolúvel em meio ácido e do teor de lignina Klason solúvel em meio ácido.

\subsubsection{Determinação do índice de cristalinidade (Ic)}

O índice de cristalinidade das fibras foi determinado através das medidas de difração de raios $X$. Essas medidas foram realizadas em um difratômetro da marca RIGAKU Rotaflex, modelo RU-200B, utilizando-se um tubo de cobre, com comprimento de onda $\mathrm{K} \alpha=\mathrm{I}, 54 \mathrm{I}$ Å, e filtro de níquel. As amostras foram colocadas em suporte e analisadas em forma de pó. 
Os índices de cristalinidade foram obtidos pelos valores de intensidade observados no gráfico de intensidade versus ângulo de difração. As principais características que diferem cada forma polimórfica (região cristalina e não cristalina) da celulose, macromolécula que confere cristalinidade às fibras lignocelulósicas, são as difrações próximas aos ângulos de Bragg (2Ө). Assim, é a partir dos picos característicos da celulose que se obtém o índice de cristalinidade da celulose nas fibras lignocelulósicas, que foi calculado segundo a Equação 9, descrita por Buschle-Diller e Zeronian (1992):

$$
\% I_{c}=\frac{\left(I_{22^{2}}-I_{\left.18^{*}\right)}\right.}{I_{22^{2}}} \times 100
$$

$\% I_{\mathrm{c}}=$ porcentagem de cristalinidade

$I_{22^{\circ}}=$ intensidade em $22^{\circ}$ (ângulo de Bragg, 2Ө)

$I_{18^{\circ}}=$ intensidade em $18^{\circ}$ (ângulo de Bragg, 2Ө)

As fibras também foram caracterizadas por microscopia eletrônica de varredura (como descrito posteriormente no item 3.8.4), Análise termogravimétrica (TG) (descrito posteriormente no item 3.3.4), e espectroscopia na região do infravermelho (descrito no item 3.3.2).

\subsection{Caracterização do lignossulfonato de sódio (NaLS)}

\subsection{Análise elementar}

A análise elementar foi realizada pelo Service Central d'Analyse, CNRS (Villeurbaine, France). Os teores de carbono, hidrogênio, nitrogênio, enxofre e sódio foram determinados para $\circ \mathrm{NaLS}$. $\bigcirc$ teor de oxigênio foi determinado por diferença. $\bigcirc$ resultado de análise elementar é importante para a obtenção de estrutura aproximada do NaLS e consequentemente, o valor do teor de hidroxilas estimado.

\subsubsection{Espectroscopia na região do infravermelho}

O espectro na região de infravermelho do NaLS foi obtido no FTIR Spectrometer Paragon 1000 (Perkin Elmer), no intervalo da região do infravermelho de 4000 a $400 \mathrm{~cm}^{-1}$, 
resolução $4 \mathrm{~cm}^{-1}$, com 16 varreduras, utilziando pastilhas de $\mathrm{KBr}(\mathrm{I} \mathrm{mg}$ amostra/ $100 \mathrm{mg} \mathrm{KBr})$, sendo a amostra e o $\mathrm{KBr}$ secos anteriormente em estufa à $80^{\circ} \mathrm{C}$.

\subsubsection{Determinação do teor de cinzas}

As cinzas do NaLS foram determinadas segundo a norma TAPPI 413 om-02 (adaptada), em triplicata, conforme descrito no item 3.2.2.

\subsubsection{Análise termogravimétrica}

A análise termogravimétrica foi realizada utilizando-se um equipamento da marca Shimadzu, modelo TGA-50. A amostra, com massa de 5,0 mg, foi colocada em panela de platina e aquecida de 25 a $900{ }^{\circ} \mathrm{C}$ com razão de aquecimento de $10^{\circ} \mathrm{C} \mathrm{min}{ }^{-1}$, sob atmosfera de nitrogênio com fluxo de $20 \mathrm{~mL} \mathrm{~min}^{-1}$.

\subsubsection{Determinação de grupos ionizáveis}

No intuito de investigar o teor de hidroxilas do NaLS, realizou-se uma titulação condutométrica para determinar os grupamentos funcionais ionizáveis (cargas totais) associados ao NaLS. O método descrito na norma SCAN-CM 65:02 (Total acidic group content) também foi descrito por Fras et al. (2004), e uma adaptação do mesmo foi realizada para determinar teor de grupos ácidos do lignossulfonato de sódio. Inicialmente, o NaLS foi submetido a uma etapa de protonação: I g de NaLS foi solubilizado em $100 \mathrm{~mL}$ de água destilada e então adicionou-se $48 \mathrm{~mL}$ de ácido clorídrico $0, \mathrm{I} \mathrm{N}$, ○ que fez a solução chegar em $\mathrm{pH}$ I,7, para garantir que todas as espécies presentes fossem protonadas. A titulação foi realizada com a adição de solução de hidróxido de sódio $0,05 \mathrm{~mol} \mathrm{~L}^{-1}$, medindo simultaneamente a condutividade e o $\mathrm{pH}$. Um curva condutância versus volume de $\mathrm{NaOH} 0, \mathrm{I}$ $M$ foi plotada, e nesta curva pontos de equivalências aparente foram observados. A partir da diferença entre os valores de volumes nos pontos de equivalência foi possível obter o número de mols de hidróxido de sódio que foram necessários para desprotonar as espécies ácidas presentes no NaLS. 
3.3.6 Determinação do teor de hidroxilas fenólicas por espectroscopia na região do ultravioleta visível (UV-Vis)

O teor de hidroxilas fenólicas do NaLS foi determinado por espectroscopia na região do ultravioleta visível (UV-Vis) conforme um estudo descrito por Wexler (1964). Foram obtidos espectros de diferença de soluções alcalina e ácida de NaLS e foram utilizados três abordagens para estimar o teor de grupos hidroxilas fenólicas. Nestes cálculos, descritos a seguir, os teores podem ser obtidos a partir da absortividade máxima da curva de diferença resultante e o máximo da absortividade molar de substâncias modelos determinadas do mesmo modo.

Inicialmente, $0,200 \mathrm{~g}$ de $\mathrm{NaLS}$ (previamente seco em estufa à $70^{\circ} \mathrm{C}$ ) foi transferido para um balão volumétrico de $100 \mathrm{~mL}$ e dissolvidos em água destilada seguido pelo ajuste do volume, à temperatura ambiente. Uma segunda diluição foi realizada pipetando $5 \mathrm{~mL}$ da solução anterior em outros dois balões volumétricos de $100 \mathrm{~mL}$. Em um balão foi adicionado $10 \mathrm{~mL}$ de solução de $\mathrm{KOH} I, 0 \mathrm{~N}$, e no outro foi adicionado $10 \mathrm{~mL}$ de solução de $\mathrm{HCl} I, 0 \mathrm{~N}$. Os volumes finais foram ajustados para $100 \mathrm{~mL}$ com a adição água destilada. Desta maneira, foram preparadas soluções de concentração $1,0.10^{-1} \mathrm{~g} \mathrm{~L}^{-1}$ (NaLS em solução $0,1 \mathrm{~N}$ álcali (amostra) e 0,I $\mathrm{N}$ ácida (referência). Cubetas de $\mathrm{I} \mathrm{cm}$ foram utilizadas para as medidas. Foram preparadas também soluções $0,5 \cdot 10^{-1}$ e $1,33 \cdot 10^{-1} \mathrm{~g} \mathrm{~L}^{-1}$. Os espectros de diferença foram obtidos colocando a solução alcalina na posição da amostra e solução ácida na posição de referência.

\section{Descrição dos cálculos:}

Cálculo A (GOLDSCHMID, 1954): o teor de hidroxilas fenólicas corresponde à absortividade do comprimento de onda mais longo em cerca de $300 \mathrm{~nm}$ no espectro de diferença, multiplicado pelo fator 0,4l4. Goldschmid (1954) chegou a este fator à partir de investigações em espectros de diferença de derivados de guaiacila (eugenol e conidrendina) como substâncias modelos.

Cálculo B (WEXLER, 1964): o teor de hidroxilas fenólicas é igual à absortividade corrigida do comprimento de onda mais curto em cerca de $250 \mathrm{~nm}$ no espectro de diferença, multiplicado pelo fator 0,192. A absortividade corrigida é estimada à partir de uma linha base que liga os mínimos em cerca de 229 e $278 \mathrm{~nm}$. O fator 0,192 é resultado de investigações com as substâncias modelo: ácido 4-hidroxi3-metoxitouleno- $\omega$-sulfônico, ácool 
4-hidroxi-3-metoxibenzílico, 4-hidroxi-3-metoxi-I-propilbenzeno e 6-hidroxi-5-metoxi-Imetil-3-propilbenzeno.

Cálculo C (WEXLER, 1964): o teor de hidroxilas é obtida pela multiplicação da absortividade bruta em $250 \mathrm{~nm}$ por 0,192, no espectro de diferença.

As absortividades são expressas em $\mathrm{L} \mathrm{g}^{-1} \mathrm{~cm}^{-1}$ (Equação 10):

$$
\varepsilon=\frac{\mathrm{A}}{\mathrm{cd}}
$$

em que,

$\varepsilon=$ absortividade

A = absorbância

$c=$ concentração da espécie

$\mathrm{d}=$ comprimento da trajetória

\subsection{Síntese de poliuretanos, lignopoliuretanos e preparação dos respectivos compósitos}

Em todo o estudo, os compósitos foram preparados com um teor de $30 \%$ em massa de fibras de sisal, após extração em mistura de cicloexano/etanol, com comprimento de 3,0 $\mathrm{cm}$ e distribuição aleatória na matriz. A porcentagem e comprimento de fibras foram escolhidos a partir de resultados de estudos anteriores (PAIVA; TRINDADE; FROLLINI, 1999; PAIVA, 200I; SILVA; BENADUCCI; FROLLINI, 20I2; DE OLIVEIRA SANTOS et al., 2014). As porcentagens mencionadas na sequencia deste texto sempre corresponderão a \% em massa. Para melhor classificar os materiais, alguns termos foram definidos da seguinte maneira:

Poliuretanos: refere-se à matriz de poliuretano cuja formulação inclui apenas o uso de polióis convencionais (DEG, PEG ou OM).

Lignopoliuretanos: refere-se à matriz de poliuretano cuja formulação inclui o uso de lignossulfonatos (modificados ou não) como polióis, seja como única fonte de hidroxilas ou em combinação com outros polióis.

Compósitos: material que corresponde à matriz polimérica, seja ela poliuretânica ou lignopoliuretânica, reforçada por fibras de sisal. 
Os materiais preparados neste estudo foram agrupados em três grupos. No Grupo I, foram preparados PUs e respectivos compósitos a partir de polióis convencionais (DEG, PEG e OM). Ainda neste grupo, foram preparados lignopoliuretanos e respectivos compósitos a partir da combinação do NaLS com os polióis convencionais DEG, PEG e OM. Informações sobre a formulação e preparação dos materiais do Grupo I estão descritos nos Quadros I e 2.

No Grupo 2, detalhados no Quadro 3, o NaLS foi submetido à modificação via oxipropilação (reação com OP) e lignopoliuretanos e respectivos compósitos foram preparados a partir do NaLS e NaLS oxipropilado. Em algumas formulações o $\mathrm{NaLS}$ ou NaLS oxipropilado foi associado com OM. Parte deste estudo incluído no Grupo 2 foi desenvolvido no Laboratoire Génie des Procédes Papetiers (Grenoble INP/Pagora, Grenoble, França) sob a supervisão do prof. Mohamed Naceur Belgacem.

No Grupo 3, descritos nos Quadros 4 e 5, o NaLS foi modificado via hidroxialquilação (reação com glutaraldeído e formaldeído) e lignopoliuretanos e respectivos compósitos foram preparados a partir do lignossulfonato modificado com glutaraldeído (NaLS-Glu) e lignossulfonato modificado com formaldeído (NaLS-For). Formulações foram preparadas com e sem associação do NaLS-modificado com OM.

\subsection{Grupo I: poliuretanos, lignopoliuretanos e respectivos compósitos à partir do NaLS e polióis convencionais (DEG, PEG e OM)}

Os lignopoliuretanos deste grupo foram preparados considerando uma proporção molar em que foi utilizado $30 \%$ dos grupos $\mathrm{OH}$ oriundos do lignossulfonato de sódio ( $\mathrm{NaLS}$ ) e $70 \%$ de $\mathrm{OH}$ a partir de polióis (DEG, PEG e OM). Neste grupo, também foram preparados PUs sem a presença de NaLS, apenas com os polióis DEG, PEG e OM, os quais foram considerados como amostras-controle.

O procedimento de obtenção do primeiro lignopoliuretano preparado e respectivo compósito será descrito no próximo item e servirá como procedimento base para todos os demais compósitos preparados neste estudo. A descrição da preparação dos demais lignopoliuretanos e compósitos, com eventuais mudanças ou detalhes adicionais, serão apresentadas em quadros posteriores. 
3.5.I Procedimento de obtenção do compósito lignopoliuretano DEG/NaLS/MDI/Sisal e do lignopoliuretano não reforçado DEG/NaLS/MDI

Para estes materiais, foi utilizada uma razão $\mathrm{NCO} / \mathrm{OH}=\mathrm{I}, \mathrm{I}$ (razão molar entre grupos isocianatos e grupos hidroxilas); razão em massa DEG/NaLS/MDI = 0,28:0,7I: I,00.

Para obtenção do compósito lignopoliuretânico DEG/NaLS/MDI/sisal, as fibras de sisal e o NaLS foram secos em estufa de circulação de ar à $105{ }^{\circ} \mathrm{C}$ por $4 \mathrm{~h}$. Em seguida, as fibras e os demais reagentes foram resfriados em geladeira, em uma temperatura aproximada de $10{ }^{\circ} \mathrm{C}$ por I h, como uma tentativa de retardar o início da polimerização durante o processo de impregnação fibra/matriz, visto que as reações de obtenção de PU, dependendo dos reagentes considerados, podem ter início em temperaturas próximas à temperatura ambiente. Então, aproximadamente $60 \%$ do NaLS foi misturado com MDI e os demais $40 \%$ com o DEG. A mistura NaLS-MDI foi adicionada às fibras de sisal, seguido pela adição da mistura NaLS-DEG. Após cada adição, as fibras foram misturadas com o auxílio de pinças, e em seguida em misturador mecânico (Misturador JVJ, Pardinho, SP) por 5 min (rotação de 20 rpm).

Após estes procedimentos, as fibras impregnadas foram vertidas no molde metálico $(30,0 \times 14,0 \times 0,5 \mathrm{~cm})$, previamente revestido com película de politetrafluoretileno (PTFE) de 0,02 $\mathrm{mm}$ de espessura (agente desmoldante), e então submetido ao ciclo descrito na Tabela I. A Figura 23 mostra de forma esquemática o processo de obtenção dos compósitos contendo matriz poliuretânica ou lignopoliuretânica e fibras de sisal. 
Figura 23 - Representação do processo de obtenção dos compósitos de matriz lignopoliuretânica e fibras de sisal.

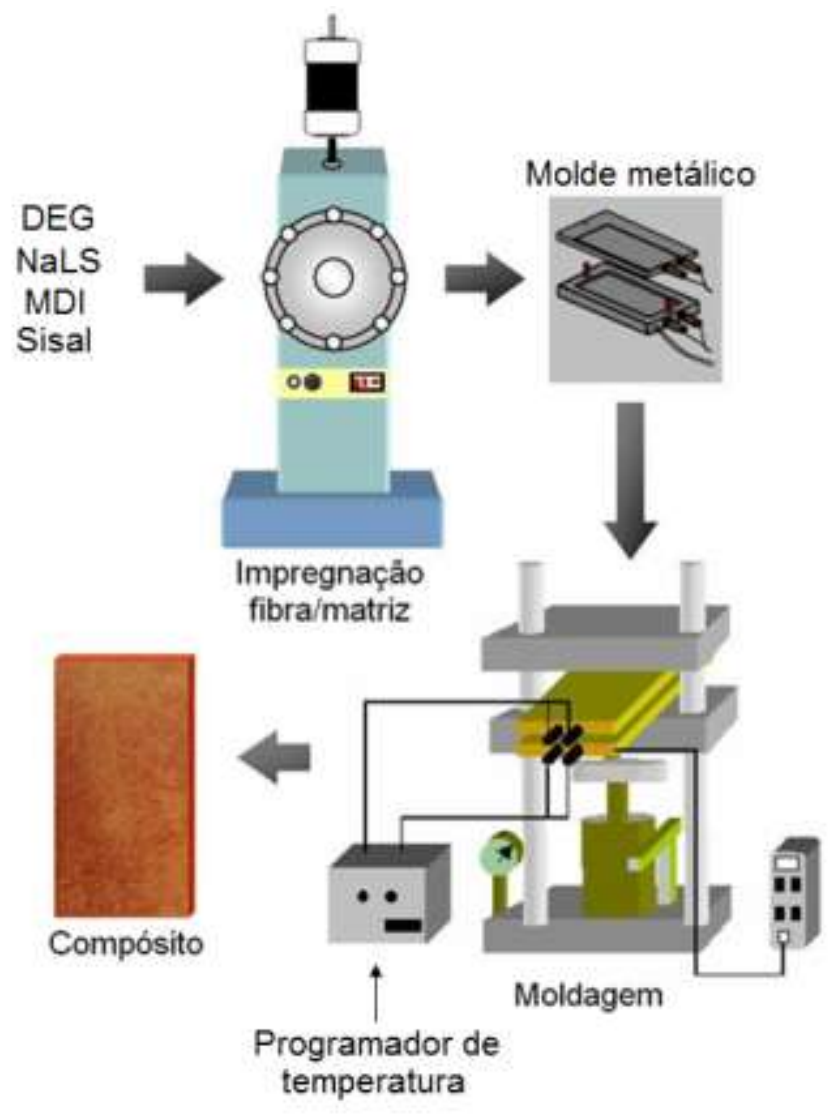

Para obtenção do lignopoliuretano não reforçado DEG/NaLS/MDI, os reagentes foram previamente resfriados a $10{ }^{\circ} \mathrm{C}$ por I h. Metade do NaLS foi misturada manualmente usando espátulas (até máxima homogeneização) com MDI e a outra metade foi misturada com DEG. Em seguida, as duas misturas foram vertidas e misturadas diretamente no molde com o auxílio de espátulas. O molde foi então fechado e submetido à um ciclo semelhante ao descrito na Tabela I, diferenciando apenas na pressão final aplicada (2,80 MPa).

\subsubsection{Demais procedimentos}

As informações pertinentes ao preparo dos demais lignopoliuretanos estão apresentadas nos Quadros I e 2 (Experimental). O primeiro compósito descrito no Quadro I (DEG/NaLS/MDI/Sisal) e seu respectivo lignopoliuretano (DEG/NaLS/MDI) corresponde aos mesmos descrito detalhadamente no item anterior.

Os ciclos utilizados, que correspondem às temperaturas e pressões utilizadas durante a moldagem, são apresentados nas Tabelas I, 2 e 3 . Estes ciclos foram estabelecidos após explorações iniciais envolvendo a reação do NaLS e polióis convencionais com o MDI. Em 
alguns casos, as reações foram iniciadas a temperatura ambiente. No entanto, os resultados obtidos nesta exploração inicial indicaram que temperaturas acima da ambiente deveriam ser utilizadas no ciclo, como forma de viabilizar o processo como um todo.

Tabela I - Ciclo I para obtenção de PUs, lignopoliuretanos e respectivos compósitos.

\begin{tabular}{ccc}
\hline Temperatura $\left({ }^{\circ} \mathrm{C}\right)$ & Tempo (min) & Pressão (MPa) \\
\hline $60^{\circ} \mathrm{C}$ & 60 & 3,73 \\
$85^{\circ} \mathrm{C}$ & 60 & 3,73 \\
$120^{\circ} \mathrm{C}$ & 60 & 3,73 \\
$150^{\circ} \mathrm{C}$ & 60 & 3,73 \\
\hline
\end{tabular}




\section{QUADRO I}

\begin{tabular}{|c|c|c|c|c|}
\hline Material & $\begin{array}{c}\text { Formulação e proporção } \\
\text { dos reagentes }\end{array}$ & Detalhes do processo & $\begin{array}{c}\text { Razão } \\
\text { NCO/OH }\end{array}$ & Ciclo \\
\hline \multirow{3}{*}{ 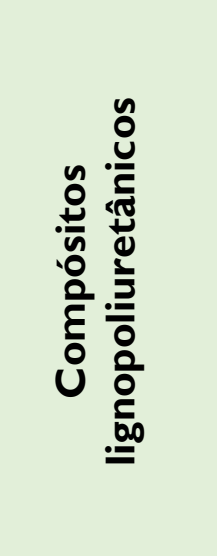 } & $\begin{array}{l}\text { DEG/NaLS/MDI, Sisal 30\% } \\
\text { Razão 0,28: 0,71 : } 1,00\end{array}$ & Informado no item 3.5.I & $\mathrm{I}, \mathrm{I}$ & Tabela I \\
\hline & $\begin{array}{l}\text { PEG/NaLS/MDI, Sisal 30\% } \\
\text { Razão 0,79: 0,71 : 1,00 }\end{array}$ & $\begin{array}{l}\text { Mistura de } 50 \% \text { do NaLS com MDI; } \\
\text { Mistura de } 50 \% \text { do NaLS com PEG; } \\
\text { Impregnação das fibras com NaLS-MDI; } \\
\text { Impregnação das fibras com NaLS-DEG; } \\
\text { Mistura em misturador mecânico } 5 \text { min). }\end{array}$ & $\mathrm{I}, \mathrm{I}$ & Tabela I \\
\hline & $\begin{array}{l}\text { OM/NaLS/MDI, Sisal 30\% } \\
\text { Razão I,73:0,7I: I,00 }\end{array}$ & Idem ao anterior & $\mathrm{I}, \mathrm{I}$ & Tabela I \\
\hline \multirow{2}{*}{ 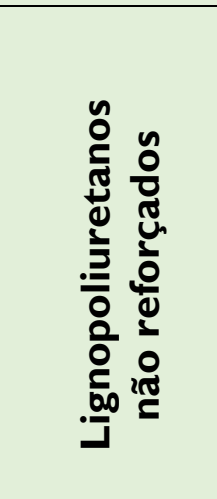 } & $\begin{array}{c}\text { DEG/NaLS/MDI } \\
\text { Razão } 0,28: 0,71: 1,00\end{array}$ & $\begin{array}{l}\text { Mistura de } 50 \% \text { do } \mathrm{NaLS} \text { com MDI; } \\
\text { Mistura de } 50 \% \text { do NaLS com PEG; } \\
\text { Duas misturas vertidas e misturadas no molde. }\end{array}$ & $\mathrm{I}, \mathrm{I}$ & Tabela I \\
\hline & $\begin{array}{c}\text { OM/NaLS/MDI } \\
\text { Razão } 1,73: 0,71: 1,00\end{array}$ & Idem ao anterior & $\mathrm{I}, \mathrm{I}$ & Tabela I \\
\hline
\end{tabular}




\section{QUADRO 2}

\begin{tabular}{|c|c|c|c|c|}
\hline Material & $\begin{array}{l}\text { Formulação e proporção } \\
\text { dos reagentes }\end{array}$ & Detalhes do processo & $\begin{array}{c}\text { Razão } \\
\text { NCO/OH }\end{array}$ & Ciclo \\
\hline \multirow{3}{*}{ 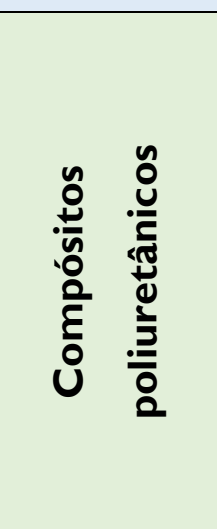 } & $\begin{array}{l}\text { DEG/MDI, Sisal 30\% } \\
\text { Razão 0,40: I,00 }\end{array}$ & $\begin{array}{l}\text { Impregnação das fibras com MDI; } \\
\text { Mistura em misturador mecânico (5 min); } \\
\text { Impregnação das fibras com DEG; } \\
\text { Mistura em misturador mecânico (I min) }\end{array}$ & 1,0 & Tabela I \\
\hline & $\begin{array}{l}\text { PEG/MDI, Sisal 30\% } \\
\text { Razão I,I2: I,00 }\end{array}$ & $\begin{array}{l}\text { Impregnação das fibras com PEG; } \\
\text { Mistura em misturador mecânico ( } 5 \text { min); } \\
\text { Impregnação das fibras com MDI }\end{array}$ & $\mathrm{I}, 0$ & Tabela I \\
\hline & $\begin{array}{l}\text { OM /MDI, Sisal } \mathbf{3 0 \%} \\
\text { Razão 2,72: } 1,00\end{array}$ & $\begin{array}{l}\text { Mistura do OM e MDI; } \\
\text { Impregnação das fibras com OM/MDI; } \\
\text { Mistura em misturador mecânico ( } 3 \text { min). }\end{array}$ & $\mathrm{I}, 0$ & Tabela I \\
\hline \multirow{3}{*}{ 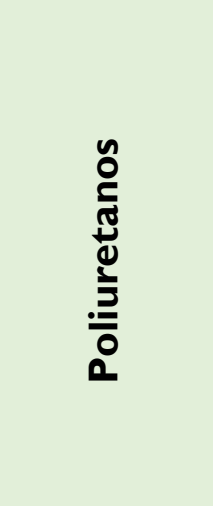 } & $\begin{array}{c}\text { DEG/MDI } \\
\text { Razão } 0,40: 1,00\end{array}$ & $\begin{array}{l}\text { Mistura de DEG e MDI; } \\
\text { Pressão aplicada após I } 5 \text { min do início do ciclo. }\end{array}$ & $\mathrm{I}, 0$ & Tabela I \\
\hline & $\begin{array}{c}\text { PEG/MDI } \\
\text { Razão I,I2 : I,00 }\end{array}$ & Mistura de PEG e MDI. & 1,0 & Tabela I \\
\hline & $\begin{array}{c}\text { OM/ /MDI } \\
\text { Razão } 2,72: 1,00\end{array}$ & $\begin{array}{l}\text { Mistura de OM e MDI; } \\
\text { Pressão aplicada após } 40 \text { min do início do ciclo }\end{array}$ & $\mathrm{I}, 0$ & Tabela I \\
\hline
\end{tabular}




\subsection{Grupo 2: lignopoliuretanos e respectivos compósitos a partir do NaLS oxipropilado (LS-Oxi) e OM}

\subsection{Oxipropilação do lignossulfonato de sódio}

A reação de oxipropilação foi realizada em uma proporção de lignossulfonato/óxido de propileno (NaLS/OP, w/v) de 30/70. Reações com diferentes proporções NaLS/OP $(25 / 75,35 / 65,30 / 70$ e 40/60) foram realizadas como investigações prévias a este trabalho, com base em estudos anteriores em que outros tipos de lignina (obtidas pelos processo Kraft, soda e organosolv) foram oxipropiladas (CATETO et al., 2009; CATETO et al., 20I3).

A proporção 30/70 foi escolhida pelo fato de o lignopoliol resultante desta reação apresentar uma viscosidade adequada para ser usado posteriormente na preparação dos compósitos lignopoliuretânicos, devido à maior facilidade de impregnação das fibras. A quantidade de catalisador (C) foi mantida em $5 \%$ em relação à massa de $\mathrm{NaLS}(\mathrm{C} /(\mathrm{C}+\mathrm{NaLS})$, $\% \mathrm{w} / \mathrm{w})$. A escolha do catalisador foi baseada em estudos prévios que mostraram que o $\mathrm{KOH}$ é adequado para este tipo de reação (GANDINI; BELGACEM, 2008). Além disso, $\mathrm{KOH}$ é muito utilizado industrialmente na síntese de polióis poliéteres (IONESCU, 2005).

A reação ocorreu em massa utilizando um reator Parr de $300 \mathrm{~mL}$ equipado com uma manta de aquecimento, agitador mecânico, termopar e manômetro. O NaLS, OP e $\mathrm{KOH}$ foram colocados dentro do reator que foi fechado e aquecido até $150{ }^{\circ} \mathrm{C}$. A partir do estado inicial, a pressão e a temperatura começaram a aumentar progressivamente até um valor máximo de $240^{\circ} \mathrm{C}$, permanecendo nesta temperatura por $48 \mathrm{~min}$. Após alcançar a pressão máxima de 20 bar, esta diminuiu rapidamente indicando o consumo de OP. Quando a pressão relativa alcançou zero, o reator foi resfriado sob agitação e o lignopoliol resultante, chamado doravante de LS-Oxi, foi recuperado.

\subsubsection{Caracterização do LS-Oxi}

\subsubsection{Espectroscopia na região do infravermelho do lignopoliol}

Após a oxipropilação do $\mathrm{NaLS}$, o espectro na região de infravermelho do lignopoliol resultante (LS-Oxi, na forma líquida) foi obtido no FTIR Spectrometer Paragon 1000 (Perkin Elmer), no intervalo da região do infravermelho de 4000 a $400 \mathrm{~cm}^{-1}$, resolução $4 \mathrm{~cm}^{-1}$, com 16 varreduras, utilizando um dispositivo com células de $\mathrm{CaF}_{2}$. 


\subsubsection{Medidas de viscosidade aparente $\left(\eta_{a}\right)$}

A viscosidade do NaLS-Oxi foi medida em um reômetro Physica MCR30I da Anton Paar, utilizando a geometria do tipo placas paralelas com $50 \mathrm{~mm}$ de diâmetro. Os testes foram conduzidos variando a taxa de cisalhamento de 0 a $1000 \mathrm{~s}^{-1}$ a $25^{\circ} \mathrm{C}$, com tempo de cisalhamento de I min e pré-cisalhamento de $30 \mathrm{~s}$.

\subsubsection{Determinação do índice de hidroxilas $\left(I_{O H}\right)$ do lignopoliol}

O número (ou índice) de hidroxilas do lignopoliol LS-Oxi foi determinado de acordo com a norma ISO 14900:200I (E), com algumas adaptações. A amostra de LS-Oxi foi refluxada à $115^{\circ} \mathrm{C}$ em $50 \mathrm{~mL}$ de uma solução de reagente de acetilação. A amostra controle (solução do reagente de acetilação) foi refluxada nas mesmas condições. Esta solução foi preparada através da mistura de $12,7 \mathrm{~mL}$ de anidrido acético com $100 \mathrm{~mL}$ de piridina livre de umidade e I,6 de imidazol (catalisador). Depois do período de refluxo $(2 \mathrm{~h})$, os frascos foram resfriados em temperatura ambiente, e o excesso de anidrido acético foi hidrolisado com água destilada. $O$ ácido acético resultante foi em seguida titulado com hidróxido de sódio $(I, 0 \mathrm{~N})$ e a diferença entre a concentração de ácido acético do branco e das amostras de lignina permitiram a determinação do teor de hidroxilas. As titulações foram realizadas com um pHmetro. A quantidade de amostra foi ajustada de um modo que o volume da solução de hidróxido de sódio utilizado para a titulação do LS-Oxi fosse menor que $80 \%$ do volume necessário para o branco.

$\mathrm{O}$ número de hidroxilas, em $\mathrm{mg}$ de $\mathrm{KOH} \mathrm{\textrm {g } ^ { - 1 }}$, foi determinado de acordo com a Equação I I;

$$
\text { Número de hidroxila }(\# O H)=\frac{\left(V_{1}-V_{2}\right) \times C \times 56.1}{m}(\mathrm{II})
$$

em que:

$\mathrm{V}_{1}=$ é o volume de $\mathrm{NaOH}$ necessário para a titulação do branco, em $\mathrm{mL}$

$\mathrm{V}_{2}=$ é o volume de $\mathrm{NaOH}$ necessário para titulação do poliol, in $\mathrm{mL}$

$\mathrm{C}=$ é a concentração de $\mathrm{NaOH}$, in $\mathrm{mol} \mathrm{L}^{-1}$

$\mathrm{m}=$ é a massa do poliol, em $\mathrm{g}$ 


\subsubsection{Procedimentos de preparação de lignopoliuretanos e compósitos}

No Grupo 2, lignopoliuretanos foram preparados pelos lignopolióis NaLS ou LS-Oxi, MDI, e em algumas formulações, o OM (OM), resultando nos lignopoliuretanos NaLS/MDI, OM/NaLS/MDI, LS-Oxi/MDI e OM/LS-Oxi, e seus respectivos compósitos. Detalhes dos procedimentos podem ser encontrados no Quadro 3.

Uma proporção estequiométrica $\mathrm{NCO} / \mathrm{OH}$ de I,2 foi utilizada para calcular a massa dos reagentes. Nas formulações em que OM (índice de hidroxila de $155 \mathrm{mg} \mathrm{KOH} \mathrm{g} \mathrm{g}^{-1}$ ) foi usado, a proporção deste poliol correspondeu à $30 \%$ do total de hidroxilas, enquanto que os outros $70 \%$ de $\mathrm{OH}$ correspondeu ao NaLS ou LS-Oxi, cujos índices de hidroxilas utilizados foram II8,8 e 574,I mg $\mathrm{KOH} \mathrm{g}^{-1}$, respectivamente. $\mathrm{Na}$ preparação da placa lignopoliuretânica a partir de NaLS/MDI um excesso de NCO foi utilizado para que fosse possível a mistura do NaLS (um pó) ao MDI (líquido), modificando naturalmente a razão $\mathrm{NCO} / \mathrm{OH}$ neste material.

O ciclo utilizado para os materiais do Grupo 2 encontra-se descrito na Tabela 2.

Tabela 2 - Ciclo 2 para obtenção de PUs, lignopoliuretanos e respectivos compósitos.

\begin{tabular}{ccc}
\hline Temperatura $\left({ }^{\circ} \mathrm{C}\right)$ & Tempo (min) & Pressão (MPa) \\
\hline $60^{\circ} \mathrm{C}$ & 60 & 3,74 \\
$85^{\circ} \mathrm{C}$ & 60 & 3,74 \\
$120^{\circ} \mathrm{C}$ & 60 & 3,74 \\
\hline
\end{tabular}




\section{QUADRO 3}

\begin{tabular}{|c|c|c|c|c|}
\hline Material & $\begin{array}{l}\text { Formulação e proporção } \\
\text { dos reagentes }\end{array}$ & Detalhes do processo & $\begin{array}{l}\text { Razão } \\
\text { NCO/OH }\end{array}$ & Ciclo \\
\hline \multirow{4}{*}{ 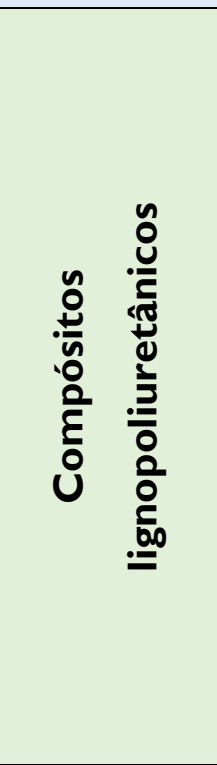 } & $\begin{array}{l}\text { NaLS/MDI, Sisal 30\% } \\
\text { Razão I,00:I,00 }\end{array}$ & $\begin{array}{l}\text { Mistura (manual e mecânica) de NaLS e MDI; } \\
\text { Impregnação manual e mistura mecânica ( } 5 \text { min) das fibras com } \\
\text { a mistura NaLS/MDI. }\end{array}$ & 3,5 & Tabela 2 \\
\hline & $\begin{array}{l}\text { OM/NaLS/MDI, Sisal } 30 \% \\
\text { Razão } 2,00: 0,67: 1,00\end{array}$ & $\begin{array}{l}\text { Mistura de } 50 \% \text { do NaLS com MDI; } \\
\text { Mistura de } 50 \% \text { do NaLS com OM; } \\
\text { Impregnação das fibras com NaLS/MDI; } \\
\text { Mistura em misturador mecânico (5 min); } \\
\text { Impregnação das fibras com NaLS/OM; } \\
\text { Mistura em misturador mecânico (5 min). }\end{array}$ & $\mathrm{I}, 2$ & Tabela 2 \\
\hline & $\begin{array}{l}\text { LS-Oxi/MDI, Sisal 30\% } \\
\quad \text { Razão } 0,61: 1,00\end{array}$ & $\begin{array}{l}\text { Impregnação das fibras com LS-Oxi; } \\
\text { Mistura em misturador mecânico (3 min); } \\
\text { Impregnação das fibras com MDI; } \\
\text { Mistura em misturador mecânico (3 min). }\end{array}$ & $\mathrm{I}, 2$ & Tabela 2 \\
\hline & $\begin{array}{l}\text { OM/LS-Oxi/MDI, Sisal } 30 \% \\
\text { Razão } 0,67: 0,42: 1,00\end{array}$ & $\begin{array}{l}\text { Mistura do LS-Oxi e OM; } \\
\text { Impregnação das fibras com LS-Oxi/OM; } \\
\text { Mistura em misturador mecânico (5 min). } \\
\text { Impregnação das fibras com MDI; } \\
\text { Mistura em misturador mecânico (3 min). }\end{array}$ & $\mathrm{I}, 2$ & Tabela 2 \\
\hline \multirow{4}{*}{ 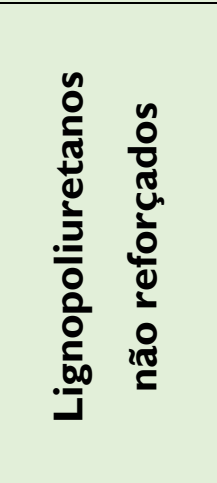 } & $\begin{array}{c}\text { NaLS/MDI } \\
\text { Razão } 1,00: 1,00\end{array}$ & Mistura manual e mecânica do NaLS com MDI & 3,5 & Tabela 2 \\
\hline & $\begin{array}{c}\text { OM/NaLS/MDI } \\
\text { Razão 2,00: 0,67 : I,00 }\end{array}$ & $\begin{array}{l}\text { Mistura de } 50 \% \text { do NaLS com MDI; } \\
\text { Mistura de } 50 \% \text { do NaLS com OM; } \\
\text { Duas misturas vertidas e misturadas no molde. }\end{array}$ & 1,2 & Tabela 2 \\
\hline & $\begin{array}{c}\text { LS-Oxi/MDI } \\
\text { Razão } 0,61: 1,00 \\
\end{array}$ & Mistura manual de LS-Oxi e MDI. & $\mathrm{I}, 2$ & Tabela 2 \\
\hline & $\begin{array}{c}\text { OM/LS-Oxi/MDI } \\
\text { Razão } 0,67: 0,42: 1,00\end{array}$ & $\begin{array}{l}\text { Mistura mecânica de OM e LS-Oxi; } \\
\text { Mistura manual de OM/LS-Oxi e MDI. }\end{array}$ & 1,2 & Tabela 2 \\
\hline
\end{tabular}




\subsection{Grupo 3: lignopoliuretanos e respectivos compósitos à partir do NaLS hidroxialquilado (NaLS-Glu e NaLS-For)}

Visando aumentar a reatividade do lignossulfonato de sódio (NaLS) frente aos grupos NCO na síntese de lignopoliuretanos, o mesmo foi modificado com diferentes aldeídos (glutaraldeído e formaldeído). Os procedimentos descritos a seguir foram baseados em estudos anteriores em que o NaLS foi modificado com aldeídos visando à preparação de resinas do tipo fenólica (SILVA et al., 20I2).

\subsection{Hidroxialquilação do lignossulfonato de sódio: reação com glutaraldeído (NaLS-Glu)}

Os reagentes lignossulfonato de sódio ( $\mathrm{NaLS}$ ), glutaraldeído (Glu) e $\mathrm{KOH}$ foram adicionados na razão $1: 2: 0,075$, respectivamente, em massa. Em um balão de reação contendo o glutaraldeído foi adicionado gradativamente o $\mathrm{NaLS}$, sendo o sistema mantido sob agitação mecânica por 15 min para solubilização máxima do $\mathrm{NaLS}$. Em seguida, $\mathrm{KOH}$ foi adicionado, mantendo a agitação da mistura por $40 \mathrm{~min}$. Após este período, o pH foi medido para a confirmação do meio básico. Em seguida, a temperatura foi elevada a $70{ }^{\circ} \mathrm{C}$ e mantida por I h. Na sequência, a temperatura foi elevada até $97^{\circ} \mathrm{C}$ e mantida por $2 \mathrm{~h}$. Ao final deste período, o sistema foi resfriado e $\circ \mathrm{pH}$ foi ajustado para 7. O pré-polímero foi rotaevaporado sob pressão reduzida em temperaturas de 45 até $55^{\circ} \mathrm{C}$.

\subsubsection{Hidroxialquilação do lignossulfonato de sódio: reação com formaldeído (NaLS-For)}

Esta modificação também pode ser chamada de hidroximetilação do NaLS. Utilizouse a proporção de 1,0:1,4:0,07 para lignossulfonato, formaldeído (solução a 37\%) e $\mathrm{KOH}$, respectivamente. $O$ procedimento para reação se deu da mesma maneira como descrito para a modificação do lignossulfonato com glutaraldeído, descrito no item imediatamente anterior.

Quando $\circ$ NaLS foi hidroxialquilado (com formaldeído ou glutaraldeído), lignopoliuretanos foram preparados considerando a condição de $30 \%$ dos grupos $\mathrm{OH}$ oriundos do NaLS e 70\% a partir do OM. Obteve-se também PU em que 100\% dos grupos hidroxilas foram oriundos dos lignossulfonatos modificados. 


\subsubsection{Espectroscopia na região do infravermelho do NaLS-Glu e NaLS-For}

Após a hidroxialquilação do NaLS com glutaraldeído e formaldeído, espectros na região de infravermelho dos lignopolióis resultante (NaLS-Glu e NaLS-For) foram obtidos usando um espectrômetro BOMEM, modelo MB-102, no intervalo da região do infravermelho de 4000 a $400 \mathrm{~cm}^{-1}$, resolução $4 \mathrm{~cm}^{-1}$, com 16 varreduras, utilizando um suporte adequado para material viscoso, no qual foi depositada uma fina camada de prépolímeros.

\subsubsection{Procedimento de obtenção dos lignopoliuretanos e compósitos lignopoliuretânicos}

As informações pertinentes ao preparo de cada material desta fase estão apresentadas nos Quadros 4 e 5. As informações gerais já apresentadas para o entendimento dos Quadros I e 2 são válidas também para os Quadros 4 e 5.

Em alguns compósitos, foi utilizado um ciclo diferente para a reação, como o ciclo descrito na Tabela 3, definido através de testes experimentais realizados durante 0 desenvolvimento deste trabalho.

Tabela 3 - Ciclo 3 para obtenção de PUs, lignopoliuretanos e respectivos compósitos.

\begin{tabular}{ccc}
\hline Temperatura $\left({ }^{\circ} \mathrm{C}\right)$ & Tempo (min) & Pressão (MPa) \\
\hline $60^{\circ} \mathrm{C}$ & 30 & 3,74 \\
$85^{\circ} \mathrm{C}$ & 30 & 3,74 \\
$120^{\circ} \mathrm{C}$ & 30 & 3,74 \\
$150^{\circ} \mathrm{C}$ & 30 & 3,74 \\
\hline
\end{tabular}




\section{QUADRO 4}

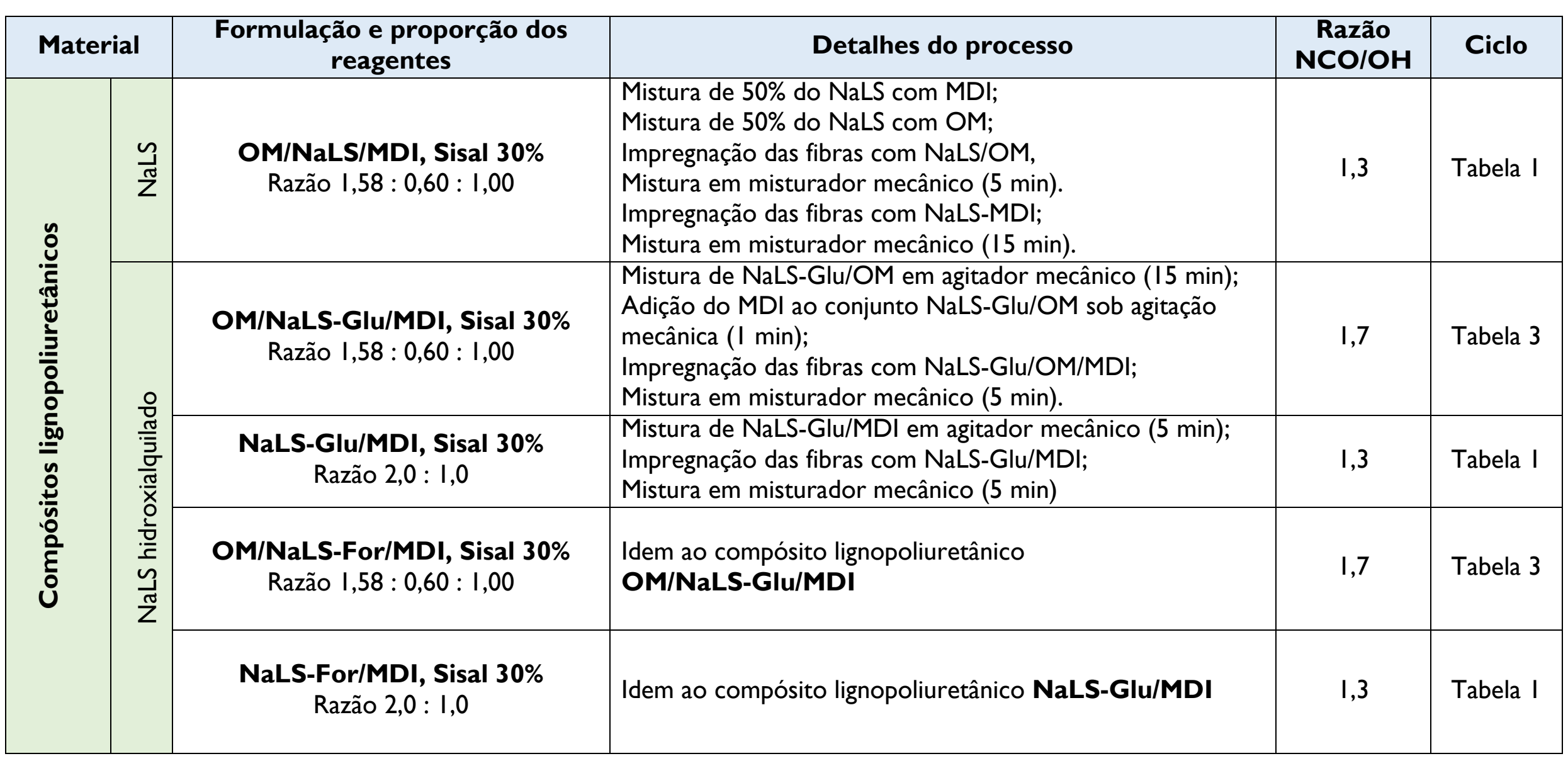




\section{QUADRO 5}

\begin{tabular}{|c|c|c|c|c|c|}
\hline \multicolumn{2}{|c|}{ Material } & $\begin{array}{c}\text { Formulação e proporção } \\
\text { dos reagentes }\end{array}$ & Detalhes do processo & $\begin{array}{c}\text { Razão } \\
\text { NCO/OH }\end{array}$ & Ciclo \\
\hline \multirow{4}{*}{ 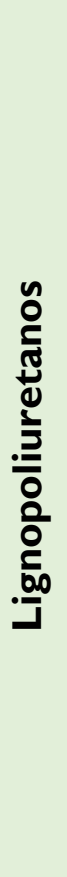 } & $\frac{n}{z}$ & $\begin{array}{c}\text { OM/NaLS/MDI } \\
\text { Razão I,58: } 0,60: 1,00\end{array}$ & $\begin{array}{l}\text { Mistura de } 50 \% \text { do NaLS com MDI; } \\
\text { Mistura de } 50 \% \text { do NaLS com OM; } \\
\text { Duas misturas vertidas e misturadas no molde. }\end{array}$ & $\mathrm{I}, 3$ & Tabela 3 \\
\hline & \multirow{3}{*}{ 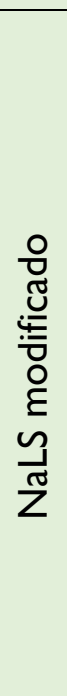 } & $\begin{array}{l}\text { OM/NaLS-Glu/MDI } \\
\text { Razão I,58: } 0,60: \text { I,00 }\end{array}$ & $\begin{array}{l}\text { Mistura de NaLS-Glu/OM em agitador mecânico ( } 15 \text { min); } \\
\text { Adição do MDI ao conjunto NaLS-Glu/OM sob agitação } \\
\text { mecânica ( } 1 \text { min); }\end{array}$ & $\mathrm{I}, 7$ & Tabela 3 \\
\hline & & $\begin{array}{l}\text { NaLS-Glu/MDI } \\
\text { Razão } 2,0: 1,0\end{array}$ & $\begin{array}{l}\text { Mistura de NaLS-Glu/MDI em agitador mecânico ( } 3 \mathrm{~min} \text { ); } \\
\text { Pressão aplicada no ciclo: } 2,33 \mathrm{MPa}\end{array}$ & $\mathrm{I}, 3$ & Tabela I \\
\hline & & $\begin{array}{l}\text { OM/NaLS-For/MDI } \\
\text { Razão I,58: } 0,60: 1,00\end{array}$ & Idem ao lignopoliuretano OM/NaLS-GIu/MDI & $\mathrm{I}, 7$ & Tabela 3 \\
\hline
\end{tabular}




\subsection{Caracterização dos poliuretanos, lignopoliuretanos e compósitos}

\subsection{Espectroscopia na região do infravermelho}

Para os PUs e lignopoliuretanos as análises foram realizadas conforme descrita no item 3.3.2. Para as amostras líquidas e viscosas (como os reagentes DEG, PEG e OM), foi utilizado um suporte adequado para material viscoso, no qual foi depositada uma fina camada da amostra.

\subsubsection{Análise termogravimétrica}

A análise termogravimétrica foi realizada utilizando-se um equipamento da marca Shimadzu, modelo TGA-50. As amostras, com massa de 5,0 mg, foram colocadas em portaamostra de platina e aquecida de 25 a $900^{\circ} \mathrm{C}$ com razão de aquecimento de $10^{\circ} \mathrm{C} \mathrm{min}^{-1}$, sob

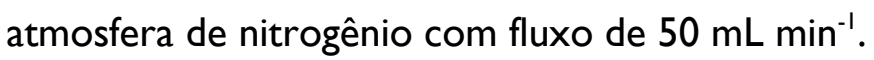

\subsubsection{Ensaio de resistência ao impacto Izod}

O ensaio de impacto Izod foi realizado com corpos de prova não entalhados, conforme a norma ASTM D256, utilizando o equipamento CEAST Resil 25 (DEMa, Universidade Federal de São Carlos, São Carlos, SP). Os testes foram realizados utilizando, para cada amostra, 15 corpos de prova à temperatura ambiente, velocidade de impacto de $4 \mathrm{~m} \mathrm{~s}^{-1} \mathrm{e}$ energia incidente de 2,75 J (para os PUs e lignopoliuretanos não reforçados) e 5,5 J (para os compósitos poliuretânicos e lignopoliuretânicos).

\subsubsection{Microscopia eletrônica de varredura}

Após o ensaio de impacto lzod, as superfícies de fratura dos PUs e lignopoliuretanos e compósitos destas matrizes foram analisadas por Microscopia Eletrônica de Varredura (MEV). As imagens de MEV foram obtidas na Central de Análises Químicas Instrumentais do Instituto de Química de São Carlos (CAQI/IQSC/USP) em um equipamento ZEISS LEO 440 (Cambridge, England) com detector OXFORD (model 7060), operando com feixe de elétrons de $15 \mathrm{kV}$, corrente de $2,82 \AA$ e I probe de $200 \mathrm{p} \AA$. As amostras foram recobertas com 6nm de ouro em um metalizador Coating System BAL-TEC MED 020 (BAL-TEC, Liechtenstein) e mantidas em dessecador até o momento de análise. Condições de 
metalização: pressão na câmara $=2,00 \times 10^{-2} \mathrm{mbar}$; corrente $=60 \mathrm{~mA}$; taxa de deposição $0,60 \mathrm{~nm} \mathrm{~s}^{-1}$.

Para ter acesso à superfície de fratura de compósitos que apresentaram fiber-bridging, fenômeno em que a maior parte das fibras não rompem, as fibras que ligavam as duas partes da matriz foram cortadas com o auxílio de uma tesoura.

\subsubsection{Ensaio de resistência à flexão}

Os ensaios de resistência à flexão foram realizados segundo a norma $D$ 790, que descreve o método de carregamento em um sistema de três pontos (Figura 24). Utilizou-se uma máquina universal de ensaios INSTRON, modelo 5569 (DEMa, Universidade Federal de São Carlos, São Carlos, SP).

Figura 24 - Esquema representativo do ensaio de flexão em três pontos.

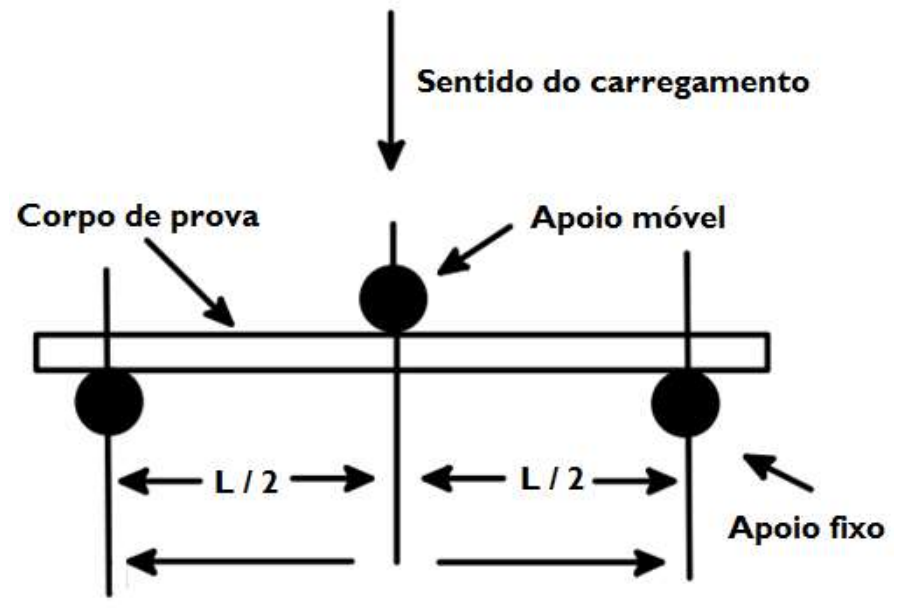

Foram obtidos corpos de prova de dimensões $127 \mathrm{~mm}$ (comprimento), 12,7 mm (largura) e 3,2 mm (espessura). Conforme determinado pela norma, utilizou-se razão L/d = 16 (distância do vão de ensaios). Para um ensaio de flexão em três pontos, a deflexão na qual a máxima deformação permitida $(5,0 \%)$ irá ocorrer pode ser calculada através da Equação 12. A velocidade do ensaio foi calculada de acordo a Equação I3. Foi utilizado uma célula de carga com capacidade de 0,5 kN. Para cada amostra, foram realizados ensaios de flexão em seis corpos-de-prova, em média.

$$
D=r L^{2} / 6 d
$$




$$
R=Z L^{2} / 6 d
$$

onde:

$D=$ deflexão no ponto médio entre os apoios

$r=$ deformação

$L=$ distância entre os apoios

$\mathrm{d}=$ espessura do corpo de provas

$\mathrm{R}=$ velocidade da travessa fixa

$Z=$ taxa de deformação na superfície oposta ao carregamento

A resistência à flexão () é a máxima tensão sob flexão sustentada pelo corpo de prova durante o ensaio de flexão

A resistência à flexão ( $\sigma$ máx $)$ é a máxima tensão sob flexão sustentada pelo corpo de prova durante o ensaio de flexão. Para um ensaio em três pontos, a resistência a flexão é dada pela Equação 14 .

$$
\rho_{\max }=\frac{3 P_{\operatorname{máx}} L}{2 b d^{2}}
$$

sendo:

$\sigma_{\text {máx }}=$ resistência à flexão

$\mathrm{P}_{\text {máx }}=$ carga máxima de ruptura $(\mathrm{em} \mathrm{N})$

$L=$ distância entre os apoios

$\mathrm{b}=$ largura do corpo de prova

$\mathrm{d}=$ espessura do corpo de prova

O módulo de flexão $\left(\mathrm{E}_{\mathrm{f}}\right)$, também chamado de módulo de elasticidade, é a razão dentro do limite de elasticidade entre a tensão de flexão e a deformação correspondente. É calculado traçando-se uma tangente na porção linear inicial da curva carga versus deflexão, utilizando a Equação 15.

$$
E_{f}=\frac{L^{3} m}{4 b d^{3}}
$$


3.8.6 Análise térmica dinâmico-mecânica (DMA)

O comportamento dinâmico-mecânico dos lignopoliuretanos foram estudados utilizando o DMA thermal analyzer, modelo Q800 (TA Instruments). Os experimentos foram realizados em modo de flexão, utilizando a garra 3-Point Bending. As dimensões dos corpos de prova foram $64 \mathrm{~mm} \times 12 \mathrm{~mm}$ × 3,2 mm. As condições experimentais foram: amplitude de oscilação de $20 \mathrm{~mm}, \mathrm{I} \mathrm{Hz}$ de frequência, aquecimento de $-130^{\circ} \mathrm{C}$ até $200^{\circ} \mathrm{C}$, em uma taxa de aquecimento de $2^{\circ} \mathrm{C} \mathrm{m}^{-1}$. 


\section{RESULTADOS E DISCUSSÃO}

\section{I Caracterização das fibras de sisal}

A Tabela 4 apresenta os valores médios dos teores dos principais componentes da fibra lignocelulósica de sisal. É importante ressaltar que a caracterização foi realizada após o pré-tratamento das fibras (extração com os solventes cicloexano e etanol), conforme já mencionado. Após este pré-tratamento, a fibra apresentou uma perda de massa correspondente a 7,I $\pm 0,5 \%$ em relação à massa inicial, provavelmente devido à eliminação de ceras e açúcares residuais que estavam presente na fibra. Os teores de componentes majoritários encontrados para a presente fibra são, de modo geral, semelhantes aos encontrados por Ramires et al. (2010), que obtiveram valores de 64,4\% de celulose, 23,9\% de hemiceluloses, 9,7\% de lignina e I,3\% de cinzas. Algumas discrepâncias observadas entre os valores relatados por estes autores e o presente estudo são entendidas como devido ao fato de a composição química das fibras lignocelulósicas depender de vários fatores, como a espécie, variedade, tipo de solo onde foram cultivadas, condições climáticas, parte da planta de onde são extraídas as fibras, método de extração e idade da planta (GUIMARÃES et al., 2009; FARUK et al., 2012).

Tabela 4 - Composição da fibra de sisal

\begin{tabular}{cc}
\hline Componente & Teor (\%) \\
\hline Cinzas & $0,6 \pm 0,1$ \\
Umidade & $9,6 \pm 0,3$ \\
Lignina Klason total & $15,0 \pm 1,4$ \\
Hemiceluloses & $32,1 \pm 1,2$ \\
$\alpha$-Celulose & $55,9 \pm 1,9$ \\
\hline
\end{tabular}

O índice de cristalinidade destas fibras, $62 \%$, foi calculado conforme descrito por Buschle-Diller e Zeronian (1992) através do difratograma gerado via difração de raios $X$ (Figura 25) e foi semelhante ao encontrado por Ramires et al. (2010), 6I \%. A cristalinidade da fibra é decorrente dos domínios cristalinos existentes na celulose presente. 
Figura 25 - Difratograma de raios $X$ da fibra de sisal.

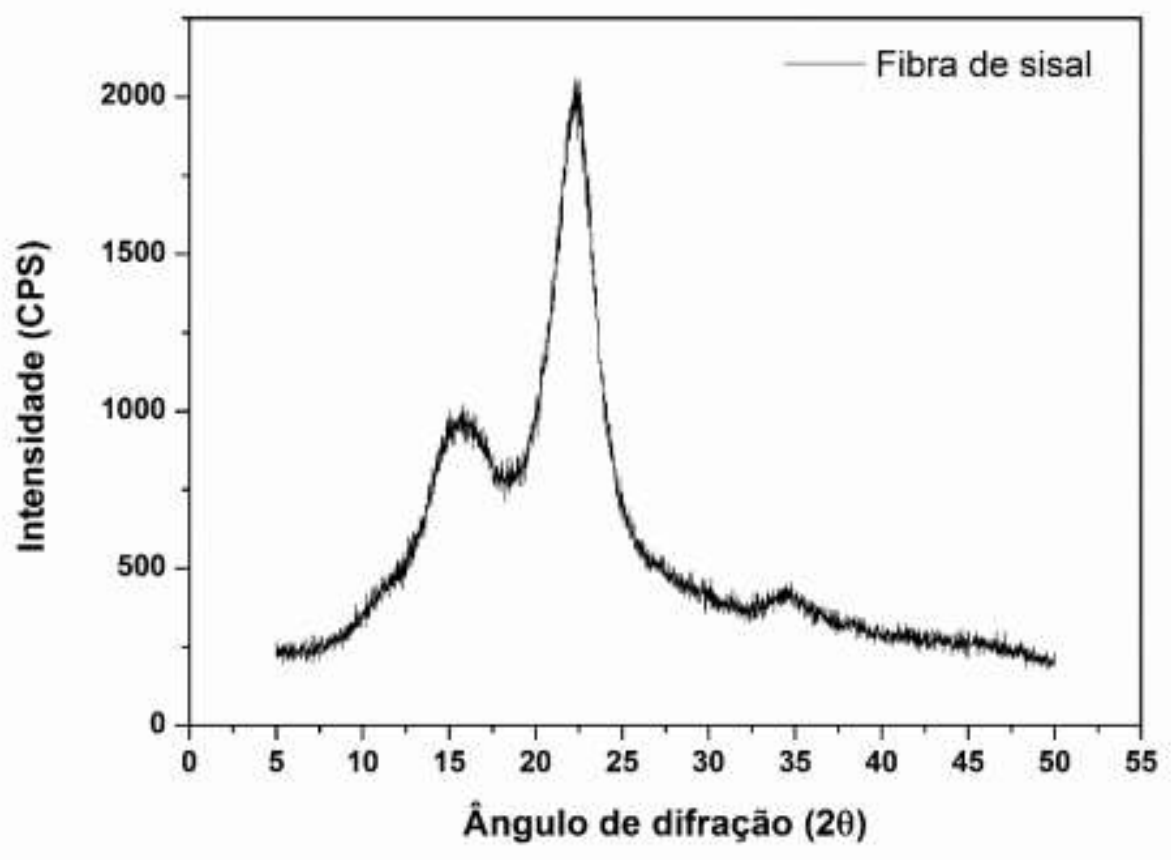

A Figura 26 mostra o espectro na região de infravermelho da fibra de sisal. Este espectro é típico de materiais lignocelulósicos, em que foram observadas bandas referentes à absorção de grupos presentes na celulose, lignina e hemiceluloses. A Tabela 5 apresenta as principais absorções que correspondem aos grupos presentes nos componentes da fibra de sisal. 
Figura 26 - Espectro na região de infravermelho da fibra de sisal.

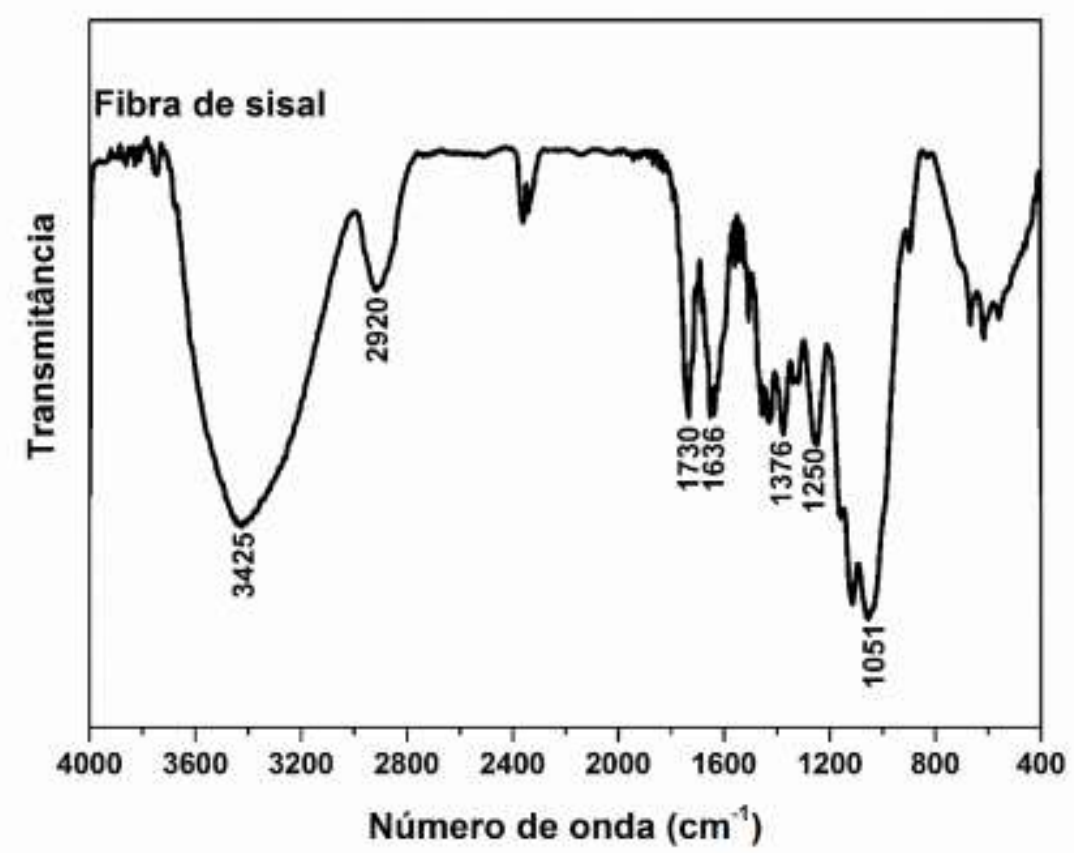

Tabela 5 - Principais absorções observadas no espectro na região do infravermelho da fibra de sisal e seus respectivos modos vibracionais (SILVERSTEIN; BASSLER; MORRIL, 1994).

Número de onda $\left(\mathrm{cm}^{-1}\right)$

Possível atribuição

$3420-3400$

$2920-2860$

Estiramento da ligação C-H de hidrocarbonetos saturados

1730

Deformação axial da ligação $C=0$

$1630-1625$

Deformação axial das ligações C-C do anel aromático (lignina)

1380

Deformação angular simétrica e assimétrica da ligação

$\mathrm{C}-\mathrm{H}$ de grupos metila

1250

Deformação angular no plano da ligação O-H

II63 Deformação axial da ligação C-O-C de grupos metoxila

$1051-1035$

Deformação axial simétrica da ligação C-O-C dos grupos metoxilas (lignina) 
A Figura 27 apresenta as curvas TG e dTG da fibra de sisal. A curva mostra perda de cerca de $4 \%$ em torno de $100^{\circ} \mathrm{C}$, que é atribuída à perda de água aderida às fibras de sisal. Até $260{ }^{\circ} \mathrm{C}$ a fibra apresenta estabilidade térmica, quando então ocorre início da decomposição, correspondente ao início da decomposição das hemiceluloses, seguido da decomposição da celulose. Em torno de $380^{\circ} \mathrm{C}$, observa-se uma mudança de inclinação na curva TG devido ao início de outro processo de decomposição, envolvendo quebra das ligações químicas presentes na lignina, prosseguindo com o aumento da temperatura até ocorrer perda de massa quase total em torno de $700^{\circ} \mathrm{C}$. A primeira derivada da curva TG mostra um primeiro "ombro" em torno de $300^{\circ} \mathrm{C}$, que corresponde à decomposição das hemiceluloses, e um pico em torno de $365^{\circ} \mathrm{C}$ correspondente à decomposição da celulose. O pico em torno de $524^{\circ} \mathrm{C}$ na curva dTG está relacionado ao processo de decomposição da lignina, que na curva TG ocorre entre 380 e $700{ }^{\circ} \mathrm{C}$ (MARTIN et al., 2009; RAMZY et a., 20I4).

Figura 27 - Curvas TG e dTG da fibra de sisal, em atmosfera de $\mathbf{N}_{2}$, fluxo de $50 \mathrm{~mL}$ $\mathrm{min}^{-1} \mathrm{e}$ razão de aquecimento de $10^{\circ} \mathrm{C} \mathrm{min}^{-1}$.

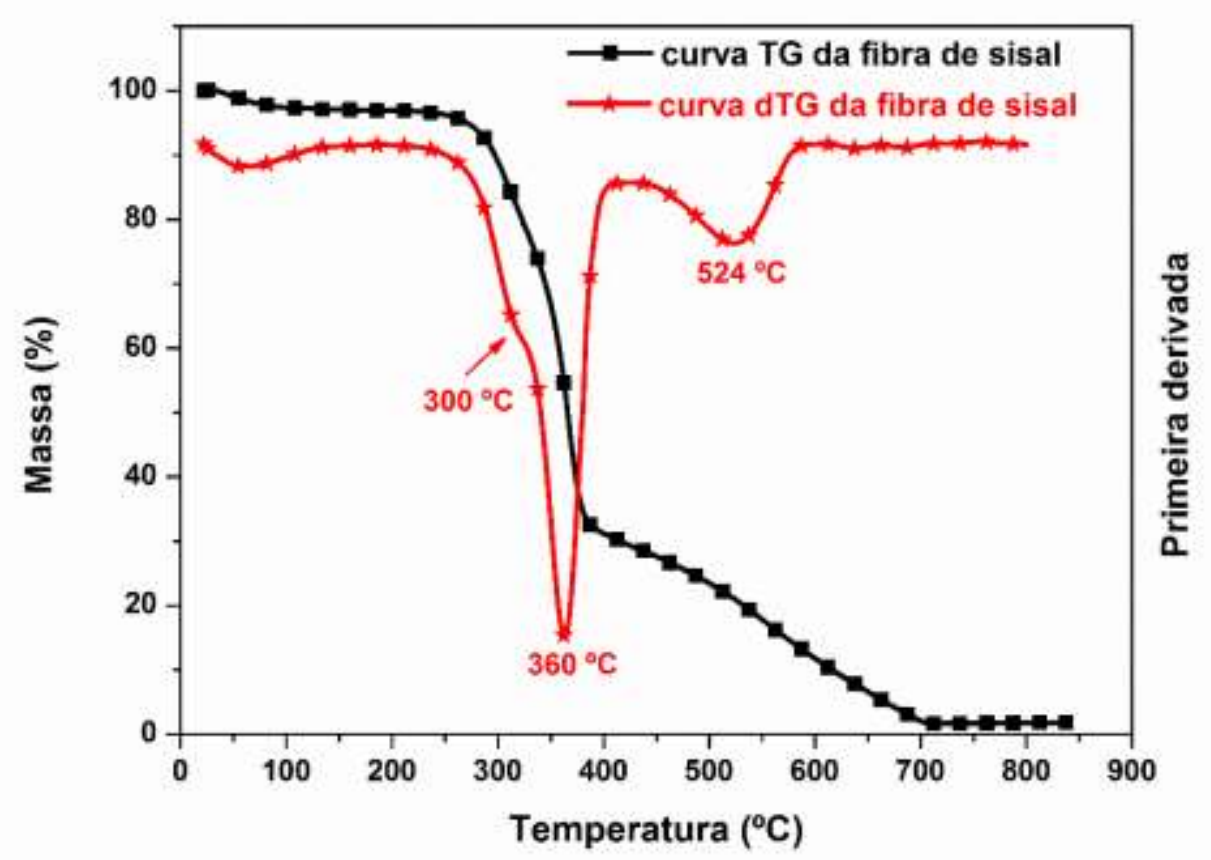

A Figura 28 apresenta imagens de MEV da superfície da fibra de sisal e do corte transversal (superfícies fraturadas em $\mathrm{N}_{2}$ líquido). As fibras de sisal são compostas por um 
feixe de microfibrilas, como mostrado na Figura 28b. O diâmetro médio das fibras de sisal é de $316 \pm 49 \mu \mathrm{m}$, conforme avaliado por imagens de MEV. Como as fibras de sisal foram cortadas em comprimento de $3 \mathrm{~cm}$ para serem usadas como reforços, foi possível obter a razão de aspecto, de aproximadamente 95 , calculado pela divisão do comprimento pelo diâmetro das fibras (L/d). Este valor de razão de aspecto classifica estas fibras como curtas (ZÁRATE; ARANGUREN; REBOREDO, 2003).

Figura 28 - Imagens de MEV da superfície (a) e do corte transversal da superfície (b) das fibras de sisal.

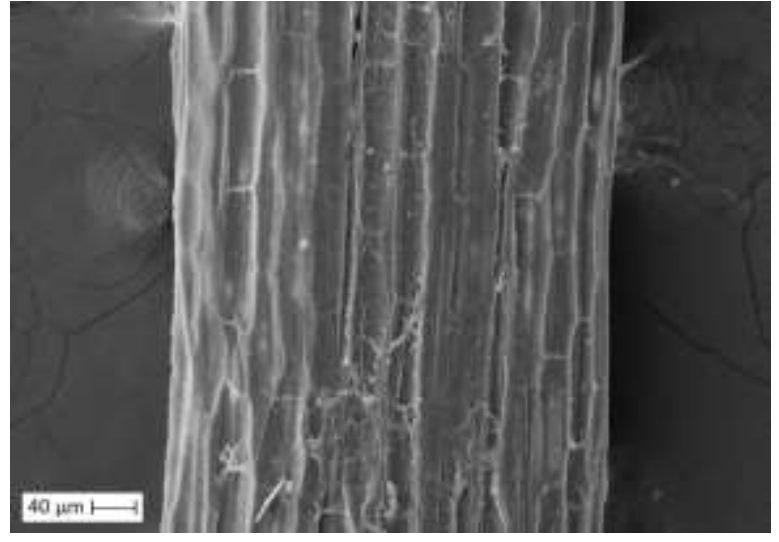

(a)

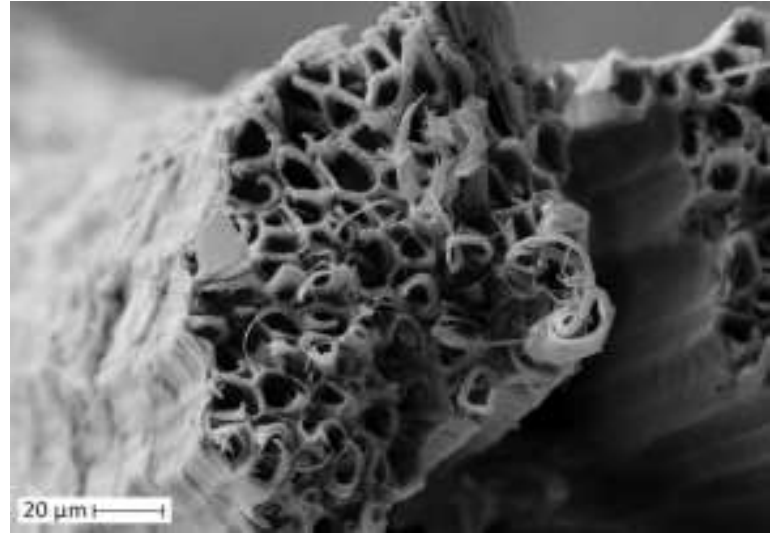

(b)

O valor médio de resistência à tração destas fibras foi $143 \pm 39 \mathrm{MPa}$, enquanto que o valor médio de alongamento, obtidos pelo mesmo teste, foi de $1,0 \pm 0,2$. Este valores são comparáveis a valores encontrados na literatura. Silva et al. (2012) encontraram um valor médio de $175 \mathrm{MPa}$ para a resistência a tração e I,7 \% de alongamento, enquanto Megiatto et al. (2007) determinaram um valor de resistência a tração de I 88 MPa e alongamento de I,4\% para a fibra de sisal. Segundo Li, Hu e Yu (2008) fibras de sisal podem apresentar resistência à tração que vão desde 100 até $700 \mathrm{MPa}$. A resistência à tração das fibras depende do conteúdo de celulose e do ângulo espiral que as microfibrilas da parede celular secundária interna faz com o eixo central da fibra. Uma vez que a composição química das fibras não são uniformes ao longo do seu comprimento, as propriedades de tração também pode variar ao longo da fibra (MARTIN et al., 2009). A fibra extraída da parte inferior (próxima à raiz da folha da planta) costuma apresentar baixa resistência à tração, o meio da fibra geralmente apresenta os maiores valores desta propriedade, enquanto que a ponta da fibra apresenta 
valores de resistência à tração intermediários em relação aos valores da ponta e do meio (MISHRA et al., 2004).

\subsection{Caracterização do lignossulfonato de sódio ( $\mathrm{NaLS}$ )}

4.2.I Análise elementar, teor de cinzas, espectroscopia na região do infravermelho e Análise termogravimétrica

A Tabela 6 apresenta o resultado de análise elementar, do teor de cinzas e também outras informações obtidas com o fornecedor do lignossulfonato de sódio. $\bigcirc$ teor de oxigênio foi estimado por diferença. A partir destes resultados, foi possível obter uma fórmula mínima: $\mathrm{C}_{17,2} \mathrm{H}_{25,8} \mathrm{O}_{6,6} \mathrm{~S}_{1} \mathrm{Na}_{1,6}$. Esta fórmula mínima, em conjunto com os demais resultados apresentados a seguir, foi utilizada para estimar uma fórmula estrutural para o lignossulfonato de sódio, apresentada no item 4.2.4 (Figura 33), e que tem como base as possíveis unidades C9 presentes nesta macromolécula.

Tabela 6 - Composição do lignossulfonato de sódio (NaLS).

\begin{tabular}{cc}
\hline Elemento & Teor (\%) \\
\hline $\mathrm{C}$ & 38,23 \\
$\mathrm{H}$ & 4,77 \\
$\mathrm{~N}$ & $<0,30$ \\
$\mathrm{~S}$ & 5,91 \\
$\mathrm{Na}$ & 6,75 \\
$\mathrm{Mg}$ & 1,43 \\
$\mathrm{Ca} *$ & 0,2 \\
$\mathrm{Fe}{ }^{*}$ & 0,04 \\
\hline Açúcares (HPLC)* & 0,9 \\
Cinzas & $22,0 \pm 0,3$ \\
\hline
\end{tabular}

*Informação do fornecedor do NaLS

O espectro na região de infravermelho do lignossulfonato de sódio é apresentado na Figura 29. A banda apresentada no espectro de infravermelho do NaLS em $652 \mathrm{~cm}^{-1}$ é característica do lignossulfonato, pois corresponde à vibração dos grupos sulfônicos 
(SHUL'GA; GOMOLKO; KRUT'KO, 2008). As demais bandas e suas possíveis atribuições são apresentadas na Tabela 7.

Figura 29 - Espectro na região do infravermelho do lignossulfonato de sódio (NaLS).

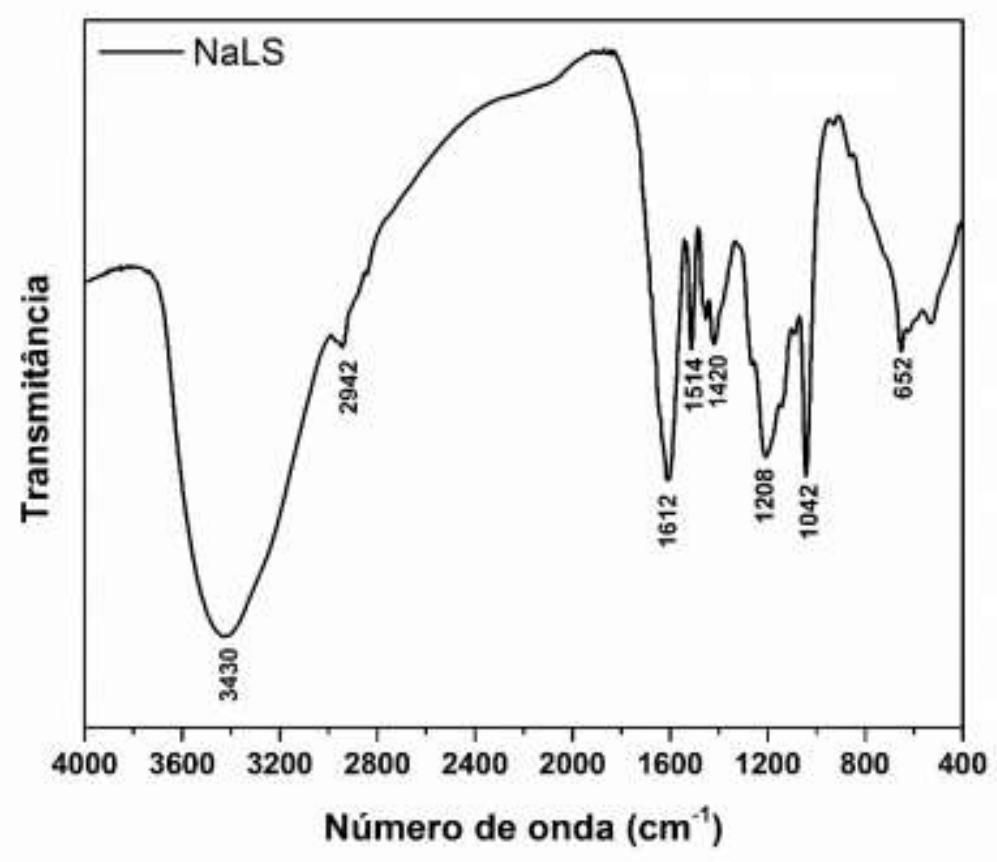

Tabela 7 - Principais absorções observadas em espectro de infravermelho de lignossulfonatos (RODRIGUEZ, 2005; SHEN; ZHANG; ZHU, 2008; SHUL'GA; GOMOLKO; KRUT'KO, 2008; KIM et al., 2009).

\begin{tabular}{cc}
\hline Número de onda $\left(\mathbf{c m}^{-1}\right)$ & Possível atribuição \\
\hline 3430 & deformação axial O-H em lignina e lignossulfonatos \\
2942 & deformação axial C-H em grupos metileno \\
1612 & deformação do anel aromático \\
1514 & deformação do anel aromático \\
1420 & estiramento C-O em lignina e lignossulfonatos \\
1208 & estiramento S=O em grupo sulfônico \\
1042 & estiramento C-O em lignossulfonatos \\
652 & vibração C-S do grupo sulfônico \\
\hline
\end{tabular}


Não foi observado nenhum pico na região de carbonilas $\left(1715-1760 \mathrm{~cm}^{-1}\right)$, o que poderia indicar a presença de grupos carboxílicos, que eventualmente aparecem em outros tipos de lignina.

Na Figura 30 são apresentadas as curvas TG e dTG do lignossulfonato de sódio. A decomposição térmica de lignina e lignossulfonatos ocorre em uma ampla faixa de temperaturas resultando em cerca de 30 a $50 \%$ de produto carbonizado e uma elevada proporção de voláteis de baixa massa molar (JAKAB et al., 1993).

Figura 30 - Curva TG e dTG do lignossulfonato de sódio ( $\mathrm{NaLS}$ ), em atmosfera de $\mathbf{N}_{2}$, fluxo de $20 \mathrm{~mL} \mathrm{min-1}$ e razão de aquecimento de $10^{\circ} \mathrm{C} \mathrm{min}^{-1}$.

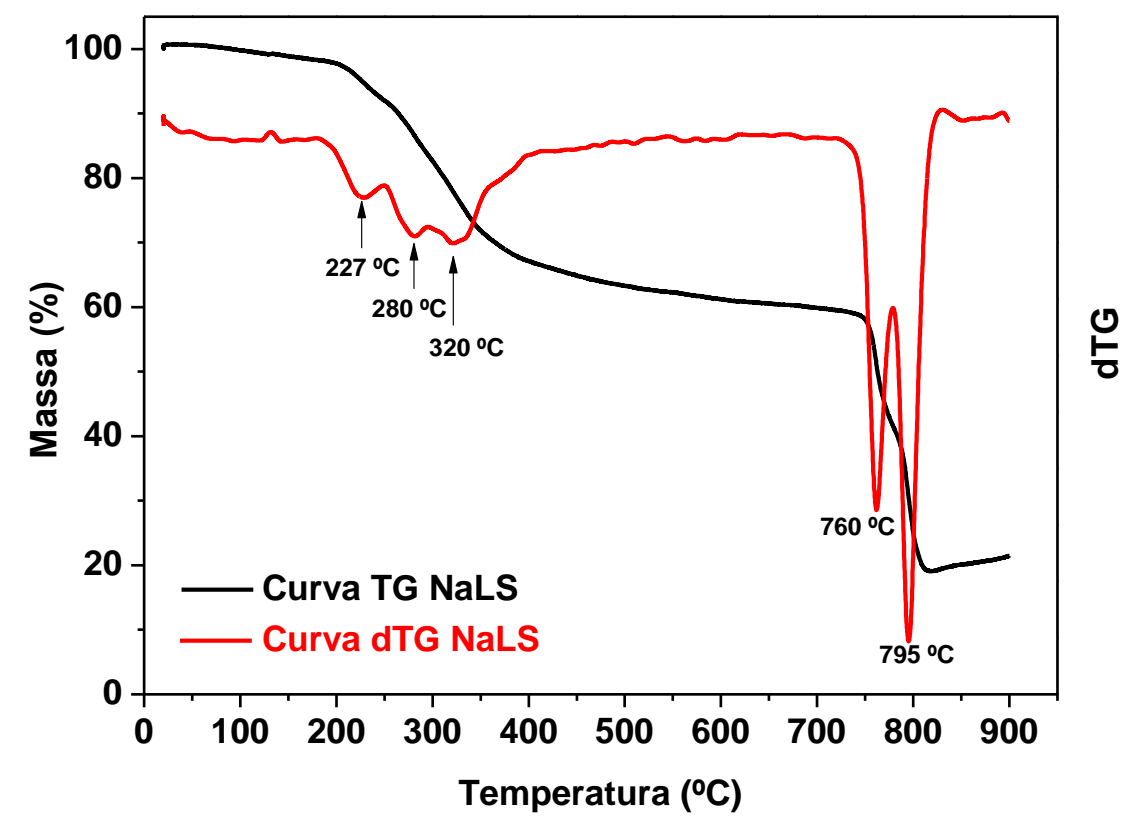

A partir $220{ }^{\circ} \mathrm{C}$ é possível observar o início da perda de massa na curva TG do lignossulfonato, correspondendo a vários picos com intensidade máxima em $320^{\circ} \mathrm{C}$ na curva dTG (Figura 30). De acordo com Jakab et al. (1993), duas etapas de decomposição ocorrem entre 200 e $400{ }^{\circ} \mathrm{C}$, que leva à liberação de $\mathrm{H}_{2} \mathrm{O}, \mathrm{CO}_{2}$ e dióxido de enxofre $\left(\mathrm{SO}_{2}\right)$, e a formação de algumas mercaptanas, as quais podem estar relacionadas aos picos em 227, 280 e $320{ }^{\circ} \mathrm{C}$ (Figura 30). Apesar de ter havido baixa perda de massa entre 400 e $700{ }^{\circ} \mathrm{C}$, provavelmente a decomposição dos anéis aromáticos iniciou neste intervalo. Durante a decomposição, os íons sódio presentes podem formar carbonato de sódio $\left(\mathrm{Na}_{2} \mathrm{CO}_{3}\right)$, que se 
decompõe entre 700 e $800{ }^{\circ} \mathrm{C}$ com a liberação de $C_{2}$ (JAKAB et al., 1993). Entre as temperaturas de 750 e $800{ }^{\circ} \mathrm{C}$ há uma perda brusca de massa, o que provavelmente corresponde à decomposição final dos anéis aromáticos. Os picos em 760 e $795^{\circ} \mathrm{C}$ podem estar relacionados a esta decomposição final dos segmentos de ligninas, assim como a liberação do $\mathrm{CO}_{2}$ resultante da decomposição do $\mathrm{Na}_{2} \mathrm{CO}_{3}$ formado (SILVA et al., 20I2). Após essa perda, a curva TG cresce suavemente, ocorrendo uma possível formação de sulfato de sódio $\left(\mathrm{Na}_{2} \mathrm{SO}_{3}\right)$.

\subsubsection{Determinação dos grupos ionizáveis por titulação condutométrica}

A Figura $3 \mathrm{I}$ apresenta a curva de titulação condutométrica de Ig lignossulfonato de sódio em solução aquosa, onde foram adicionados $48 \mathrm{~mL}$ de $\mathrm{HCl} \mathrm{0,I} \mathrm{M.} \mathrm{A} \mathrm{adição} \mathrm{do} \mathrm{HCl}$ é necessária para garantir que todas as espécies ionizáveis permaneçam na forma ácida (protonadas). A região da curva indicada pela fase I, corresponde à região do excesso de $\mathrm{HCl}$ presente. $\mathrm{O} V_{1}(65,4 \mathrm{~mL})$ foi o volume de $\mathrm{NaOH} 0,05 \mathrm{~mL}$ necessário para esta neutralização. Em seguida, foram encontradas duas fases (fases 2 e 3) com diferentes inclinações, que podem ser atribuídas à presença de espécies ácidas com $\mathrm{pK}_{\mathrm{a}}$ diferentes.

Figura 3 I - Titulação condutométrica do lignossulfonato de sódio na presença de $48 \mathrm{~mL}$ de $\mathrm{HCl}$ 0, I M.

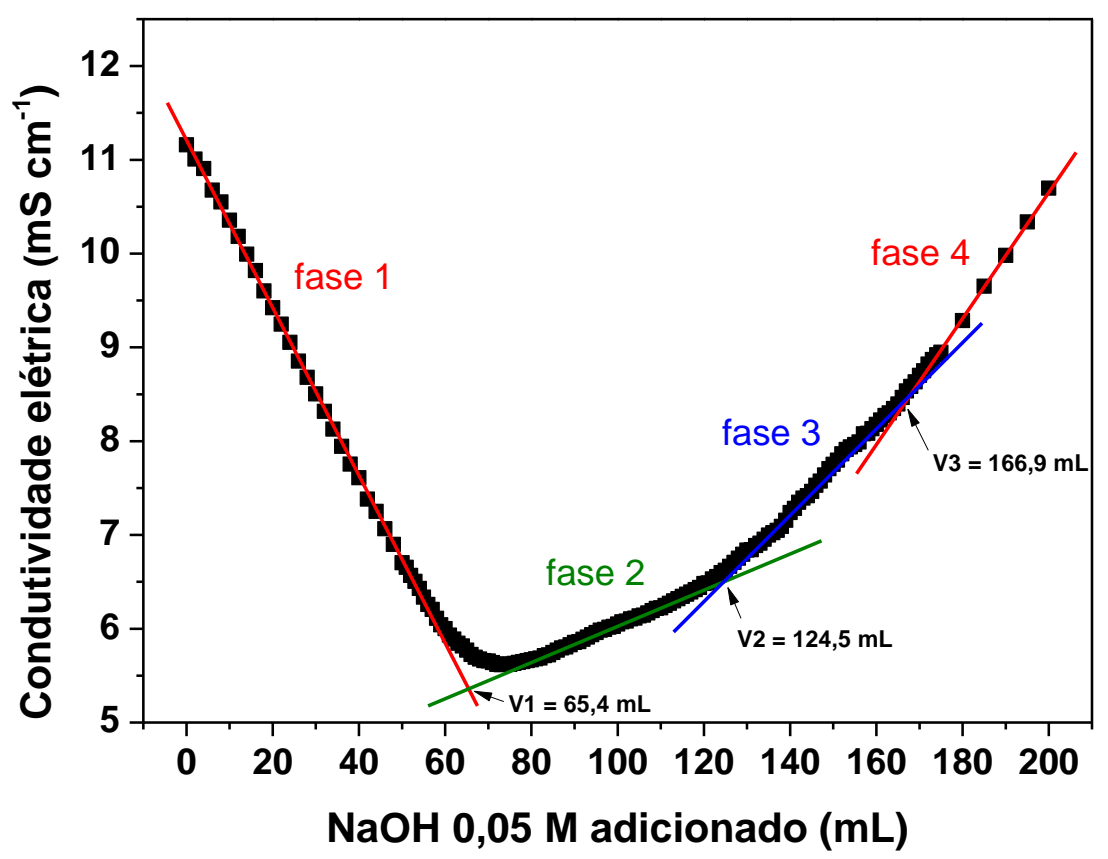


A fase 2 foi atribuída aos ácidos sulfônicos $\left(\mathrm{R}-\mathrm{SO}_{3} \mathrm{H}\right)$ e a fase 3 às hidroxilas (alcóolicas e fenólicas) presentes no lignossulfonato de sódio. Como $\circ \mathrm{pK}_{\mathrm{a}}$ dos ácidos sulfônicos é menor que $0 \mathrm{pK}_{\mathrm{a}}$ de álcoois e fenóis, é esperado que os ácidos sulfônicos sejam neutralizados primeiro que as hidroxilas. Assim, é esperado neste tipo de titulação que a desprotonação inicie pelos grupos ácidos lignossulfônico, seguida pelas hidroxilas fenólicas, e por fim, as hidroxilas alcóolicas. Neste contexto, era esperado o aparecimento de duas diferentes inclinações na região da fase 3 , separando hidroxilas fenólicas e alcóolicas. No entanto, foi observado apenas uma fase, sugerindo que a desprotonação das hidroxilas alcóolicas ocorreu de tal forma que não foi possível a observação separada da desprotonação das hidroxilas fenólicas. A fase 4 corresponde ao excesso de $\mathrm{NaOH}$ adicionado, após a desprotonação de todas as espécies ácidas presentes no meio.

Através da diferença de volume entre os pontos de interseção $V_{1}$ e $V_{2}$ (fase 2), foi possível determinar a quantidade de grupos $\mathrm{SO}_{3}{ }^{-}$presente no lignossulfonato: $2,96 \mathrm{mmol}$ de $\mathrm{SO}_{3^{-}} \mathrm{g}^{-1}$ (ou 23,7\%), sendo este resultado próximo ao teor obtido a partir da estrutura proposta na Figura 33 (2,64 $\mathrm{mmol}$ de $\mathrm{SO}_{3}{ }^{-} \mathrm{g}^{-1}$ ou $\left.21,1 \%\right)$.

Após a acidificação do NaLS, o mesmo se torna o ácido lignossulfônico. Através da protonação, os grupos sulfonatos antes presentes no $\mathrm{NaLS}\left(-\mathrm{SO}_{3}{ }^{-}\right)$se tornam grupos ácidos sulfônicos $\left(-\mathrm{SO}_{3} \mathrm{H}\right)$. Em se tratando do ácido lignossulfônico, o teor total de hidroxilas corresponderá a soma das fases 2 e 3 (diferença entre $V_{1}$ e $V_{3}$ ), uma vez que a fase 2 se refere às hidroxilas provenientes dos grupos sulfônicos e a fase 3 às hidroxilas fenólicas e alcóolicas. Dessa forma, o teor de hidroxilas do ácido lignossulfônico é $5,07 \mathrm{mmol} \mathrm{OH} \mathrm{g} \mathrm{g}^{-1}$ (ou $\mathrm{I}_{\mathrm{OH}}=285 \mathrm{mg} \mathrm{KOH} \mathrm{g} \mathrm{g}^{-1}$ ). Este resultado é importante uma vez que o $\mathrm{NaLS}$ pode ser submetido a reações químicas em que o grupo sulfonato pode ser um sítio reativo.

O espectro na região de infravermelho do lignossulfonato de sódio (Figura 29) não apresentou banda característica de carbonila de grupos carboxílicos na região de $1760 \mathrm{~cm}^{-1}$, conforme já mencionado. Esta observação indica que a fase 3 da curva de titulação corresponde apenas à neutralização de grupos hidroxilas. Portanto, foi possível determinar o teor de hidroxilas totais (fenólicas e alcóolicas) através da diferença entre os pontos de interseção $V_{2}$ e $V_{3}$ (fase 3 da curva de titulação): 2,12 mmol de $\mathrm{OH} \mathrm{g}^{-1}$, que corresponde a $3,6 \%$. 


\subsubsection{Determinação do teor de hidroxilas fenólicas por espectroscopia UV-Vis}

As análises de UV foram efetuadas segundo um estudo descrito por Wexler (1964), em que foram obtidos espectros de diferença na região do ultravioleta visível para avaliar a porcentagem de grupos hidroxilas fenólicas em lignossulfonatos. Na Figura 32 são apresentados os espetros de diferença obtidos a partir de uma solução ácida (referência) e uma solução básica, ambas soluções preparadas com lignossulfonato de sódio em diferentes concentrações.

Figura 32 - Espectros de diferença na região do ultravioleta visível do lignossulfonato de sódio.

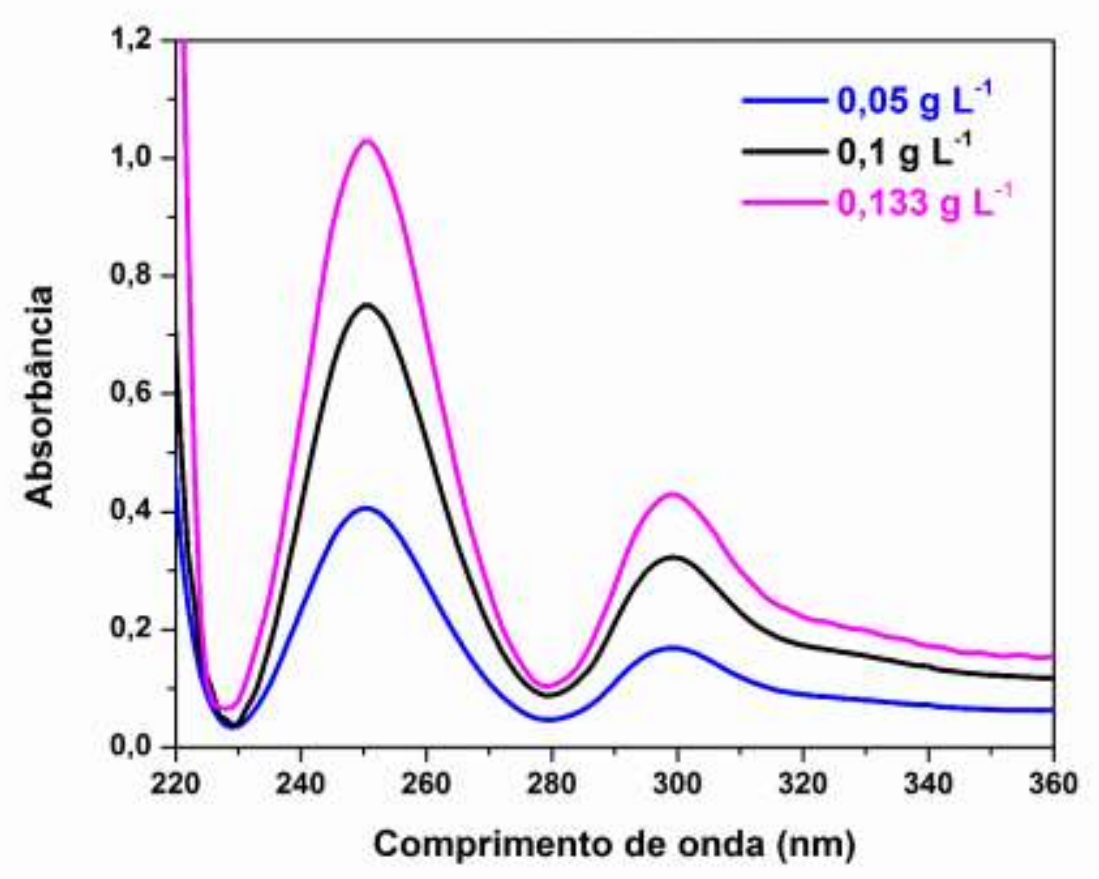

Na Tabela 8 são apresentadas as absortividades do lignossulfonato de sódio obtidos através dos espectros UV de diferença e os teores de hidroxilas fenólicas calculados a partir de três diferentes maneiras, descritas no item 3.3.6. 
Tabela 8 - Absortividades e teores de OH fenólicas do lignossulfonato de sódio obtidos à partir dos espectros UV de diferença.

\begin{tabular}{cccc}
\hline $\begin{array}{c}\text { Concentração da } \\
\text { solução NaLS } \\
\left(\mathrm{g} \mathrm{L}^{-1}\right)\end{array}$ & $\begin{array}{c}\text { Cálculo A } \\
\text { (Goldschimid) } \\
300 \mathrm{~nm}\end{array}$ & $\begin{array}{c}\text { Cálculo B } \\
\text { (linha base) } \\
250 \mathrm{~nm}\end{array}$ & Cálculo C \\
& & $250 \mathrm{~nm}$ \\
0,05 & 3,36 & 7,31 & \\
0,1 & 3,22 & 6,89 & 7,12 \\
0,13 & 3,31 & 7,43 & 7,97 \\
& & & \\
& & Teor de OH $(\%)$ & \\
0,05 & 1,39 & 1,40 & 1,56 \\
0,1 & 1,33 & 1,32 & 1,44 \\
0,13 & 1,37 & 1,43 & 1,53 \\
& & & 1,51 \\
Média & 1,37 & 1,38 & 0,06 \\
Desvio & 0,03 & 0,05 & \\
\hline
\end{tabular}

É possível observar que os valores, tanto das absortividades quanto para os teores de hidroxilas, são semelhantes mesmo utilizando concentrações diferentes de lignossulfonato para fazer a análise. Os teores de hidroxilas fenólicas encontrados vão de 1,37 a I,5I\%, o que leva a um valor médio de $\mathrm{I}, 42 \pm 0,08 \%$, correspondendo a $0,8 \mathrm{I} \mathrm{mmol}$ de $\mathrm{OH}_{\text {fenólicas }} \mathrm{g}^{-1}$. Este resultado se encontra dentro do intervalo de porcentagens determinadas em outros estudos. Por exemplo, Alonso et al. (200I) determinaram um teor I,I2\% para o NaLS oriundo da LignoTech Noruega, enquanto que El Mansouri e Salavadó (2006) chegaram num teor de 2,00\% para o NaLS da LignoTech Iberica (Espanha).

\subsubsection{Considerações envolvendo todas as análises em relação ao teor de hidroxilas do lignossulfonato de sódio}

Ao propor uma estrutura para o lignossulfonato, foi levado em consideração a presença de grupos hidroxilas alifáticas e fenólicas, e ainda hidroxilas que estariam bloqueadas devido à existência de ligações aril-éter e alquil-éter entre as unidades da lignina (DIMMEL, 20I0). Os resultados de análise elementar, de determinação de grupos ionizáveis 
e de determinação do teor de hidroxilas fenólicas foram úteis na elaboração desta proposta, apresentada na Figura 33.

Figura 33 - Proposta das principais unidades presentes na estrutura do lignossulfonato de sódio.

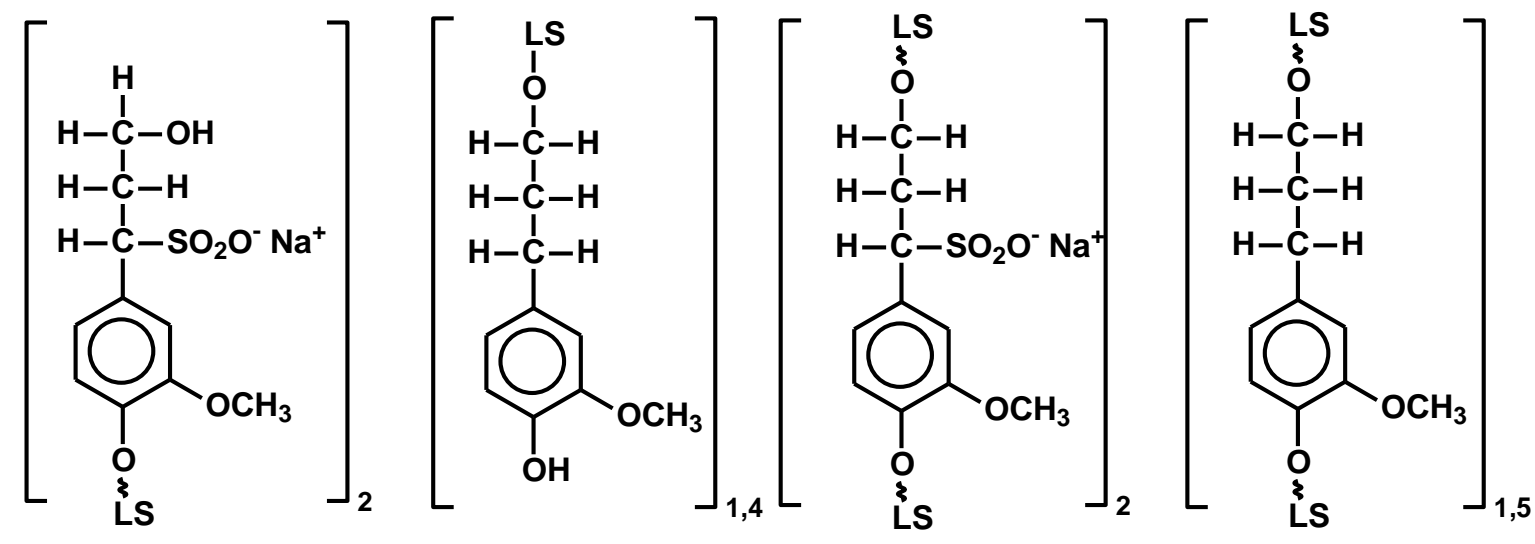

A fórmula mínima da soma de todas as unidades com suas respectivas proporções, mostradas na Figura 33, é $\mathrm{C}_{17,2} \mathrm{H}_{20,6} \mathrm{O}_{7,2} \mathrm{~S}_{1} \mathrm{Na}_{1}$, que se aproxima daquela obtida via análise elementar $\left(\mathrm{C}_{17,2} \mathrm{H}_{25,8} \mathrm{O}_{6,6} \mathrm{~S}_{1} \mathrm{Na}_{1,6}\right)$. A partir desta proposta de estrutura, a porcentagem em massa dos grupos sulfonatos foi estimada como $21,1 \%$, que corresponde a 2,64 $\mathrm{mmol}$ de $\mathrm{SO}_{3}-\mathrm{g}^{-1}$.

As porcentagens em massa dos grupos hidroxilas e de grupos sulfonatos do lignossulfonato de sódio estão resumidas na Tabela 9.

Tabela 9 - Porcentagens em massa e teor em $\mathrm{mmol}^{-1}$ de grupos hidroxilas e sulfonatos no lignossulfonato de sódio.

\begin{tabular}{|c|c|c|c|c|}
\hline & \multicolumn{2}{|c|}{ Valores experimentais } & \multicolumn{2}{|c|}{$\begin{array}{c}\text { Valores baseados na estrutura } \\
\text { proposta na Figura } 33\end{array}$} \\
\hline & $(\%)$ & $\left(\mathrm{mmol} \mathrm{g}^{-1}\right)$ & (\%) & $\left(m m o l g^{-1}\right)$ \\
\hline $\begin{array}{c}\text { Hidroxilas totais } \\
\text { (titulação condutométrica) }\end{array}$ & 3,6 & 2,12 & 3,6 & 2,12 \\
\hline $\begin{array}{l}\text { Hidroxilas fenólicas } \\
\text { (espectroscopia UV) }\end{array}$ & I,4 & 0,81 & I,5 & 0,90 \\
\hline $\begin{array}{l}\text { Hidroxilas alifáticas } \\
\text { (por subtração) }\end{array}$ & 2,2 & 1,27 & 2,2 & 1,32 \\
\hline $\begin{array}{c}\text { Grupos sulfonatos }\left(-\mathrm{SO}_{3}{ }^{-}\right) \\
\text {(titulação condutométrica) }\end{array}$ & 23,7 & 2,96 & 21,1 & 2,64 \\
\hline
\end{tabular}


A partir da porcentagem total de hidroxilas do lignossulfonato foi possível obter o índice de hidroxilas $\left(\mathrm{I}_{\mathrm{OH}}\right)$ através da equação $I_{O H}=(33) .(\% O H)($ IONESCU, 2005). Assim, o teor total de hidroxilas de 3,6\% corresponde ao índice de hidroxilas de $118,8 \mathrm{mg} \mathrm{KOH} \mathrm{g}{ }^{-1}$. Este teor foi utilizado para calcular a razão $\mathrm{NCO} / \mathrm{OH}$ na formulação dos lignopoliuretanos preparados a partir do NaLS sem modificação prévia e após modificação via hidroxialquilação.

É importante ressaltar que diversas outras técnicas e métodos foram utilizados na tentativa de determinar o teor de hidroxilas do lignossulfonato, embora não tenha sido possível obter resultados devido às limitações provenientes das próprias características do lignossulfonato de sódio, como a insolubilidade em solventes orgânicos. No entanto, considera-se que os valores obtidos foram suficientes para estimar a estequiometria de reagentes na etapa de preparação de lignopoliuretanos.

\subsection{Grupo I: poliuretanos, lignopoliuretanos e respectivos compósitos à partir do NaLS e polióis convencionais (DEG, PEG e OM)}

\subsection{Espectroscopia na região do infravermelho}

Os espectros obtidos para o óleo de mamona (OM), polietilenoglicol (PEG) e dietilenoglicol (DEG) são apresentados na Figura 34. As principais absorções para estes polióis estão apresentados na Tabela 10. 
Figura 34 - Espectro na região de infravermelho OM (OM), polietilenoglicol (PEG) e dietilenoglicol (DEG).

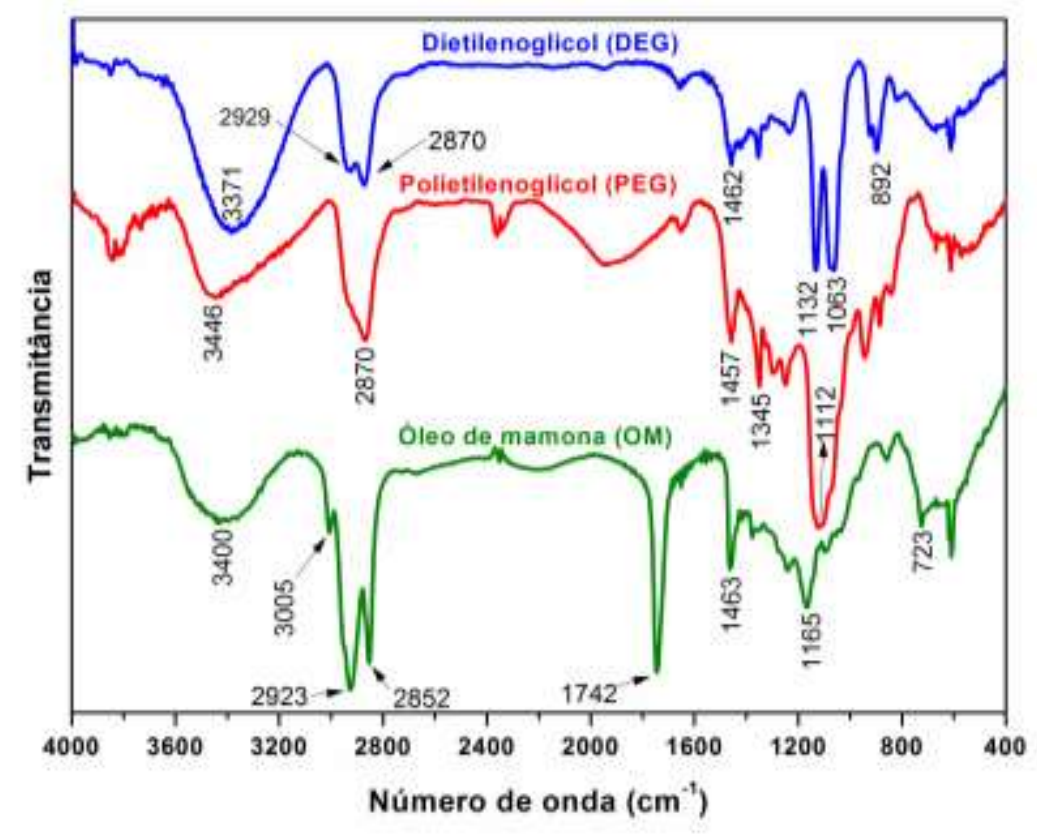

Tabela 10 - Principais absorções observadas nos espectros de óleo de mamona, polietilenoglicol e dietilenoglicol (SCHNEIDER, 2002).

\begin{tabular}{|c|c|c|c|c|c|}
\hline \multicolumn{2}{|c|}{ Óleo de mamona } & \multicolumn{2}{|r|}{ Polietilenoglicol } & \multicolumn{2}{|c|}{ Dietilenoglicol } \\
\hline$v\left(\mathrm{~cm}^{-1}\right)$ & Possível atribuição & $v\left(\mathrm{~cm}^{-1}\right)$ & Possível atribuição & $v\left(\mathrm{~cm}^{-1}\right)$ & $\begin{array}{l}\text { Possível } \\
\text { atribuição }\end{array}$ \\
\hline 3400 & $\mathrm{OH}$ & 3446 & $\mathrm{OH}$ & 3371 & $\mathrm{OH}$ \\
\hline 3005 & $\mathrm{C}-\mathrm{H}$ & 2870 & $\mathrm{CH}_{2}$ def. axial & 2929 & $\mathrm{C}-\mathrm{H}$ \\
\hline 2923 & $\mathrm{CH}_{2}$ assimétrico & 1457 & $\mathrm{CH}_{2}$ def. angular & 2870 & $\mathrm{C}-\mathrm{H}$ \\
\hline 2852 & $\mathrm{CH}_{2}$ simétrico & 1345 & $\mathrm{OH}$ def. angular no plano & 1462 & $\mathrm{CH}_{2}$ \\
\hline 1742 & $\mathrm{C}=\mathrm{O}$ & 1112 & $\mathrm{C}-\mathrm{O}-\mathrm{C}$ def. axial & 1132 & $\mathrm{C}-\mathrm{O}-\mathrm{C}$ \\
\hline 1463 & $\mathrm{CH}_{2}$ & & simétrica & 1063 & $\mathrm{C}-\mathrm{O}-\mathrm{C}$ \\
\hline 1165 & C-O assimétrico (éster) & & & & \\
\hline 723 & $\mathrm{CH}_{2}$ & & & & \\
\hline
\end{tabular}

Alguns grupos funcionais, como o grupo $\mathrm{OH}$, absorve em números de onda diferentes para cada poliol, conforme observado na Tabela I0. Esta variação ocorre pelo fato de tais grupos estarem ligados a estruturas diferentes próprias de cada poliol. Por exemplo, no PEG, há uma grande cadeia de poliéter ligada ao grupo $\mathrm{OH}$ (Figura $22 \mathrm{~g}$ ), enquanto que no DEG os grupos $\mathrm{OH}$ estão ligados a uma estrutura menor (Figura 22f), que possui apenas uma ligação éter. Já no principal componente do OM (Figura 16a), o grupo OH se encontra no meio de uma longa cadeia hidrocarbônica, próxima de uma ligação dupla.

O espectro na região de infravermelho do DEG/NaLS/MDI se destaca do DEG/MDI pela presença da banda $655 \mathrm{~cm}^{-1}$ que caracteriza a vibração de grupos sulfônicos (Figura 35a). 
O mesmo comportamento pode ser observado para os materiais PEG/MDI e PEG/NaLS/MDI, mostrado na Figura 35b e para o OM/MDI e OM/NaLS/MDI, mostrado na Figura 35c. De modo geral, também, nos materiais preparados com NaLS, pode ocorrer fusão da banda em $3310 \mathrm{~cm}^{-1}$, que correspondem ao grupos $\mathrm{N}-\mathrm{H}$ livres, com a banda em $3420 \mathrm{~cm}^{-1}$, correspondente às hidroxilas de lignina (WANG et al., 2010). As bandas de absorções características de PUs e lignopoliuretanos são apresentadas na Tabela II.

Figura 35 - Espectros na região de infravermelho de (a) poliuretano DEG/MDI e lignopoliuretano DEG/NaLS/MDI; (b) poliuretano PEG/MDI e lignopoliuretano PEG/NaLS/MDI; (c) poliuretano OM/MDI e lignopoliuretano OM/NaLS/MDI.

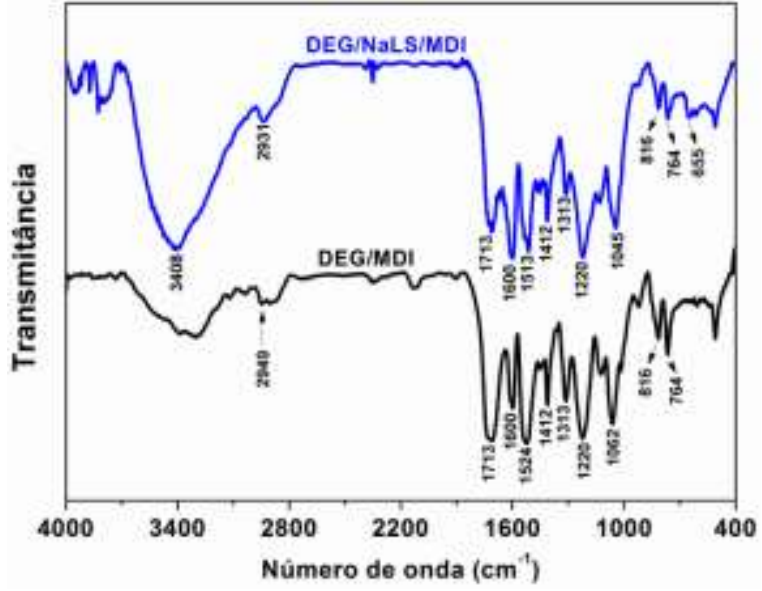

(a)

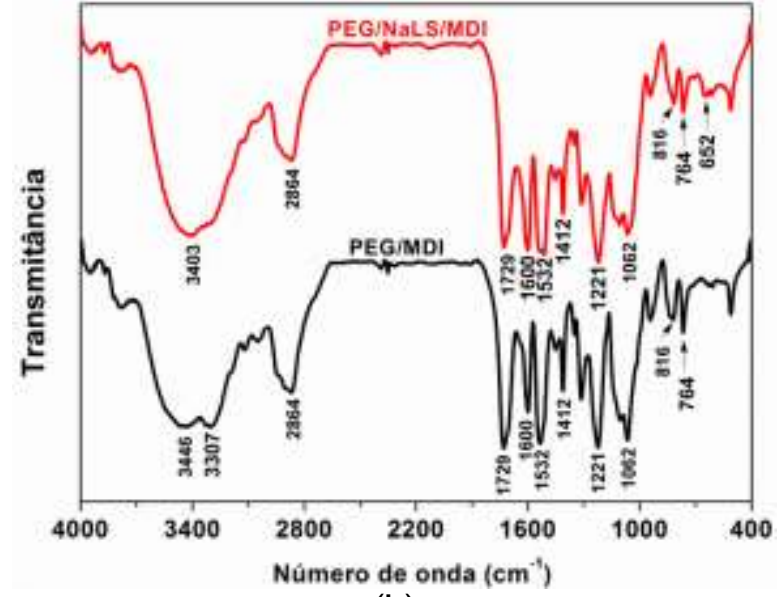

(b)

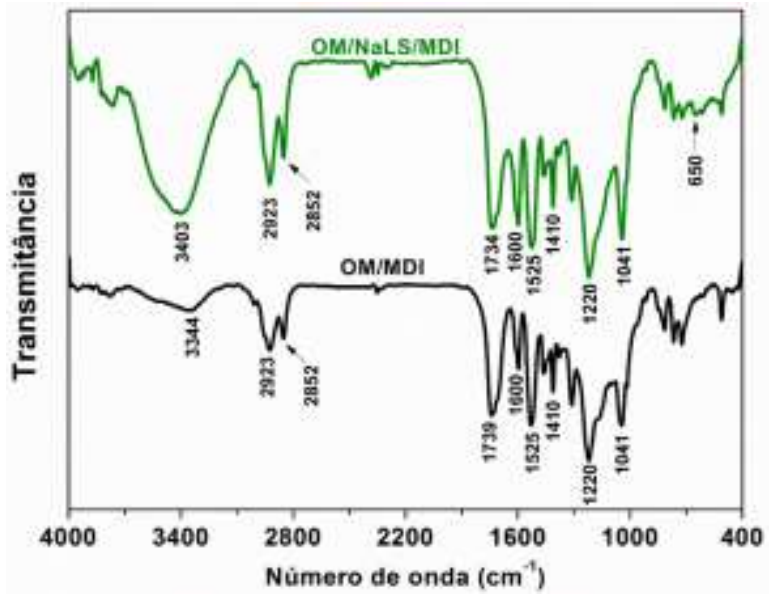

(c) 
Tabela I I - Principais absorções observadas em espectro de PUs e lignopoliuretanos preparados à partir de DEG, PEG, OM e NaLS (CIOBANU et al., 2004; CUI et al., 2007; WANG et al., 20I0; HUO et al., $20 \mathrm{I}$ I; FARIA et al., 20I 2; RISTIĆ et al., 20I2)

\begin{tabular}{cc}
\hline Número de onda $\left(\mathbf{c m}^{-1}\right)$ & Possível atribuição \\
\hline 3420 & $\mathrm{O}-\mathrm{H}$ hidroxilas \\
3485 & $\mathrm{~N}-\mathrm{H}$ livre \\
3310 & $\mathrm{~N}-\mathrm{H}$ ligado à hidrogênio \\
2980,2940 & $\mathrm{CH}_{2}$ \\
$2928-2855$ & $\mathrm{CH}_{2}$ \\
$1680-1760,1605$ & $\mathrm{C}=\mathrm{O}$ uretano, éster \\
$1610-1535$ & $\mathrm{C}=\mathrm{C}$ anel aromático \\
1535 & $\mathrm{~N}-\mathrm{H}$ e C-N (amida II) \\
1320 & $\mathrm{~N}-\mathrm{H}$ e C-N (amida III) \\
1075 & $\mathrm{C}-\mathrm{O}-\mathrm{C}$ \\
1030 & $\mathrm{C}-\mathrm{O}-\mathrm{C}$ \\
652 & $\mathrm{CH}$ anel aromático \\
$870,820,775,725,650,625,520$ & $\mathrm{C}-\mathrm{S}$ vibração do grupo sulfônico (lignossulfonato) \\
\hline
\end{tabular}

Em todos os espectros de PUs e lignopoliuretanos, não foi observado absorção em $2270 \mathrm{~cm}^{-1}$ (correspondente ao grupo NCO), indicando que não houve isocianato residual nestes materiais.

\subsubsection{Análise termogravimétrica}

A Análise termogravimétrica permite avaliar a estabilidade térmica dos materiais, que permite definir a faixa de aplicação de um determinado material.

Em estudos já realizados em que PUs foram preparados com ligninas, foram observados três estágios de decomposição. O primeiro estágio, que pode ir de 240 até $360^{\circ} \mathrm{C}$, corresponde à quebra das ligações uretânicas. $\mathrm{O}$ segundo estágio, geralmente de 360 a $460{ }^{\circ} \mathrm{C}$, corresponde à decomposição dos segmentos flexíveis da cadeia poliuretânica. $\mathrm{O}$ terceiro estágio, aproximadamente entre 460 e 700, é responsável pela decomposição de anéis aromáticos provenientes de isocianatos aromáticos ou da lignina (WANG et al., 2010; POHJANLEHTO et al., 20I4). No entanto, devido à contribuição estrutural de diferentes componentes que formam o lignopoliuretano, como no caso do presente trabalho, a identificação de todos os estágios de decomposição pode se tornar uma tarefa complexa. Ainda, durante $\circ$ processo de decomposição térmica dos PUs pode ocorrer a despolimerização tendo como resultado a formação de dióxido de carbono, aminas, isocianatos e álcoois, ou seja, a dissociação do poliuretano na forma de seus precursores (KROL, 2007; SAHOO; MISRA; MOHANTY, 20I4).

Na Figura 36 são mostradas as curvas TG e na 
Figura 37 são mostradas as curvas dTG, ambas para os PUs, lignopoliuretanos e respectivos compósitos, descritos nos Quadros I e 2 (Experimental). As curvas foram apresentadas duas a duas, comparando materiais que foram preparados sem $\mathrm{NaLS}$ e com a presença do mesmo. As curvas TG permitem avaliar a temperatura em que se inicia a decomposição do material em questão. Os picos na curva dTG indicam a temperatura em que a velocidade de decomposição (taxa de variação de massa) foi máxima.

Em todas as curvas TG (Figura 36), em torno de $250^{\circ} \mathrm{C}$ foi possível observar o início da perda de massa, correspondendo a um pico com intensidade máxima entre 320 e $350^{\circ} \mathrm{C}$ nas curvas dTG (

Figura 37). Este pico está relacionado à quebra da ligação uretana, ou seja, à decomposição dos segmentos rígidos da matriz poliuretana (ASANO; HATAKEYAMA; HATAKEYAMA, 2003; BAKARE et al., 2010). Aliado a esta decomposição, nesta temperatura $\left(250^{\circ} \mathrm{C}\right.$, curvas $\left.\mathrm{TG}\right)$ também tem início a decomposição de estruturas típicas do lignossulfonato de sódio presente na matriz, nos materiais em que este está presente. A decomposição da celulose presente nas fibras utilizadas como reforço, em se tratando de compósitos, também ocorreu nesta mesma região, resultando em picos de 320 a $350{ }^{\circ} \mathrm{C}$ nas curvas dTG (Figura 37). Em torno de $450{ }^{\circ} \mathrm{C}$ inicia um novo estágio de perda de massa nos PUs [Figura 36 (a, c, e)], com picos nas curvas dTG [Figura 37 (a, c, e)] pouco intensos para os materiais preparados com DEG e PEG, e mais intenso para os materiais preparados com OM. Estes picos correspondem à decomposição dos segmentos flexíveis da matriz poliuretânica provenientes do uso de DEG, PEG e OM.

Em temperaturas entre 750 e $800{ }^{\circ} \mathrm{C}$ foi possível observar pico relacionado à decomposição de estruturas típicas de NaLS [Figura 37 (a, c, e)], que também é observado na curva dTG do NaLS (Figura 30). 
Figura 36 - (a, c, e) Curvas TG de poliuretanos e lignopoliuretanos e (b, $d, f)$ respectivos compósitos, em atmosfera de $\mathbf{N}_{2}$, fluxo de $50 \mathrm{~mL} \mathrm{~min}^{-1}$ e razão de aquecimento de $10^{\circ} \mathrm{C} \mathrm{min}^{-1}$.

\section{Poliuretanos e Lignopoliuretanos não reforçados}

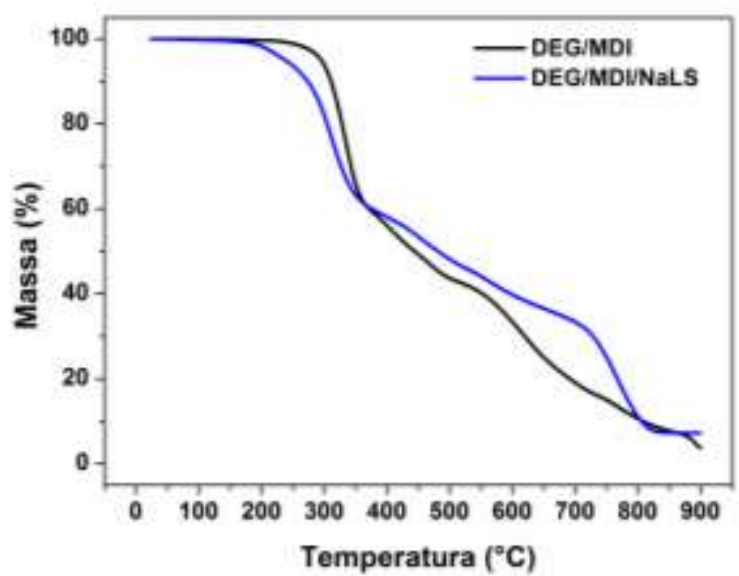

(a)

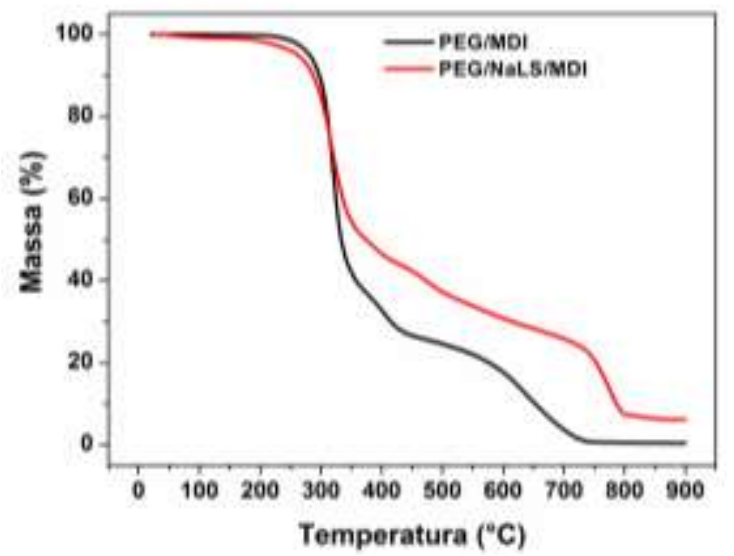

(c)

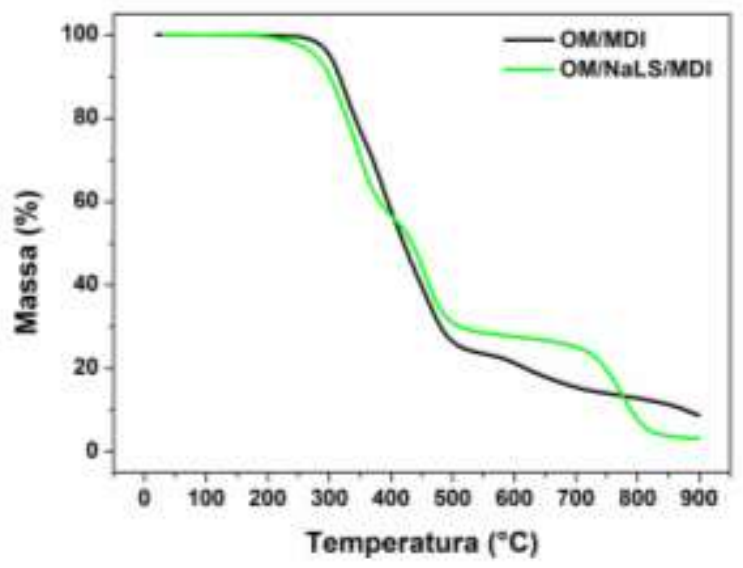

(e)
Compósitos poliuretânicos e lignopoliuretânicos

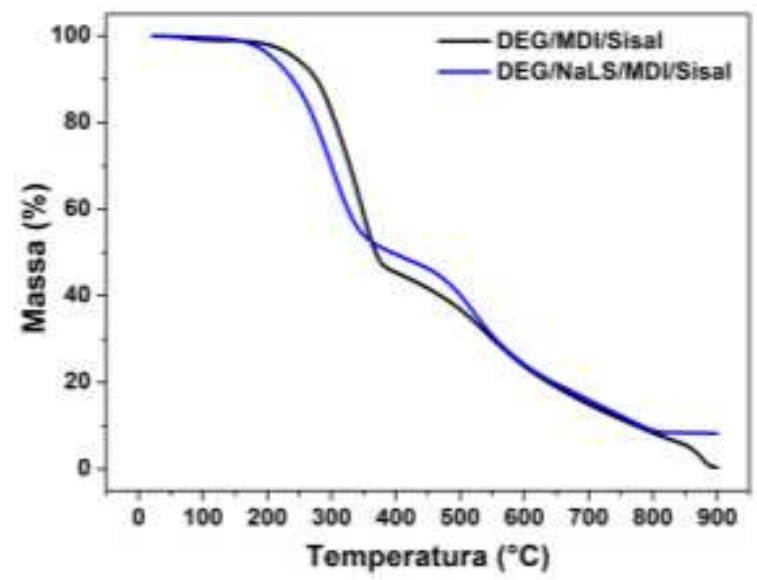

(b)

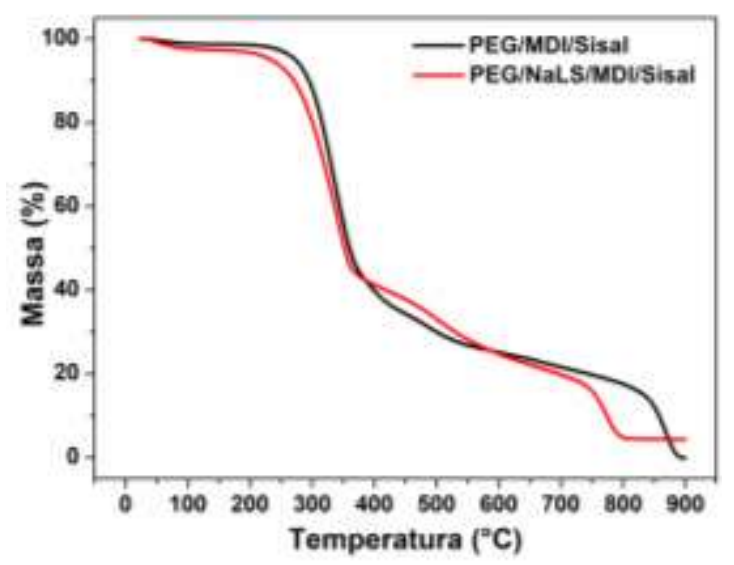

(d)

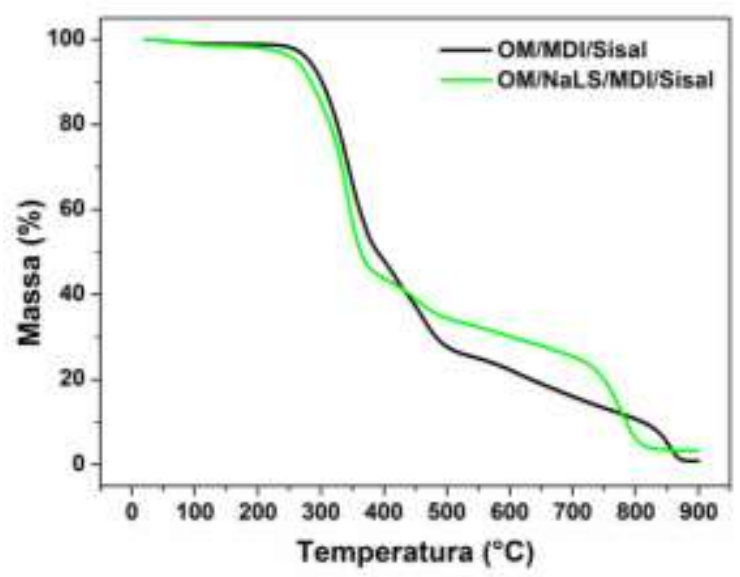

(f) 
Figura 37 - (a, c, e) Curvas dTG de poliuretanos e lignopoliuretanos e (b, d, f) respectivos compósitos, em atmosfera de $\mathbf{N}_{2}$, fluxo de $50 \mathrm{~mL} \mathrm{~min}^{-1}$ e razão de aquecimento de $10^{\circ} \mathrm{C} \mathrm{min}^{-1}$.

Poliuretanos e Lignopoliuretanos não reforçados

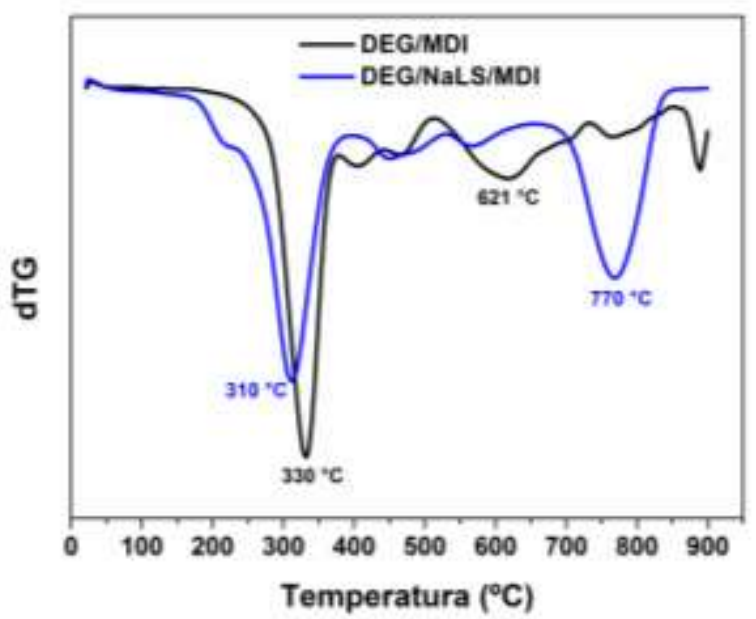

(a)

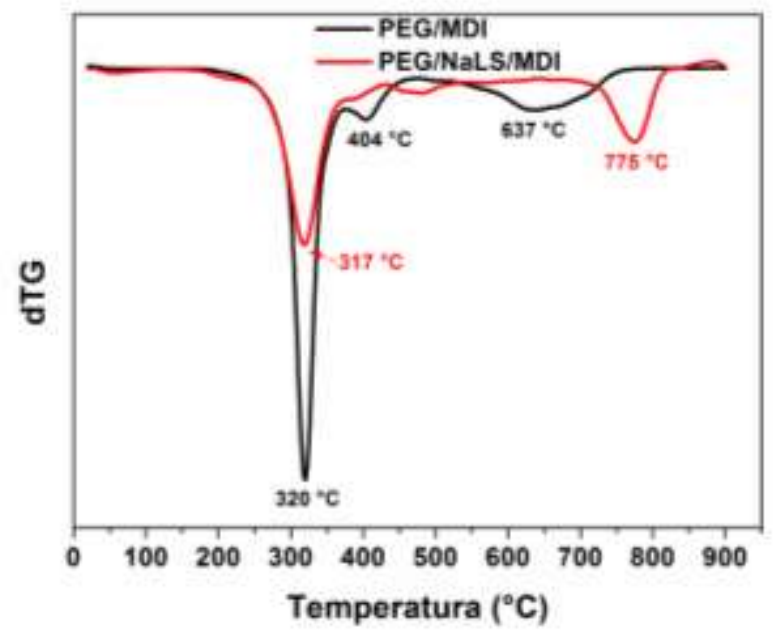

(c)

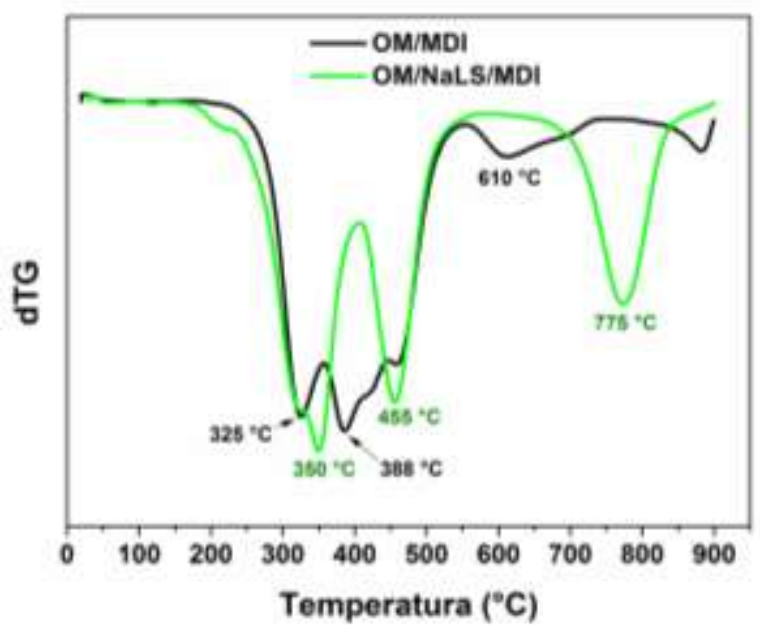

(e)
Compósitos poliuretânicos e lignopoliuretânicos

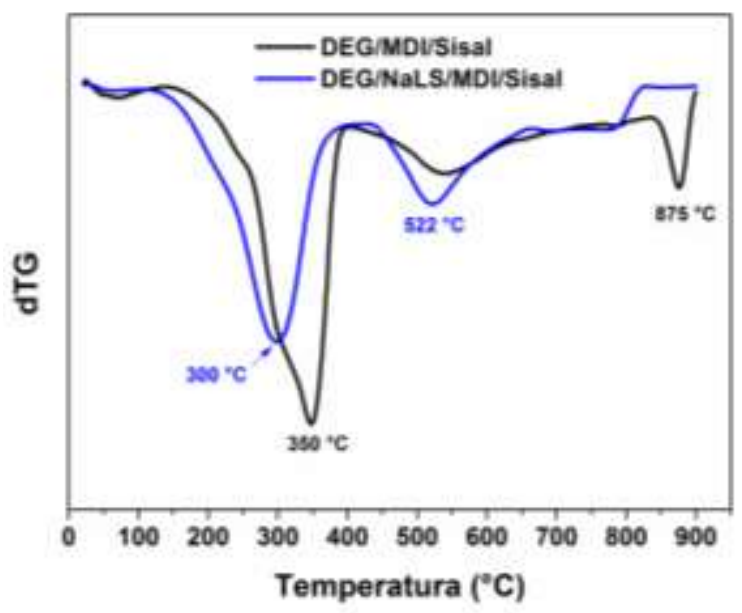

(b)

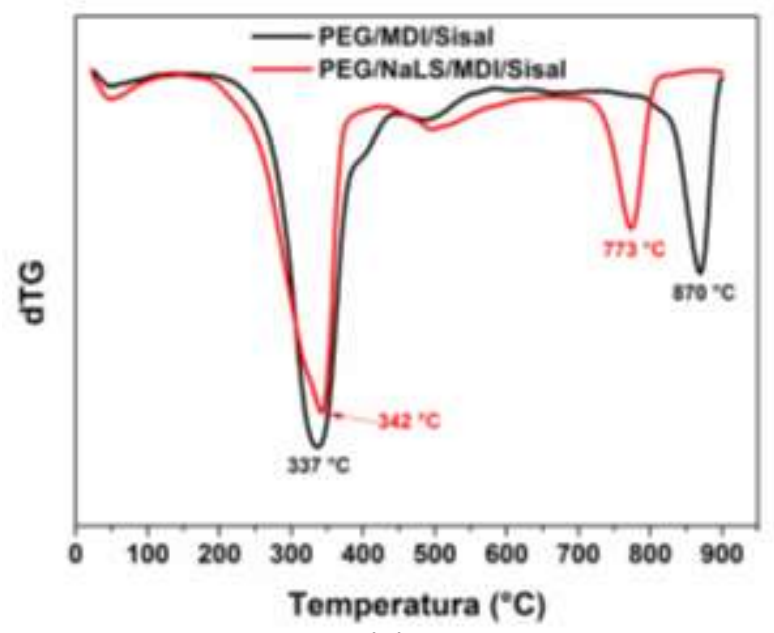

(d)

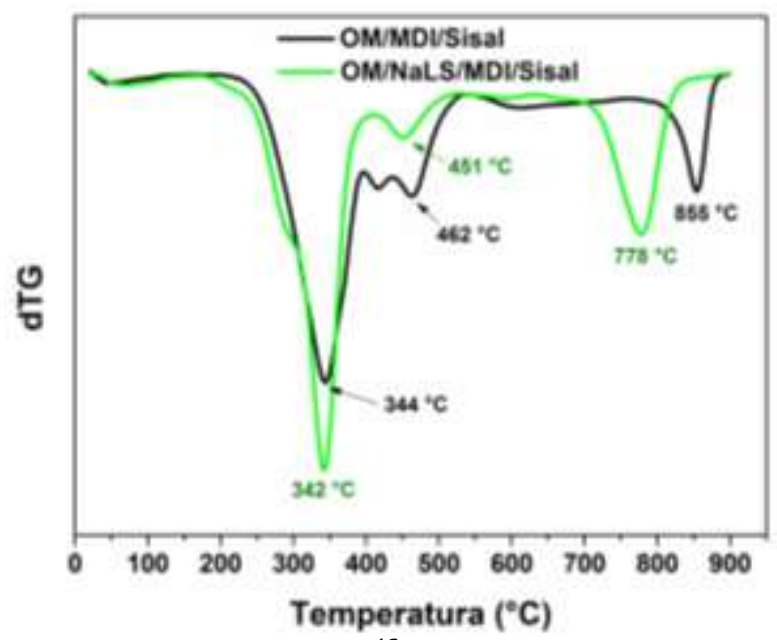

(f) 
Em se tratando da decomposição dos compósitos poliuretânicos e lignopoliuretânicos [Figura 36 (b, d, f)], observa-se que, com a introdução de NaLS na formulação desses compósitos, há um deslocamento do início de decomposição para temperaturas menores, observados nestas curvas TG [de $250{ }^{\circ} \mathrm{C}$ no compósito OM/MDI/Sisal para $210{ }^{\circ} \mathrm{C}$ no $\mathrm{OM} / \mathrm{NaLS} / \mathrm{MDI} /$ Sisal (Figura 36f); de $220^{\circ} \mathrm{C}$ no compósito PEG/MDI/Sisal para $200{ }^{\circ} \mathrm{C}$ no PEG/NaLS/MDI/Sisal (Figura 36d); e de $180^{\circ} \mathrm{C}$ no compósito DEG/MDI/Sisal para $150^{\circ} \mathrm{C}$ no DEG/NaLS/MDI/Sisal (Figura 36b)]. Nas curvas dTG, este deslocamento do início de decomposição resultou no deslocamento do pico em $350^{\circ} \mathrm{C}$ no compósito DEG/MDI/Sisal para $300{ }^{\circ} \mathrm{C}$ no compósito DEG/NaLS/MDI/Sisal (Figura 37b). Nos compósitos $\mathrm{PEG} / \mathrm{NaLS} / \mathrm{MDI} /$ Sisal e OM/NaLS/MDI/Sisal, os picos que aparecem deslocados são aqueles referentes à decomposição final dos compósitos: de $870{ }^{\circ} \mathrm{C}$ no compósito PEG/MDI/Sisal para $773{ }^{\circ} \mathrm{C}$ no PEG/NaLS/MDI/Sisal (Figura 37d); e de $855{ }^{\circ} \mathrm{C}$ no compósito OM/MDI/Sisal para $773{ }^{\circ} \mathrm{C}$ no OM/NaLS/MDI/Sisal (Figura 37f).

\subsubsection{Resistência ao impacto}

A Figura 38 apresenta a resistência ao impacto dos materiais descritos nos Quadros I e 2 (Experimental). Foi possível observar que houve aumento da resistência ao impacto do PU DEG/MDI e dos lignopoliuretanos (DEG/NaLS/MDI, PEG/NaLS/MDI e OM/NaLS/MDI), quando fibras de sisal foram inseridas nestas matrizes (DEG/MDI/Sisal, DEG/NaLS/MDI/Sisal, PEG/NaLS/MDI/Sisal e OM/NaLS/MDI/Sisal).

Figura 38 - Resistência ao impacto Izod (corpos de prova não-entalhados) de (a) Poliuretanos e Compósitos poliuretânicos e (b) Lignopoliuretanos e Compósitos lignopoliuretânicos; ambos grupos de materiais descritos nos Quadros I e 2.

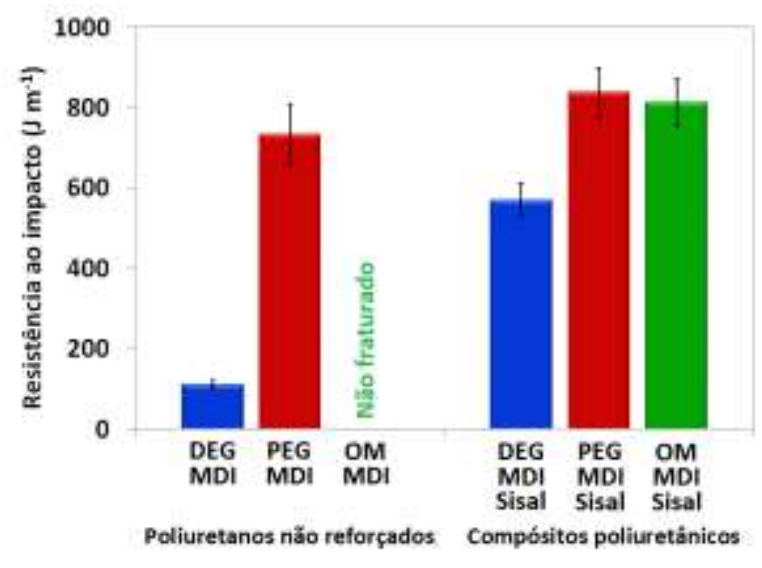

(a)

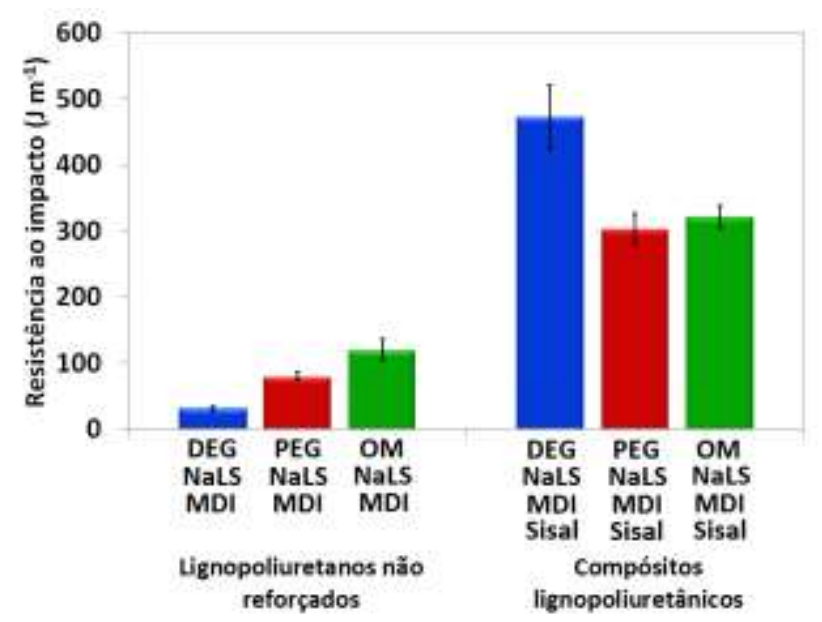

(b) 
Considerando o desvio padrão, as fibras tiveram pouca ação de reforço no compósito PEG/MDI/Sisal, uma vez que o poliuretano não reforçado PEG/MDI apresentou resistência ao impacto próxima a este compósito. Não foi possível obter a resistência ao impacto do poliuretano OM/MDI, pois o corpo de prova não fraturou ao realizar o ensaio, indicando uma resistência ao impacto superior em comparação aos outros materiais preparados. Provavelmente, o fato de não ter ocorrido a fratura é devido à característica elastomérica que o $\mathrm{OM}$ conferiu a este poliuretano. Já para o respectivo compósito OM/MDI/Sisal, as fibras diminuem proporcionalmente a influência da fase elastomérica diminuindo assim a resistência ao impacto, comparativamente ao material não reforçado (OM/MDI).

Após o ensaio de impacto, observou-se o fenômeno fiber bridging (Figura 39) em todos os compósitos, indicando boa adesão entre fibra e matriz. Os compósitos PEG/MDI e OM/MDI apresentaram maiores resistências ao impacto (838 e $813 \mathrm{Jm}^{-1}$, respectivamente) que $\circ$ DEG/MDI (57l $\mathrm{J} \mathrm{m}^{-1}$ ) (Figura 38a), possivelmente devido ao maior tamanho das cadeias dos polióis PEG e do ácido ricinoléico presente no OM, comparado ao poliol DEG. A mobilidade molecular pode ser limitada quando cadeias curtas, como as de dietilenoglicol, DEG, são introduzidas na estrutura do material. Polióis com cadeias mais longas, como PEG e OM, podem gerar PUs com características mais elastoméricas, uma consequência do menor grau de entrecruzamento destas cadeias, e a resistência ao impacto superior pode estar ligado ao fato de estas cadeias possuírem uma maior mobilidade molecular (ASANO; HATAKEYAMA; HATAKEYAMA, 2003). A Figura 40 mostra as diferenças nas estruturas de poliuretano obtido a partir de DEG e PEG.

Figura 39 - Fenômeno fiber bridging observado em corpos de prova do compósito DEG/NaLS/MDI/Sisal* após o ensaio de impacto.

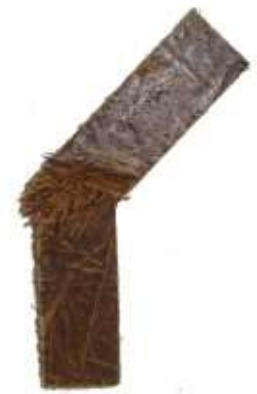

*O mesmo fenômeno foi observado em todos os compósitos do Grupo I 
Figura 40 - Representação estrutural de poliuretano obtido à partir de (a) DEG e (b) PEG.

(a)<smiles>CC(=O)Nc1ccc(Cc2ccc(NC(=O)OCCOC(C)(C)C)cc2)cc1</smiles>

(b)<smiles>CC(C)OCCOCCOCCOCCOCCOCCOCCOC(=O)Nc1ccc(Cc2ccc(NC(C)(C)C)cc2)cc1</smiles>

Os lignopoliuretanos sem fibras (Figura 38b) também apresentaram uma tendência de aumento na resistência ao impacto, conforme o aumento da cadeia do poliol utilizado (DEG, PEG e OM, respectivamente). Os compósitos lignopoliuretânicos apresentaram resistência ao impacto elevadas $\left(472,302\right.$ e $321 \mathrm{~J} \mathrm{~m}^{-1}$, Figura 38b) se comparado aos respectivos lignopoliuretanos não reforçados (3I, 80 e $120 \mathrm{~J} \mathrm{~m}^{-1}$, Figura 38b). A presença de NaLS na composição dos lignopoliuretanos não reforçados (DEG/NaLS/MDI, PEG/NaLS/MDI e $\mathrm{OM} / \mathrm{NaLS} / \mathrm{MDI}$, Figura 38b) fez com que a resistência ao impacto destes materiais diminuísse em relação aos poliuretanos não reforçados (DEG/MDI, PEG/MDI e OM/MDI, Figura 38a), preparados sem NaLS, sendo que uma diminuição mais acentuada desta propriedade pode ser observada para os poliuretanos preparados com PEG e OM (PEG/MDI e OM/MDI, respectivamente), Figura 38a. A estrutura do NaLS, abundante em anéis aromáticos, proporciona mais segmentos rígidos e menos segmentos flexíveis na estrutura do lignopoliuretano, o que pode diminuir a resistência do material. No entanto, é importante ressaltar que, embora ocorra diminuição na resistência ao impacto, os valores observados se situam em um bom patamar, sendo que o compósito lignopoliuretânico DEG/NaLS/MDI/Sisal merece destaque, pois a resistência ao impacto (472 $\mathrm{J} \mathrm{m}^{-1}$, Figura 38a) se aproxima, pelos

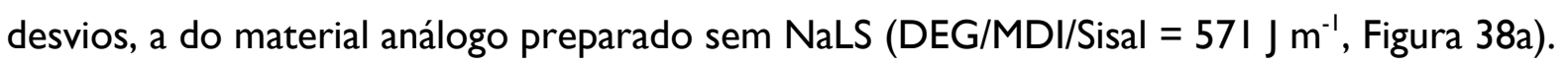

\subsubsection{Microscopia eletrônica de varredura}

Nas Figuras 4I e 42 são apresentadas as imagens de MEV para os PU/compósitos poliuretânicos e lignopoliuretanos/compósitos lignopoliuretanos (Quadros I e 2). Para ter acesso à superfície de fratura de compósitos que apresentaram fiber-bridging, fenômeno em 
que a maior parte das fibras não rompem, as fibras que ligavam as duas partes da matriz foram separadas através de corte.

De modo geral, é possível observar que a superfície de fratura dos PU se mostrou mais uniforme, apresentando estruturas do tipo marcas de rios (setas vermelhas, Figura 4I), se comparado aos lignopoliuretanos (Figura 42), onde foi possível observar estruturas mistas com a presença de microcavidades e do tipo celular, com depressões esferoidais (PURSLOW, 1986), o que sugere diferentes tipos de mecanismos de fraturas para PUs e lignopoliuretanos. 
Figura 4I - Imagens de MEV das superfícies fraturadas do (a) DEG/MDI; (b) DEG/MDI/Sisal; (c) PEG/MDI; (d) PEG/MDI/Sisal; (e) OM/MDI (fraturado em N2); e (f) OM/MDI/Sisal.

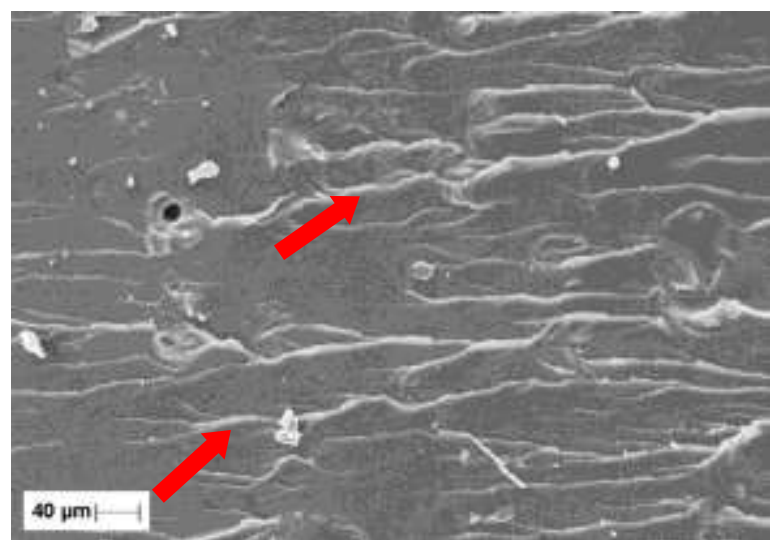

(a)

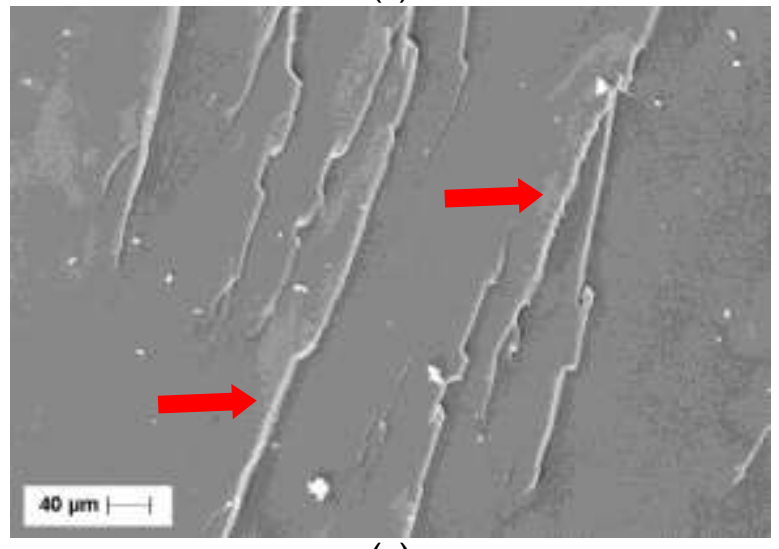

(c)

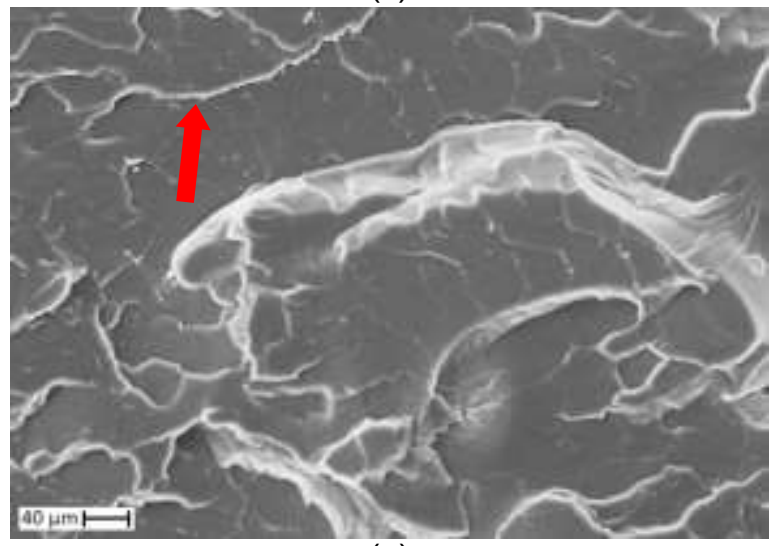

(e)

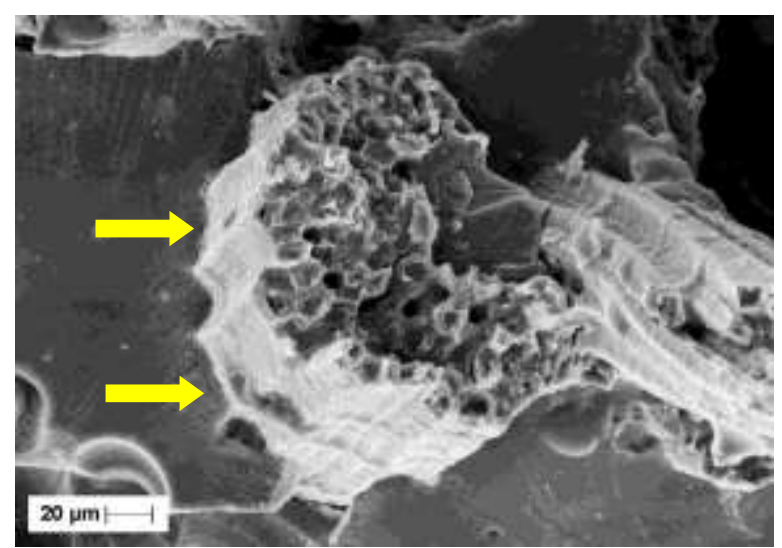

(b)

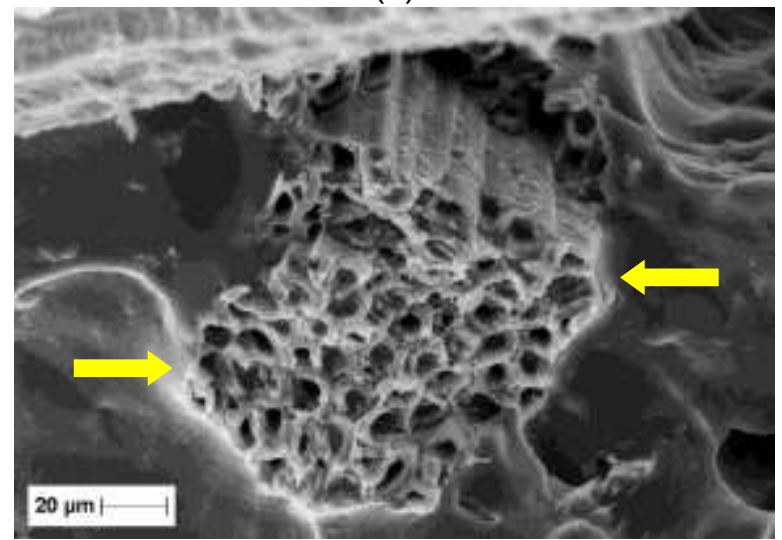

(d)

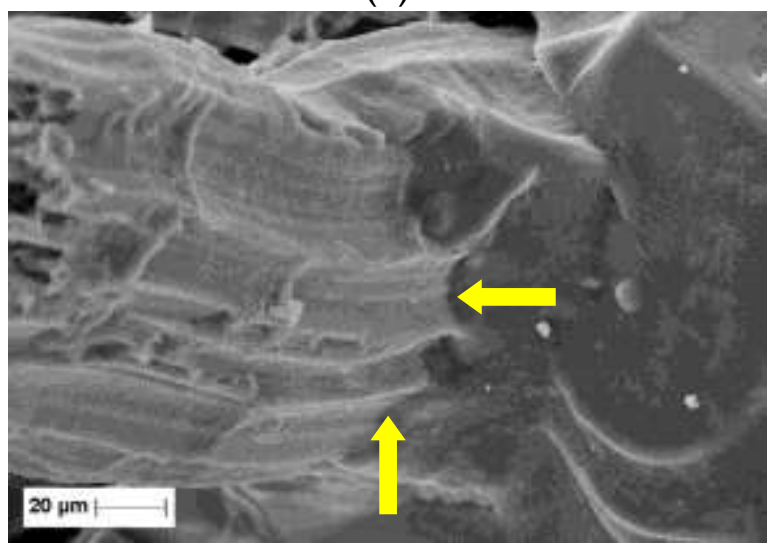

(f) 
Figura 42 - Imagens de MEV das superfícies fraturadas do (a) DEG/NaLS/MDI;

(b) DEG/NaLS/MDI/Sisal; (c) PEG/NaLS/MDI; (d) PEG/NaLS/MDI/Sisal;

(e) OM/NaLS/MDI; e (f) OM/NaLS/MDI/Sisal.

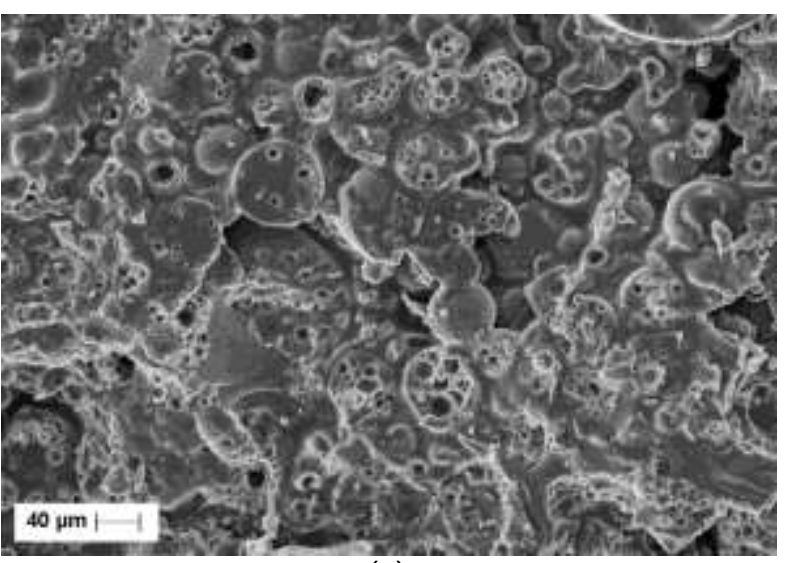

(a)

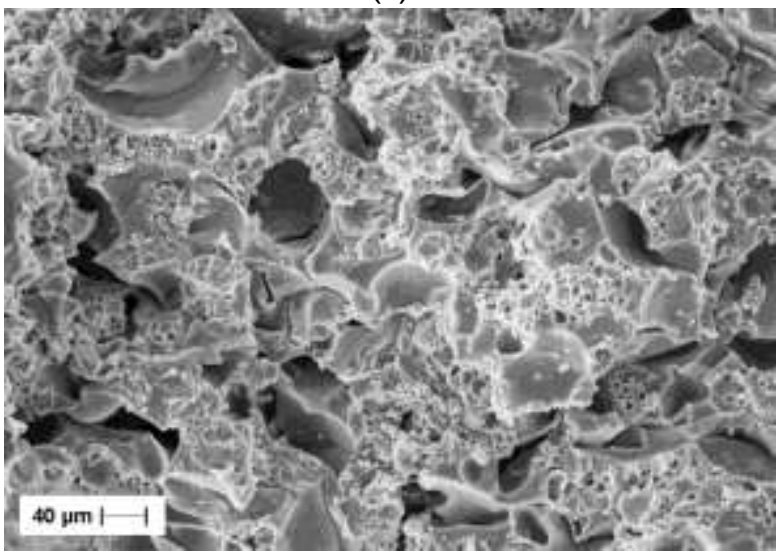

(c)

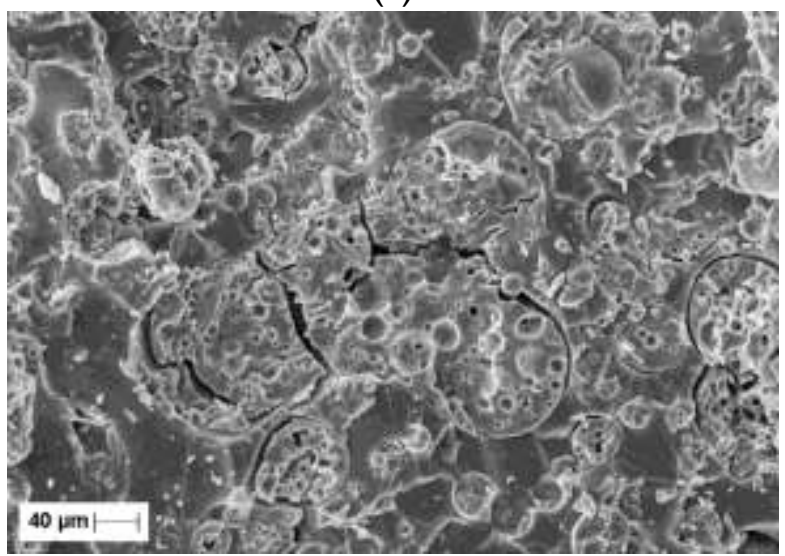

(e)

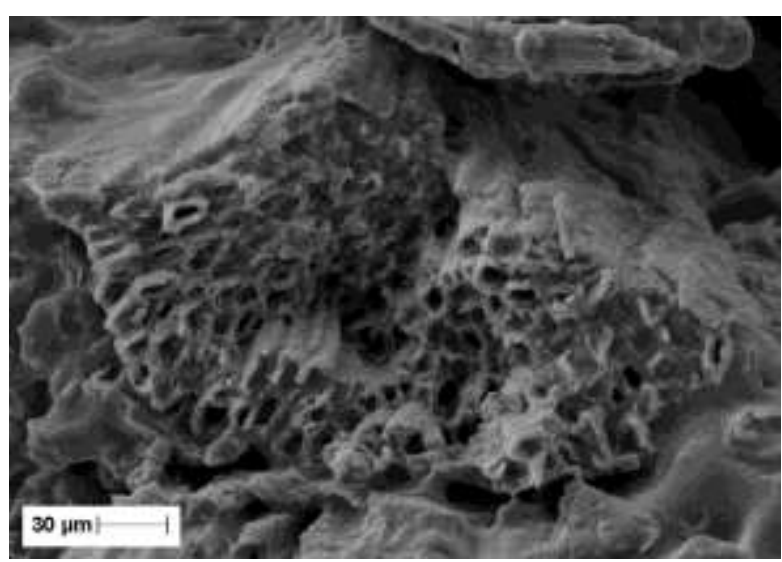

(b)

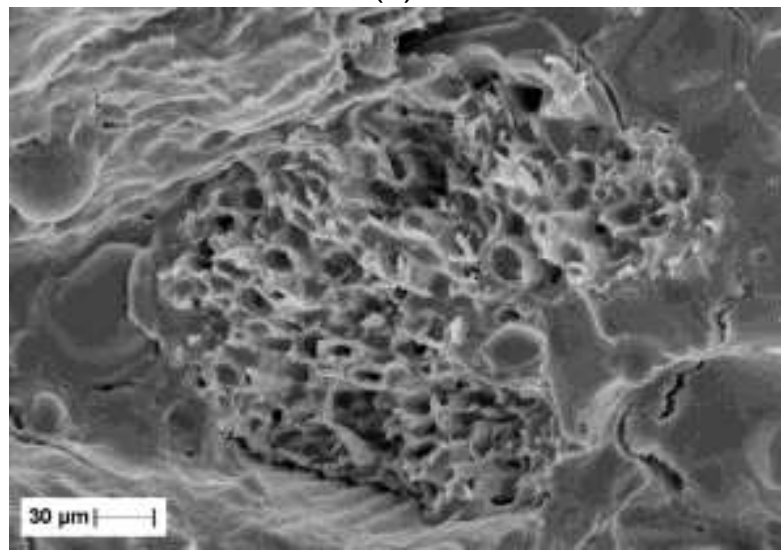

(d)

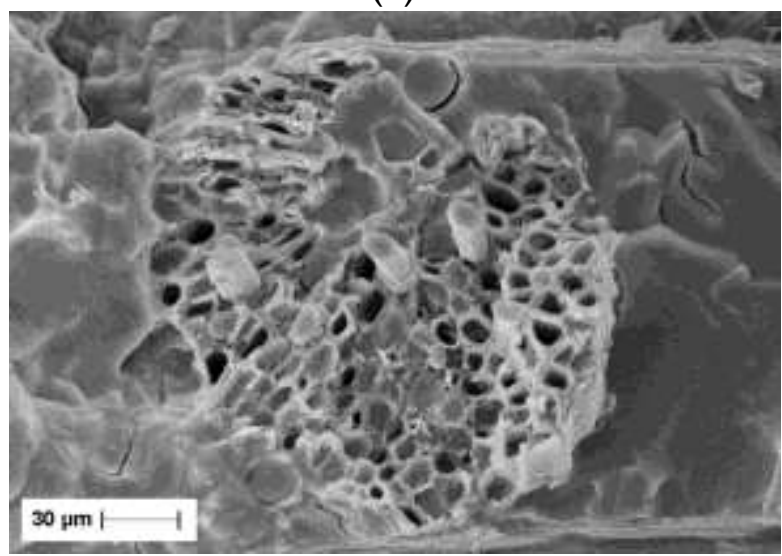

(f)

Nos compósitos poliuretânicos (Figura 4I) foi possível observar ótima adesão entre fibra e matriz na interface, indicada pelas setas amarelas. Nos compósitos lignopoliuretânicos (Figura 42), também é possível observar essa boa adesão e, além disso, observa-se também a presença de matriz aderida à superfície das fibras. Esta excelente adesão se deve, provavelmente, a presença de ligações hidrogênio entre os grupos uretanos da matriz e os 
grupos hidroxila das fibras, além das interações entre os domínios hidrofóbicos presente em ambos, fibra e matriz, como podemos observar na Figura 21. Os grupos hidroxilas presentes na fibra podem ter reagido com os grupos isocianatos do MDI durante a preparação do compósito, formando ligações covalente entre a matriz e as fibras e, consequentemente levando a uma forte adesão entre fibra e matriz (ARANGUREN; RÁCZ; MARCOVICH, 2007). No entanto, deve-se destacar que no presente estudo não se teve comprovações que ligações covalentes teriam sido desenvolvidas entre fibras e matriz.

\subsubsection{Resistência à flexão}

A Tabela 12 apresenta informações sobre a ocorrência do rompimento e deformação máxima durante o ensaio de flexão dos materiais preparados nos Quadros I e 2 (Experimental). É importante ressaltar que este ensaio utiliza o carregamento em um sistema com três pontos, como já mencionado na parte experimental. Este tipo de ensaio é geralmente aplicados à materiais poliméricos rígidos e semirrígidos. O corpo de prova é defletido até que sua ruptura ocorra na superfície oposta ao carregamento, ou até que uma deformação máxima de 5,0\% seja alcançada. Entretanto, a resistência à flexão na ruptura não pode ser determinada para aqueles materiais que não rompem ou não falham na superfície oposta ao carregamento dentro de um limite máximo de 5,0\% (CANTO; PESSAN, 2004). Assim, para os materiais que não romperam, a resistência à flexão apresentada corresponde à tensão sob flexão à uma deformação de 5,0\%. 
Tabela 12 - Informações sobre fratura e deformação durante o ensaio de flexão (sistema 3 pontos) para os materiais descritos nos Quadros I e 2 (Experimental).

\begin{tabular}{|c|c|c|c|}
\hline & \multicolumn{2}{|c|}{ Material } & Deformação máxima (\%) \\
\hline \multirow{6}{*}{ 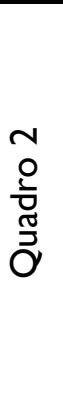 } & & DEG/MDI & $3,4 \pm 0,3$ \\
\hline & Poliuretanos & PEG/MDI & $5,0 * *$ \\
\hline & \multirow{4}{*}{$\begin{array}{l}\text { Compósitos } \\
\text { poliuretânicos }\end{array}$} & OM/MDI* & não testado \\
\hline & & DEG/MDI/Sisal & $3,4 \pm 0,4$ \\
\hline & & PEG/MDI/Sisal & $5,0 * *$ \\
\hline & & OM/MDI/Sisal & $5,0 * *$ \\
\hline \multirow{6}{*}{ 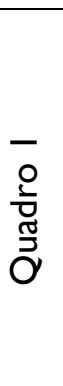 } & \multirow{3}{*}{ Lignopoliuretanos } & DEG/NaLS/MDI & $\mathrm{I}, 2 \pm 0, \mathrm{I}$ \\
\hline & & PEG/NaLS/MDI & $5,0 * *$ \\
\hline & & OM/NaLS/MDI & $5,0 * *$ \\
\hline & \multirow{3}{*}{$\begin{array}{l}\text { Compósitos } \\
\text { lignopoliuretânicos }\end{array}$} & DEG/NaLS/MDI/Sisal & $2,4 \pm 0,1$ \\
\hline & & PEG/NaLS/MDI/Sisal & $2,7 \pm 0,1$ \\
\hline & & OM/NaLS/MDI/Sisal & $5,0 * *$ \\
\hline
\end{tabular}

*Característica elastomérica acentuada não permitiu a realização do ensaio no sistema de três pontos.

** Não houve ruptura durante o ensaio

As Figura 43 e Figura 44 apresentam, respectivamente, a resistência à flexão e o módulo de flexão dos PU, lignopoliuretanos e respectivos compósitos dessas matrizes reforçados com fibras de sisal.

Figura 43 - Resistência à flexão de (a) PUs e Compósitos poliuretânicos (Quadro 2) e (b) Lignopoliuretanos e Compósitos lignopoliuretânicos (Quadro I).

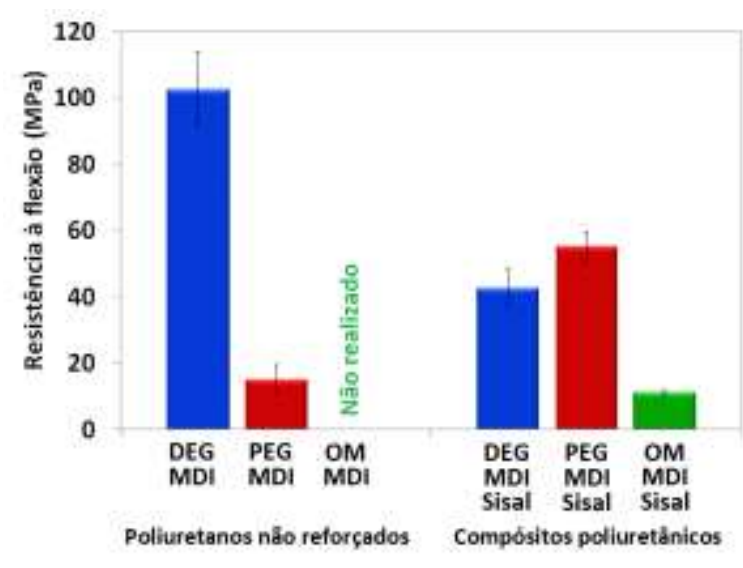

(a)

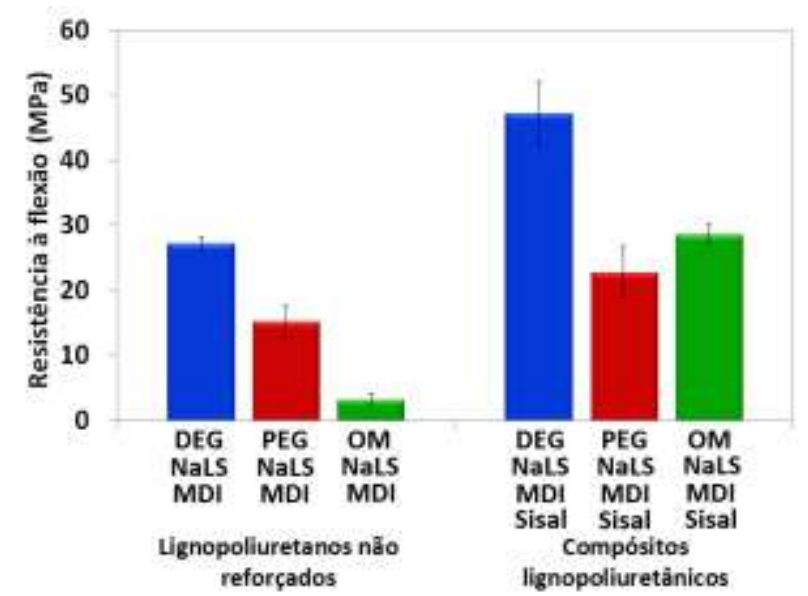

(b) 
Figura 44 - Módulo de flexão de (a) PUs e compósitos poliuretânicos (Quadro 2) e (b) lignopoliuretanos e compósitos lignopoliuretânicos (Quadro I).

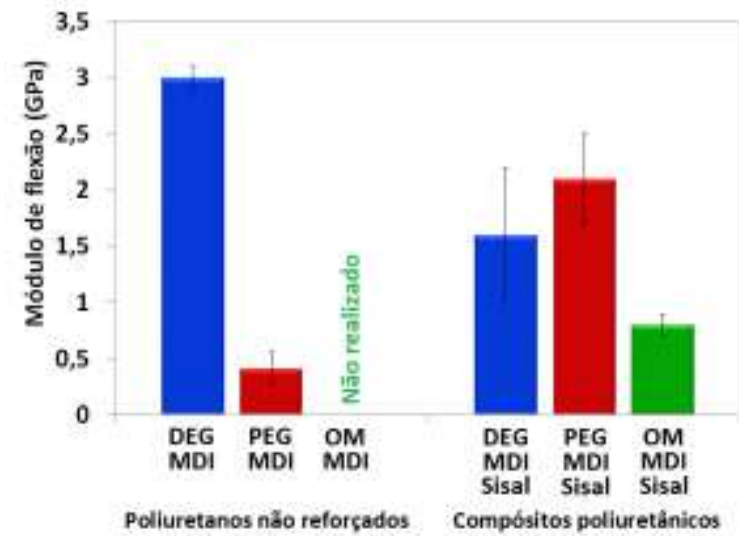

(a)

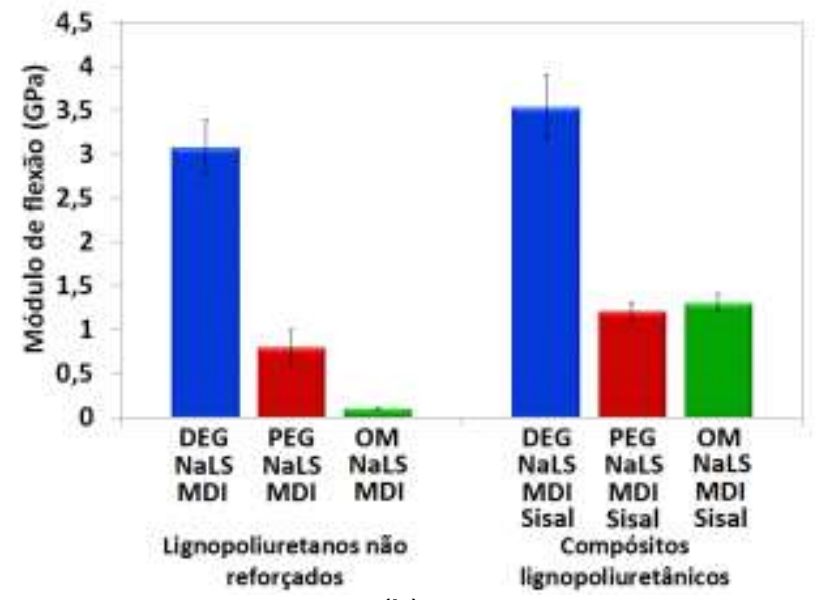

(b)

Tanto a resistência à flexão como o módulo de flexão seguiram a mesma tendência para os materiais avaliados. Em se tratando dos materiais sem a presença de NaLS, o poliuretano DEG/MDI teve as propriedades de flexão reduzidas quando as fibras de sisal foram inseridas (DEG/MDI/Sisal) (Figura 43a). Como o poliuretano DEG/MDI é um polímero formado majoritariamente por domínios rígidos, como uma consequência do pequeno tamanho da molécula de DEG (usada como reagente para gerar o polímero), a presença das fibras diminuiu a influência dos domínios flexíveis, levando à mudança desta propriedade mecânica para o material. Para o poliuretano PEG/MDI, que possui um maior número de segmentos flexíveis se comparado ao DEG/MDI, houve aumento nas propriedades com a inserção das fibras sisal (PEG/MDI/Sisal) e, neste caso, a presença das fibras levou a um material com maior resistência.

Não foi possível realizar o ensaio para o poliuretano OM/MDI, pois este material apresentou característica elastomérica acentuada, o que dificultou a sustentação do corpo de prova sobre o sistema de três pontos. Com a inserção das fibras, esta característica elastomérica diminui, sendo possível obter valores de resistência à flexão e módulo de flexão.

Com a inserção de NaLS nestes materiais, observou-se um decréscimo no valor dessas propriedades (Figura 43b), assim como já observado nos resultados de resistência ao impacto destes materiais. A presença de estruturas rígidas no NaLS proporcionou um aumento de segmentos rígidos e diminuição de segmentos flexíveis nos lignopoliuretanos, que ocasionou o decréscimo da resistência à flexão. 
Comparando os lignopoliuretanos e compósitos lignopoliuretanos, observa-se que houve notável aumento na resistência à flexão (Figura 43b) e módulo de flexão (Figura 44b) após a inserção das fibras de sisal. Comparando-se os valores dos materiais lignopoliuretânicos (Figura 43b) é possível observar que aqueles preparados com DEG/NaLS/MDI apresentam as maiores resistências à flexão (27 MPa para o lignopoliuretano não reforçado e $47 \mathrm{MPa}$ para o compósito, Figura 43b) e os maiores módulos de flexão (3, I GPa para o lignopoliuretano não reforço e 3,5 GPa para o compósito, Figura 44b). Como já mencionado, o DEG é um poliol de cadeia curta (Figura 22d) e, portanto, seu uso leva a uma maior proporção de segmentos rígidos no poliuretano obtido (Figura 40a) quando comparado ao PEG (Figura 22e) e ao OM (Figura 22f) que são polióis de cadeias longas e, consequentemente, quando na formação do poliuretano formam um segmento mais longo e mais flexível, como o da Figura 40b. $O$ aumento da proporção de segmentos rígidos no lignopoliuretano DEG/NaLS/MDI leva ao aumento da rigidez do material e, consequentemente, a um maior módulo de flexão (3,I GPa, Figura 44b) se comparados aos lignopoliuretanos PEG/NaLS/MDI e OM/NaLS/MDI (0,8 e 0,I GPa, respectivamente; Figura 44b).

\subsubsection{Comparação com estudos anteriores}

Em trabalhos desenvolvidos anteriormente, lignopoliuretanos foram preparadas a partir do NaLS em associação com DEG, PEG e OM, semelhante aos lignopoliuretanos preparados no Grupo I do presente estudo. No entanto, fibras de cuarauá e coco foram utilizadas como reforços destes lignopoliuretanos (RAMIRES; DE OLIVEIRA; FROLLINI, 2013). A Tabela II mostra os resultados das propriedades mecânicas de impacto e flexão obtidos por Ramires et al. (2010) e aqueles obtidos no presente estudo (Grupo I), para efeito de comparação. Todos os compósitos mostrados foram preparados com $30 \%$ em massa de fibras lignocelulósicas (cuarauá, coco ou sisal), $3 \mathrm{~cm}$ de comprimento e distribuição aleatória de fibras na matriz. 
Tabela 13 - Comparação entre compósitos de matrizes lignopoliuretanas reforçadas com diferentes fibras lignocelulósicas (curauá, coco e sisal).

\begin{tabular}{|c|c|c|c|c|}
\hline Compósitos & $\begin{array}{l}\text { Resistência ao } \\
\text { Impacto }\left(\mathrm{J} \mathrm{m}^{-1}\right)\end{array}$ & $\begin{array}{l}\text { Resistência à } \\
\text { flexão (MPa) }\end{array}$ & $\begin{array}{c}\text { Módulo de } \\
\text { flexão (GPa) }\end{array}$ & Referência \\
\hline DEG/NaLS/MDI/Curauá & $404 \pm 37$ & $68 \pm 4$ & $7,3 \pm 0,4$ & $\begin{array}{l}\text { Ramires et al. } \\
(2013)\end{array}$ \\
\hline DEG/NaLS/MDI/Coco & $170 \pm 7$ & $27 \pm 3$ & $3,0 \pm 0,2$ & $\begin{array}{l}\text { Ramires et al. } \\
\qquad(2013)\end{array}$ \\
\hline DEG/NaLS/MDI/Sisal & $472 \pm 48$ & $48 \pm 5$ & $3,5 \pm 0,4$ & Atual estudo \\
\hline PEG/NaLS/MDI/Curauá & $319 \pm 15$ & $35 \pm 2$ & $1,8 \pm 0,2$ & $\begin{array}{l}\text { Ramires et al. } \\
(2013)\end{array}$ \\
\hline PEG/NaLS/MDI/Coco & $120 \pm 8$ & $10 \pm 1$ & $0,3 \pm 0,03$ & $\begin{array}{l}\text { Ramires et al. } \\
(2013)\end{array}$ \\
\hline PEG/NaLS/MDI/Sisal & $302 \pm 24$ & $36 \pm 1$ & $3,4 \pm 0,3$ & Atual estudo \\
\hline OM/NaLS/MDI/Curauá & $463 \pm 9$ & $44 \pm 1$ & $2,4 \pm 0,2$ & $\begin{array}{l}\text { Ramires et al. } \\
(2013)\end{array}$ \\
\hline OM/NaLS/MDI/Coco & $180 \pm 12$ & $25 \pm 1$ & $0,9 \pm 0,03$ & $\begin{array}{l}\text { Ramires et al. } \\
\qquad(2013)\end{array}$ \\
\hline OM/NaLS/MDI/Sisal & $321 \pm 17$ & $29 \pm 2$ & $1,3 \pm 0,1$ & Atual estudo \\
\hline
\end{tabular}

Os compósitos reforçados com fibras de curauá apresentaram resistência ao impacto superior em relação àqueles reforçados com fibras de coco, em todos os três tipos de lignopoliuretanos usados como matrizes. O compósito de sisal (DEG/NaLS/MDI/Sisal) do presente estudo apresentou maior resistência ao impacto $\left(472 \mathrm{~J} \mathrm{~m}^{-1}\right)$ que os compósitos de mesma matriz reforçados com curauá e coco (404 e $170 \mathrm{~J} \mathrm{~m}^{-1}$, respectivamente). Os compósitos PEG/NaLS/MDI/Sisal assumiram valor de resistência ao impacto que se aproxima com aquele do compósito reforçado por curauá, e OM/NaLS/MDI/Sisal apresentou resistência ao impacto entre os compósitos análogos preparados com fibras de curauá e coco, como observado Tabela 13.

O compósito de sisal DEG/NaLS/MDI/Sisal apresentou resistência à flexão (48 MPa) situada entre os valores dessa propriedades para os compósitos de curauá (68 MPa) e coco (27 MPa) preparados com a mesma matriz (DEG/NaLS/MDI). Quando o lignopoliuretano PEG/NaLS/MDI foi utilizado como matriz, o compósito de curauá e sisal apresentaram a resistência à flexão muito próximas (35 e $36 \mathrm{MPa}$, respectivamente); e quando foi utilizado o lignopoliuretano OM/NaLS/MDI, os compósitos de coco e sisal apresentarem resistência à flexão semelhantes (25 e $29 \mathrm{MPa}$, respectivamente). 
Em termos de módulo de flexão, o compósitos de sisal PEG/NaLS/MDI apresentou o maior módulo (3,4 GPa), comparado aos compósitos análogos preparados com curauá (I,8 $\mathrm{GPa})$ e coco (0,3 GPa). Em relação às matrizes DEG/NaLS/MDI e OM/NaLS/MDI o compósitos de sisal (DEG/NaLS/MDI/Sisal) apresentaram módulo de flexão superiores aos compósitos de coco, no entanto inferiores em relação aos compósitos de curauá (Tabela 13).

\subsubsection{Análise térmica dinâmico-mecânica}

A análise térmica dinâmico-mecânica (DMA) fornece informações a respeito do módulo de elasticidade ou armazenamento (E'), do módulo de dissipação viscosa ou perda (E') e do amortecimento mecânico ou atrito interno ( $\tan \delta=$ E'/E') de um material, quando sujeito a uma solicitação dinâmica. As propriedades dinâmico-mecânicas dos compósitos são determinadas pelas propriedades de seus componentes, pela morfologia do sistema e pela natureza da interação entre os dois componentes. A camada da matriz do que recobre as fibras, imediatamente posterior a interface, pode ter propriedades diferentes do restante do material, pois as interações com as fibras podem alterar a mobilidade das cadeias poliméricas da matriz (DE PAIVA; FROLLINI, 200I; TRINDADE et al., 2005).

A Figura 45 apresenta as curvas de módulo de armazenamento e módulo de perda versus temperatura para os lignopoliuretanos preparados com diferentes polióis (DEG, PEG e OM) associados ao NaLS, descritos no Quadro I (Experimental).

Simplificadamente, pode-se considerar que o módulo de armazenamento aumenta, conforme a movimentação de segmentos da cadeia torna-se mais difícil. $O$ lignopoliuretano DEG/NaLS/MDI apresentou valores de módulo de armazenamento maior que o lignopoliuretano PEG/NaLS/MDI, que por sua vez teve valores maiores que o OM/NaLS/MDI (Figura 45a). Por exemplo, a $-100{ }^{\circ} \mathrm{C}$, o módulo de armazenamento foi 5562, 4226 e 3300 $\mathrm{MPa}$, para os lignopoliuretanos DEG/NaLS/MDI, PEG/NaLS/MDI e OM/NaLS/MDI, respectivamente. A $25{ }^{\circ} \mathrm{C}$, os valores de módulo de armazenamento foram 1958, 995 e 364 $\mathrm{MPa}$, respectivamente para os mesmos lignopoliuretanos supracitados. Esta tendência já havia sido observada nos resultados de módulo de flexão destes materiais (Figura 44b), uma vez que no lignopoliuretano DEG/NaLS/MDI há uma quantidade menor de segmentos flexíveis se comparados ao PEG/NaLS/MDI e OM/NaLS/MDI, devido ao tamanho da 
molécula de DEG. Assim, a movimentação dos segmentos de cadeia nos lignopoliuretanos PEG/NaLS/MDI e OM/NaLS/MDI é maior que no DEG/NaLS/MDI.

As $T_{g} s$ de PUs depende da natureza e da composição de segmentos rígidos e flexíveis. Em estudos envolvendo PUs entrecruzados, obtidas a partir de diferentes polióis, isocianatos e extensores de cadeia, foram obtidas $\mathrm{Tg}$ em amplo intervalo, ou seja de $-17^{\circ} \mathrm{C}$ até $107^{\circ} \mathrm{C}$ (RATNA, 20I2). Na Figura 45b, os picos observados em 3, 9 e $16{ }^{\circ} \mathrm{C}$ nos lignopoliuretanos (DEG/NaLS/MDI, PEG/NaLS/MDI e OM/NaLS/MDI, respectivamente), podem ser atribuídos à temperatura de transição vítrea $\left(\mathrm{T}_{\mathrm{g}}\right)$. $\mathrm{O}$ pico em $3{ }^{\circ} \mathrm{C}$ no lignopoliuretano $\mathrm{DEG} / \mathrm{NaLS} / \mathrm{MDI}$ faz parte de um pico largo que se inicia por volta de $-40{ }^{\circ} \mathrm{C}$ e vai até cerca de $100^{\circ} \mathrm{C}$, com a presença de um ombro em torno de $45{ }^{\circ} \mathrm{C}$, que deve englobar a movimentação de segmentos rígidos presentes neste lignopoliuretano. Além do pico em $16{ }^{\circ} \mathrm{C}$, o lignopoliuretano $\mathrm{OM} / \mathrm{NaLS} / \mathrm{MDI}$ apresentou um ombro em $-5{ }^{\circ} \mathrm{C}$, que pode ser resultado da movimentação de segmentos flexíveis provenientes dos componentes do óleo de mamona, uma vez que o poliuretano sem NaLS (OM/MDI, curva não mostrada) apresenta $\mathrm{Tg}$ em uma temperatura subambiente $\left(-13{ }^{\circ} \mathrm{C}\right)$. Para os lignopoliuretanos PEG/NaLS/MDI e $\mathrm{OM} / \mathrm{NaLS} / \mathrm{MDI}$, que possuem uma maior quantidade de segmentos flexíveis, as larguras dos picos foram menores se comparado ao DEG/NaLS/MDI (Figura 45b).

Os resultados obtidos no presente estudo indicam que lignopoliuretanos com grau de reticulação intermediário foram obtidos.

Figura 45 - Curvas DMA dos lignopoliuretanos não reforçados descritos no Quadro I (Experimental): (a) módulo de armazenamento (E'); e (b) módulo de perda (E’) versus temperatura.

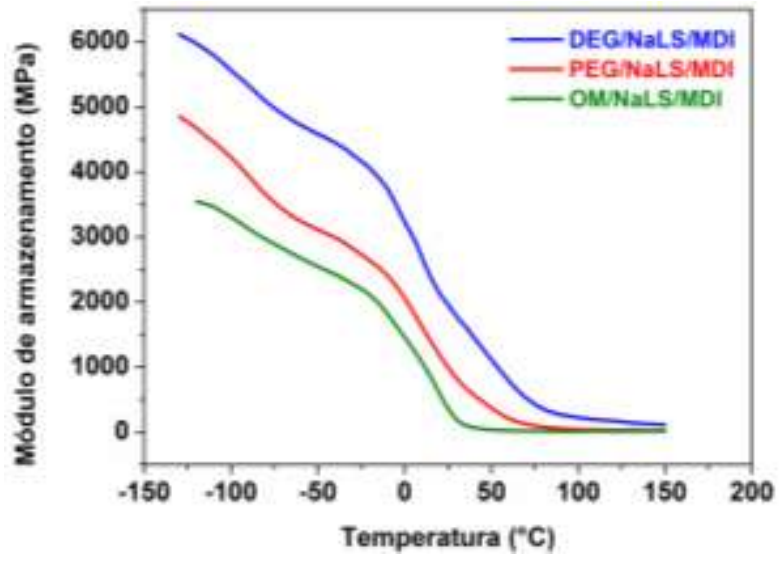

(a)

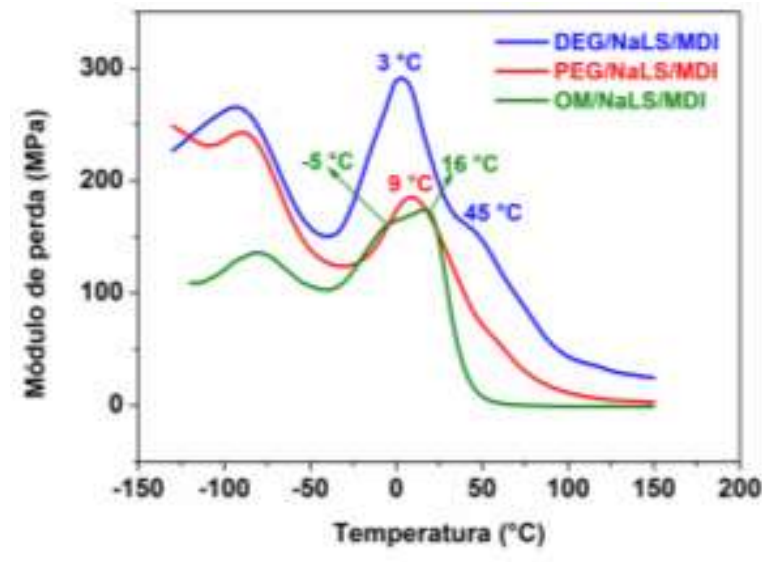

(b) 
A Figura 46 apresenta as curvas de módulo de armazenamento e módulo de perda versus a temperatura dos compósitos lignopoliuretânicos (Quadro I, Experimental). Em temperaturas acima da ambiente, o compósito DEG/NaLS/MDI/Sisal apresentou módulo de armazenamento superior aos compósitos PEG/NaLS/MDI/Sisal e OM/NaLS/MDI/Sisal (Figura 46b), seguindo a mesma tendência que esses lignopoliuretanos não reforçado nestas temperaturas. No entanto, em temperaturas subambientes, o compósito DEG/NaLS/MDI/Sisal foi o que apresentou menor módulo de armazenamento, se comparado aos compósitos PEG/NaLS/MDI/Sisal e OM/NaLS/MDI/Sisal (Figura 46a).

Figura 46 - Curvas DMA dos compósitos lignopoliuretânicos descritos no Quadro I (Experimental): (a) módulo de armazenamento (E'); e (b) módulo de perda (E’') versus temperatura.

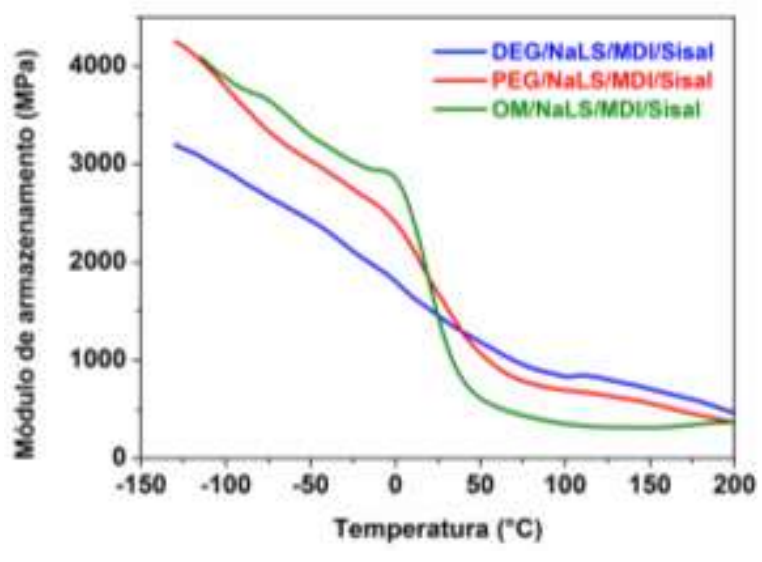

(a)

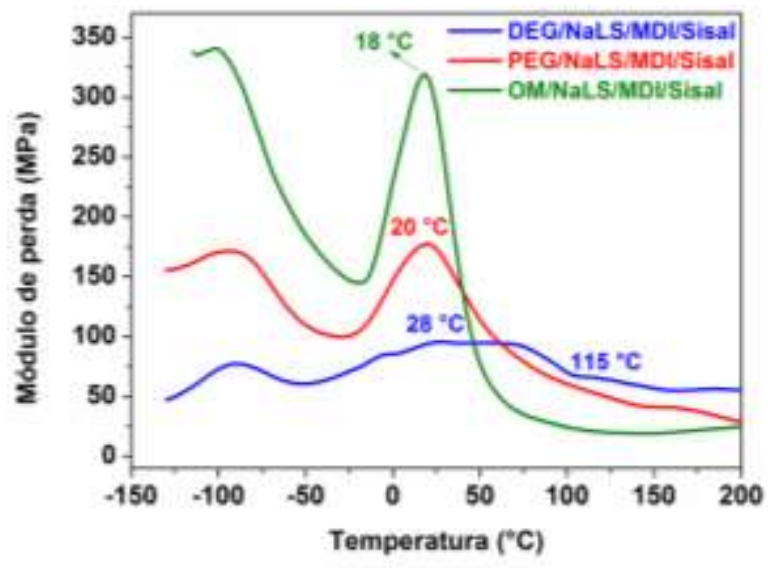

(b)

Devido à boa interação na interface fibra matriz dos compósitos lignopoliuretânicos (Figura 42), a introdução dos agentes de reforço dificultou a movimentação dos segmentos da cadeia polimérica da matriz, deslocando a temperatura de transição vítrea dos compósitos para maiores temperaturas $\left(28,20\right.$ e $18{ }^{\circ} \mathrm{C}$ para DEG/NaLS/MDI/Sisal, $\mathrm{PEG} / \mathrm{NaLS} / \mathrm{MDI} /$ Sisal e OM/NaLS/MDI/Sisal, respectivamente; Figura 46b) em relação à $\mathrm{T}_{\mathrm{g}}$ dos lignopoliuretanos não reforçados $\left(3,9\right.$ e $16{ }^{\circ} \mathrm{C}$ para DEG/NaLS/MDI, PEG/NaLS/MDI e $\mathrm{OM} / \mathrm{NaLS} / \mathrm{MDI}$, respectivamente; Figura 45b). Observou-se ainda que após a introdução das fibras, houve um alargamento do pico do compósito DEG/NaLS/MDI/Sisal (Figura 46b), se comparado ao respectivo lignopoliuretano não reforçado (DEG/NaLS/MDI, Figura 45b). 


\subsection{Grupo 2: lignopoliuretanos e respectivos compósitos à partir do NaLS, NaLS oxipropilado (LS-Oxi) e OM}

Os materiais do Grupo 2 correspondem à lignopoliuretanos preparados a partir dos seguintes polióis: NaLS, NaLS oxipropilado e OM. O NaLS foi submetido à modificação via oxipropilação (reação com OP) a fim de aumentar a reatividades de seus grupos hidroxilas frente à reação com grupos isocianatos na obtenção de lignopoliuretanos. O OM, presente em algumas formulações, foi utilizado em associação ao NaLS ou NaLS oxipropilado. Diferentemente do Grupo I, em que polióis como DEG e PEG foram utilizados, os materiais apresentados no Grupo 2 foram preparados apenas à partir de polióis obtidos a partir de fontes renováveis.

\subsection{Oxipropilação do lignossulfonato de sódio}

Comparando-se espectros de NaLS e do LS-Oxi (Figura 47), observa-se o aumento de intensidade das bandas entre 2970 e $2870 \mathrm{~cm}^{-1}$ (estiramentos $\mathrm{CH}_{3}, \mathrm{CH}_{2}$ e $\mathrm{CH}$ de grupos alifáticos); da absorção na região de estiramento das ligações CO (1000-1100 cm $\mathrm{cm}^{-1}$, associadas à ligações do tipo éter; e o aumento da banda $1376 \mathrm{~cm}^{-1}$, relacionado à introdução de grupos $\mathrm{CH}_{3}$. Estas mudanças confirmaram a ocorrência da oxipropilação (CATETO et al., 2009).

Figura 47 - Espectros na região do infravermelho do lignossulfonato de sódio (NaLS) e do lignossulfonato oxipropilado (LS-Oxi).

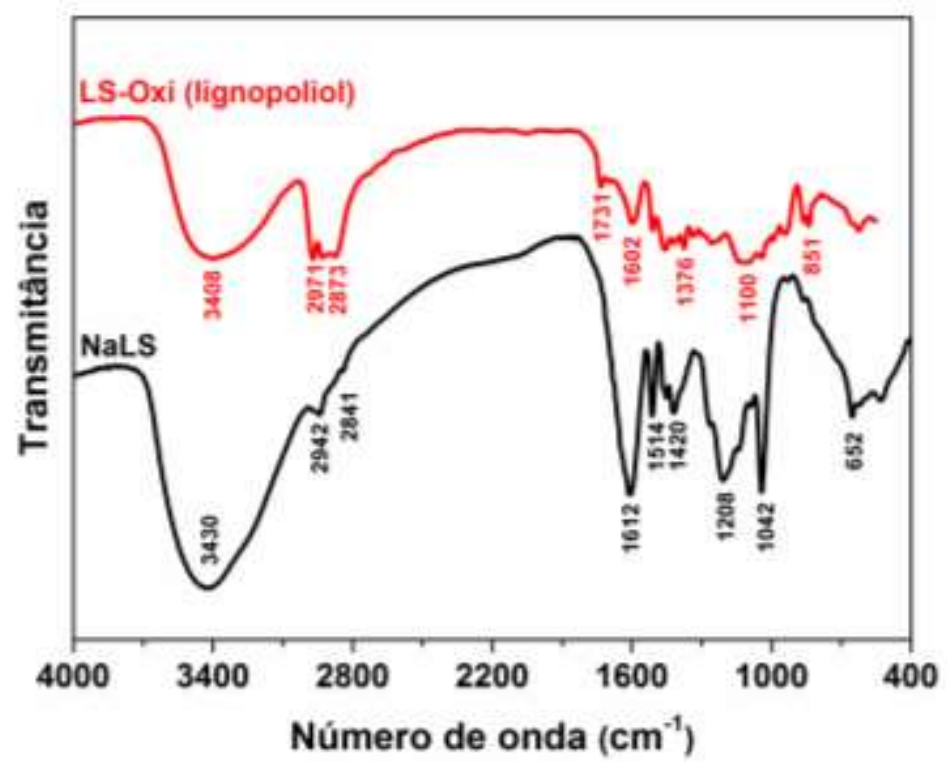


Reações com diferentes proporções NaLS/OP (25/75, 35/65, 30/70 e 40/60) foram realizadas como investigações prévias a este trabalho, com base em estudos anteriores em que outros tipos de lignina (obtidas pelos processos Kraft, soda e organosolv) foram oxipropiladas (CATETO et al., 2009; CATETO et al., 2013). A proporção 30/70 foi escolhida pelo fato de o lignopoliol resultante desta reação apresentar viscosidade adequada para realizar a mistura do lignopoliol com os demais reagentes na preparação dos compósitos lignopoliuretânico. A viscosidade aparente $\left(\eta_{\mathrm{a}}\right.$, viscosidade a uma taxa de cisalhamento $100 \mathrm{~s}^{-1}$ à $25^{\circ} \mathrm{C}$ ) deste lignopoliol, obtida diretamente da curva viscosidade versus taxa de cisalhamento (não mostrada), foi de 9,59 Pa s. Os lignopolióis resultantes da oxipropilação de lignina podem corresponder a uma mistura de lignina oxipropilada, ou NaLS oxipropilado, como no presente estudo (Figura 48a) e alguns produtos de baixa massa molecular, como os oligômeros de poli (óxido de propileno) formados pela homopolimerização do OP (CATETO et al., 2009), Figura 48b.

Figura 48 - Representação esquemática da (a) reação de oxipropilação do lignossulfonato de sódio e (b) reação de polimerização do OP iniciada por um grupo hidroxila.

(a)<smiles>COc1cc(C(C[C@H](O)C(F)F)[S](=O)([O-])[O-])ccc1O</smiles>

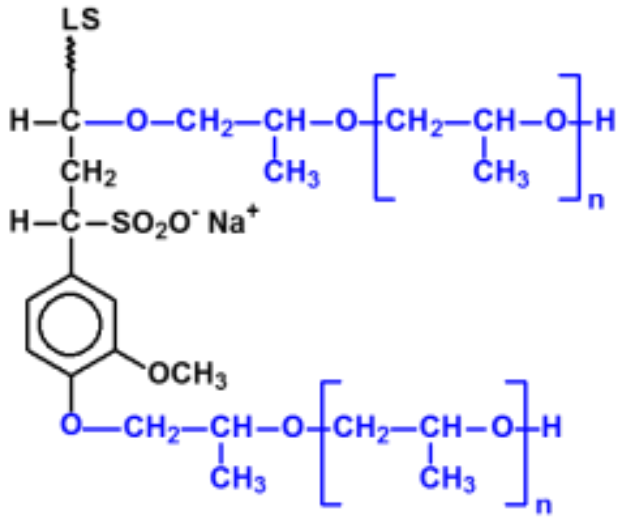<smiles>[R]C(C)(C)OCC(C)C(C)(C)O</smiles>

(b)<smiles>[R]O[SH+]=C1OC1C</smiles>

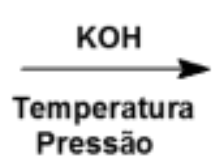

Experimentos foram previamente realizados afim de se obter 0 índice de hidroxilas do ácido lignossulfônico (forma protonada do $\mathrm{NaLS}$ ), ou seja $285 \mathrm{mg} \mathrm{KOH} \mathrm{g}$, que representa todos os sítios do NaLS onde podem ocorrer a oxipropilação, ou seja, hidroxilas alcóolicas e fenólicas, assim como hidroxilas de grupos ácidos sulfônicos que estão presentes 
na forma protonada do $\mathrm{NaLS}$. Os grupos sulfonatos $\left(-\mathrm{SO}_{3}{ }^{-}\right)$na presença de umidade, podem também reagir com o OP, gerando hidroxilas ao final das cadeias enxertadas, por exemplo [-SO $\mathrm{S}_{2} \mathrm{O}-\mathrm{CH}_{2}-\mathrm{CH}\left(\mathrm{CH}_{3}\right)-\mathrm{O}-\mathrm{CH}_{2}-\mathrm{CH}\left(\mathrm{CH}_{3}\right)-\mathrm{OH}$ ]. Como resultado da aplicação da norma ISO I4900:200 I(E), o índice de hidroxilas ( $\mathrm{I}_{\mathrm{OH}}$ ) do lignopoliol LS-Oxi foi de $574 \mathrm{mg} \mathrm{KOH} \mathrm{g}{ }^{-1}$, sendo este valor maior que o índice de hidroxilas do ácido lignossulfônico ( $285 \mathrm{mg} \mathrm{KOH} \mathrm{g}^{-1}$ ). Esse aumento pode também ser devido à presença dos oligômeros do poli (óxido de propileno), os quais contribuíram com uma determinada quantidade de hidroxilas (Figura 48b).

Estes resultados foram considerados na formulação dos lignopoliuretanos, ou seja, a quantidade de MDI usada foi suficiente para que oligômeros de poli(óxido de propileno) reagissem e se inserissem na estrutura do lignopoliuretano gerado.

\subsubsection{Espectroscopia na região do infravermelho dos lignopoliuretanos}

A Figura 49 apresenta os espectros na região do infravermelho dos lignopoliuretânicos NaLS/MDI, OM/NaLS/MDI, LS-Oxi/MDI e OM/LS-Oxi/MDI (Quadro 3). Os picos de baixa intensidade em 749 e $810 \mathrm{~cm}^{-1}$ no espectro do NaLS/MDI (Figura 49b) correspondem a vibrações C-H fora do plano de anéis aromáticos (CIOBANU et al., 2004), e aqueles em 1558 e $1539 \mathrm{~cm}^{-1}$ correspondem ao grupo $\mathrm{NH}$ e estiramento do grupo $\mathrm{CN}$, respectivamente (RISTIĆ et al., 20I2). Ainda, o pico em $2260 \mathrm{~cm}^{-1}$ pode corresponder aos grupos NCO livres nos finais de cadeia.

A variedade de polióis e de diisocianato que pode ser usada na síntese de poliuretanas faz com que picos correspondentes a grupos uretânicos, como $C=0$, possam aparecer em números de onda um tanto diferentes, dependendo da estrutura dos reagentes utilizados (RANGEL-VÁZQUEZ et al., 2009; D'SOUZA; CAMARGO; YAN, 20I4). Absorções referentes à carbonila do grupo uretano têm sido atribuídas a bandas observadas desde $1670 \mathrm{~cm}^{-1}$ (DUONG et al., 2014) até $1730 \mathrm{~cm}^{-1}$ (FARIA et al., 20I2; LI; RAGAUSKAS, 2012; SAITO et al., 20I3). Ainda, a absorção na região entre 1720 e $1730 \mathrm{~cm}^{-1}$ foi atribuída à carbonila livre, na região entre 1704 e $1709 \mathrm{~cm}^{-1}$ à carbonila em ligação hidrogênio com grupos uretano, e em torno de $1642 \mathrm{~cm}^{-1}$ à carbonila em ligação hidrogênio com grupos ureia (WANG et al., 20I3; XUE; WEN; SUN, 20I4).

No contexto do acima exposto, no lignopoliuretano NaLS/MDI a absorção da carbonila gerada pela reação de grupos hidroxila presentes no lignossulfonato deve estar 
contida na banda relativamente larga (de 1565 até $1760 \mathrm{~cm}^{-1}$ ) com máximo em $1605 \mathrm{~cm}^{-1}$ (Figura 49b). Esta atribuição é reforçada pelo fato que no espectro do lignopoliuretano OM/NaLS/MDI um ombro é em $1710 \mathrm{~cm}^{-1}$ é observado nesta banda (Figura 49a). As hidroxilas presentes na estrutura do OM geraram grupos uretanos ligados a segmentos diferentes daqueles vizinhos dos grupos uretanos gerados por hidroxilas presentes no NaLS. A natureza dos grupos vizinhos ao grupo uretana influencia na quantidade de energia necessária para ocorrer a transição entre níveis vibracionais e, portanto, no número de onda em que a respectiva absorção é observada. A baixa intensidade relacionada ao ombro observado é decorrente da baixa porcentagem de óleo na formulação deste lignopoliuretano (30\% das hidroxilas totais foram oriundas do OM, ver Experimental). O pico observado em $1400 \mathrm{~cm}^{-1}$ pode ser atribuído à formação de uretidiona devido à dimerização do MDI (DELEBECQ et al., 20I3). Os picos de baixa intensidade em 1558 e $1539 \mathrm{~cm}^{-1}$ (Figura 49b), podem ser atribuídos às ligações $\mathrm{N}-\mathrm{H}$ e $\mathrm{C}-\mathrm{N}$. 
Figura 49 - Espectros na região do infravermelho dos lignopoliuretanos NaLS/MDI, OM/LS/MDI, LS-Oxi/MDI e OM/LS-Oxi/MDI. (a) 4000-400 cm-1, (b) 2000-720 cm-1.

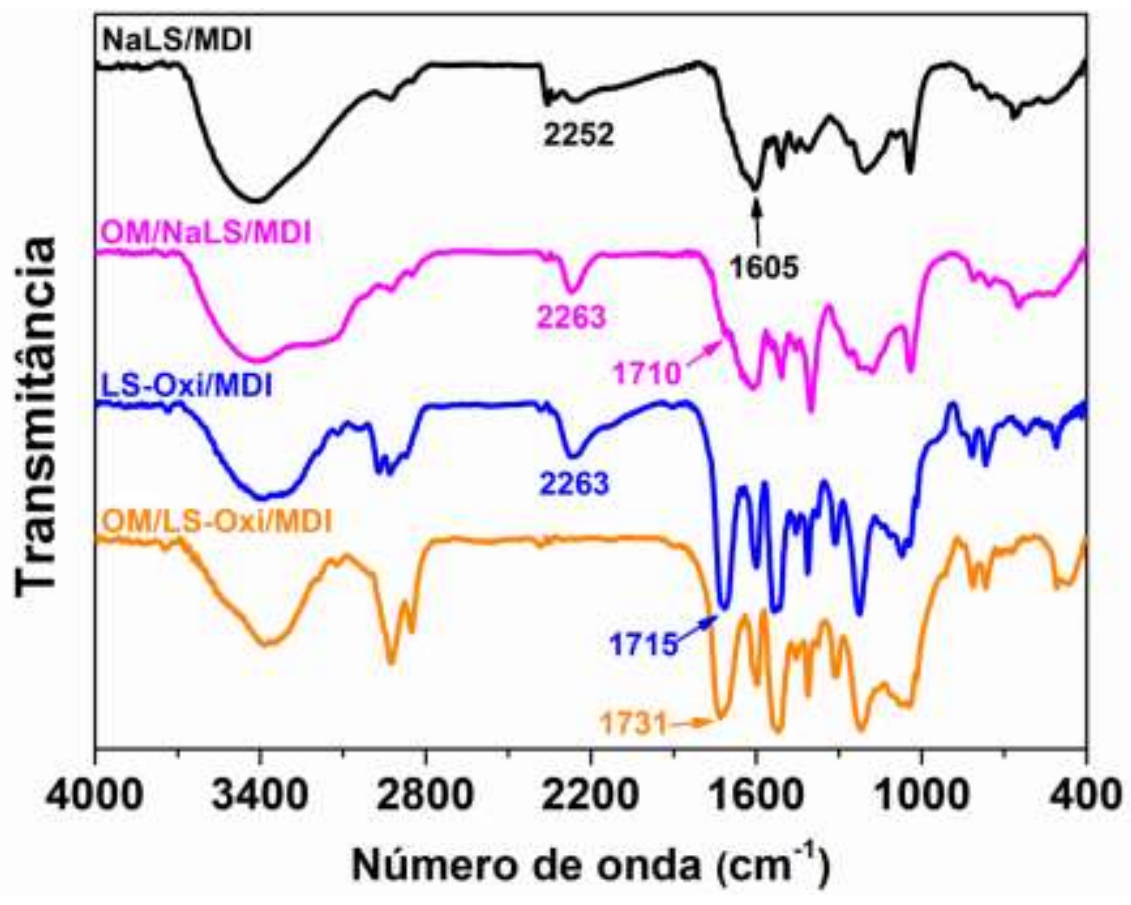

(a)

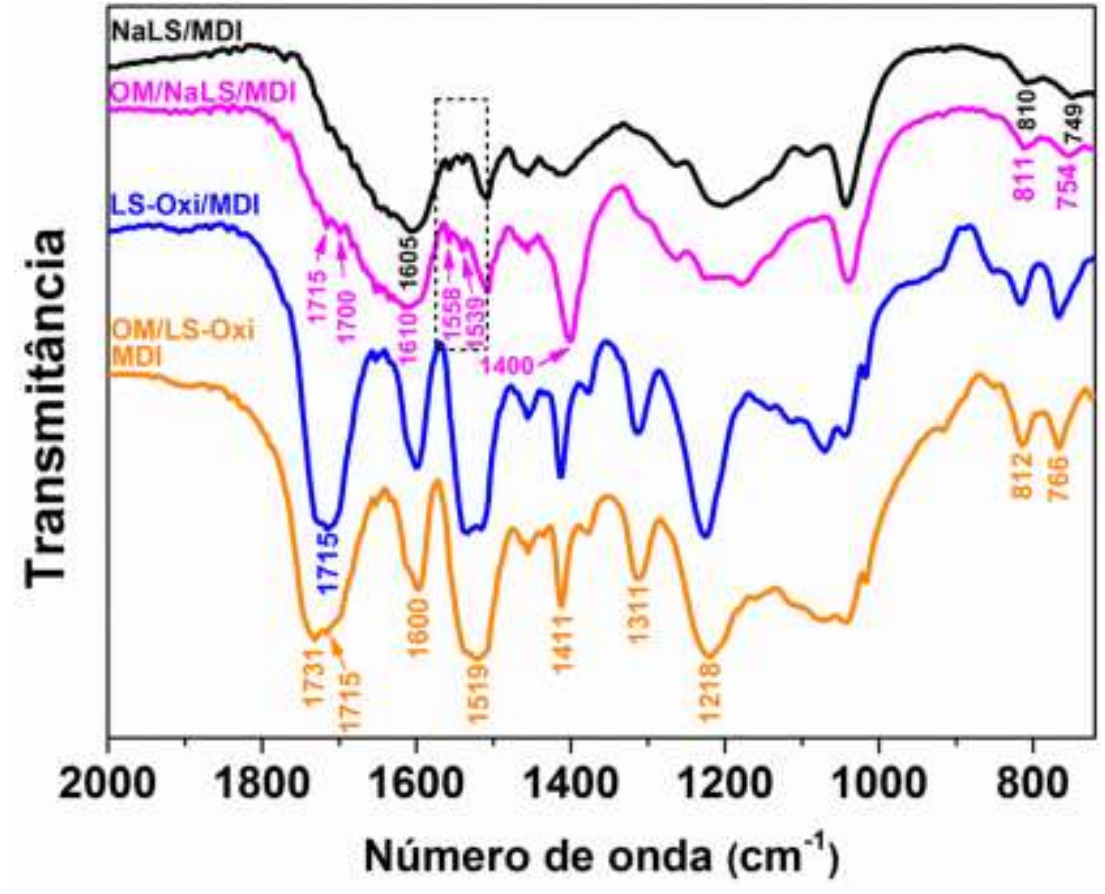

(b) 
Os espectros dos lignopoliuretanos LS-Oxi/MDI e OM/LS-Oxi/MDI são apresentados na Figura 49. Destaca-se que as hidroxilas que geraram os grupos uretanos nestes lignopoliuretanos, tinham um caráter mais homogêneo em relação àquelas presentes nos lignopoliuretanos preparados a partir de NaLS não modificado. As hidroxilas do LS-Oxi geralmente estão localizadas na extremidade de segmentos hidrocarbônicos gerados pela oxipropilação, ou seja, os vizinhos do grupo uretana formados não diferem muito entre si nesta macromolécula. No NaLS não modificado as hidroxilas estão presentes em diferentes partes da estrutura complexa do lignossulfonato. Os picos de carbonilas do grupo uretano são visualizados em 1731 e $1715 \mathrm{~cm}^{-1}$ (Figura 49a). Observa-se que o uso de OM levou a certo alargamento da banda com máximo em $173 \mathrm{I} \mathrm{cm}^{-1}$, comparativamente à banda com máximo em $1715 \mathrm{~cm}^{-1}$. A banda que vai de aproximadamente 1540 até $1507 \mathrm{~cm}^{-1}$ (Figura $49 b)$ corresponde à ligação $\mathrm{CN}$ de grupo uretano, o pico em $1411 \mathrm{~cm}^{-1}$ pode corresponder à formação de uretidionas e/ou isocianuratos, encontra-se levemente deslocado em relação ao pico semelhante encontrado no OM/NaLS/MDI $\left(1400 \mathrm{~cm}^{-1}\right)$. O pico em $1218 \mathrm{~cm}^{-1}$ pode corresponder às ligações COC de grupos éteres (RISTIĆ et al., 2012) presentes nos lignopoliuretanos preparados a partir do LS-Oxi, uma vez que na reação que levou ao lignopoliol NaLS oxipropilado podem ter sido gerado oligômeros de poli(óxido de propileno), que possui a ligação éter em sua estrutura, sendo que estes oligômeros podem ter sido incorporados na estrutura do material polimérico futuramente gerado.

A banda em $3350 \mathrm{~cm}^{-1}$ corresponde ao grupo -NH (Figura 49a). No lignopoliuretano OM/NaLS/MDI esta banda pode estar englobada pela intensa banda em torno de $3420 \mathrm{~cm}^{-1}$, presente também em $\mathrm{NaLS} / \mathrm{MDI}$, correspondente às hidroxilas não reagidas do $\mathrm{NaLS}$ (WANG et al., 2010).

Os picos na região de $2263 \mathrm{~cm}^{-1}$, observados em NaLS/MDI, OM/NaLS/MDI e LSOxi/MDI, devem corresponder a grupos NCO. O LS-Oxi/MDI foi submetido à extração com tolueno, solvente em que o MDI é solúvel, e não houve perda de massa, indicando que todo MDI utilizado na formulação foi incorporado ao material. Este resultado indica que a absorção correspondente a NCO é decorrente de grupos presentes nos finais das cadeias.

\subsubsection{Análise termogravimétrica}

A estabilidade térmica de um poliuretano é influenciada por diversos fatores, como a natureza dos reagentes de partida, densidade de ligações entrecruzadas presentes na cadeia 
e a presença de ligações hidrogênio. Tipicamente, um poliuretano forma ligações hidrogênios em toda sua extensão, sendo essas interações formadas pelo grupo NH da ligação uretânica e pelo oxigênio presente no grupo $\mathrm{C}=\mathrm{O}$ da ligação uretânica ou outros oxigênios presentes nos segmentos flexíveis. Neste estudo, a fonte de hidroxilas para obtenção de lignopoliuretanos foi variada: o NaLS, NaLS oxipropilado, oligômeros de poli(óxido de propileno) gerado na reação de oxipropilação e OM. Em todas as formulações de lignopoliuretanos do Grupo 2 de resultados, exceto o NaLS/MDI, mais de um desses reagentes estavam presentes. Esta variedade de reagentes de partida provavelmente contribuiu para a formação de uma rede espacial onde estão envolvidos diferentes segmentos e/ou grupos funcionais. Ainda, pode estar presente na estrutura destes lignopoliuretanos outros tipos de ligações cruzadas, como a formação de alofanatos e biuretos, devido à reação de isocianatos com grupos uretanos e ureias, respectivamente (LAPPRAND et al., 2005).

Até aproximadamente $180^{\circ} \mathrm{C}$ os lignopoliuretanos OM/NaLS/MDI, LS-Oxi/MDI e OM/LS-Oxi/MDI apresentaram estabilidade térmica, como mostrado nas curvas TG da Figura 50a. O lignopoliuretano NaLS/MDI apresentou uma perda de massa inicial de $8 \%$ até a temperatura de $180^{\circ} \mathrm{C}$, com pico máximo na curva $\mathrm{dTG}$ em $85^{\circ} \mathrm{C}$, que pode estar relacionado à perda de umidade.

Figura 50 - Curvas (a) TG e (b) dTG dos lignopoliuretanos não reforçados NaLS/MDI, OM/NaLS/MDI, LS-Oxi/MDI e OM/LS-Oxi/MDI, em atmosfera de $\mathbf{N}_{2}$, fluxo de $50 \mathrm{~mL} \mathrm{~min}^{-1}$ e razão de aquecimento de $10^{\circ} \mathrm{C} \mathrm{min}-1$.

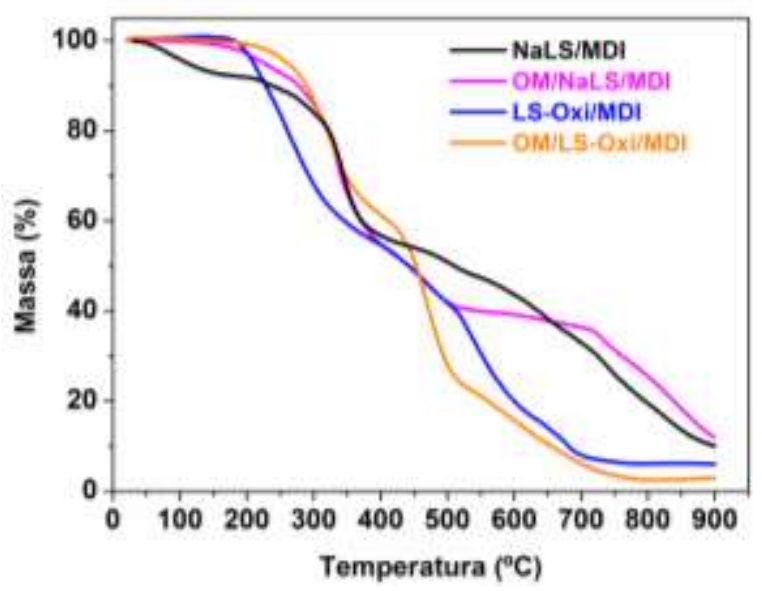

(a)

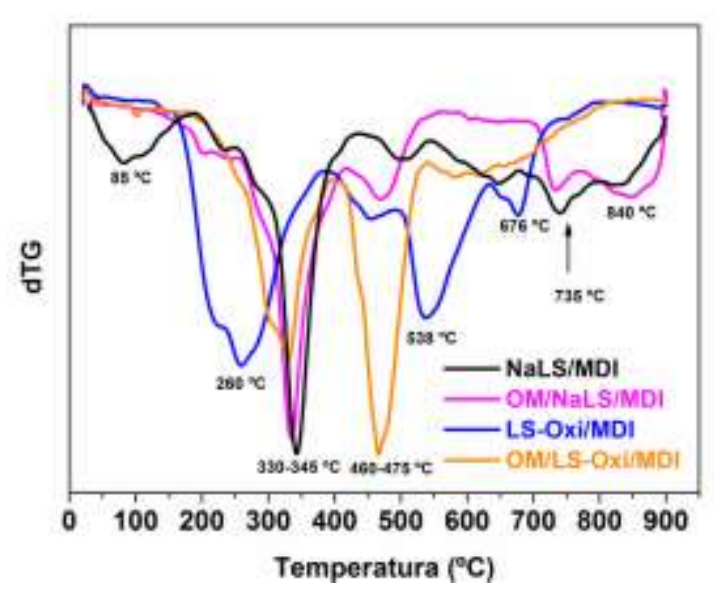

(b) 
A partir de $180^{\circ} \mathrm{C}$ tem início o processo de decomposição nestes lignopoliuretanos, sendo observados diferentes perfis de decomposição térmica, devido aos diferentes polióis usados, assim como devido à combinação destes reagentes. $O$ primeiro estágio de decomposição dos lignopoliuretanos NaLS/MDI, OM/NaLS/MDI e OM/LS-Oxi/MDI, que geralmente corresponde à quebra das ligações uretânicas, pode ser acompanhado pelos picos nas curvas dTG entre 330 e $345^{\circ} \mathrm{C}$. O lignopoliuretano LS-Oxi/MDI apresentou esse pico deslocado para temperaturas inferiores (em torno de $260^{\circ} \mathrm{C}$ ). Entre 460 e $475^{\circ} \mathrm{C}$ foi observado, em todos os lignopoliuretanos, picos que podem ser atribuídos ao segundo estágio de decomposição destes materiais, em que ocorre provavelmente a quebra de ligações dos segmentos alifáticos provenientes dos polióis [NaLS, NaLS oxipropilado, OM e oligômeros de poli(óxido de propileno)] usados em cada formulação. Em um terceiro estágio de decomposição, pode-se observar picos em $538^{\circ} \mathrm{C}$ e $676^{\circ} \mathrm{C}$ para o LS-Oxi/MDI e em 735 ${ }^{\circ} \mathrm{C}$ e $840{ }^{\circ} \mathrm{C}$ para o $\mathrm{NaLS} / \mathrm{MDI}$ e OM/NaLS/MDI. O lignopoliuretano OM/LS-Oxi/MDI não apresentou pico definido na faixa de temperatura que vai de 530 até $900{ }^{\circ} \mathrm{C}$. Neste estágio, pode ter ocorrido a decomposição de anéis aromáticos provenientes do NaLS e do diisocianato (MDI).

A Figura $5 \mathrm{I}$ apresenta as curvas TG e dTG dos compósitos obtidos pela inserção de fibras de sisal nos termorrígidos já apresentados. Os compósitos apresentaram estabilidade térmica até $180^{\circ} \mathrm{C}$, exceto o compósito LS-Oxi/MDI/Sisal cuja estabilidade vai até cerca de $150{ }^{\circ} \mathrm{C}$ (Figura $5 \mathrm{la}$ ), indicando que estes compósitos podem ser utilizados em uma ampla faixa de temperatura acima da temperatura ambiente. 
Figura 5 I - Curvas (a) TG e (b) dTG dos compósitos NaLS/MDI/Sisal, OM/NaLS/MDI/Sisal, LS-Oxi/MDI/Sisal e OM/NaLS-Oxi/MDI/Sisal; em atmosfera de $\mathrm{N}_{2}$, fluxo de $50 \mathrm{~mL} \mathrm{~min}^{-1}$ e razão de aquecimento de $10^{\circ} \mathrm{C} \mathrm{min}^{-1}$.

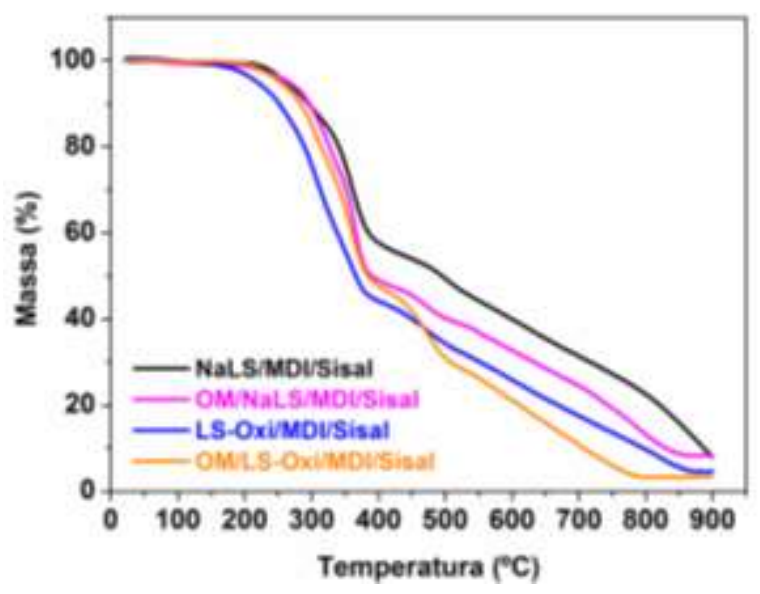

(a)

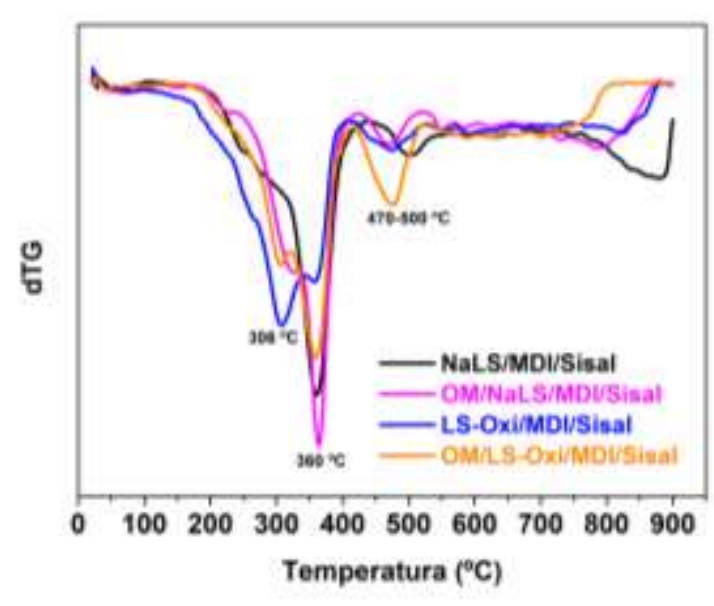

(b)

A presença de material lignocelulósico nas matrizes influencia o processo de decomposição das matrizes lignopoliuretânicas, fazendo que as curvas TG dos compósitos tivessem um padrão semelhante de decomposição térmica entre si (Figura 5la) e também contribuindo para que os picos de decomposição nas curvas dTG (Figura 5lb) também fossem semelhantes.

Os picos das curvas dTG (Figura 5lb) em torno de 306 a $320{ }^{\circ} \mathrm{C}$ podem corresponder à decomposição da hemiceluloses presente nas fibras e também à quebra das ligações uretânicas presentes nas matrizes. Os picos em $360{ }^{\circ} \mathrm{C}$ corresponde à decomposição da celulose, e pode corresponder também a dois estágios de decomposição das matrizes lignopoliuretânicas, ou seja, a quebra ainda de ligações uretânicas bem como a decomposição de segmentos flexíveis presentes nessas matrizes. Os picos entre 470 e 500 ${ }^{\circ} \mathrm{C}$ podem corresponder à decomposição dos anéis aromáticos presentes na matriz lignopoliuretano, e também daqueles presentes na lignina da fibra de sisal, presentes em menor quantidade.

\subsubsection{Resistência ao impacto}

A Figura 52a apresenta o resultado do ensaio de resistência ao impacto lzod dos lignopoliuretanos não-reforçados e dos compósitos destas matrizes reforçados com fibras de sisal (Figura 52b). Os segmentos flexíveis (soft) introduzidos quando LS-Oxi e/ou OM 
foram usados na preparação dos lignopoliuretanos (OM/NaLS/MDI, LS-Oxi/MDI e OM/LSOxi/MDI) permitiram que a energia do impacto fosse melhor dissipada, comparativamente a NaLS/MDI, e os lignopoliuretanos (OM/NaLS/MDI, LS-Oxi/MDI e OM/LS-Oxi/MDI) apresentaram resistência suficiente para serem testados. $O$ melhor resultado obtido foi para

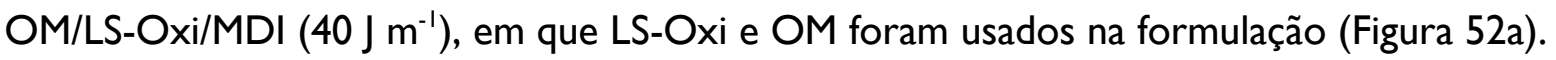

A inserção de fibras lignocelulósicas de sisal nas matrizes lignopoliuretânicas elevou consideravelmente a resistência ao impacto destes materiais, como esperado para polímeros entrecruzados quando são reforçados por fibras de sisal (MELO; PASA, 2002; MEGIATTO et al., 2008; RAMIRES; MEGIATTO; et al., 20I0; RAMIRES; DE OLIVEIRA; FROLLINI, 20I3). No caso de NaLS/MDI, não testado devido à fragilidade do material obtido (Figura 52a), a adição de sisal viabilizou a análise, embora o respectivo compósito tenha apresentado a menor resistência ao impacto $\left(145 \mathrm{~J} \mathrm{~m}^{-1}\right)$ comparativamente aos demais (Figura 52b).

A resistência ao impacto dos compósitos também foi favorecida pela presença de segmentos introduzidos por OM e/ou LS-Oxi. No entanto, no caso dos compósitos, a adesão na interface fibra/matriz tem forte influência sobre a propriedade, e a tendência não foi a mesma observada no lignopoliuretano não reforçado. O LS-Oxi/MDI/Sisal apresentou a maior resistência ao impacto (459 $\mathrm{J} \mathrm{m}^{-1}$, Figura 52b). A maior quantidade de LS-Oxi usada na formulação desta matriz, comparativamente a OM/LS-Oxi/MDI/Sisal $\left(370 \mathrm{~J} \mathrm{~m}^{-1}\right)$, introduziu maior proporção de anéis aromáticos e outros grupos apolares, assim como grupos polares, que provavelmente interagiram mais favoravelmente com domínios com características similares presentes na lignina, celulose e hemiceluloses presentes na fibra de sisal. Assim, neste compósito a carga recebida pela matriz foi transferida mais eficientemente para a fibra através da interface. Ressalta-se no entanto que a resistência ao impacto de OM/LSOxi/MDI/Sisal (370 $\mathrm{J} \mathrm{m}^{-1}$, Figura 52b) também foi significativamente mais alta que a do respectivo lignopoliuretano não reforçado $\left(40 \mathrm{Jm}^{-1}\right.$, Figura 52a), indicando boa transferência de carga da matriz para a fibra através da interface. 
Figura 52 - Resistência ao impacto Izod (corpos de prova não-entalhados): (a) lignopoliuretanos não reforçados e (b) compósitos lignopoliuretânicos reforçados com fibras de sisal; fotos que mostram o fenômeno fiber bridging observado nos compósitos LS-Oxi/MDI/Sisal e OM/LS-Oxi/MDI/Sisal.

Lignopoliuretanos não reforçados

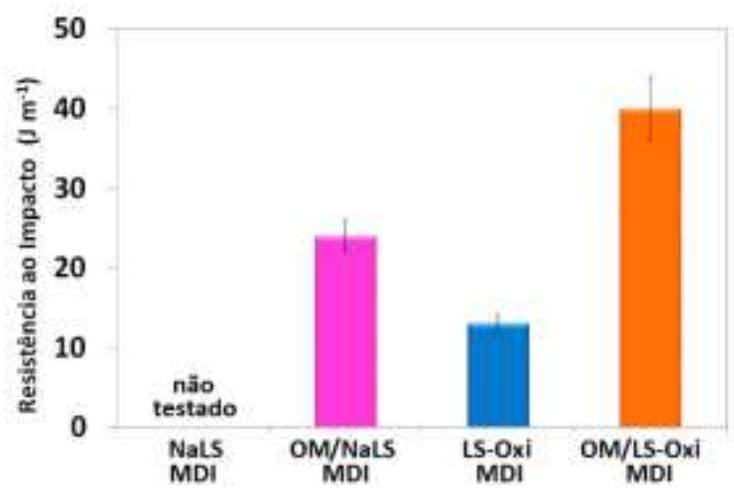

(a)
Compósitos lignopoliuretânicos

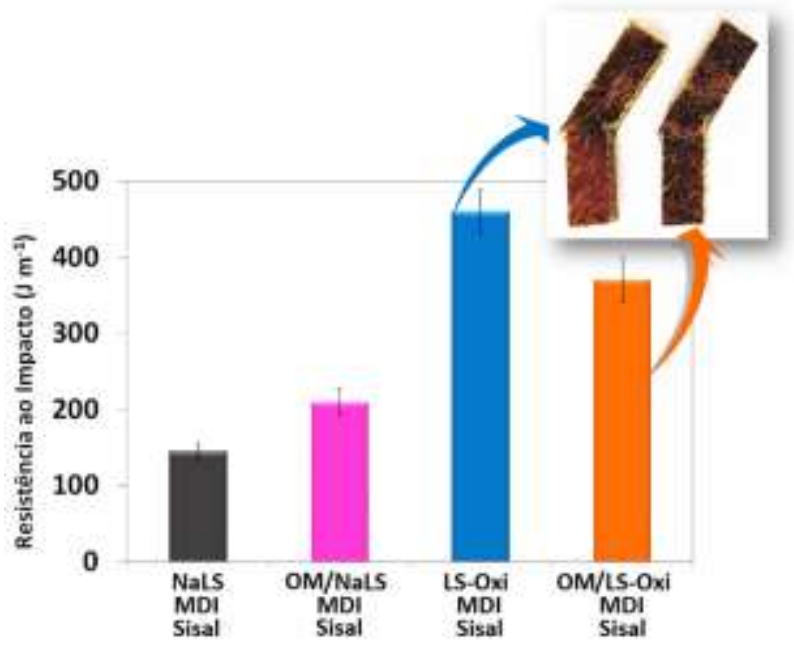

(b)

O fenômeno fiber-bridging foi observado após a fratura dos compósitos LSOxi/MDI/Sisal e OM/LS-Oxi/MDI/Sisal (Figura 52b, imagem acima do gráfico), confirmando a forte interação entre fibra e matriz na interface, pois a fibra não rompeu durante o ensaio.

\subsubsection{Microscopia eletrônica de varredura}

A Figura 53 apresenta as imagens de MEV da fratura de superfície (pós-impacto) dos lignopoliuretanos OM/NaLS/MDI, LS-Oxi/MDI e OM/LS-Oxi/MDI. A fractografia do lignopoliuretano OM/NaLS/MDI (Figura 53a) revelou uma estrutura mista com a presença de microcavidades e do tipo celular, com depressões esferoidais (PURSLOW, 1986). lignopoliuretano preparado com NaLS oxipropilado (LS-Oxi/MDI, Figura 53b) apresentou uma estrutura com indicações de coalescência das depressões esferoidais e de início de formação de marcas de rios (seta em amarelo). Já para o OM/LS-Oxi/MDI (Figura 53c), observou-se predominância de marcas de rios (setas em amarelo) na direção da fratura. A Figura 53 mostra uma mudança no mecanismo de fratura quando NaLS (Figura 53a) é substituído por LS-Oxi (Figura 53b), principalmente quando este último é combinado com OM (Figura 53c). 
Figura 53 - Imagens de MEV da superfície de fratura dos lignopoliuretanos não reforçados OM/NaLS/MDI, LS-Oxi/MDI e OM/LS-Oxi/MDI

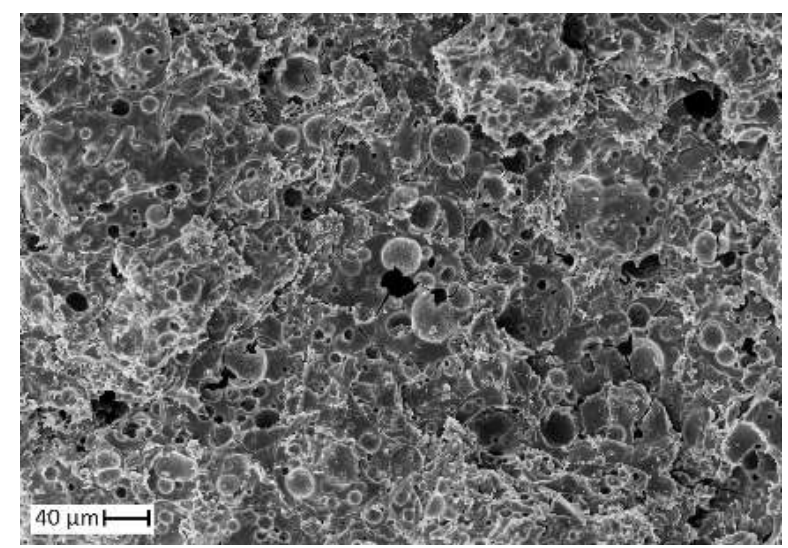

(a) $\mathrm{OM} / \mathrm{NaLS} / \mathrm{MDI}$

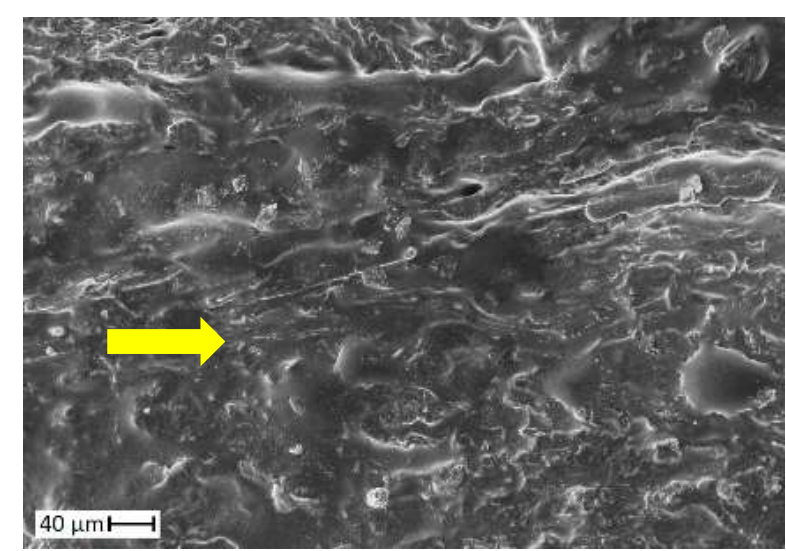

(b)LS-Oxi/MDI

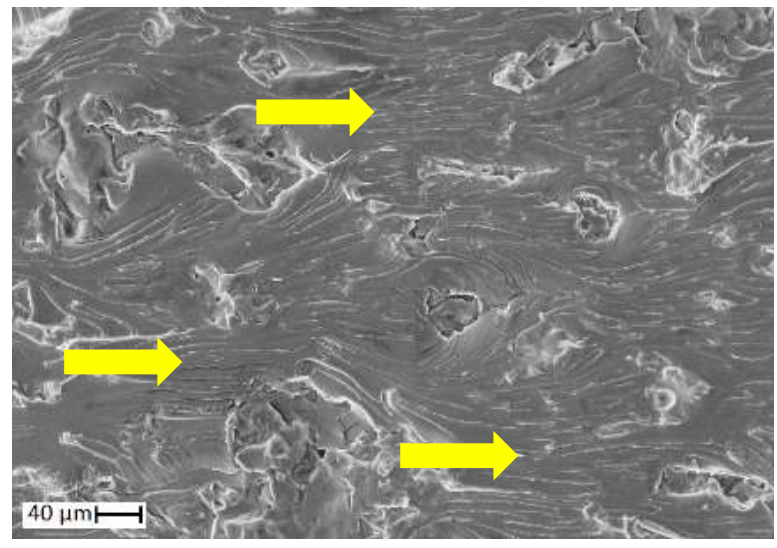

(c) OM/LS-Oxi/MDI

A Figura 54 apresenta as imagens de MEV da superfície de fratura dos compósitos lignopoliuretânicos preparados neste estudo: NaLS/MDI/Sisal, OM/NaLS/MDI/Sisal, LSOxi/MDI/Sisal e OM/LS-Oxi/MDI/Sisal. Para ter acesso à superfície de fratura de compósitos que apresentaram fiber-bridging, fenômeno em que a maior parte das fibras não rompem, as fibras que ligavam as duas partes da matriz foram cortadas com o auxílio de uma tesoura. 
Figura 54 - Imagens de MEV da superfície de fratura dos compósitos lignopoliuretânicos (Quadro 3).

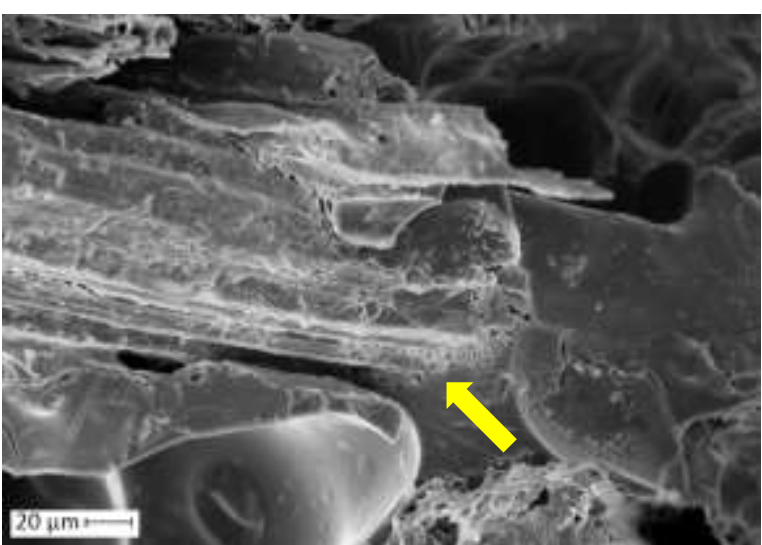

(a) $\mathrm{NaLS} / \mathrm{MDI} / \mathrm{Sisal}$

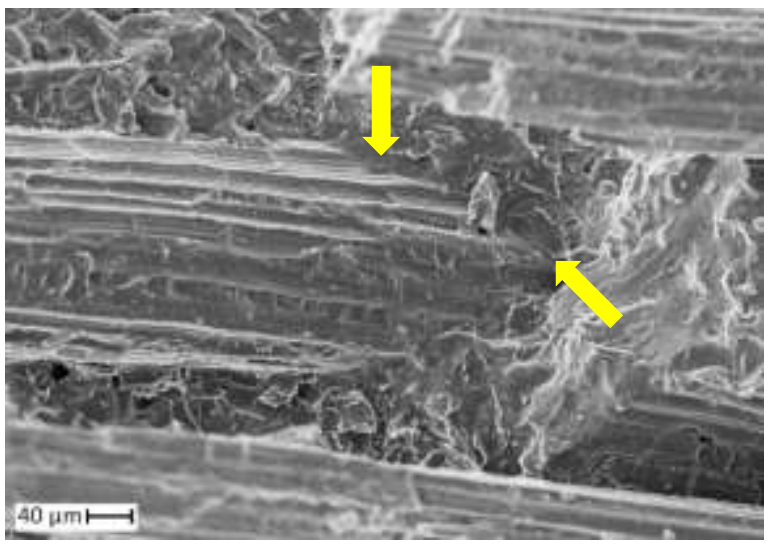

(c) LS-Oxi/MDI/Sisal

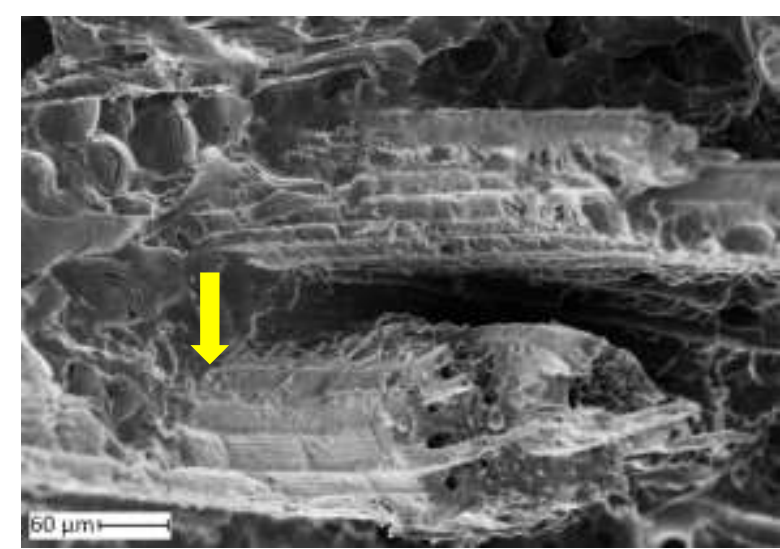

(b) OM/NaLS/MDI/Sisal

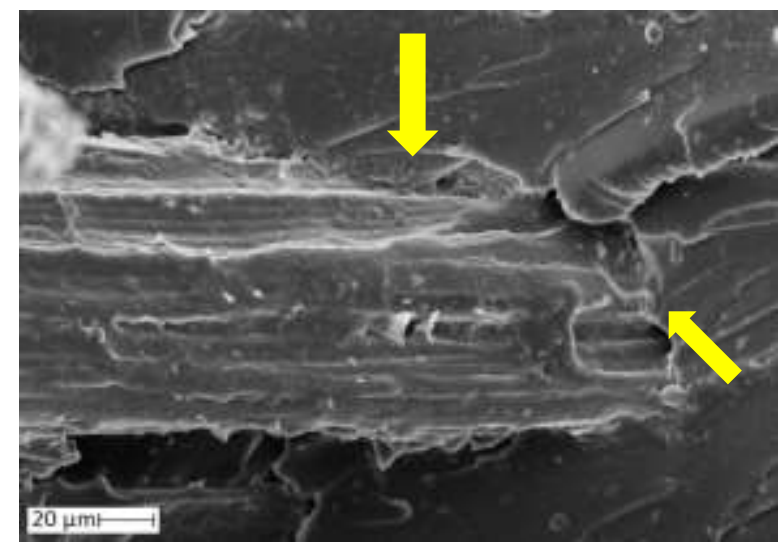

(d) OM/LS-Oxi/MDI/Sisal

A presença de fibras de sisal aleatoriamente distribuídas dificulta a detecção de sinais típicos de mecanismos de fratura. A presença de domínios polares e apolares nas matrizes, assim como nos componentes da fibra de sisal (lignina, hemiceluloses e celulose), favorece interações intermoleculares entre fibra e matriz, levando a regiões com boa adesão na interface (veja setas, Figura 54). No entanto, devido aos motivos já mencionados na discussão sobre resistência ao impacto, OM/LS-Oxi/MDI/Sisal e LS-Oxi/MDI/Sisal exibiram melhor desempenho no que se refere a esta propriedade.

\subsubsection{Resistência à flexão}

A Tabela 14 apresenta informações sobre o ensaio de flexão dos materiais preparados. Os lignopoliuretanos NaLS/MDI e LS-Oxi/MDI não foram avaliados, devido à fragilidade das respectivas placas. Foi utilizado o carregamento em um sistema de três 
pontos geralmente aplicado à materiais poliméricos rígidos e semirrígidos. O corpo de prova é defletido até que sua ruptura ocorra na superfície oposta ao carregamento. A inserção de OM na formulação do lignopoliuretano introduziu segmentos flexíveis nos materiais, diminuindo a fragilidade dele. Assim, enquanto que NaLS/MDI e LS-Oxi/MDI se mostraram muito frágil para o teste, OM/NaLS/MDI e OM/LS-Oxi/MDI puderam ser testados. A introdução de mais segmentos flexíveis devido à combinação de OM e LS-Oxi na formulação levou a um material mais flexível, com maior deformação (OM/LS-Oxi/MDI, 4,5\%, Tabela 14) e menor módulo ( $1,0 \mathrm{GPa}$, Figura 55b), comparativamente a OM/NaLS/MDI (0,9\% e 2,6 $\mathrm{GPa})$.

Tabela I 4 - Fratura e deformação durante o ensaio de flexão (sistema de 3 pontos) para os lignopoliuretanos não reforçados e respectivos compósitos.

\begin{tabular}{|c|c|c|}
\hline & Material & Deformação máxima (\%) \\
\hline \multirow{4}{*}{ 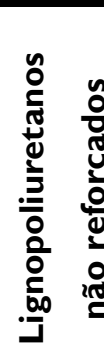 } & NaLS/MDI* & não testado \\
\hline & OM/NaLS/MDI & $0,9 \pm 0,1$ \\
\hline & LS-Oxi/MDI* & não testado \\
\hline & OM/LS-Oxi/MDI & $4,5 \pm 0,3$ \\
\hline \multirow{4}{*}{ 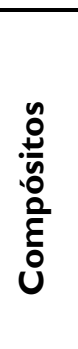 } & NaLS/MDI/Sisal & $1,7 \pm 0,2$ \\
\hline & OM/NaLS/MDI/Sisal & $1,9 \pm 0,3$ \\
\hline & LS-Oxi/MDI/Sisal & $2,9 \pm 0,8$ \\
\hline & OM/LS-Oxi/MDI/Sisal & $5,0 * *$ \\
\hline
\end{tabular}

A inserção das fibras de sisal nas matrizes NaLS/MDI e LS-Oxi/MDI levou a materiais mais resistentes, sendo possível obter corpos de prova para o ensaio de flexão, sendo que os respectivos compósitos apresentaram $42 \mathrm{MPa}$ e $43 \mathrm{MPa}$ como resistência a flexão. $\mathrm{A}$ adição de fibras de sisal ao lignopoliuretano OM/NaLS/MDI (16 MPa) aumentou a forma significativa a resistência à flexão do material (OM/NaLS/MDI/Sisal, $37 \mathrm{MPa}$ ). No caso de OM/LS-Oxi/MDI/Sisal, o material foi avaliado na deformação máxima de 5,0\% pois não 
rompeu até este ponto. Nesta deformação, o material exibiu resistência à flexão próxima à do respectivo lignopoliuretano (em torno de $38 \mathrm{MPa}$ ).

O uso de OM e/ou LS-Oxi na formulação da matriz lignopoliuretânica levou a materiais menos rígidos, com menor módulo, sendo que OM/LS-Oxi/MDI/Sisal, que não rompeu durante o ensaio, apresentou o menor módulo (Figura 55b).

Figura 55 - (a) Resistência à flexão e (b) Módulo de flexão dos lignopoliuretanos não reforçados e dos compósitos lignopoliuretânicos reforçados com fibras de sisal (Quadro 3 - Experimental).

\section{Lignopoliuretanos não reforçados}

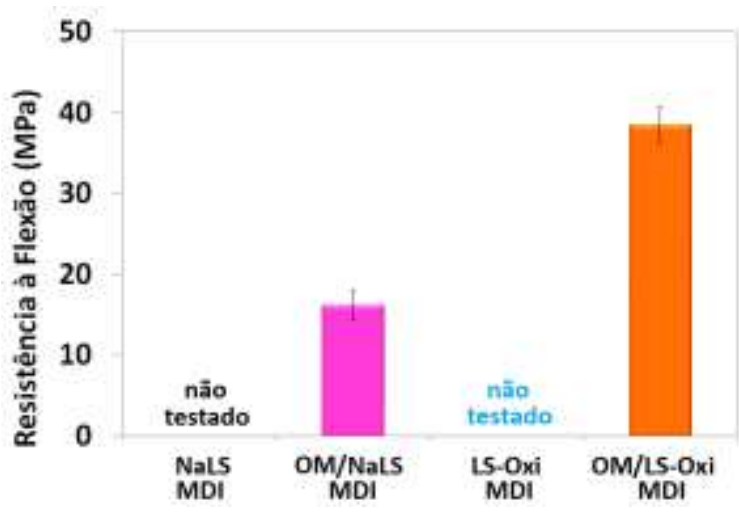

\section{Compósitos lignopoliuretânicos}

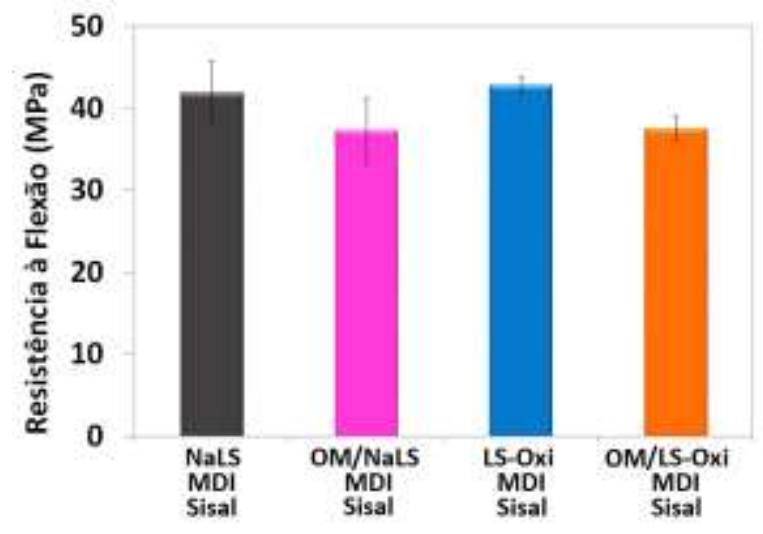

(a)

\section{Lignopoliuretanos não reforçados}

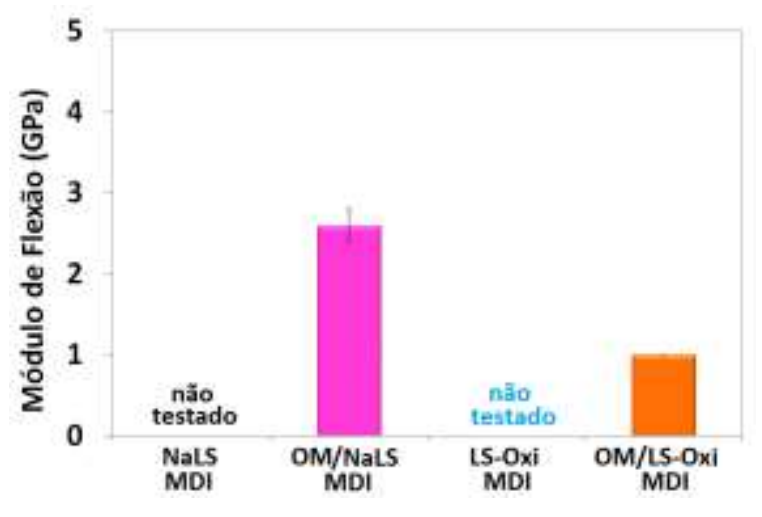

Compósitos lignopoliuretânicos

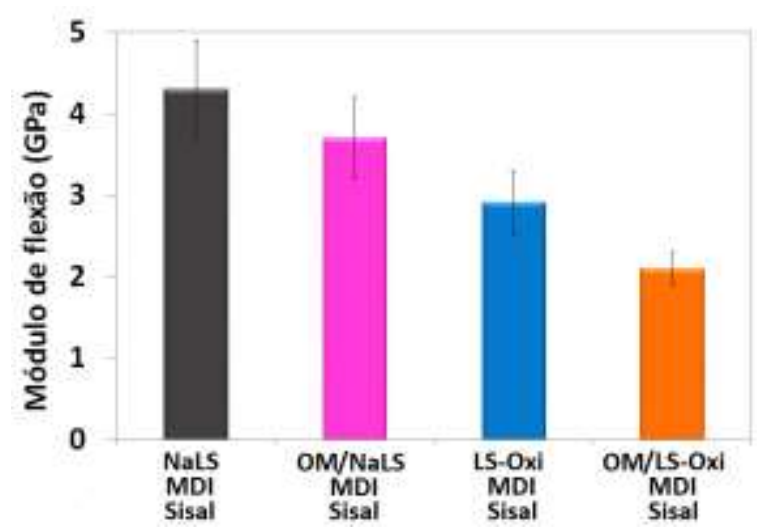

(b)

De modo geral, tanto a resistência à flexão (Figura 55a) como o módulo de flexão (Figura 55b) seguiram a mesma tendência para os materiais avaliados. A inserção das fibras de sisal em todas as matrizes aumentou a rigidez em todos os materiais, característica que é expressa pelo módulo de flexão. 


\subsubsection{Análise térmica dinâmico-mecânica (DMA)}

A Figura 56 mostra as curvas de módulo de armazenamento (E'), módulo de perda (E”) e versus temperatura dos lignopoliuretanos OM/NaLS/MDI, LS-Oxi/MDI e OM/LSOxi/MDI. A fragilidade de NaLS/MDI não permitiu a obtenção dos corpos de prova requisitados para esta análise.

Em temperaturas subambientes, os lignopoliuretanos OM/NaLS/MDI e LS-Oxi/MDI apresentaram módulo de armazenamento mais elevados, se comparados ao lignopoliuretano OM/LS-Oxi/MDI, como pode ser observado na Figura 56a. Devido ao uso de OM em OM/LS-Oxi/MDI, ocorreu um aumento nos segmentos flexíveis presentes, pois os segmentos oriundos do OM se somaram aos introduzidos pelo uso de LS-Oxi na formulação (Figura 48a), o que justifica o comportamento deste material até aproximadamente $25^{\circ} \mathrm{C}$.

Figura 56 - Curvas DMA dos lignopoliuretanos não reforçados (Quadro 3 Experimental): (a) Módulo de armazenamento (E') versus temperatura e (b) Módulo de perda (E”) versus temperatura.

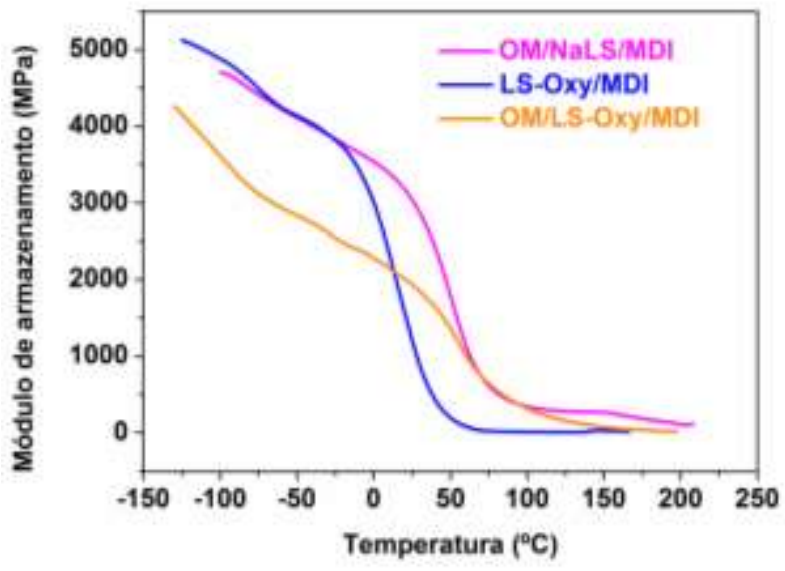

(a)

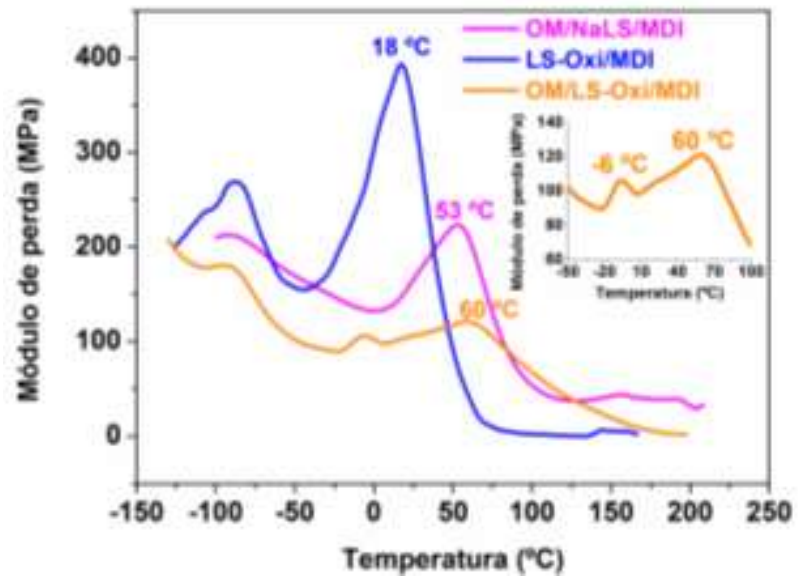

(b)

Os picos observados a 18 e $53^{\circ} \mathrm{C}$ nas curvas do módulo de perda (Figura 56b) podem ser atribuídos à temperatura de transição vítrea $\left(\mathrm{T}_{\mathrm{g}}\right)$ de LS-Oxi/MDI e $\mathrm{OM} / \mathrm{NaLS} / \mathrm{MDI}$, respectivamente. $\mathrm{A}$ introdução de segmentos flexíveis no NaLS através da oxipropilação, a qual gerou o LS-Oxi, fez com que o uso deste último na preparação do lignopoliuretano resultasse em um material com menor $\mathrm{T}_{\mathrm{g}}$. Adicionalmente, os segmentos introduzidos pelo poli(óxido de propileno) também contribuíram para este efeito sobre $T_{g}$. 
Quando OM e LS-Oxi foram usados na formulação do lignopoliuretano (OM/LSOxi/MDI) observou-se um pico a $-6^{\circ} \mathrm{C}$, o qual pode ser atribuído principalmente à mobilidade dos segmentos inseridos por $\mathrm{CO}$, e um pico largo, com início em torno de $7^{\circ} \mathrm{C} \mathrm{e}$ máximo em torno de $60^{\circ} \mathrm{C}$, o qual deve englobar a movimentação dos segmentos restantes mais rígidos, incluindo aqueles introduzidos por LS-Oxi (Figura 56b, quadro superior inserido).

As $T_{g} s$ de PUs depende da natureza e da composição de segmentos rígidos e flexíveis. Em estudos envolvendo PUs entrecruzados, obtidas a partir de diferentes polióis, isocianatos e extensores de cadeia, foram obtidas $\mathrm{Tg}$ em amplo intervalo, ou seja de $-17^{\circ} \mathrm{C}$ até $107^{\circ} \mathrm{C}$ (RATNA, 2012). Os resultados obtidos no presente estudo indicam que lignopoliuretanos com grau de reticulação intermediário foram obtidos.

A Figura 57 mostra as curvas de módulo de armazenamento (E'), módulo de perda (E”) e versus temperatura dos compósitos lignopoliuretânicos NaLS/MDI/Sisal, OM/NaLS/MDI/Sisal, LS-Oxi/MDI/Sisal e OM/LS-Oxi/MDI/Sisal.

Figura 57 - Curvas DMA dos compósitos lignopoliuretânicos (Quadro 3): (a) Módulo de armazenamento (E') versus temperatura e (b) Módulo de perda (E") versus temperatura.

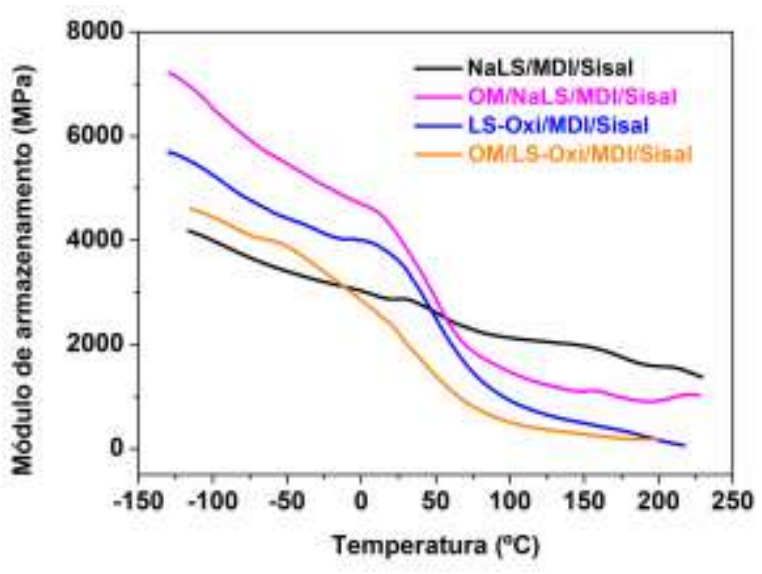

(a)

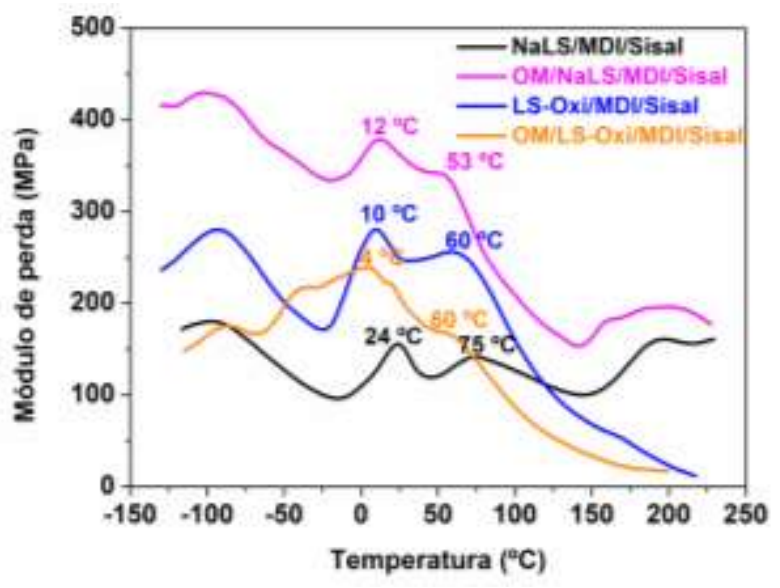

(b)

A maioria dos compósitos lignopoliuretanos apresentaram valores de módulo de armazenamento superiores aos respectivos lignopoliuretanos não reforçados (Figura 57a). A presença das fibras de sisal pode dificultar a movimentação dos segmentos poliméricos, fazendo com que o módulo de armazenamento aumente. Conforme já observado nos 
resultados do ensaio de flexão (Figura 55b), a inserção das fibras de sisal nos lignopoliuretanos também aumenta a rigidez destes materiais.

A introdução dos fibras de sisal provocou um alargamento nas curvas de módulo de perda dos compósitos lignopoliuretânicos (Figura 57b). Em todas estas curvas foi possível observar mais de um pico (às vezes na forma de ombro), que podem representar transições dos diferentes segmentos presentes no lignopoliuretanos, assim como transições relacionadas à inserção das fibras. Provavelmente, os segmentos das cadeias da matriz que se encontravam mais distantes da interface tiveram maior facilidade de movimentação que aqueles que se encontravam na interface fibra-matriz, devido às interações entre fibra e matriz, que dificultam a mobilidade das cadeias poliméricas. Assim, a introdução das fibras nestes lignopoliuretanos provocou esse alargamento na curva de módulo de perda, já que segmentos com diferentes características estão presentes.

\subsection{Grupo 3: lignopoliuretanos e respectivos compósitos a partir do NaLS hidroxialquilado (NaLS-Glu e NaLS-For)}

No Grupo 3, assim como no Grupo 2, todos os lignopoliuretanos foram preparados a partir de polióis oriundos de fonte renovável: NaLS, NaLS hidroxialquilado e OM. A modificação realizada no NaLS foi a hidroxialquilação (reação com glutaraldeído e formaldeído) e lignopoliuretanos e respectivos compósitos foram preparados a partir do lignossulfonato modificado com glutaraldeído (NaLS-Glu) e lignossulfonato modificado com formaldeído (NaLS-For). O óleo de mamona foi associado ao $\mathrm{NaLS}$ ou $\mathrm{NaLS}$ hidroxialquilados em algumas formulações.

\subsection{Hidroxialquilação do lignossulfonato de sódio}

Os espectros na região de infravermelho do lignossulfonato de sódio não modificado (NaLS), lignossulfonato modificado com formaldeído (NaLS-For) e lignossulfonato modificado com glutaraldeído (NaLS-Glu) são mostrados na Figura 58. 
Figura 58 - Espectro na região de infravermelho do lignossulfonato de sródio (NaLS), lignossfulfonato de sódio modificado com formaldeído (NaLS-For) e lignossulfonato de sódio modificado com glutaraldeído (NaLS-Glu).

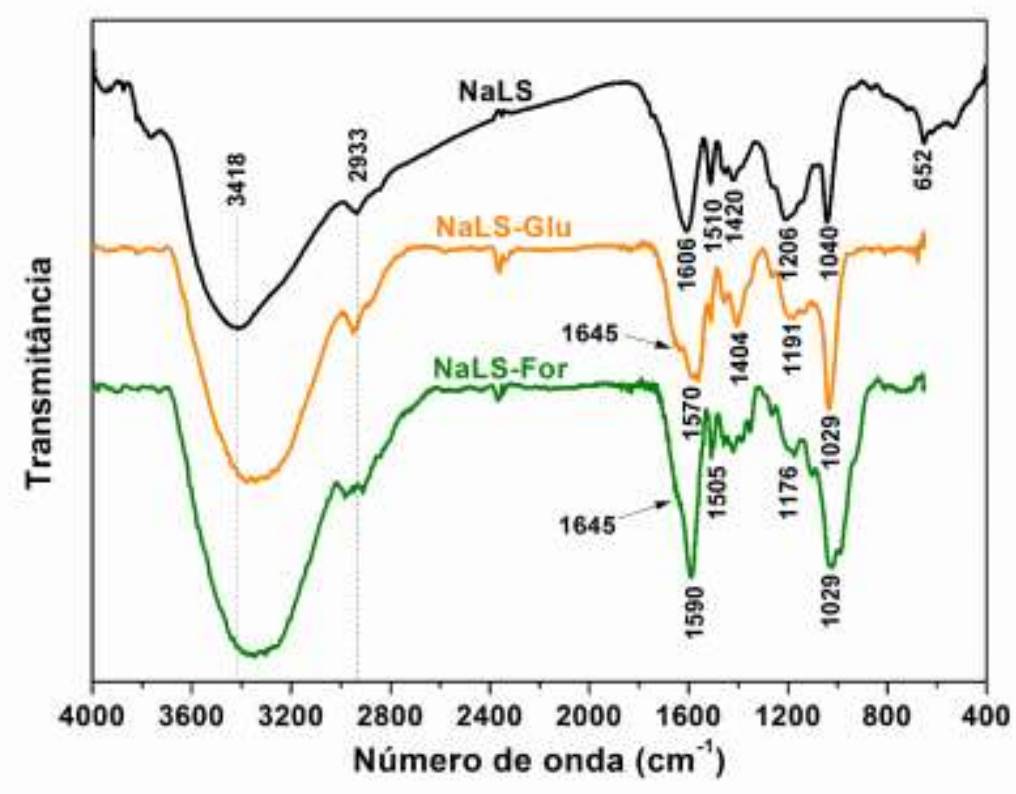

Após a modificação do lignossulfonato de sódio foi possível perceber deslocamentos de algumas bandas como o de $1606 \mathrm{~cm}^{-1}$ do NaLS (que corresponde à deformação do anel aromático) que desloca para 1590 e $1570 \mathrm{~cm}^{-1}$ no NaLS-For e NaLS-Glu, respectivamente. A banda que aparece em $1206 \mathrm{~cm}^{-1}$ (estiramento $\mathrm{S}=0$ do grupo sulfônico) no espectro do NaLS, teve um pequeno deslocamento e se tornou menos intenso após a modificação do mesmo, tanto com glutaraldeído $\left(1191 \mathrm{~cm}^{-1}\right)$ quanto formaldeído $\left(1176 \mathrm{~cm}^{-1}\right)$. A banda em $1040 \mathrm{~cm}^{-1}$ (estiramento C-O em lignossulfonatos) no NaLS, se deslocou para $1029 \mathrm{~cm}^{-1}$ nos lignossulfonatos modificados. As modificações com glutaraldeído e formaldeído inserem cadeias hidrocarbônicas e grupo hidroxilas no NaLS, como mostrado na Figura 20, estes grupos e estruturas inseridas não diferem daqueles já presentes na estrutura do NaLS. Detalhes do espectro do NaLS já foram mostrados na Tabela 7 (item 4.2.I).

\subsubsection{Espectroscopia na região do infravermelho dos lignopoliuretanos (Quadro 5)}

Como pode ser observado na Figura 59, os lignopoliuretanos OM/NaLS-Glu/MDI e OM/NaLS-For/MDI apresentaram a banda característica de carbonila de grupo uretano em $1737 \mathrm{~cm}^{-1}$. Como já discutido no item 4.4.2, o sinal da carbonila de grupo uretânico pode ser 
encontrado deslocados daqueles sinais tradicionalmente conhecidos, devido à influência dos grupos vizinhos ligados ao grupo carbonila. Assim, para os lignopoliuretanos preparados com lignossulfonato hidroxialquilado (NaLS-Glu/MDI e NaLS-For/MDI), a absorção relacionada à carbonila uretânica deve estar contida na banda que vai de 1545 até $1800 \mathrm{~cm}^{-1}$, com máximo em $1600 \mathrm{~cm}^{-1}$. Nesta região, o espectro do lignopoliuretano NaLS-Glu/MDI possui um ombro em $1718 \mathrm{~cm}^{-1}$, indicando a presença da carbonila de ligação uretânica, porém, deslocada em relação ao pico correspondente dos lignopoliuretanos preparados com OM $\left(1737 \mathrm{~cm}^{-1}\right)$. Para o NaLS-For/MDI observa-se também um ombro próximo à $1766 \mathrm{~cm}^{-1}$, que pode indicar a presença de carbonila. Ainda, no NaLS-For/MDI a banda em $1600 \mathrm{~cm}^{-1}$, que corresponde à deformação $\mathrm{C}=\mathrm{C}$ em anel aromático e que deve conter a absorção da carbonila, aparece mais intensa que nos demais lignopoliuretanos (NaLS-ForMDI, CO/NaLSFor/MDI e CO/NaLS-Glu/MDI, Figura 59).

Figura 59 - Espectros na região de infravermelho dos lignopoliuretanos OM/NaLSGlu/MDI, OM/NaLS-Glu-FOR/MDI, NaLS-Glu/MDI e NaLS-For/MDI.

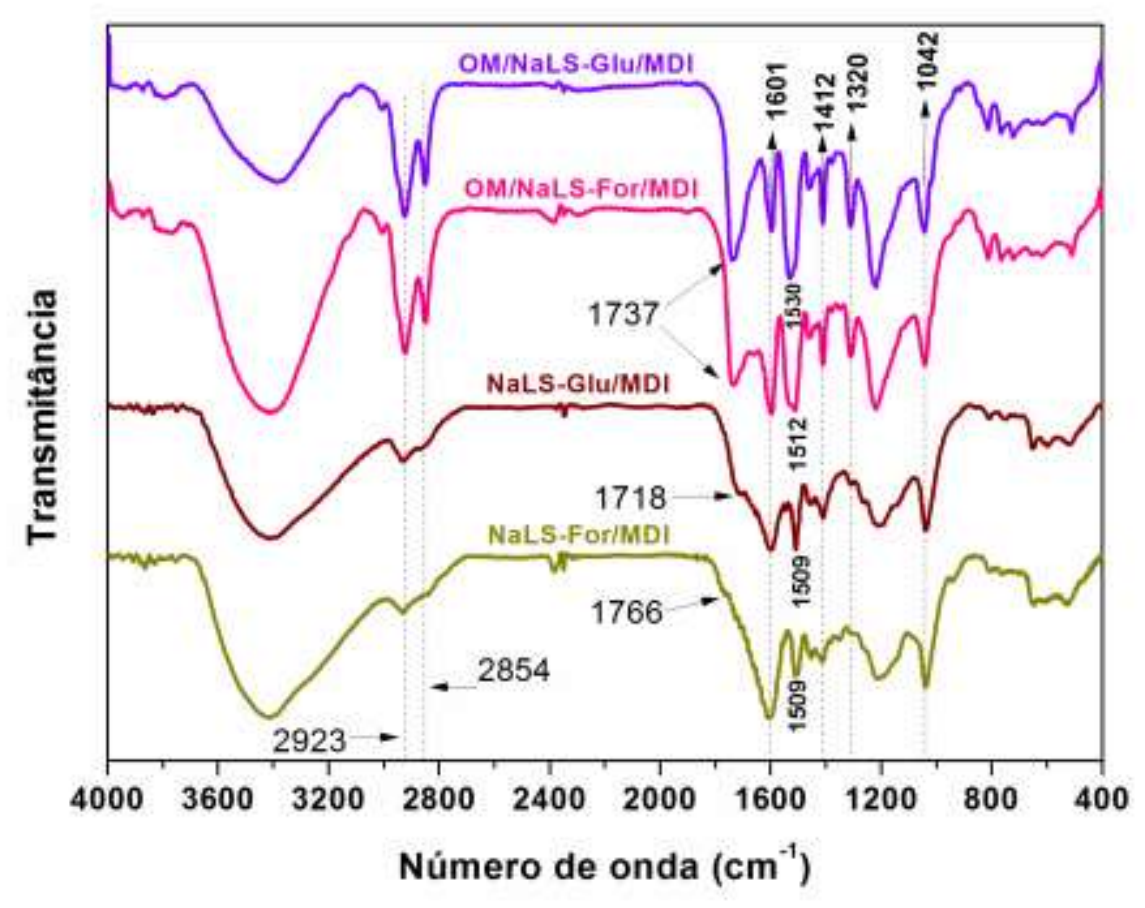

Em todos os lignopoliuretanos da Figura 59 é possível observar bandas na região entre 1509 e $1530 \mathrm{~cm}^{-1}$. Bandas na região de $1535 \mathrm{~cm}^{-1}$ são características de ligação $\mathrm{C}-\mathrm{N}$ em grupos uretanos (CORCUERA et al., 2010). Assim, a presença de picos nessa região, 
mesmo que deslocadas, indica que essa ligação está presente nestes materiais. Para os lignopoliuretanos NaLS-Glu/MDI e NaLS-For/MDI a banda nesta região (1509 cm $)$ aparece com menor intensidade se comparada aos lignopoliuretanos preparados com OM (OM/NaLS-Glu/MDI e OM/NaLS-For/MDI).

Uma importante observação que deve ser feita, é que em todos os materiais preparados, não foi observado nenhum sinal próximo de $2270 \mathrm{~cm}^{-1}$, que corresponde ao grupo NCO, ou seja, de grupos isocianatos livres.

\subsubsection{Análise termogravimétrica}

Na Figura 60 são mostradas as curvas TG e dTG para lignopoliuretanos descritos no Quadro 5 (Experimental). As curvas para o lignopoliuretano e compósito preparados a partir de $\mathrm{OM} / \mathrm{NaLS} / \mathrm{MDI}$ não são mostradas, pois os eventos são semelhantes aos apresentados na Figura 37f, uma vez que se trata do mesmo tipo de material (com NaLS e OM em sua estrutura).

As curvas TG dos lignopoliuretanos (OM/NaLS-Glu/MDI, NaLS-Glu/MDI, OM/NaLSFor/MDI e NaLS-For/MDI; Figura 60) mostraram que a decomposição destes materiais iniciou em torno de $190{ }^{\circ} \mathrm{C}$, indicando estabilidade térmica do material até essa temperatura.

Figura 60 - Curvas (a) TG e (b) dTG para lignopoliuretanos (Grupo 3); em atmosfera de $\mathrm{N}_{2}$, fluxo de $50 \mathrm{~mL} \mathrm{~min}^{-1}$ e razão de aquecimento de $10^{\circ} \mathrm{C} \mathrm{min}^{-1}$.

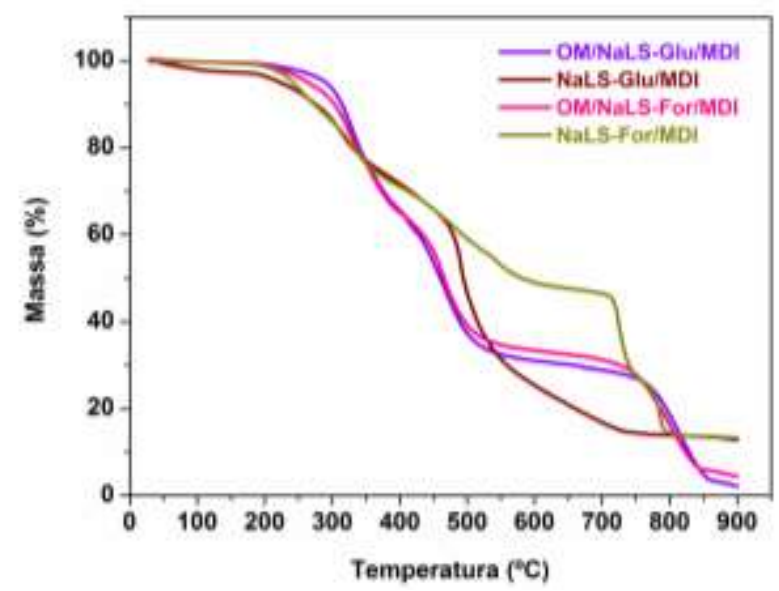

(a)

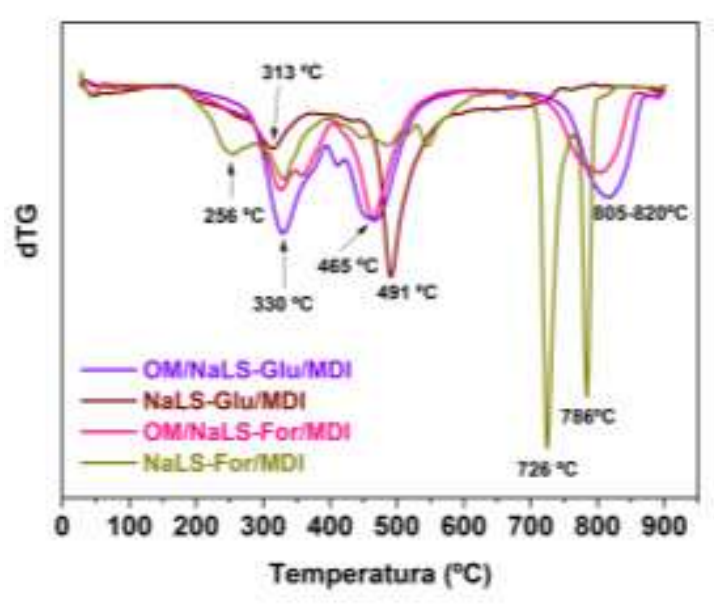

(b)

Os lignopoliuretanos preparados com OM (OM/NaLS-Glu e OM/NaLS-For/MDI, Figura 60b), apresentaram curvas TG e dTG semelhantes, indicando que os processos de 
decomposição nestes materiais foram similares. Nas dTG dos lignopoliuretanos OM/NaLSGlu e OM/NaLS-For/MDI (Figura 60b) observou-se três picos, onde as velocidades de decomposição foram máxima: o primeiro em torno de $330{ }^{\circ} \mathrm{C}$, relacionado à quebra das ligações uretânicas; o segundo em torno de $465{ }^{\circ} \mathrm{C}$, relacionado à decomposição de segmentos flexíveis (oriundos em grande parte do OM); e um terceiro pico em $805{ }^{\circ} \mathrm{C}$ $\left(\mathrm{OM} / \mathrm{NaLS}\right.$-For/MDI) e $820^{\circ} \mathrm{C}(\mathrm{OM} / \mathrm{NaLS}-\mathrm{Glu} / \mathrm{MDI})$, relacionado à decomposição de anéis aromáticos oriundos do MDI e do NaLS.

No lignopoliuretano NaLS-Glu/MDI, que não possui $O M$ em sua estrutura, apenas dois picos na curva dTG foram observados (Figura 60b), o primeiro em $313^{\circ} \mathrm{C}$ e o segundo em 49I ${ }^{\circ} \mathrm{C}$. As curvas TG (Figura 60a) mostraram que a decomposição do NaLS-For/MDI seguiu um perfil semelhante ao do lignopoliuretano NaLS-Glu/MDI até cerca de $470{ }^{\circ} \mathrm{C}$. A partir desta temperatura, há uma mudança no perfil de decomposição destes materiais, no entanto, ambos resultam em resíduo de aproximadamente $14 \%$ à $900{ }^{\circ} \mathrm{C}$. Nas temperaturas finais da curva dTG (Figura 60a) do lignopoliuretano NaLS-For/MDI foram observados dois picos de decomposição em $726^{\circ} \mathrm{C}$ e $786^{\circ} \mathrm{C}$, que podem ser relacionados aos dois picos de decomposição final de estruturas típicas de lignossulfonato (Figura 30).

A Figura 61 apresenta as curvas TG e dTG para os compósitos lignopoliuretânicos descritos no Quadro 4. A estabilidade térmica dos compósitos que possuem o $O M$ em sua formulação (OM/NaLS-Glu/MDI e OM/NaLS-For/MDI) é maior que naqueles compósitos preparados apenas com o NaLS hidroxialquilado (NaLS-Glu/MDI/Sisal e NaLS-For/MDI), conforme observado nas curvas TG (Figura 6la). O início da decomposição dos compósitos OM/NaLS-Glu/MDI/Sisal e OM/NaLS-For/MDI foi em torno de $230{ }^{\circ} \mathrm{C}$, enquanto que para os compósitos NaLS-Glu/MDI/Sisal e NaLS-For/MDI/Sisal foi em torno de $190^{\circ} \mathrm{C}$. 
Figura 6 I - Curvas (a) TG e (b) dTG para compósitos lignopoliuretânicos (Grupo 3); em atmosfera de $N_{2}$, fluxo de $50 \mathrm{~mL} \mathrm{~min}^{-1}$ e razão de aquecimento de $10^{\circ} \mathrm{C} \mathrm{min}^{-1}$.

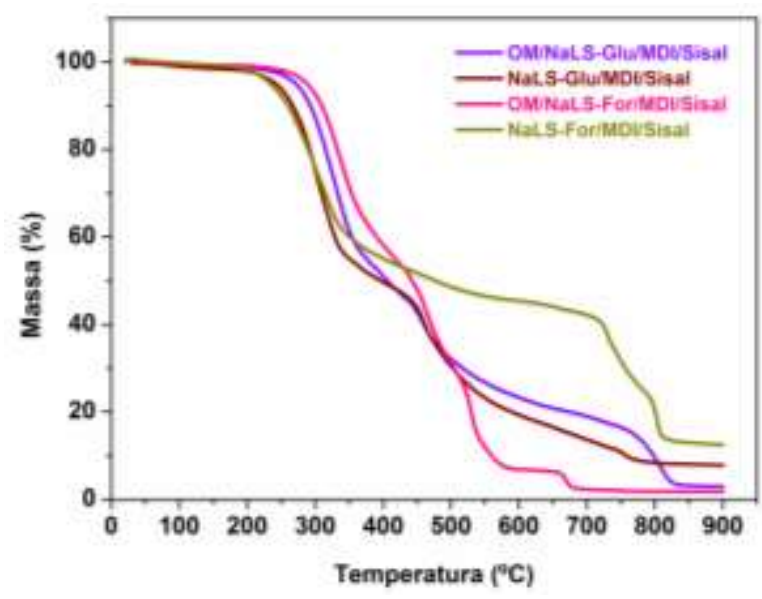

(a)

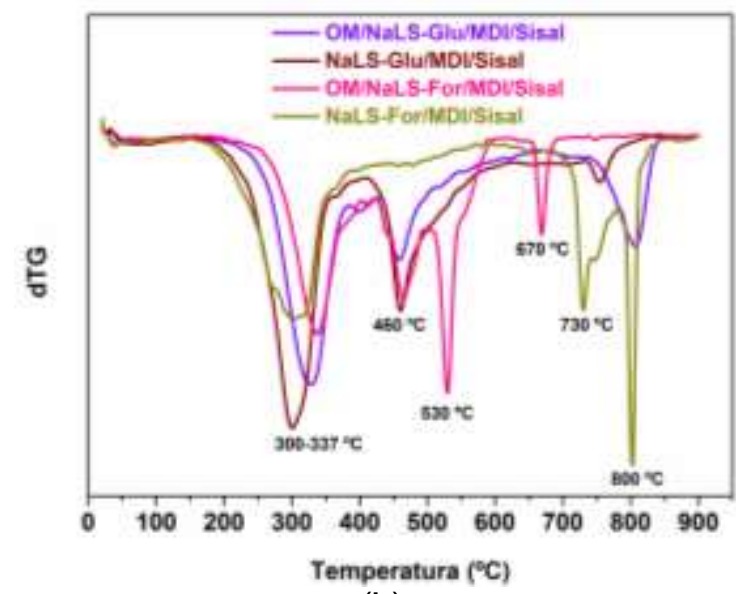

(b)

De modo geral, todos compósitos apresentaram três fases de decomposição. No entanto, em alguns casos (como o compósito OM/NaLS-For/MDI/Sisal), mais de três picos foram observados na curva dTG (Figura 6lb), provavelmente, devido ao fato que os compósitos lignopoliuretânicos presentes possuem em sua estrutura contribuição de reagentes diversificados.

\subsubsection{Resistência ao impacto}

A seguir são apresentados os resultados de ensaio de resistência ao impacto lzod (Figura 62) para os materiais descritos nos Quadros 4 e 5 (Experimental). É válido lembrar que estes materiais foram preparados apenas com polióis oriundos de fontes renováveis (óleo de mamona e lignossulfonatos hidroxialquilados ou não). Foi observado um considerável aumento na resistência ao impacto destes lignopoliuretanos (Figura 62a) quando fibras de sisal foram inseridas (Figura 62b), confirmando mais uma vez sua excelente atuação como reforço.

Visando uma melhor impregnação das fibras pelos reagentes de partida OM, NaLS e MDI, o compósito OM/NaLS/MDI/Sisal do Grupo 3 foi preparado com um tempo de impregnação maior se comparado ao compósito de mesma formulação preparado no Grupo I. O tempo de mistura mecânica para este compósito passou de 5 min (Grupol, Quadro I) para 20 min (Grupo 3, Quadro 4). O maior tempo de impregnação (se comparado ao mesmo compósito preparado no Quadro I) exerceu pouca influência na resistência ao 
impacto final, indo de $32 \mathrm{I} \mathrm{J} \mathrm{m}^{-1}$ (5 min de mistura) para $342 \mathrm{~J} \mathrm{~m}^{-1}$ (20 min de mistura), uma vez que os desvios aproximam esses valores.

Figura 62 - Resistência ao impacto (corpos de prova não-entalhados) de lignopoliuretanos não reforçados e compósitos lignopoliuretânicos descritos nos Quadros 4 e 5 (Experimental).

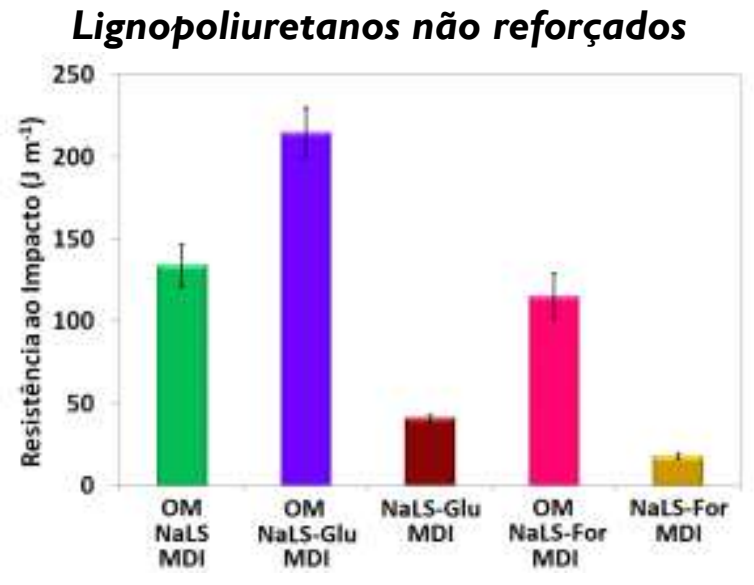

(a)

\section{Compósitos lignopoliuretânicos}

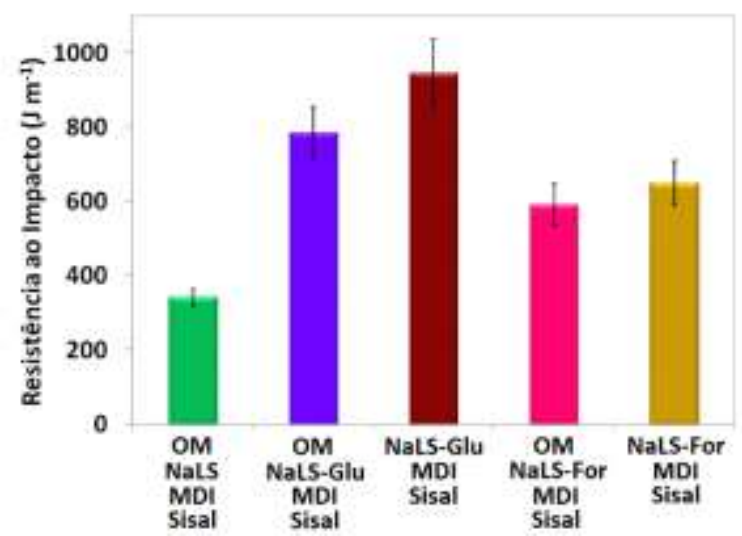

(b)

Entre os lignopoliuretanos não reforçados, o OM/NaLS-Glu/MDI (óleo de mamona combinado com lignossulfonato modificado com glutaraldeído) foi o que apresentou maior resistência ao impacto $\left(215 \mathrm{~J} \mathrm{~m}^{-1}\right.$, Figura $\left.62 \mathrm{a}\right)$. O compósito preparado a partir desta matriz (OM/NaLS-Glu/MDI/Sisal), apresentou ótimo resultado de resistência ao impacto $\left(785 \mathrm{~J} \mathrm{~m}^{-1}\right.$, Figura 62b).

Quando o NaLS foi modificado com glutaraldeído (Figura 20b), cadeias mais longas, originárias do glutaraldeído, foram inseridas na estrutura do lignossulfonato se comparado à modificação com formaldeído. Estas cadeias mais longas no NaLS-Glu levaram a uma maior proporção de segmentos flexíveis no lignopoliuretano NaLS-Glu/MDI do que no NaLSFor/MDI. Assim, o lignopoliuretano NaLS-Glu/MDI resultou em um material com resistência ao impacto maior (4I $\mathrm{J} \mathrm{m}^{-1}$, Figura $62 \mathrm{a}$ ) se comparado ao lignopoliuretano NaLS-For/MDI (18 $\mathrm{J} \mathrm{m}^{-1}$, Figura 62a).

O compósito NaLS-Glu/MDI/Sisal, também mostrou um elevado valor de resistência ao impacto $\left(945 \mathrm{~J} \mathrm{~m}^{-1}\right)$, se comparado à sua matriz sem fibras $\left(4 \mathrm{l} \mathrm{J} \mathrm{m}^{-1}\right)$. Ainda, este compósito (NaLS-Glu/MDI/Sisal) apresentou maior resistência ao impacto $\left(945 \mathrm{~J} \mathrm{~m}^{-1}\right)$ que o compósito NaLS-For/MDI/Sisal $\left(650 \mathrm{~J} \mathrm{~m}^{-1}\right)$, possivelmente pelo mesmo motivo já citado no parágrafo anterior. Ainda é válido lembrar que, em todas as composições, os grupos 
hidroxilas das fibras podem ter reagido com o MDI presente na composição da matriz durante $\circ$ processamento, embora não tenha sido feita uma investigação neste sentido no presente estudo.

O compósito OM/NaLS-For/MDI (óleo de mamona associado com lignossulfonato modificado com formaldeído), apresentou resistência ao impacto de $590 \mathrm{~J} \mathrm{~m}^{-1}$, enquanto que o compósito NaLS-For/MDI apresentou resistência ao impacto superior $\left(650 \mathrm{~J} \mathrm{~m}^{-1}\right)$, ० que indica mais uma vez que a estrutura do lignopoliuretano formado predominantemente pelas estruturas do lignossulfonato favorece a interação com as estruturas típicas presente nas fibras lignocelulósicas, como mostrado na Figura 21.

Os compósitos poliuretânicos do Grupo I (sem a presença de NaLS nas formulações, Quadro 2), apresentaram resistências ao impacto que vão de $57 \mathrm{I} \mathrm{J} \mathrm{m}^{-1}$ para o DEG/MDI/Sisal até $838 \mathrm{~J} \mathrm{~m}^{-1}$ para $\circ \mathrm{PEG} / \mathrm{MDI} /$ Sisal (Figura 38a). É importante destacar que todos os compósitos cujas matrizes tiveram em sua formulação lignossulfonatos modificados (seja com formaldeído ou glutaraldeído), sendo estes lignossulfonatos associados ou não com OM, obtiveram ótimos valores resistência ao impacto (Figura 62b), comparáveis aos compósitos poliuretânicos do Grupo I (Figura 38a). Estes valores vão de $590 \mathrm{~J} \mathrm{~m}^{-1}$ para 0 OM/NaLS-For/MDI/Sisal até $945 \mathrm{~J} \mathrm{~m}^{-1}$ para o NaLS-Glu/MDI/Sisal, sendo essas resistências ao impacto similares e até superiores às dos compósitos poliuretânicos.

Em todos os compósitos do Grupo 3 observou-se o fenômeno fiber bridging (Figura 65c), indicando uma forte adesão fibra-matriz nestes materiais. Assim, demonstrou-se que é possível preparar compósitos de matriz lignopoliuretânica reforçada com fibras de sisal com ótimas propriedades de impacto, comparáveis às matrizes em cuja formulação não há presença de NaLS.

\subsubsection{Microscopia eletrônica de varredura}

A Figura 63 mostra imagens de MEV da superfície de fratura do lignopoliuretano OM/NaLS/MDI e compósito OM/NaLS/MDI/Sisal (com novo tempo total de mistura: 20min, descrito no Quadro 4 da seção Experimental). Para ter acesso à superfície de fratura de compósitos que apresentaram fiber-bridging, fenômeno em que a maior parte das fibras não rompem, as fibras que ligavam as duas partes da matriz foram separadas por corte.

O lignopoliuretano não reforçado (OM/NaLS/MDI) apresentou uma estrutura mista com a presença de microcavidades e do tipo celular (PURSLOW, 1986) (Figura 63a). No 
compósito (OM/NaLS/MDI/Sisal) é possível observar boa adesão entre fibra e matriz, indicada pelas setas amarelas.

Figura 63 - Imagens de MEV das superfícies fraturadas do (a) OM/NaLS/MDI e (b) OM/NaLS/MDI/Sisal (novo tempo de mistura)

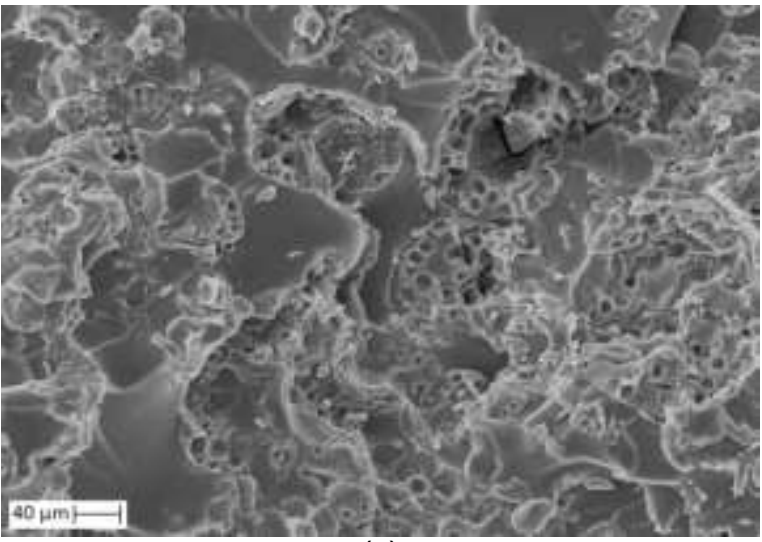

(a)

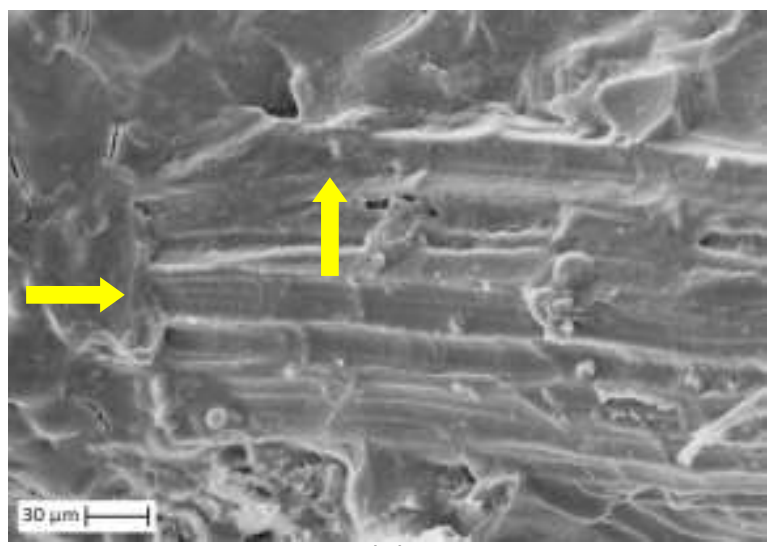

(b)

As superfícies de fratura do lignopoliuretano OM/NaLS-Glu/MDI e do respectivo compósito OM/NaLS-Glu/MDI/Sisal são mostradas na Figura 64. O lignopoliuretano OM/NaLS-Glu/MDI apresentou superfície de fratura a predominância da estrutura com depressões esferoidais (Figura 64a) e uma quantidade menor de microcavidades, se comparado ao OM/NaLS/MDI (onde o NaLS sem modificação prévia foi utilizado). O compósito OM/NaLS-Glu/MDI/Sisal apresentou regiões de ótima adesão entre fibra e matriz (indicadas pelas setas amarelas), possivelmente devido à combinação de OM com NaLS-Glu. A estrutura típica do NaLS presente na matriz favorece a adesão com a fibra lignocelulósicas, pois possibilita provavelmente a presença de ligações hidrogênio entre os grupos uretânicos da matriz e os grupos hidroxila das fibras. Ainda, as hidroxilas presentes na fibra podem reagir com grupos isocianatos do MDI, e se tornarem ligadas covalentemente à matriz, conforme já mencionado. 
Figura 64 - Imagens de MEV das superfícies fraturadas do (a) lignopoliuretano OM/NaLS-Glu/MDI e (b) compósito OM/NaLS-Glu/MDI/Sisal.

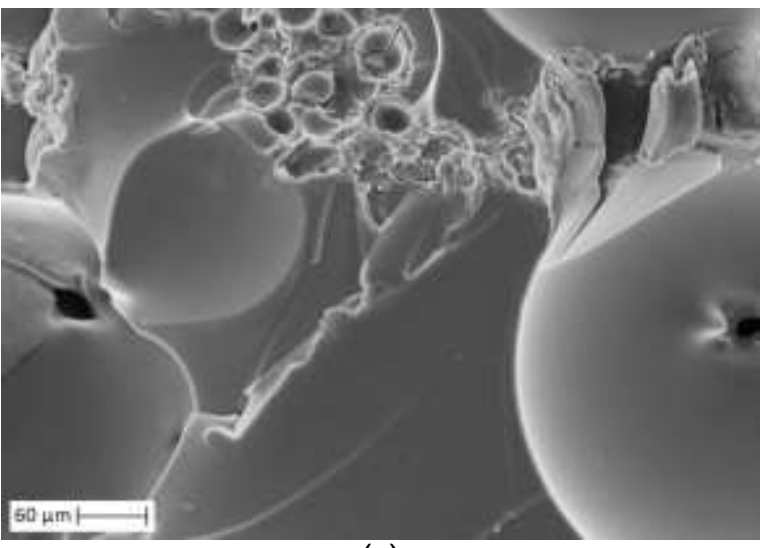

(a)

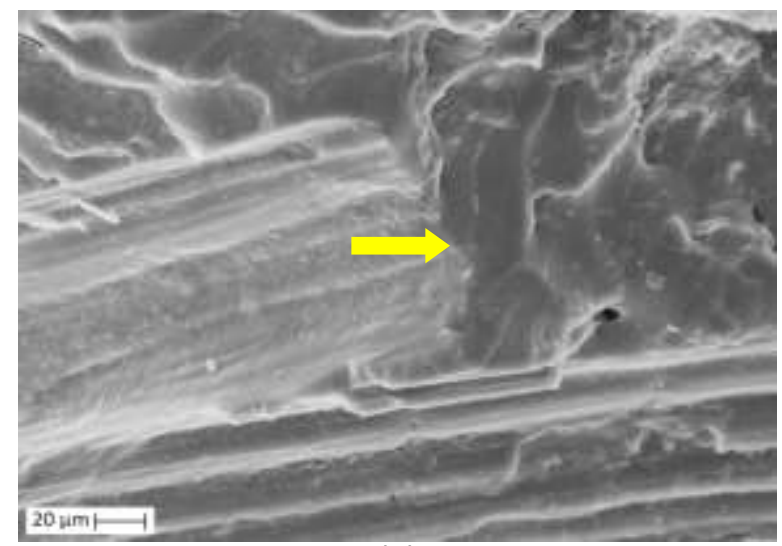

(b)

A Figura 65a mostra a superfície de fratura do lignopoliuretano e compósito preparado a partir de NaLS-Glu/MDI. Este lignopoliuretano apresentou uma superfície de fratura com alto número de microcavidades e de estrutura celular. A fractografia que mais se assemelhou a deste material foi a do lignopoliuretano OM/NaLS/MDI (Figura 53a). O lignopoliuretano OM/NaLS/MDI apresentou este mesmo tipo de estrutura, mas com menor presença destes elementos (Figura 63a), comparativamente aos dois materiais citados, e o lignopoliuretano OM/NaLS-Glu/MDI apresentou uma quantidade menor de microcavidades de estrutura celular (Figura 64a, parte superior). Durante a preparação do NaLS-Glu/MDI, a volatilização de água residual, não eliminada durante a prévia rotoevaporação do NaLS-Glu, pode ter contribuído para com a presença de microcavidades neste material. 
Figura 65 - Imagens de MEV das superfícies fraturadas do (a) lignopoliuretano NaLSGlu/MDI e (b) compósito NaLS-Glu/MDI/Sisal; (c) fenômeno fiber bridging em corpo de prova do compósito NaLS-Glu/MDI/Sisal.

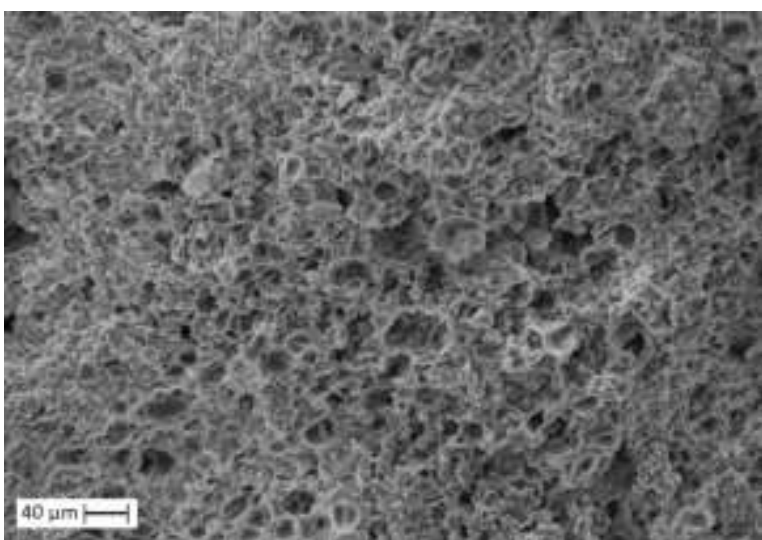

(a)

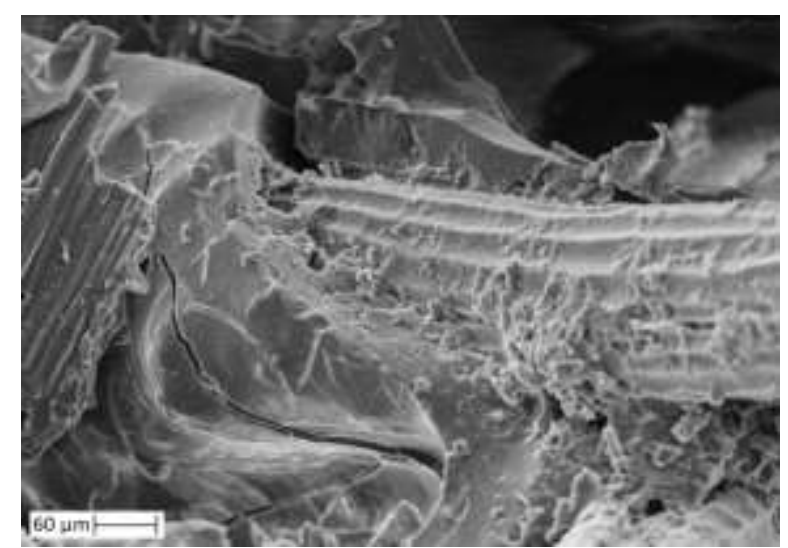

(b)

No compósito NaLS-Glu/MDI/Sisal, foi possível observar parte da matriz lignopoliuretânica fragmentada e parte não-fragmentada, que estava aderida à superfície das fibras. Poucas imagens de MEV foram obtidas deste compósito, pois em todos os corpos de prova ensaiados ocorreu o fenômeno fiber bridging de maneira mais intensa que nos demais compósitos deste grupo, o que dificultou a visualização da superfície de fratura. $\bigcirc$ resultado de impacto deste compósito (945 $\mathrm{J} \mathrm{m}^{-1}$, Figura $62 \mathrm{~b}$ ) sugere uma adesão intensa entre fibra e matriz, pelos motivos já relatados aqui.

Nas imagens de MEV do compósito OM/NaLS-For/MDI/Sisal, foi possível observar a matriz polimérica entre as fibras e aderidas sobre a superfície (Figura 66a), no entanto foram observadas também regiões em que a adesão não se mostrava eficiente (Figura 66b).

Figura 66 - Imagens de MEV das superfícies fraturadas do compósito OM/NaLS-For/MDI/Sisal

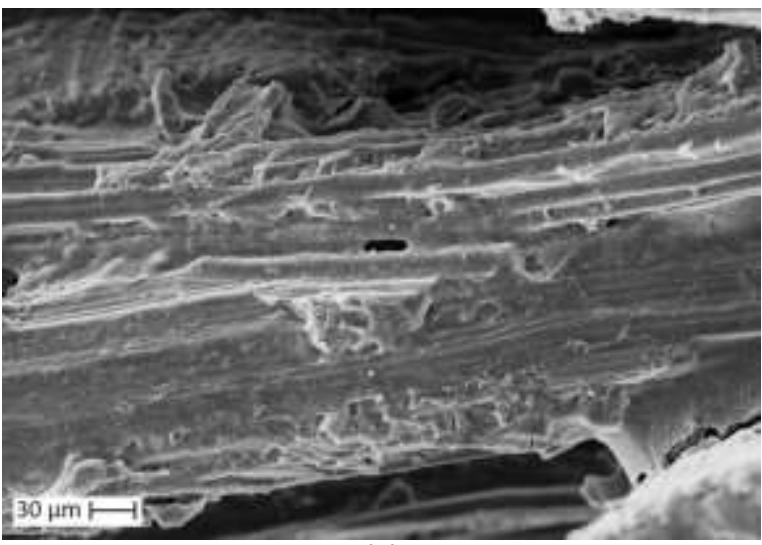

(a)

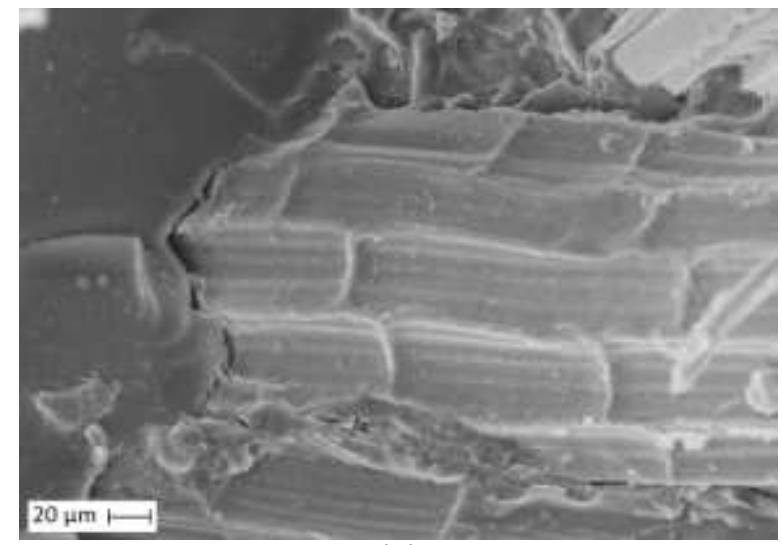

(b) 
Não foi possível obter imagens de MEV do compósito NaLS-For/MDI/Sisal, devido a ocorrência do fenômeno fiber bridging de maneira muito intensa, com um pequeno espaço entre as partes separadas, o que praticamente impediu a separação das mesmas via corte, sem danificá-las. No entanto, acredita-se que houve uma ótima adesão entre fibra e matriz neste compósito, justamente devido às características do fiber bridging.

\subsubsection{Resistência à flexão}

A Tabela 15 fornece informações sobre o rompimento de amostras durante o ensaio de flexão e deformação máxima alcançada para os materiais descritos nos Quadros 4 e 5 (Experimental). As Figura 67 e Figura 68 apresentam, respectivamente, a resistência à flexão e o módulo de flexão desses materiais.

Tabela 15 - Informações sobre fratura e deformação durante o ensaio de flexão (sistema 3 pontos) para os materiais preparados conforme descrito nos Quadros 4 e 5

\begin{tabular}{|c|c|c|}
\hline & Material & Deformação máxima (\%) \\
\hline \multirow{5}{*}{ 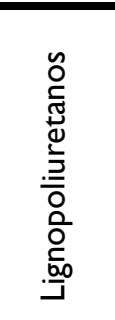 } & $\mathrm{OM} / \mathrm{NaLS} / \mathrm{MDI}$ & $5,0^{* *}$ \\
\hline & OM/NaLS-Glu/MDI* & não testado \\
\hline & NaLS-Glu/MDI & $2, I \pm 0,1$ \\
\hline & OM/NaLS-For/MDI & $5,0 * *$ \\
\hline & NaLS-For/MDI & $\mathrm{I}, 5 \pm 0,2$ \\
\hline \multirow{5}{*}{ 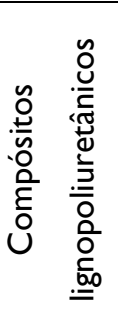 } & OM/NaLS/MDI/Sisal & $4,0 \pm 0,3$ \\
\hline & OM/NaLS-Glu/MDI/Sisal & $5,0 * *$ \\
\hline & NaLS-Glu/MDI/Sisal & $2,1 \pm 1,3$ \\
\hline & OM/NaLS-For/MDI/Sisal & $5,0 * *$ \\
\hline & NaLS-For/MDI/Sisal & $3,2 \pm 0,7$ \\
\hline
\end{tabular}

\footnotetext{
* Ensaio não realizado, devido o material ter apresentado característica elastomérica acentuada, dificultando a sustentação do corpo de prova sobre o sistema de três pontos. ** não houve ruptura durante o ensaio
}

A inserção de fibras de sisal nos lignopoliuretanos conferiu aumento da resistência à flexão (Figura 67) e módulo de flexão (Figura 68) nestes materiais.

O compósito OM/NaLS/MDI/Sisal apresentou a maior resistência à flexão (60 MPa, Figura 67b) e também maior módulo de flexão (3,3 GPa, Figura 68b), comparado aos demais compósitos preparados com NaLS hidroxialquilado (OM/NaLS-Glu/MDI/Sisal, NaLS- 
Glu/MDI/Sisal, OM/NaLS-For/MDI/Sisal e NaLS-For/MDI/Sisal), que apresentaram resistência à flexão entre 17 e 30 MPa (Figura 67b) e módulo de flexão entre I,2 e 2,5 GPa (Figura 68b). Deve-se no entanto levar em consideração que a resistência à flexão e o módulo de flexão do OM/NaLS/MDI/Sisal são referentes ao ponto de ruptura (assim como para NaLSGlu/MDI/Sisal e NaLS-For/MDI/Sisal), enquanto os valores referentes a OM/NaLSGlu/MDI/Sisal e OM/NaLS-For/MDI/Sisal se referem 5\% de deformação, pois estes materiais não romperam durante o ensaio (Tabela 15).

O módulo de flexão para o compósito NaLS-Glu/MDI/Sisal se mostrou maior $(2,5$ GPa, Figura 68b) que para o compósito OM/NaLS-Glu/MDI/Sisal (I,2 GPa, Figura 68b). Este resultado pode ser explicado pelo fato de a matriz lignopoliuretânica NaLS-Glu/MDI ter sido preparada a partir de reagente com estruturas típicas de ligninas, com uma grande quantidade de anéis aromáticos (Figura 8) que levam a uma matriz com estrutura mais rígida, e que resiste mais à tensão aplicada nos estágios iniciais do ensaio, comparativamente à estruturas em que segmentos mais flexíveis, típicos de OM, estão presentes.

Figura 67 - Resistência à flexão de lignopoliuretanos e compósitos lignopoliuretânicos descritos nos Quadros 4 e 5 (Experimental).

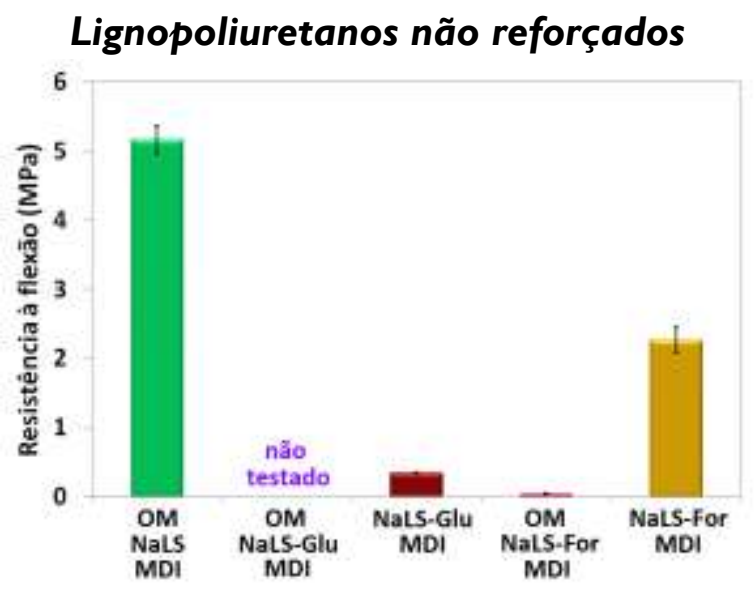

(a)

\section{Compósitos lignopoliuretânicos}

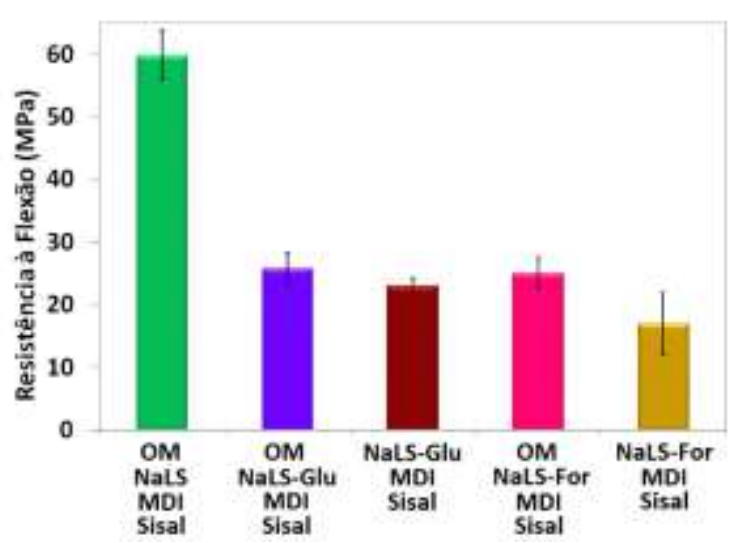

(b) 
Figura 68 - Módulo de flexão de lignopoliuretanos e compósitos lignopoliuretânicos que compreendem os Quadros 4 e 5 (Experimental).

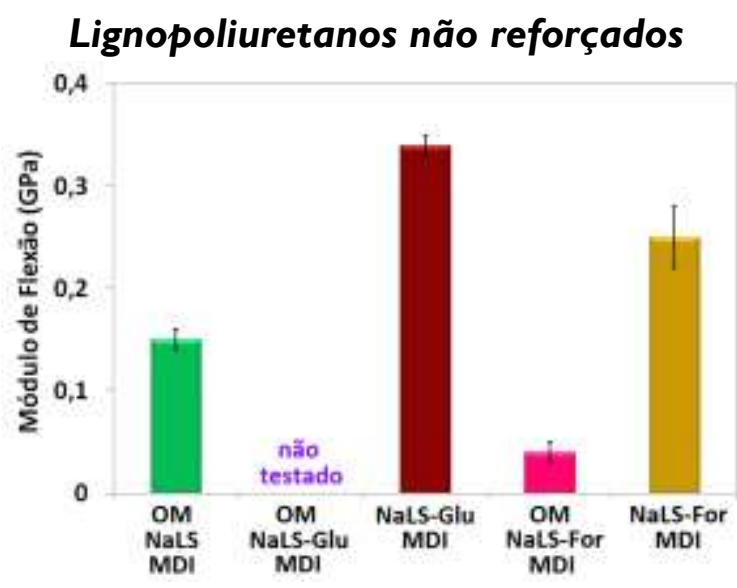

(a)

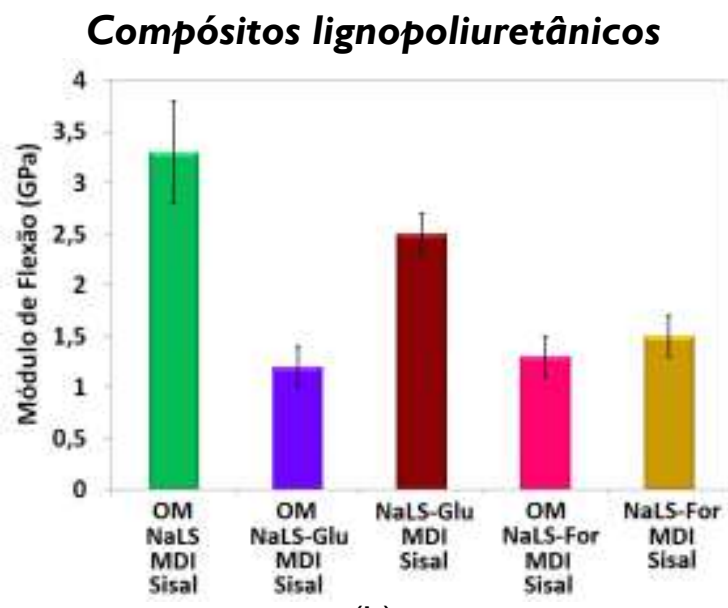

(b)

A resistência à flexão a $5 \%$ de deformação (Figura 67 ) do compósito OM/NaLSFor/MDI/Sisal (25,0 MPa), se mostrou próxima do compósito OM/NaLS-Glu/MDI/Sisal (25,8 $\mathrm{MPa}$ ), mostrando que o tipo de modificação realizada no NaLS não influenciou a propriedade dos materiais posteriormente preparados a partir de NaLS-For e NaLS-Glu, pois as demais condições foram as mesmas, ou seja, estes compósitos foram preparados utilizando o mesmo procedimento e mesma proporção de reagentes. Uma observação similar pode ser considerada para o módulo de flexão (Figura 68). No compósito NaLS-For/MDI/Sisal, ocorreu aumento do módulo de flexão (I,5 GPa), comparado ao compósito OM/NaLSFor/MDI/Sisal ( I,3 GPa), embora os desvios aproximem os valores. O fato de a matriz NaLSFor/MDI apresentar estrutura mais rígida que a preparada com OM (OM/NaLS-For/MDI), pode explicar a tendência observada. Uma diminuição na resistência à flexão foi observada (de $25 \mathrm{MPa}$, OM/NaLS-For/MDI/Sisal para $17 \mathrm{MPa}$, NaLS-For/MDI/Sisal). A presença de segmentos mais flexíveis em OM/NaLS-For/MDI/Sisal pode explicar este resultado. Destacase que neste compósito a resistência se refere a $5 \%$ de deformação, pois o mesmo não se rompeu até esta deformação (Tabela I5). 


\section{CONCLUSÕES}

Os resultados obtidos indicam que o lignossulfonato de sódio pode ser utilizado na preparação de lignopoliuretanos, e estes por sua vez, serem utilizados como matrizes em compósitos reforçados com fibras lignocelulósicas de sisal. A escolha da fibra de sisal como agente de reforço nas matrizes foi acertada, uma vez que resultou na melhoria das propriedades mecânicas dos compósitos, aumentando a resistência ao impacto, resistência à flexão e módulo de flexão. Além disso, a substituição de parte do material polimérico pelas fibras representam um ganho, pois as mesmas têm menor custo quando comparados à matriz, e são obtidas de fontes renováveis.

A associação do lignossulfonato de sódio (NaLS) com os polióis DEG, PEG e óleo de mamona na formulação de lignopoliuretanos (Grupo I), levou a compósitos destas matrizes com ótimas propriedades mecânicas. O compósito DEG/NaLS/MDI merece destaque, com resistência ao impacto de $472 \mathrm{~J} \mathrm{~m}^{-1}$ e resistência à flexão de $47 \mathrm{MPa}$.

O uso do lignossulfonato oxipropilado (modificação via oxipropilação, Grupo 2) se mostrou como uma forma eficiente de utilizar essa macromolécula, e trouxe resultados promissores. O compósito LS-Oxi/MDI/Sisal apresentou resistência ao impacto de $459 \mathrm{~J} \mathrm{~m}^{-1}$ e resistência à flexão de $43 \mathrm{MPa}$. Até onde vai o nosso conhecimento, não existe relatos na literatura que envolvem $\circ$ uso de lignopoliuretanos obtidos a partir de lignossulfonato oxipropilado na preparação de compósitos reforçados com fibras de sisal.

O uso de aldeídos na modificação do NaLS (hidroxialquilação, Grupo 3), até onde se tenha conhecimento, foi uma abordagem inédita no que se refere à síntese de lignopoliuretanos. Quando o lignossulfonato foi modificado com glutaraldeído (NaLS-Glu), esta modificação resultou no compósito lignopoliuretânico de maior resistência ao impacto (NaLS-Glu/MDI/Sisal, $945 \mathrm{~m}^{-1}$ ) no presente estudo, e resistência à flexão de $23 \mathrm{MPa}$.

As imagens de MEV revelaram que os compósitos apresentaram uma excelente adesão na interface fibra/matriz, provavelmente, devido à presença de ligações hidrogênio entre os grupos uretânicos da matriz e os grupos hidroxila das fibras, além de interações dos domínios hidrofóbicos de ambos, fibra e matriz.

Materiais com grau de entrecruzamento diversificados, com características entre elastomérica a termorrígidos, foram obtidos a partir do uso do NaLS e do OM, o que faz 
com que eles se tornem atrativos para diferentes aplicações, como em partes automotivas e painéis de uso arquitetônico.

Em linhas gerais, pode-se concluir que os objetivos traçados para o presente trabalho foram alcançados com sucesso, pois foram desenvolvidos materiais com alto teor de materiais obtidos de fontes renováveis e com boas propriedades. 


\section{REFERÊNCIAS}

ACHA, B. A.; MARCOVICH, N. E.; REBOREDO, M. M. Lignin in jute fabric-polypropylene composites. Journal of Applied Polymer Science, v. I I3, n. 3, p. I480- I 487, 2009.

ADLER, E. Lignin chemistry - past, present and future. Wood Science and Technology, v. II, p. I69-2I8, 1977.

AHVAZI, B.; WOJCIECHOWICZ, O.; TON-THAT, T. M.; HAWARI, J. Preparation of lignopolyols from wheat straw soda lignin. Journal of Agricultural Food Chemistry, v. 59, n. 19, p. 10505-16, 2011.

ALLPORT, D. C.; GILBERT, D. S.; OUTTERSIDE, S. M. Mdi and tdi usage: Responsible risk management. In: ALLPORT, D. C.; GILBERT, D. S.; OUTTERSIDE, S. M. (Ed.). Mdi and tdi: safety, health and the environment. New York: John Wiley, 2003. p. I-I0.

ALONSO, M. V.; OLIET, M.; RODRÍGUEZ, F.; ASTARLOA, G.; ECHEVERRÍA, J. M. Use of a methylolated softwood ammonium lignosulfonate as partial substitute of phenol in resol resins manufacture. Journal of Applied Polymer Science, v. 94, n. 2, p. 643-650, 2004.

ALONSO, M. V.; RODRÍGUEZ, J. J.; OLIET, M.; RODRÍGUEZ, F.; GARCÍA, J.; GILARRANZ, M. A. Characterization and structural modification of ammonic lignosulfonate by

methylolation. Journal of Applied Polymer Science, v. 82, n. I I, p. 266I-2668, 200 I.

ANICETO, J. P. S.; PORTUGAL, I.; SILVA, C. M. Biomass-based polyols through oxypropylation reaction. ChemSusChem, v. 5, n. 8, p. I358-I368, 2012.

ARANGUREN, M. I.; RÁCZ, I.; MARCOVICH, N. E. Microfoams based on castor oil polyurethanes and vegetable fibers. Journal of Applied Polymer Science, v. I05, n. 5, p. 279|-2800, 2007.

ASANO, Y.; HATAKEYAMA, H.; HATAKEYAMA, T. Thermal and mechanical properties of sodium lignosulfonate-based rigid polyurethane foams prepared with three kinds of polyols.

Sen'i Gakkaishi, v. 59, n. 12, p. 465-470, 2003.

BAHL, K.; JANA, S. C. Surface modification of lignosulfonates for reinforcement of styrenebutadiene rubber compounds. Journal of Applied Polymer Science, v. I3I, n. 7, 2014. No prelo. Disponível em: <http://onlinelibrary.wiley.com/doi/I0.1002/app.40 I23/pdf>. Acesso em: 24 set. 2014.

BAKARE, I. O.; OKIEIMEN, F. E.; PAVITHRAN, C.; ABDUL KHALIL, H. P. S.; BRAHMAKUMAR, M. Mechanical and thermal properties of sisal fiber-reinforced rubber seed oil-based polyurethane composites. Materials \& Design, v. 3 I, n. 9, p. 4274-4280, 2010. 
BASU, G.; ROY, A. N.; SATAPATHY, K. K.; ABBAS, S. M. J.; MISHRA, L.; CHAKRABORTY, $R$. Potentiality for value-added technical use of indian sisal. Industrial Crops and

Products, v. 36, n. I, p. 33-40, 2012.

BATHIAS, C. Interface fibre/matrice. In: BATHIAS, C. (Ed.). Matériaux composites 2e édition. Paris: Dunod, 2009. p. 73-82.

BERLIN, A. A.; VOLFSON, S. A.; ENIKOLOPIAN, N. S.; NEGMATOV, S. S. Composites manufacturing: materials, products and processing engineering. Berlin: Springer-Verlag, 1986. $124 \mathrm{p}$.

BISMARCK, A.; MISHRA, S.; LAMPKE, T. Plant fibers as reinforcement for green composites. In: MOHANTY, A. K.; MISRA, M.; DRZAL, L. T. (Ed.). Natural fibers, biopolymers, and biocomposites. Boca Raton: Taylor \& Francis, 2005. p. 37-I08.

BLEDZKI, A. K.; GASSAN, J. Composites reinforced with cellulose based fibres. Progress in Polymer Science (Oxford), v. 24, n. 2, p. 22I-274, 1999.

BONFIL, M.; SIRKECIOGLU, A.; BINGOL-OZAKPINAR, O.; URAS, F.; GÜNER, F. S. Castor oil and peg-based shape memory polyurethane films for biomedical applications. Journal of Applied Polymer Science, v. I3I, n. 15, 2014. No prelo. Disponível em: <http://onlinelibrary.wiley.com/doi//0.1002/app.40590/pdf>. Acesso em: 24 set. 2014.

BONINI, C.; D'AURIA, M.; EMANUELE, L.; FERRI, R.; PUCCIARIELLO, R.; SABIA, A. R. Polyurethanes and polyesters from lignin. Journal of Applied Polymer Science, v. 98, n. 3, p. |45|-|456, 2005.

BUSCHLE-DILLER, G.; ZERONIAN, S. H. Enhancing the reactivity and strength of cotton fibers. Journal of Applied Polymer Science, v. 45, n. 6, p. 967-979, 1992.

CALVO-FLORES, F. G.; DOBADO, J. A. Lignin as renewable raw material.

ChemSusChem, v. 3, n. II, p. I227-35, 2010.

CANTO, L. B.; PESSAN, L. A. Resistência à tração, flexão e compressão. In: CANEVAROLO JÚNIOR, S. V. (Ed.). Técnicas de caracterização de polímeros. São Paulo: Artliber, 2004. p. 34I-360.

CARDOSO, O. R.; DE CARVALHO BALABAN, R. Preparation of polyurethane resins based on castor oil and diethanolamine and their application in electronic circuits. Polimeros, $v$. 23, n. 4, p. 552-558, 2013.

CATETO, C. A.; BARREIRO, M. F.; OTTATI, C.; LOPRETTI, M.; RODRIGUES, A. E.; BELGACEM, M. N. Lignin-based rigid polyurethane foams with improved biodegradation. Journal of Cellular Plastics, v. 50, n. I, p. 8I-95, 2013.

CATETO, C. A.; BARREIRO, M. F.; RODRIGUES, A. E.; BELGACEM, M. N. Optimization study of lignin oxypropylation in view of the preparation of polyurethane rigid foams.

Industrial and Engineering Chemistry Research, v. 48, n. 5, p. 2583-2589, 2009. 
CATETO, C. A. Lignin-based polyurethanes: Characterisation, synthesis and applications. 2008. 230f. Tese (Doutorado) - Faculdade de Engenharia da Universidade do Porto/Ecole International du Papier, de la Communcation Imprimée et des Biomatériaux, Universidade do Porto/Instituto Polytechnique de Grenoble, Porto/Grenoble, 2008.

CAZACU, G.; MIHAIES, M.; PASCU, M. C.; PROFIRE, L.; KOWARSKIK, A. L.; VASILE, C. Polyolefin/lignosulfonate blends, 9. Macromolecular Materials and Engineering, v. 289, n. 10, p. 880-889, 2004.

CHAKAR, F. S.; RAGAUSKAS, A. J. Review of current and future softwood kraft lignin process chemistry. Industrial Crops and Products, v. 20, n. 2, p. I3I-I4I, 2004.

CHANG, C. W.; LU, K. T. Natural castor oil based 2-package waterborne polyurethane wood coatings. Progress in Organic Coatings, v. 75, n. 4, p. 435-443, 2012.

CHAUHAN, M.; GUPTA, M.; SINGH, B.; SINGH, A. K.; GUPTA, V. K. Effect of functionalized lignin on the properties of lignin-isocyanate prepolymer blends and composites. European Polymer Journal, v. 52, p. 32-43, 2014.

CHAWLA, K. K. Composite materials. New York: Springer, 1998. 483 p.

CHEN, S.; WANG, Q.; WANG, T. Physical properties of aramid fiber reinforced castor oilbased polyurethane/epoxy resin ipn composites. Journal of Reinforced Plastics and Composites, v. 32, n. 15, p. II36-II42, 2013.

CHERUBINI, F.; STRØMMAN, A. H. Chemicals from lignocellulosic biomass: Opportunities, perspectives, and potential of biorefinery systems. Biofuels, Bioproducts and Biorefining, v. 5, n. 5, p. 548-56I, $201 \mathrm{I}$.

CHIERICE, G.; CLARONETO, S. Aplicação industrial do óleo. In: AZEVEDO, D. M. P.; LIMA, E. F. (Ed.). O agronegócio da mamona no brasil. Brasília: Embrapa Informação Tecnológica, 200I. p. 504.

CIOBANU, C.; UNGUREANU, M.; IGNAT, L.; UNGUREANU, D.; POPA, V. I. Properties of lignin-polyurethane films prepared by casting method. Industrial Crops and Products, v. 20, n. 2, p. 23I-24I, 2004.

CORCUERA, M. A.; RUEDA, L.; FERNANDEZ D'ARLAS, B.; ARBELAIZ, A.; MARIETA, C.; MONDRAGON, I.; ECEIZA, A. Microstructure and properties of polyurethanes derived from castor oil. Polymer Degradation and Stability, v. 95, n. II, p. 2175-2 I84, 2010.

COUTINHO, F. M. B.; DELPECH, M. C. Poliuretanos como materiais de revestimento de superfície. Polímeros: Ciência e Tecnologia, v. 9, n. I, p. 4I-48, 1999.

CUI, G.; XIA, W.; CHEN, G.; WEI, M.; HUANG, J. Enhanced mechanical performances of waterborne polyurethane loaded with lignosulfonate and its supramolecular complexes.

Journal of Applied Polymer Science, v. I06, n. 6, p. 4257-4263, 2007. 
CUNHA, F. O. V.; MELO, D. H. R.; VERONESE, V. B.; FORTE, M. M. D. C. Study of castor oil polyurethane - poly(methyl methacylate) semi-interprenetrating polymer networf (sipn) reaction parameters using a $2^{\wedge} 3$ factorial experimental design. Materials Research, v. $7, \mathrm{n}$. 4, p. 539-543, 2004.

D'SOUZA, J.; CAMARGO, R.; YAN, N. Polyurethane foams made from liquefied bark-based polyols. Journal of Applied Polymer Science, v. I3I, n. 16, 2014. No prelo. Disponível em: <http://onlinelibrary.wiley.com/doi/l0.1002/app.40599/pdf>. Acesso em: 24 set. 2014.

DA SILVA, C. G.; GRELIER, S.; PICHAVANT, F.; FROLLINI, E.; CASTELLAN, A. Adding value to lignins isolated from sugarcane bagasse and miscanthus. Industrial Crops and Products, v. 42, p. 87-95, 2013.

DE MENEZES, A.; PASQUINI, D.; CURVELO, A.; GANDINI, A. Self-reinforced composites obtained by the partial oxypropylation of cellulose fibers. 2. Effect of catalyst on the mechanical and dynamic mechanical properties. Cellulose, v. 16, n. 2, p. 239-246, 2009.

DE OLIVEIRA SANTOS, R. P.; CASTRO, D. O.; RUVOLO-FILHO, A. C.; FROLLINI, E. Processing and thermal properties of composites based on recycled pet, sisal fibers, and renewable plasticizers. Journal of Applied Polymer Science, v. I3I, n. I2, p., 2014.

DE PAIVA, J. M. F.; FROLLINI, E. Sugarcane bagasse reinforced phenolic and lignophenolic composites. Journal of Applied Polymer Science, v. 83, n. 4, p. 880-888, 2001.

DE PAIVA, J. M. F.; FROLLINI, E. Unmodified and modified surface sisal fibers as reinforcement of phenolic and lignophenolic matrices composites: Thermal analyses of fibers and composites. Macromolecular Materials and Engineering, v. 29I, n. 4, p. 405-4I7, 2006.

DELEBECQ, E.; PASCAULT, J. P.; BOUTEVIN, B.; GANACHAUD, F. On the versatility of urethane/urea bonds: Reversibility, blocked isocyanate, and non-isocyanate polyurethane. Chemical Reviews, v. II3, n. I, p. 80-II8, 2013.

DENG, Y.; ZHANG, W.; WU, Y.; YU, H.; QIU, X. Effect of molecular weight on the adsorption characteristics of lignosulfonates. The Journal of Physical Chemistry B, v. II5, n. 49, p. I4866-73, $20 \mid$ I.

DIMMEL, D. Overview. In: HEITNER, C.; DIMMEL, D.; SCHMIDT, J. A. (Ed.). Lignins and lignans: advances in chemistry. Boca Raton: CRC, 2010. p. I-9.

DOMÍNGUEZ, J. C.; OLIET, M.; ALONSO, M. V.; ROJO, E.; RODRÍGUEZ, F. Structural, thermal and rheological behavior of a bio-based phenolic resin in relation to a commercial resol resin. Industrial Crops and Products, v. 42, p. 308-3 I4, 2013.

DUONG, L. D.; NAM, G.-Y.; OH, J.-S.; PARK, I.-K.; LUONG, N. D.; YOON, H.-K.; LEE, S.H.; LEE, Y.; YUN, J.-H.; LEE, C.-G.; HWANG, S.-H.; NAM, J.-D. High molecular-weight thermoplastic polymerization of kraft lignin macromers with diisocyanate. BioResouces, v. 9, n. 2, p. 2359-237I, 2014. 
DUVAL, A.; MOLINA-BOISSEAU, S.; CHIRAT, C. Comparison of kraft lignin and lignosulfonates addition to wheat gluten-based materials: Mechanical and thermal properties. Industrial Crops and Products, v. 49, p. 66-74, 2013.

EL MANSOURI, N.-E.; FARRIOL, X.; SALVADÓ, J. Structural modification and characterization of lignosulfonate by a reaction in an alkaline medium for its incorporation into phenolic resins. Journal of Applied Polymer Science, v. I02, n. 4, p. 3286-3292, 2006.

EL MANSOURI, N.-E.; PIZZI, A.; SALVADÓ, J. Lignin-based wood panel adhesives without formaldehyde. Holz als Roh- und Werkstoff, v. 65, n. I, p. 65-70, 2007.

EL MANSOURI, N.-E.; YUAN, Q.; HUANG, F. Study of chemical modification of alkaline lignin by the glyoxalation reaction. BioResources, v. 6, n. 4, p. 4523-4536, 201 I.

EL MANSOURI, N. E.; PIZZI, A.; SALVADO, J. Lignin-based polycondensation resins for wood adhesives. Journal of Applied Polymer Science, v. I03, n. 3, p. 1690-1699, 2007.

EL MANSOURI, N. E.; SALVADO', J. Structural characterization of technical lignins for the production of adhesives: Application to lignosulfonate, kraft, soda-anthraquinone, organosolv and ethanol process lignins. Industrial Crops and Products, v. 24, n. I, p. 8- I6, 2006.

EVTIOUGUINA, M.; GANDINI, A.; PASCOAL NETO, C.; BELGACEM, N. M. Urethanes and polyurethanes based on oxypropylated cork: I. Appraisal and reactivity of products. Polymer International, v. 50, n. I0, p. II50-I I55, 200 I.

EVTIOUGUINA, M.; MARGARIDA BARROS, A.; CRUZ-PINTO, J. J.; PASCOAL NETO, C.; BELGACEM, N.; PAVIER, C.; GANDINI, A. The oxypropylation of cork residues: Preliminary results. Bioresource Technology, v. 73, n. 2, p. I87-I89, 2000.

FARIA, F. A. C.; EVTUGUIN, D. V.; RUDNITSKAYA, A.; GOMES, M. T. S. R.; OLIVEIRA, J. A. B. P.; GRAÇA, M. P. F.; COSTA, L. C. Lignin-based polyurethane doped with carbon nanotubes for sensor applications. Polymer International, v. 6I, n. 5, p. 788-794, 2012.

FARUK, O.; BLEDZKI, A. K.; FINK, H.-P.; SAIN, M. Biocomposites reinforced with natural fibers: 2000-2010. Progress in Polymer Science, v. 37, n. II, p. I552-I596, 2012.

FARUK, O.; BLEDZKI, A. K.; FINK, H.-P.; SAIN, M. Progress report on natural fiber reinforced composites. Macromolecular Materials and Engineering, v. 299, n. I, p. 926, 2014.

FARUK, O.; SAIN, M.; FARNOOD, R.; PAN, Y.; XIAO, H. Development of lignin and nanocellulose enhanced bio pu foams for automotive parts. Journal of Polymers and the Environment, p., 2013.

FENGEL, D.; WEGENER, G. Wood: chemistry, ultrastructure, reactions. New York: Walter de Gruyter, 1989.613 p. 
FERNANDES, S.; FREIRE, C. S. R.; PASCOAL NETO, C.; GANDINI, A. The bulk oxypropylation of chitin and chitosan and the characterization of the ensuing polyols. Green Chemistry, v. 10, n. I, p. 93-97, 2008.

FITZPATRICK, M.; CHAMPAGNE, P.; CUNNINGHAM, M. F.; WHITNEY, R. A. A biorefinery processing perspective: Treatment of lignocellulosic materials for the production of value-added products. Bioresource Technology, v. I0I, n. 23, p. 89I5-22, 2010.

FOWLER, P. A.; HUGHES, J. M.; ELIAS, R. M. Biocomposites: Technology, environmental credentials and market forces. Journal of the Science of Food and Agriculture, v. 86, n. I2, p. $178 \mid-1789,2006$.

FRAS, L.; LAINE, J.; STENIUS, P.; STANA-KLEINSCHEK, K.; RIBITSCH, V.; DOLECEK, V. Determination of dissociable groups in natural and regenerated cellulose fibers by different titration methods. Journal of Applied Polymer Science, v. 92, n. 5, p. 3 I86-3 I 95, 2004.

FREDHEIM, G. E.; BRAATEN, S. M.; CHRISTENSEN, B. E. Molecular weight determination of lignosulfonates by size-exclusion chromatography and multi-angle laser light scattering. Journal of Chromatography A, v. 942, n. I-2, p. I91-199, 2002.

FREDHEIM, G. E.; CHRISTENSEN, B. E. Polyelectrolyte complexes: Interactions between lignosulfonate and chitosan. Biomacromolecules, v. 4, n. 2, p. 232-9, 2003.

FROLLINI, E.; SILVA, C. G.; RAMIRES, E. C. Phenolic resins as a matrix material in advanced fiber-reinforced polymer (frp) composites. In: BAI, J. (Ed.). Advanced fibre-reinforced polymer (frp) composites for structural applications. Cambridge: Woodhead Publishing, 20I3. p. 7-43.

GANDINI, A.; BELGACEM, M. N. Recent contributions to the preparation of polymers derived from renewable resources. Journal of Polymers and the Environment, v. I0, n. 3, p. 105-II4, 2002.

GANDINI, A.; BELGACEM, M. N. Partial or total oxyproylation of natural polymers and use of the ensuing materials as composites or polyol macromonomers. In: BELGACEM, M. N.; GANDINI, A. (Ed.). Monomers, polymers and composites from renewable resources. Amsterdam: Elsevier, 2008. p. 273-288.

GANETRI, I.; TIGHZERT, L.; DONY, P.; CHALLIOUI, A. New composites based on castor oil with isophorone diisocyanate polyurethanes and cellulose fibers. Journal of Materials and Environmental Science, v. 4, n. 4, p. 57I-582, 2013.

GEORGOPOULOS, S. T.; TARANTILI, P. A.; AVGERINOS, E.; ANDREOPOULOS, A. G.; KOUKIOS, E. G. Thermoplastic polymers reinforced with fibrous agricultural residues. Polymer Degradation and Stability, v. 90, n. 2, p. 303-3I2, 2005. 
GHARIBI, R.; YOUSEFI, M.; YEGANEH, H. Synthesis, characterization and assessment of poly(urethane-co-pyrrole)s derived from castor oil as anticorrosion coatings for stainless steel. Progress in Organic Coatings, v. 76, n. I0, p. I454-I464, 2013.

GLASSER, W. G.; BARNETT, C. A.; RIALS, T. G.; SARAF, V. P. Engineering plastics from lignin ii. Characterization of hydroxyalkyl lignin derivatives. Journal of Applied Polymer Science, v. 29, n. 5, p. 1815-1830, 1984.

GOLDSCHMID, O. Determination of phenolic hydroxyl content of lignin preparations by ultraviolet spectrophotometry. Analytical Chemistry, v. 26, n. 9, p. I42I-I423, 1954.

GOLDSCHMID, O. Ultraviolet spectra. In: SARKANEN, K. V.; LUDWIG, C. H. (Ed.). Lignins: occurrence, formations, structures, and reactions. New York: Wiley-Interscience, 197I. p. 24I-266.

GUAN, J.; SONG, Y.; LIN, Y.; YIN, X.; ZUO, M.; ZHAO, Y.; TAO, X.; ZHENG, Q. Progress in study of non-isocyanate polyurethane. Industrial \& Engineering Chemistry

Research, v. 50, n. II, p. 6517-6527, 201 I.

GUIMARÃES, J. L.; FROLLINI, E.; DA SILVA, C. G.; WYPYCH, F.; SATYANARAYANA, K. G. Characterization of banana, sugarcane bagasse and sponge gourd fibers of brazil. Industrial Crops and Products, v. 30, n. 3, p. 407-4I5, 2009.

GUO, Z.-X.; GANDINI, A. Polyesters from lignin-2. The copolyesterification of kraft lignin and polyethylene glycols with dicarboxylic acid chlorides. European Polymer Journal, v. 27, n. II, p. II77-II80, I99I.

HABIBI, Y.; EL-ZAWAWY, W. K.; IBRAHIM, M. M.; DUFRESNE, A. Processing and characterization of reinforced polyethylene composites made with lignocellulosic fibers from egyptian agro-industrial residues. Composites Science and Technology, v. 68, n. 7-8, p. I877-I885, 2008.

HATAKEYAMA, H.; HIROGAKI, A.; MATSUMURA, H.; HATAKEYAMA, T. Glass transition temperature of polyurethane foams derived from lignin by controlled reaction rate. Journal of Thermal Analysis and Calorimetry, v. II4, n. 3, p. 1075-1082, 2013.

HATAKEYAMA, H.; KOSUGI, R.; HATAKEYAMA, T. Thermal properties of lignin-and molasses-based polyurethane foams. Journal of Thermal Analysis and Calorimetry, v. 92, n. 2, p. 419-424, 2008.

HATAKEYAMA, H.; NAKAYACHI, A.; HATAKEYAMA, T. Thermal and mechanical properties of polyurethane-based geocomposites derived from lignin and molasses. Composites Part A: Applied Science and Manufacturing, v. 36, n. 5, p. 698-704, 2005.

HATAKEYAMA, T.; ASANO, Y.; HATAKEYAMA, H. Mechanical and thermal properties of rigid polyurethane foams derived from sodium lignosulfonate mixed with diethylene-, 
triethylene- and polyethylene glycols. Macromolecular Symposia, v. 197, n. I, p. I7I-I80, 2003.

HATAKEYAMA, T.; MATSUMOTO, Y.; ASANO, Y.; HATAKEYAMA, H. Glass transition of rigid polyurethane foams derived from sodium lignosulfonate mixed with diethylene, triethylene and polyethylene glycols. Thermochimica Acta, v. 4I6, n. I-2, p. 29-33, 2004.

HERAKOVICH, C. T. Mechanics of fibrous composites. New York: John-Wiley, 1998. $480 \mathrm{p}$.

HU, S.; LUO, X.; LI, Y. Polyols and polyurethanes from the liquefaction of lignocellulosic biomass. ChemSusChem, v. 7, n. I, p. 66-72, 2014.

HUO, S.-P.; NIE, M.-C.; KONG, Z.-W.; WU, G.-M.; CHEN, J. Crosslinking kinetics of the formation of lignin-aminated polyol-based polyurethane foam. Journal of Applied Polymer Science, v. I25, n. I, p. I52-157, 201 I.

HUO, S.-P.; WU, G.-M.; CHEN, J.; LIU, G.-F.; KONG, Z.-W. Curing kinetics of lignin and cardanol based novolac epoxy resin with methyl tetrahydrophthalic anhydride.

Thermochimica Acta, v. 587, p. 18-23, 2014.

IBRAHIM, M. N. M.; LIM, S. L.; AHMED-HARAS, M. R.; FAYYADH, F. S. Preparation and characterization of lignin graft copolymer as a filtrate loss control agent for the hydrocarbon drilling industry. Bioresources, v. 9, n. I, p. I472-I487, 2014.

IONESCU, M. Chemistry and technology of polyols for polyurethanes. Shrewsbury: Rapra Technology, 2005. 602 p.

ISLAM, M. N.; RAHMAN, M. R.; HAQUE, M. M.; HUQUE, M. M. Physico-mechanical properties of chemically treated coir reinforced polypropylene composites. Composites Part A: Applied Science and Manufacturing, v. 4I, n. 2, p. 192-198, 2010.

ISMAIL, T. N. M. T.; HASSAN, H. A.; HIROSE, S.; TAGUCHI, Y.; HATAKEYAMA, T.; HATAKEYAMA, $H$. Synthesis and thermal properties of ester-type crosslinked epoxy resins derived from lignosulfonate and glycerol. Polymer International, p. I8I-I86, 2009.

JAKAB, E.; FAIX, O.; TILL, F.; SZEKELY, T. The effect of cations on the thermal decomposition of lignins. Journal of Analytical and Applied Pyrolysis, v. 25, p. I85-194, 1993.

JAWAID, M.; ABDUL KHALIL, H. P. S. Cellulosic/synthetic fibre reinforced polymer hybrid composites: A review. Carbohydrate Polymers, v. 86, n. I, p. I-I8, 201 I.

JIANG, D.; LIU, L.; ZHAO, F.; ZHANG, Q.; SUN, S.; HE, J.; JIANG, B.; HUANG, Y. Improved interfacial properties of carbon fiber/unsaturated polyester composites through coating polyhedral oligomeric silsesquioxane on carbon fiber surface. Fibers and

Polymers, v. I5, n. 3, p. 566-573, 2014. 
JOHN, M.; THOMAS, S. Biofibres and biocomposites. Carbohydrate Polymers, v. 7I, n. 3, p. 343-364, 2008.

KALIA, S.; THAKUR, K.; CELLI, A.; KIECHEL, M. A.; SCHAUER, C. L. Surface modification of plant fibers using environment friendly methods for their application in polymer composites, textile industry and antimicrobial activities: A review. Journal of

Environmental Chemical Engineering, v. I, n. 3, p. 97-II2, 2013.

KATHALEWAR, M. S.; JOSHI, P. B.; SABNIS, A. S.; MALSHE, V. C. Non-isocyanate polyurethanes: From chemistry to applications. RSC Advances, v. 3, n. I3, p. 4II0, 2013.

KAUSHIK, A.; GARG, A. Castor oil based polyurethane nanocomposites with cellulose nanocrystallites fillers. Advanced Materials Research, v. 856, p. 309-3I3, 20 I4.

KELLEY, S. S.; GLASSER, W. G.; WARD, T. C. Multiphase materials with lignin: 9. Effect of lignin content on interpenetrating polymer network properties. Polymer, v. 30, n. I2, p. 2265-2268, 1989.

KIM, S.; SILVA, C.; ZILLE, A.; LOPEZ, C.; EVTUGUIN, D. V.; CAVACO-PAULO, A. Characterisation of enzymatically oxidised lignosulfonates and their application on lignocellulosic fabrics. Polymer International, v. 58, n. 8, p. 863-868, 2009.

KIZILCAN, N. Lignosulphonate modified ketonic resins. Pigment and Resin Technology, v. 4I, n. 3, p. I63-I7I, 2012.

KOMPELLA, M. K.; LAMBROS, J. Micromechanical characterization of cellulose fibers.

Polymer Testing, v. 2I, n. 5, p. 523-530, 2002.

KRICHELDORF, H. R.; NUYKEN, O.; SWIFT, G. Handbook of polymer synthesis. New York: Marcel Dekker, 2005. 946 p.

KROL, P. Synthesis methods, chemical structures and phase structures of linear polyurethanes. Properties and applications of linear polyurethanes in polyurethane elastomers, copolymers and ionomers. Progress in Materials Science, v. 52, n. 6, p. 9I5I0I5, 2007.

LA MANTIA, F. P.; MORREALE, M. Green composites: A brief review. Composites Part A: Applied Science and Manufacturing, v. 42, n. 6, p. 579-588, 201 I.

LAMBA, N. M. K.; WOODHOUSE, K. A.; COOPER, S. L. Polyurethanes in biomedical applications. Boca Raton: CRC, 1998. 28I p.

LAPPRAND, A.; BOISSON, F.; DELOLME, F.; MÉCHIN, F.; PASCAULT, J. P. Reactivity of isocyanates with urethanes: Conditions for allophanate formation. Polymer Degradation and Stability, v. 90, n. 2, p. 363-373, 2005.

LAURICHESSE, S.; AVÉROUS, L. Chemical modification of lignins: Towards biobased polymers. Progress in Polymer Science, v. 39, n. 7, p. I266-I290, 20 I4. 
LEE, N.; KWON, O.-J.; CHUN, B. C.; CHO, J. W.; PARK, J.-S. Characterization of castor oil/polycaprolactone polyurethane biocomposites reinforced with hemp fibers. Fibers and Polymers, v. 10, n. 2, p. 154-160, 2009.

LI, X. F. Preparation and properties of biodegradable sodium lignosulfonate/poly(vinyl alcohol) blend films. Advanced Materials Research, v. 160-I62, p. 676-68I, 2010.

LI, Y.; HU, C.; YU, Y. Interfacial studies of sisal fiber reinforced high density polyethylene (hdpe) composites. Composites Part A: Applied Science and Manufacturing, v. 39, n. 4, p. 570-578, 2008.

LI, Y.; RAGAUSKAS, A. J. Kraft lignin-based rigid polyurethane foam. Journal of Wood Chemistry and Technology, v. 32, n. 3, p. 210-224, 2012.

LIN, S.; HUANG, J.; CHANG, P. R.; WEI, S.; XU, Y.; ZHANG, Q. Structure and mechanical properties of new biomass-based nanocomposite: Castor oil-based polyurethane reinforced with acetylated cellulose nanocrystal. Carbohydrate Polymers, v. 95, n. I, p. 9I-99, 2013.

LIU, X.; XU, Y.; YU, J.; LI, S.; WANG, J.; WANG, C.; CHU, F. Integration of lignin and acrylic monomers towards grafted copolymers by free radical polymerization. International Journal of Biological Macromolecules, v. 67, n. 0, p. 483-489, 2014.

LORA, J. Industrial commercial lignins: Sources, properties and applications. In: BELGACEM, M. N.; GANDINI, A. (Ed.). Monomers, polymers and composites from renewable resources. Amsterdam: Elsevier, 2008. p. 225-24I.

LORA, J. H.; GLASSER, W. G. Recent industrial applications of lignin: A sustainable alternative to nonrenewable materials. Journal of Polymers and the Environment, $v$. I0, n. I-2, p. 39-48, 2002.

MA, C.; BU, Y.; CHEN, B. Preparation and performance of a lignosulfonate-amps-itaconic acid graft copolymer as retarder for modified phosphoaluminate cement. Construction and Building Materials, v. 60, n. 0, p. 25-32, 2014.

MAHMOOD, N.; YUAN, Z.; SCHMIDT, J.; CHARLES XU, C. Production of polyols via direct hydrolysis of kraft lignin: Effect of process parameters. Bioresource Technology, $v$. 139, p. I3-20, 2013.

MARINHO, N. P.; NASCIMENTO, E. M.; NISGOSKI, S.; MAGALHÃES, W. L. E.; CLARO NETO, S.; AZEVEDO, E. C. Physical and thermal characterization of polyurethane based on castor oil composite with bamboo particles. Polimeros, v. 23, n. 2, p. 20I-205, 2013.

MARTIN, A. R.; MARTINS, M. A.; MATTOSO, L. H. C.; SILVA, O. R. R. F. Chemical and structural characterization of sisal fibers from agave sisalana variety. Polímeros, v. 19, n. I, p. 40-46, 2009. 
MAZUMDAR, S. K. Composites manufacturing: materials, products and processing engineering. Boca Raton: CRC, 2002. 420 p.

MEGIATTO, J. D.; SILVA, C. G.; ROSA, D. S.; FROLLINI, E. Sisal chemically modified with lignins: Correlation between fibers and phenolic composites properties. Polymer Degradation and Stability, v. 93, n. 6, p. I I09-I I II, 2008.

MEGIATTO JUNIOR, J. D.; HOAREAU, W.; GARDRAT, C.; FROLLINI, E.; CASTELLAN, A. Sisal fibers: Surface chemical modification using reagent obtained from a renewable source; characterization of hemicellulose and lignin as model study. Journal of Agricultural and Food Chemistry, v. 55, n. 21, p. 8576-8584, 2007.

MEGIATTO JUNIOR , J. D.; OLIVEIRA, F. B.; ROSA, D. S.; GARDRAT, C.; CASTELLAN, A.; FROLLINI, E. Renewable resources as reinforcement of polymeric matrices: Composites based on phenolic thermosets and chemically modified sisal fibers. Macromolecular bioscience, v. 7, n. 9-10, p. II2I-3I, 2007.

MELO, B. N.; PASA, V. M. D. Composites based on eucalyptus tar pitch/castor oil polyurethane and short sisal fibers. Journal of Applied Polymer Science, v. 89, p. 37973802, 2002.

MIAO, S.; WANG, P.; SU, Z.; ZHANG, S. Vegetable-oil-based polymers as future polymeric biomaterials. Acta Biomaterialia, v. 10, n. 4, p. 1692-704, 2014.

MISHRA, S.; MOHANTY, A. K.; DRZAL, L. T.; MISRA, M.; HINRICHSEN, G. A review on pineapple leaf fibers, sisal fibers and their biocomposites. Macromolecular Materials and Engineering, v. 289, n. I I, p. 955-974, 2004.

MOHAMED, M.; VUPPALAPATI, R. R.; BHEEMREDDY, V.; CHANDRASHEKHARA, K.; SCHUMAN, T. Characterization of polyurethane composites manufactured using vacuum assisted resin transfer molding. Advanced Composite Materials, 2014. No prelo. Disponível em: <http://www.tandfonline.com/doi/pdf/I0.1080/09243046.20 I4.909975>. Acesso em: 24 set. 2014 .

MOHAN, P. A critical review: The modification, properties, and applications of epoxy resins. Polymer-Plastics Technology and Engineering, v. 52, n. 2, p. 107-I25, 2013.

MOHANTY, A. K.; MISRA, M.; DRZAL, L. T.; SELKE, S. E.; HARTE, B. R.; HINRICHSEN, G. Natural fibers, biopolymers, and biocomposites: An introduction. In: MOHANTY, A. K.; MISRA, M.; DRZAL, L. T. (Ed.). Natural fibers, biopolymers, and biocomposites. Boca Raton: Taylor \& Francis, 2005. p. I-36.

MONTEIRO, S. N.; LOPES, F. P. D.; FERREIRA, A. S.; NASCIMENTO, D. C. O. Natural-fiber polymer-matrix composites: Cheaper, tougher, and environmentally friendly. Journal of the Minerals, Metals and Materials Society, v. 6I, n. I, p. 17-22, 2009.

MOREL, É. Matrices organiques. In: BATHIAS, C. (Ed.). Matériaux composites 2e édition. Paris: Dunod, 2009. p. 31-72. 
MORRAL-RUIZ, G.; MELGAR-LESMES, P.; GARCIA, M. L.; SOLANS, C.; GARCIA-CELMA, $M$. J. Polyurethane and polyurea nanoparticles based on polyoxyethylene castor oil derivative surfactant suitable for endovascular applications. International Journal of

Pharmaceutics, v. 46I, n. I-2, p. I-I3, 2014.

MOUSAVIOUN, P.; HALLEY, P. J.; DOHERTY, W. O. S. Thermophysical properties and rheology of phb/lignin blends. Industrial Crops and Products, v. 50, p. 270-275, 2013.

MOZHEIKO, L. N.; GROMOVA, M. F.; BAKALO, L. A.; SERGEYEVA, V. N. Polyurethanes prepared from oxypropylated lignin. Polymer Science U.S.S.R., v. 23, n. I, p. |4I-I49, 1981.

MUKHERJEE, T.; KAO, N. Pla based biopolymer reinforced with natural fibre: A review. Journal of Polymers and the Environment, v. I9, n. 3, p. 7I4-725, 201 I.

MYRVOLD, B. O. A new model for the structure of lignosulphonates. Industrial Crops and Products, v. 27, n. 2, p. 214-219, 2008.

NADA, A. M. A.; YOUSEF, M. A.; SHAFFEI, K. A.; SALAH, A. M. Lignin from waste black liquors - ii: Different lignins in phenol formaldehyde resin. Pigment and Resin Technology, v. 28, n. 3, p. 143-148, 1999.

NADJI, H.; BRUZZĖSE, C.; BELGACEM, M. N.; BENABOURA, A.; GANDINI, A. Oxypropylation of lignins and preparation of rigid polyurethane foams from the ensuing polyols. Macromolecular Materials and Engineering, v. 290, n. 10, p. 1009-1016, 2005.

NAVARRETE, P.; PIZZI, A.; PASCH, H.; DELMOTTE, L. Study on lignin-glyoxal reaction by maldi-tof and cP-mas I3c-nmr. Journal of Adhesion Science and Technology, v. 26, n. 8-9, p. 1069-1082, 2012.

OLIVEIRA, F. Lignossulfonato de sódio como agente de modificação de fibras lignocelulósicas e da formulação de termorrígido fenólico. 2010. I37f. Dissertação (Mestrado em Físico-Química) - Instituto de Química de São Carlos, Universidade de São Paulo, São Carlos, 2010.

PAIVA, J. M. F. Compósitos de matrizes termorrígidas fenólicas e lignofenólicas reforçadas com fibras vegetais. 200I. 266f. Tese (Doutorado) - Programa Interunidades em Ciência e Engenharia de Materiais - IQSC/EESC/IFSC, Universidade de São Paulo, São Carlos, 2001.

PAIVA, J. M. F.; TRINDADE, W. G.; FROLLINI, E. Phenolic - matrix composites reinforced with natural fibers. Polímeros: Ciência e Tecnologia, v. 9, p. 170-I76, 1999.

PAN, X.; SADDLER, J. N. Effect of replacing polyol by organosolv and kraft lignin on the property and structure of rigid polyurethane foam. Biotechnology for Biofuels, v. 6, n. I2, p. I-10, 2013. 
PATURAU, J. M. By-products of the cane sugar industry: an introduction to their industrial utilization. 3.ed. Amsterdam: Elsevier, 1989. 436 p.

PAVIER, C.; GANDINI, A. Oxypropylation of sugar beet pulp. I. Optimisation of the reaction. Industrial Crops and Products, v. I2, n. I, p. I-8, 2000a.

PAVIER, C.; GANDINI, A. Urethanes and polyurethanes from oxypropylated sugar beet pulp: I. Kinetic study in solution. European Polymer Journal, v. 36, n. 8, p. I653-1658, 2000b.

PAVIER, C.; GANDINI, A. Oxypropylation of sugar beet pulp. 2. Separation of the grafted pulp from the propylene oxide homopolymer. Carbohydrate Polymers, v. 42, p. 13-17, 2000.

PÉREZ, J. M.; FERNÁNDEZ, A. Thermal stability and pyrolysis kinetics of lignin-phenolformaldehyde resins. Journal of Applied Polymer Science, v. I23, n. 5, p. 3036-3045, 2012 .

PÉREZ, J. M.; RODRÍGUEZ, F.; ALONSO, M. V.; OLIET, M.; ECHEVERRÍA, J. M. Characterization of a novolac resin substituting phenol by ammonium lignosulfonate as filler or extender. Bioresources, v. 2, n. 2, p. 270-283, 2007.

PETROVIĆ, Z. S.; FERGUSON, J. Polyurethane elastomers. Progress in Polymer Science, v. 16, n. 5, p. 695-836, 1991.

POHJANLEHTO, H.; SETÄLÄ, H. M.; E. KIELY, D.; MCDONALD, A. G. Lignin-xylaric acidpolyurethane-based polymer network systems: Prearation and characterization. Journal of Applied Polymer Science, v. I3I, n. I, 20I4. No prelo. Disponível em: <http://onlinelibrary.wiley.com/doi/I0.1002/app.397/4/pdf>. Acesso em: 24 set. 20 I4.

POUTEAU, C.; BAUMBERGER, S.; CATHALA, B.; DOLE, P. Lignin-polymer blends: Evaluation of compatibility by image analysis. Comptes Rendus Biologies, v. 327, n. 9-I0, p. 935-943, 2004.

PRISACARIU, C. Polyurethane elastomers from morphology to mechanical aspects. Wien: Springer Verlag, 20I I. 255 p.

PUCCIARIELLO, R.; VILLANI, V.; BONINI, C.; D'AURIA, M.; VETERE, T. Physical properties of straw lignin-based polymer blends. Polymer, v. 45, n. I2, p. 4I59-4I69, 2004.

PURSLOW, D. Matrix fractography of fibre-reinforced epoxy composites. Composites, v. I7, n. 4, p. 289-303, 1986.

QIU, X.; KONG, Q.; ZHOU, M.; YANG, D. Aggregation behavior of sodium lignosulfonate in water solution. Journal of Physical Chemistry B, v. I I4, p. I5857-I586 I, 20 I0. 
RAGHUNANAN, L.; YUE, J.; NARINE, S. Synthesis and characterization of novel diol, diacid and di-isocyanate from oleic acid. Journal of the American Oil Chemists' Society, v. 9I, n. 2, p. 349-356, 2014.

RAMIRES, E. C.; DE OLIVEIRA, F.; FROLLINI, E. Composites based on renewable materials: Polyurethane-type matrices from forest byproduct/vegetable oil and reinforced with lignocellulosic fibers. Journal of Applied Polymer Science, v. 129, n. 4, p. 2224-2233, 2013.

RAMIRES, E. C.; MEGIATTO, J. D.; GARDRAT, C.; CASTELLAN, A.; FROLLINI, E. Valorization of an industrial organosolv-sugarcane bagasse lignin: Characterization and use as a matrix in biobased composites reinforced with sisal fibers. Biotechnology and Bioengineering, v. 107, n. 4, p. 612-62I, 2010.

RAMIRES, E. C.; MEGIATTO JUNIOR, J. D.; GARDRAT, C.; CASTELLAN, A.; FROLLINI, E. Biobased composites from glyoxal-phenolic resins and sisal fibers. Bioresource Technology, v. I0I, n. 6, p. 1998-2006, 2010.

RAMZY, A.; BEERMANN, D.; STEUERNAGEL, L.; MEINERS, D.; ZIEGMANN, G. Developing a new generation of sisal composite fibres for use in industrial applications. Composites Part B: Engineering, v. 66, p. 287-298, 2014.

RANGEL-VÁZQUEZ, N. A.; SALGADO-DELGADO, R.; GARCÍA-HERNÁNDEZ, E.; MENDOZA-MARTÍNEZ, A. M. Characterization of copolymer based in polyurethane and polyaniline (pu/pani). Journal of the Mexican Chemical Society, v. 53, n. 4, p. 248-252, 2009.

RAQUEZ, J. M.; DELÉGLISE, M.; LACRAMPE, M. F.; KRAWCZAK, P. Thermosetting (bio)materials derived from renewable resources: A critical review. Progress in Polymer Science, v. 35, n. 4, p. 487-509, 2010.

RATNA, D. Thermal properties of thermosets. In: GUO, Q. (Ed.). Thermosets: structure, properties and applications. Cambridge: Woodhead, 2012. p. 62-9I.

RIBEIRO, B. D.; BARRETO, D. W.; COELHO, M. A. Z. Use of micellar extraction and cloud point preconcentration for valorization of saponins from sisal (agave sisalana) waste. Food and Bioproducts Processing, 2014. No prelo. Disponível em: <http://www.sciencedirect.com/science/article/pii/S09603085 I4000777>. Acesso em: 24 set. 2014.

RIBEIRO DA SILVA, V.; MOSIEWICKI, M. A.; YOSHIDA, M. I.; COELHO DA SILVA, M.; STEFANI, P. M.; MARCOVICH, N. E. Polyurethane foams based on modified tung oil and reinforced with rice husk ash ii: Mechanical characterization. Polymer Testing, v. 32, n. 4, p. $665-672,2013$.

RISTIĆ, I. S.; BUDINSKI-SIMENDIĆ, J.; KRAKOVSKY, I.; VALENTOVA, H.; RADIČEVIĆ, R.; CAKIĆ, S.; NIKOLIĆ, N. The properties of polyurethane hybrid materials based on castor oil. Materials Chemistry and Physics, v. I32, n. I, p. 74-8I, 2012. 
RODRIGUEZ, J. M. P. Estúdio del curado de resinas ligno-novolacas. Propriedades termomecânicas de los produtos curados. 2005. 327f. (Doctorado em Ciencias Químicas) - Facultad de Ciencias Quimicas - Departamento de Ingenieria Quimica, Universidad Complutense de Madrid, Madrid, 2005.

ROWELL, R. M.; HAN, S. J. Characterization and factors effecting fiber properties. In: FROLLINI, E.; LEÃO, A. L.; MATTOSO, L. H. C. (Ed.). Natural polymers and agrofibers based composites. São Paulo: USP/UNESP/EMBRAPA, 2000. p. 25-48.

RUDNITSKAYA, A.; EVTUGUIN, D. V.; COSTA, L. C.; GRACA, M. P.; FERNANDES, A. J;; CORREIA, M. R.; GOMES, M. T.; OLIVEIRA, J. A. Potentiometric chemical sensors from lignin-poly(propylene oxide) copolymers doped by carbon nanotubes. Analyst, v. I38, n. 2, p. $501-8,2013$.

SADEGHIFAR, H.; CUI, C.; ARGYROPOULOS, D. S. Toward thermoplastic lignin polymers. Part I. Selective masking of phenolic hydroxyl groups in kraft lignins via methylation and oxypropylation chemistries. Industrial \& Engineering Chemistry Research, v. 5I, n. 5I, p. $16713-16720,2012$.

SAHOO, S.; MISRA, M.; MOHANTY, A. K. Biocomposites from switchgrass and lignin hybrid and poly(butylene succinate) bioplastic: Studies on reactive compatibilization and performance evaluation. Macromolecular Materials and Engineering, v. 299, n. 2, p. I78-|89, 2014.

SAITO, T.; PERKINS, J. H.; JACKSON, D. C.; TRAMMEL, N. E.; HUNT, M. A.; NASKAR, A. K. Development of lignin-based polyurethane thermoplastics. RSC Advances, v. 3, n. 44, p. $21832,2013$.

SANTOS, F.; CURVELO, A. A. S. Utilização de ligninas em resinas fenólicas. I preparação de novolacas a partir de lignossulfonatos. Polímeros: Ciência e Tecnologia, v. 9, n. I, p. 4958, 1999.

SARALEGI, A.; GONZALEZ, M. L.; VALEA, A.; ECEIZA, A.; CORCUERA, M. A. The role of cellulose nanocrystals in the improvement of the shape-memory properties of castor oilbased segmented thermoplastic polyurethanes. Composites Science and Technology, v. 92, p. 27-33, 2014.

SASAKI, C.; WANAKA, M.; TAKAGI, H.; TAMURA, S.; ASADA, C.; NAKAMURA, Y. Evaluation of epoxy resins synthesized from steam-exploded bamboo lignin. Industrial Crops and Products, v. 43, p. 757-76I, 2013.

SAUNDERS, K. J. Organic polymer chemistry. London: Chapman \& Hall, 1988. 502 p.

SCHNEIDER, M. H.; PHILLIPS, J. G. Furfuryl alcohol and lignin adhesive composition. n. US6747076, 2004. 
SCHNEIDER, R. C. S. Extração, caracterização e transformação do óleo de rícino. 2002. 205f. (Doutorado em Química) - Instituto de Química, Universidade Federal do Rio Grande do Sul, Porto Alegre, 2002.

SHEN, Q.; ZHANG, T.; ZHU, M.-F. A comparison of the surface properties of lignin and sulfonated lignins by ftir spectroscopy and wicking technique. Colloids and Surfaces A: Physicochemical and Engineering Aspects, v. 320, n. I-3, p. 57-60, 2008.

SHIKINAKA, K.; HASHIMOTO, Y.; KAJITA, S.; MASAI, E.; KATAYAMA, Y.; NAKAMURA, M.; OTSUKA, Y.; OHARA, S.; SHIGEHARA, K. Thermoplastic polyesters of 2-pyrone-4,6dicarboxylic acid (pdc) obtained from a metabolic intermediate of lignin. Sen-I Gakkaishi, v. 69 , n. 2, p. 39-47, 2013.

SHOGREN, R. L.; BISWAS, A. Preparation of starch-sodium lignosulfonate graft copolymers via laccase catalysis and characterization of antioxidant activity. Carbohydrate polymers, v. 91, n. 2, p. 58I-5, 2013.

SHUL'GA, N. V.; GOMOLKO, L. A.; KRUT'KO, N. P. Dependence of composition and characteristics of lignosulfonates on the procedures of their recovery and purification. Russian Journal of Applied Chemistry, v. 8I, n. 7, p. I245-I25I, 2008.

SILVA, C. G.; BENADUCCI, D.; FROLLINI, E. Lyocell and cotton fibers as reinforcements for a thermoset polymer. Bioresources, v. 7, n. I, p. 78-98, 2012.

SILVA, C. G.; OLIVEIRA, F.; RAMIRES, E. C.; CASTELLAN, A.; FROLLINI, E. Composites from a forest biorefinery by-product and agrofibers: Lignosulfonate-phenolic type matrices reinforced with sisal fibers Tappi Journal, v. II, n. 9, p. 4I-49, 20 I2.

SILVA, E. A. B.; ZABKOVA, M.; ARAÚJO, J. D.; CATETO, C. A.; BARREIRO, M. F.; BELGACEM, M. N.; RODRIGUES, A. E. An integrated process to produce vanillin and ligninbased polyurethanes from kraft lignin. Chemical Engineering Research and Design, v. 87, n. 9, p. 1276-1292, 2009.

SILVERSTEIN, R. M.; BASSLER, G. C.; MORRIL, T. C. Identificação espectrométrica de compostos orgânicos. Rio de Janeiro: Guanabara Koogan, 1994. 460 p.

SINGHA, A. S.; RANA, R. K. Chemically induced graft copolymerization of acrylonitrile onto lignocellulosic fibers. Journal of Applied Polymer Science, v. 124, n. 3, p. I89 I-1898, 2012.

SINGHA, A. S.; THAKUR, V. K. Fabrication of hibiscus sabdariffa fibre reindforced polymer composites. Iranian Polymer Journal, v. I7, n. 7, p. 54I-553, 2008.

SIVASANKARAPILLAI, G.; MCDONALD, A. G.; LI, H. Lignin valorization by forming toughened lignin-co-polymers: Development of hyperbranched prepolymers for crosslinking. Biomass and Bioenergy, v. 47, p. 99-108, 2012. 
SPRENGER, S. Epoxy resin composites with surface-modified silicon dioxide nanoparticles: A review. Journal of Applied Polymer Science, v. I30, n. 3, p. I42 I- I428, 20 I 3.

STIRNA, U.; FRIDRIHSONE, A.; LAZDIN̦A, B.; MISĀNE, M.; VILSONE, D. Biobased polyurethanes from rapeseed oil polyols: Structure, mechanical and thermal properties. Journal of Polymers and the Environment, v. 2I, n. 4, p. 952-962, 2012.

STRASSBERGER, Z.; TANASE, S.; ROTHENBERG, G. The pros and cons of lignin valorisation in an integrated biorefinery. RSC Advances, v. 4, n. 48, p. 25310, 2014.

SUN, S.; BAI, R.; GU, Y. From waste biomass to solid support: Lignosulfonate as a costeffective and renewable supporting material for catalysis. Chemistry, v. 20, n. 2, p. 549-58, 2014.

SZYCHER, M. Szycher's handbook of polyurethanes. Boca Raton: CRC, 1999. 700 p.

TANAMACHI, N.; HATAKEYAMA, H.; FUNABASHI, M.; HATAKEYAMA, T. Thermal diffusivity of polyurethane composites filled with industrial waste fabrics. Sen'i Gakkaishi, v. 63, n. 7, p. 182-184, 2007.

THAKUR, S.; KARAK, N. Ultratough, ductile, castor oil-based, hyperbranched, polyurethane nanocomposite using functionalized reduced graphene oxide. ACS Sustainable Chemistry \& Engineering, v. 2, n. 5, p. II95-I202, 2014.

THIELEMANS, W.; WOOL, R. P. Lignin esters for use in unsaturated thermosets: Lignin modification and solubility modeling. Biomacromolecules, v. 6, n. 4, p. 1895-1905, 2005.

THOMASON, J. L.; CARRUTHERS, J.; KELLY, J.; JOHNSON, G. Fibre cross-section determination and variability in sisal and flax and its effects on fibre performance characterisation. Composites Science and Technology, v. 7I, n. 7, p. I008-I0I5, 20 II.

TRINDADE, W. G.; HOAREAU, W.; MEGIATTO, J. D.; RAZERA, I. A. T.; CASTELLAN, A.; FROLLINI, E. Thermoset phenolic matrices reinforced with unmodified and surface-grafted furfuryl alcohol sugar cane bagasse and curaua fibers: Properties of fibers and composites. Biomacromolecules, v. 6, n. 5, p. 2485-2496, 2005.

TRUTER, P.; PIZZI, A.; VERMAAS, H. Cold-setting wood adhesives from kraft hardwood lignin. Journal of Applied Polymer Science, v. 5I, n. 7, p. 1319-1322, 1994.

VALERO, M. F.; GONZALEZ, A. Polyurethane adhesive system from castor oil modified by a transesterification reaction. Journal of Elastomers and Plastics, v. 44, n. 5, p. 433-442, 2012.

VANDERLAAN, M. N.; THRING, R. W. Polyurethanes from alcell@ lignin fractions obtained by sequential solvent extraction. Biomass and Bioenergy, v. I4, n. 5-6, p. 525-53I, I 998. 
VERONESE, V. B.; MENGER, R. K.; FORTE, M. M. D. C.; PETZHOLD, C. L. Rigid polyurethane foam based on modified vegetable oil. Journal of Applied Polymer Science, v. I20, n. I, p. 530-537, 201 I.

VILAR, W. D. Química e tecnologia de poliuretanos. Rio de Janeiro: Vilar Consultoria, 2005. $400 \mathrm{p}$.

VISHTAL, A.; KRASLAWSKI, A. Challenges in industrial applications of technical lignins. BioResources, v. 6, n. 3, p. 3547-3568, $201 \mathrm{I}$.

WAMBUA, P.; IVENS, J.; VERPOEST, I. Natural fibres: Can they replace glass in fibre reinforced plastics? Composites Science and Technology, v. 63, n. 9, p. 1259-1264, 2003.

WANG, H.; NI, Y.; JAHAN, M. S.; LIU, Z.; SCHAFER, T. Stability of cross-linked acetic acid lignin-containing polyurethane. Journal of Thermal Analysis and Calorimetry, v. 103, n. I, p. 293-302, 2010.

WANG, H. H.; MOU, J.; NI, Y. H.; FEI, G. Q.; SI, C. L.; ZOU, J. Phase behavior, interaction and properties of acetic acid lignin-containing polyurethane films coupled with aminopropyltriethoxy silane. Express Polymer Letters, v. 7, n. 5, p. 443-455, 2013.

WANG, H. J.; ZHANG, C. Y.; RONG, M. Z.; ZHANG, M. Q.; CZIGÁNY, T. Interfacial effects in short sisal fiber/maleated castor oil foam composites. Composite Interfaces, v. I5, n. 2-3, p. 95-II0, 2008.

WANG, Q.; CHEN, G. X.; CHEN, S. L. Preparation of contamination free polyurethane adhesive based on biopolymer castor oil. Materials Research Innovations, v. I7, n. Supplement I, p. I62-165, 2013.

WEXLER, A. S. Characterization of lignosulfonates by ultraviolet spectrometry. Direct and difference spectrograms. Analytical Chemistry, v. 36, n. I, p. 213-22I, 1964.

WU, L. C. F.; GLASSER, W. G. Engineering plastics from lignin. I. Synthesis of hydroxypropyl lignin. Journal of Applied Polymer Science, v. 29, n. 4, p. I I I I- I 23, 1984.

XIANG, Y.; XU, W.; ZHAN, Y.; XIA, X.; XIONG, Y.; XIONG, Y.; CHEN, L. Preparation of modified sodium lignosulfonate hydrogel-silver nanocomposites. Polymer Composites, v. 34, n. 6, p. 860-866, 2013.

XUE, B.-L.; WEN, J.-L.; SUN, R.-C. Lignin-based rigid polyurethane foam reinforced with pulp fiber: Synthesis and characterization. ACS Sustainable Chemistry \& Engineering, v. 2, n. 6, p. |474-|480, $20 \mid 4$.

XUE, B.-L.; WEN, J.-L.; XU, F.; SUN, R.-C. Polyols production by chemical modification of autocatalyzed ethanol-water lignin from betula alnoides. Journal of Applied Polymer Science, p. 434-442, 2012. 
ZÁRATE, C. N.; ARANGUREN, M. I.; REBOREDO, M. M. Influence of fiber volume fraction and aspect ratio in resol-sisal composites. Journal of Applied Polymer Science, v. 89, n. I0, p. 27|4-2722, 2003.

ZHOU, H.; YANG, D.; QIU, X.; WU, X.; LI, Y. A novel and efficient polymerization of lignosulfonates by horseradish peroxidase/h(2)o(2) incubation. Applied microbiology and biotechnology, v. 97, n. 24, p. 10309-20, 2013.

ZHU, H. G.; LIU, M. Y.; YUEN, R. K.; LEUNG, C. K.; KIM, J. K. Thermal performance and flame retardancy studies of vinyl ester and glass fiber reinforced plastic composites containing nanoclay. Journal of Composite Materials, v. 48, n. 2, p. I65-I77, 2012. 